\author{
UNIVERSIDADE DE SÃO PAULO \\ INSTITUTO DE FÍSICA DE SÃO CARLOS \\ DEPARTAMENTO DE FÍSICA E INFORMÁTICA
}

\title{
UM MODELO DE VERSÕES APOIADO EM OBJETOS COMPOSTOS PARA UTILIZAÇÃO EM INSTÂNCIAS E ESQUEMAS DE BASES DE DADOS ORIENTADAS A OBJETOS
}

oke

\section{Luiz Camolesi Jr.}

Tese apresentada ao Instituto de Física de São Carlos, Universidade de São Paulo, para obtenção do título de Doutor em Ciências: "Física Aplicada - opção Física Computacional".

Orientador: Prof. Dr. Caetano Traina Jr.

São Carlos

1996

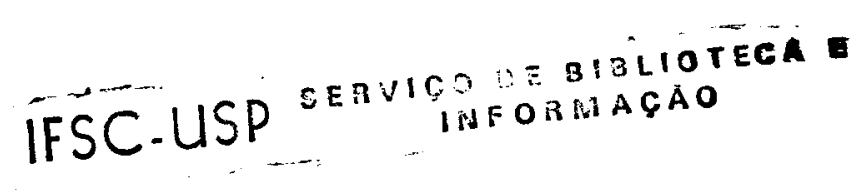


Camolesi, Luiz Júnior

Um Modelo de Versões Apoiado em Objetos Compostos para

Utilizaçăo em Inståncias e Esquemas de Bases de Dados

Orientadas a Objetos / Luiz Camolesi Júnior. - Săo Carlos, 1993.

$179 \mathrm{p}$.

Tese (Doutorado) - Instituto de Física de São Carlos, 1996

Orientador: Prof. Dr. Caetano Traina Júnior

1. Banco de Dados. 2. Controle de Versões

I. Título. 
À minha companheira Itália e aos meus pais, Luiz e Maria. 


\section{Agradecimentos}

- Ao Prof. Caetano Traina Jr., meu orientador, pela valiosa orientação e principalmente pelo apoio, amizade e confiança, depositados em mim, sem os quais este trabalho não teria sido realizado.

- À Profa. Agma Juci Machado Traina pela paciência e atenção sempre concedidas.

- Aos amigos do Grupo de Pesquisas em Bases de Dados pelo incentivo para a realização deste trabalho.

- Aos funcionários do IFSC e do ICMSC pelos serviços prestados durante a realização deste trabalho.

- Aos componentes do Grupo de Desenvolvimento de Sistemas do Instituto de Automação (IA/ Fundação CTI) pela oportunidade de estudar e atuar na busca de soluções para o sistema de apoio à programação de campanhas de petróleo na REPLAN/PETROBRAS.

- À FAPESP pelo apoio financeiro para a realização deste trabalho. 


\section{SUMÁRIO}

Lista de Figuras

vi.

Lista de Tabelas ................................................................................... vii

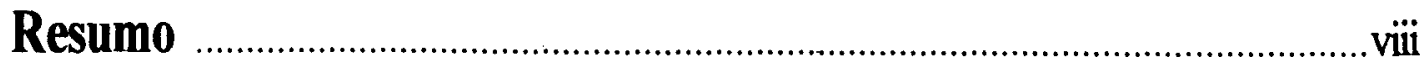

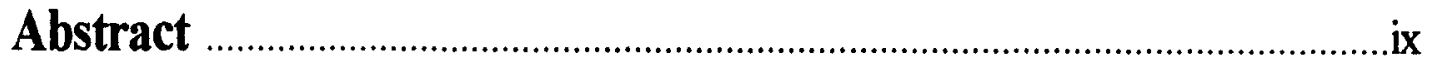

\section{Caprítulo 1}

INTRODUÇÃO

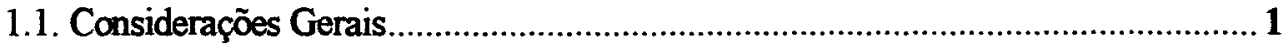

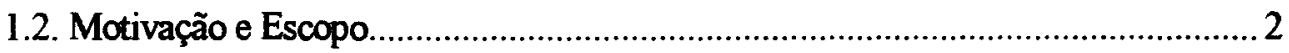

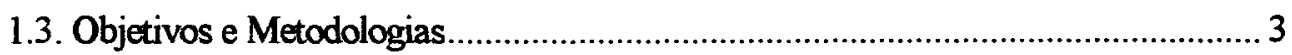

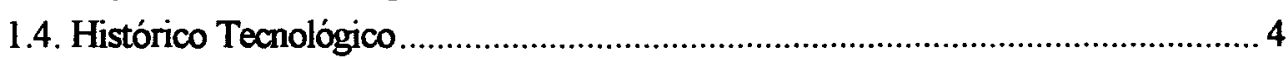

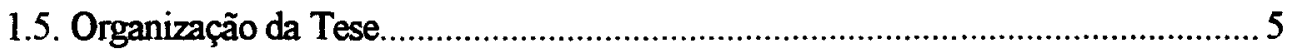

Capitulo 2

VERSÕES EM BASES DE DADOS

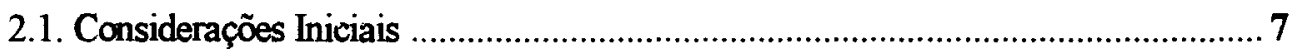

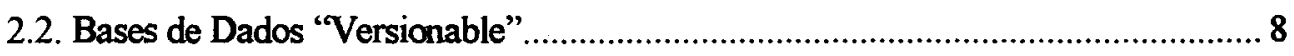

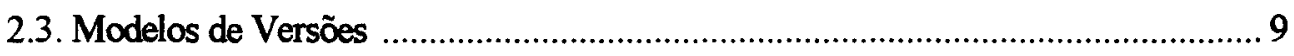

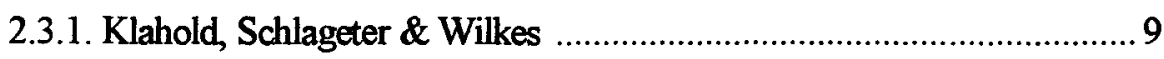

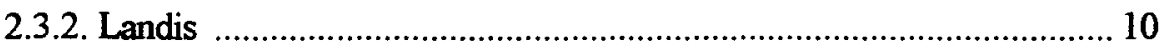

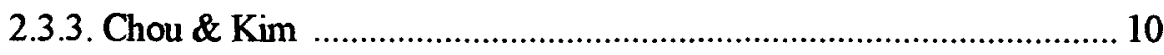

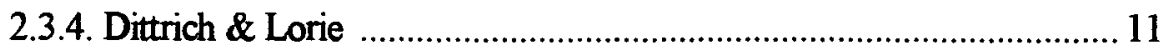

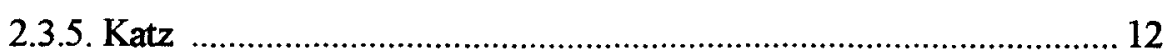

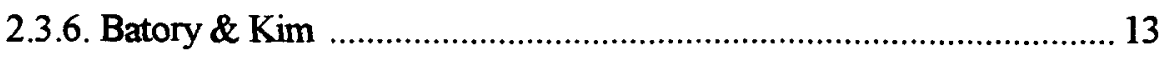

2.3.7. Ketabachi \& Berzins ........................................................................... 14

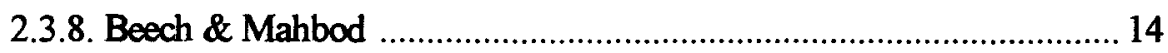

2.3.9. Vines, Vines \& King ....................................................................... 15

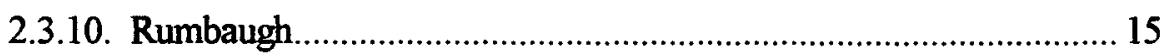

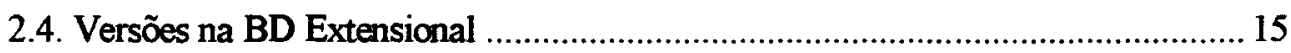

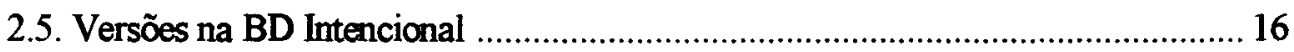


2.5.1. Téenicas de Evolução ........................................................................... 16

2.5.1.1. "Creating/Modification" ................................................... 16

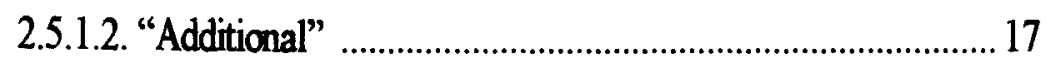

2.5.1.3. "Schema Versioning" ...................................................... 17

2.5.2. Estratégias de Propagação nas Instâncias ......................................... 18

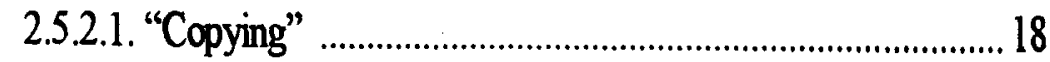

2.5.2.2. "Updating" ....................................................................... 19

2.5.2.3. "Screening" ....................................................................... 19

2.5.2.4. "Versioning" ...................................................................... 20

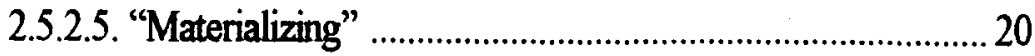

2.5.3. Técnicas de Evolução versus Estratégias de Propagação .................... 21

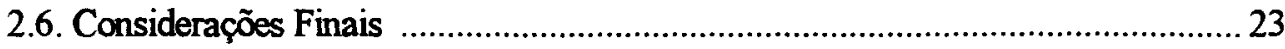

Capítulo 3

PadRóes e Modelos de Dados

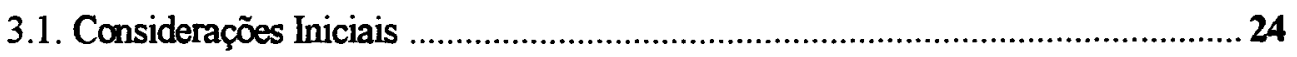

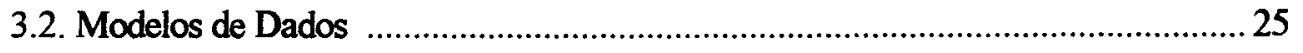

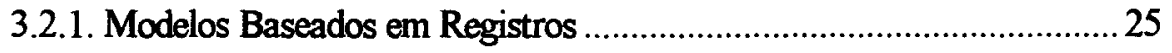

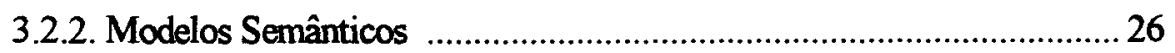

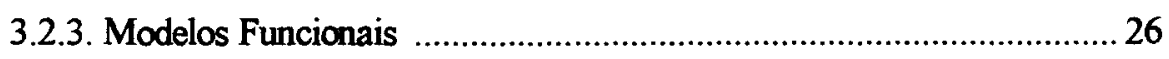

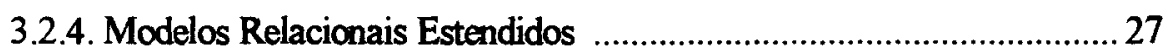

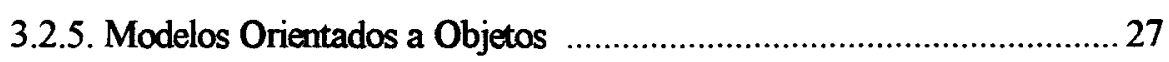

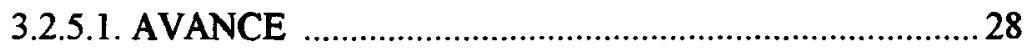

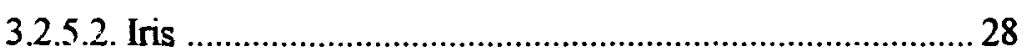

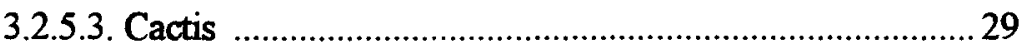

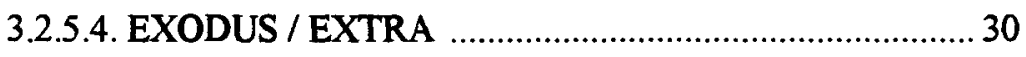

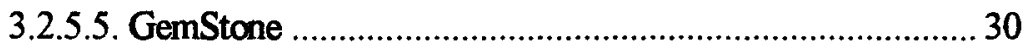

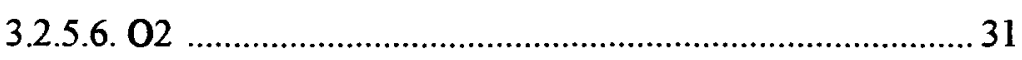

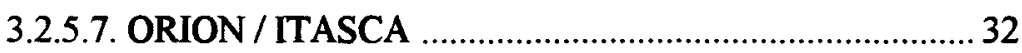

3.2.5.8. ODE

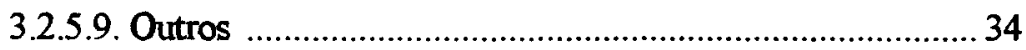

3.2.6. Análise Comparativa ...................................................................... 34

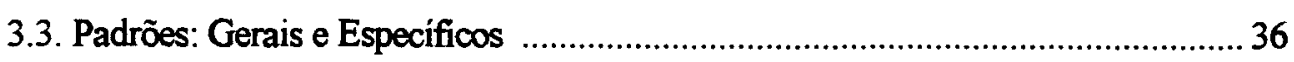

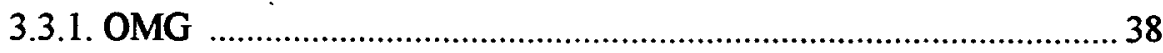

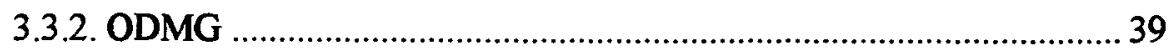

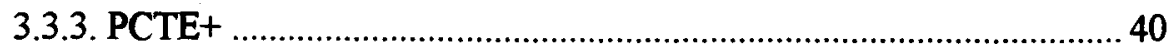

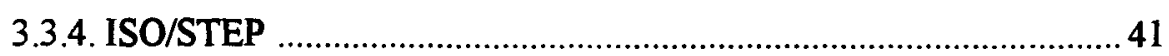

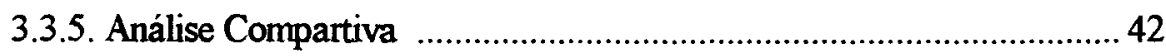

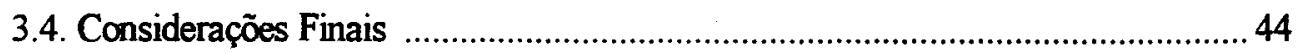




\section{Capítulo + MOdELO de REPRESENTAÇÃo de OBJETO - MRO*}

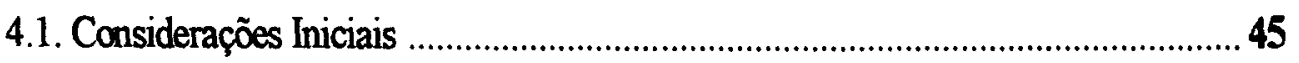

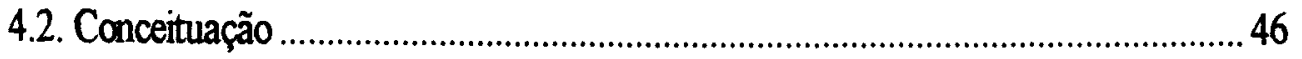

4.2.1. Diagramas de Representação …………………………..................... 46

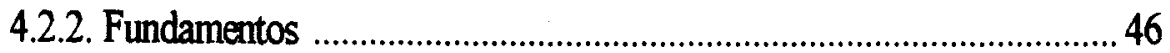

4.2.3. Esquema e Meta-Esquema de Dados ................................................ 47

4.2.4. Abstrações de Dados........................................................................... 47

4.3. Formalismo …............................................................................................. 51

4.4. Extensões ao MRO* .................................................................................. 51

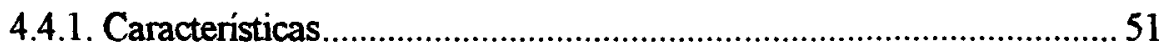

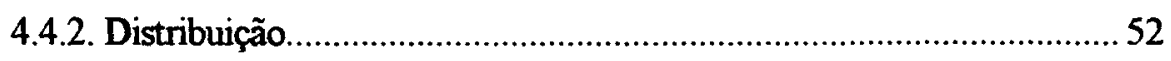

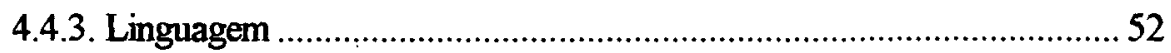

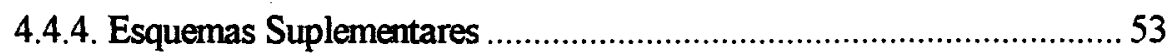

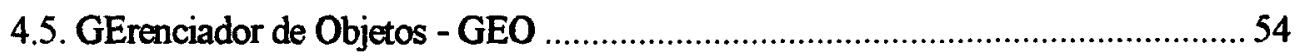

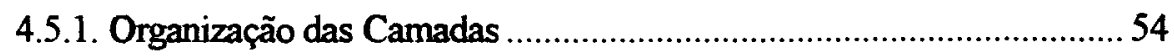

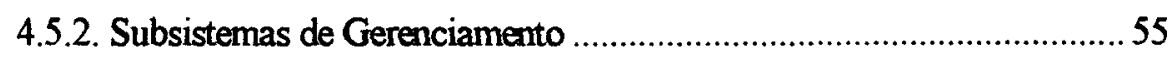

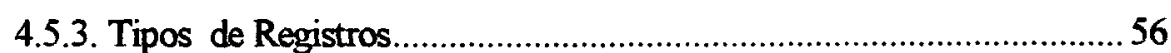

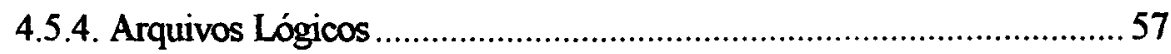

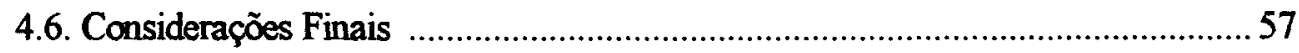

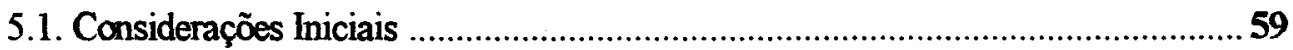

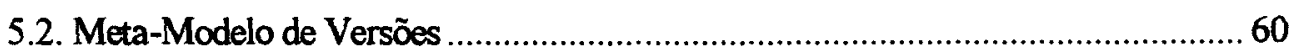

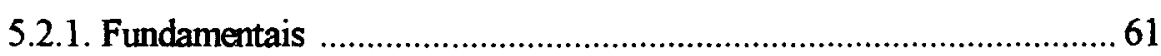

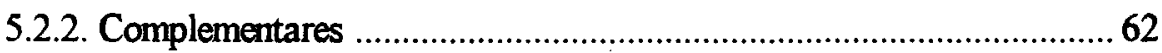

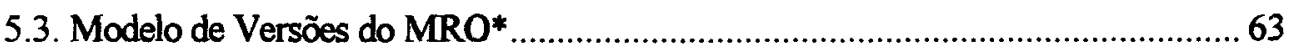

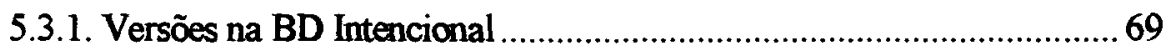

5.3.2. Versões na BD Extensional ........................................................ 71

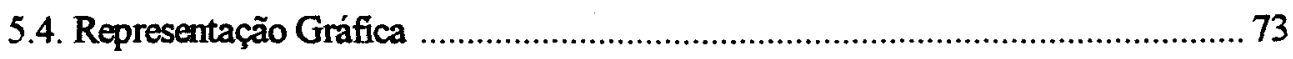

5.4.1. Diagrama Hierárquico de Versões (DHV) ……………………........ 73

5.4.2. Diagrama Hierárquico de Colônias (DHC) …………….................... 74

5.4.3. Diagrama de Representação de Instâncias (DRI) ................................ 74

5.4.4. Diagrama de Representação de Objetos (DRO) ............................... 75

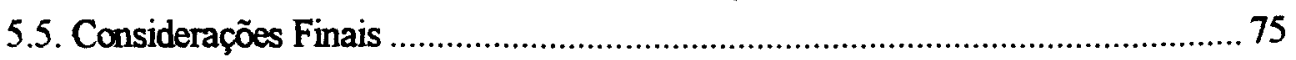


Capítulo 6

LINGUAGEM DE ACESSO DO MRO* (EXTENSÃO)

6.1. Considerações Iniciais .................................................................................. 76

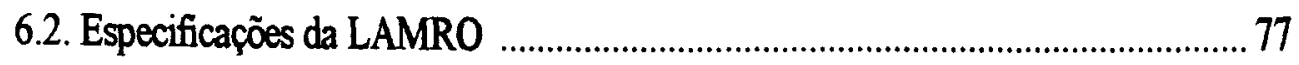

6.2.1. Classificação dos Comandos ........................................................... 77

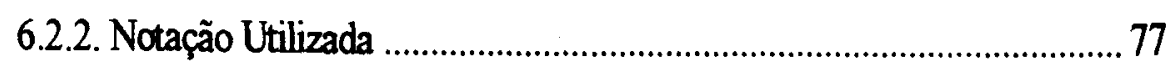

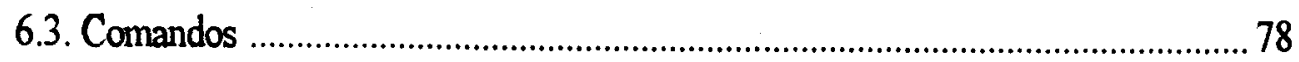

6.3.1. Sub-linguagem de Definição (LAMRO/D) ..................................... 78

6.3.1.1. Inserção .................................................................... 78

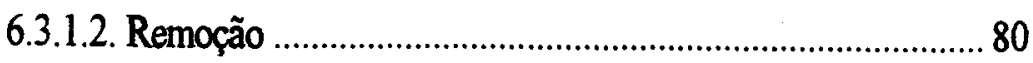

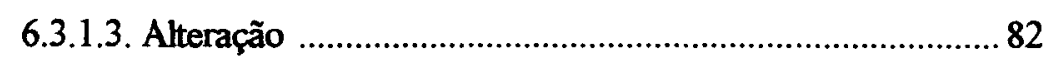

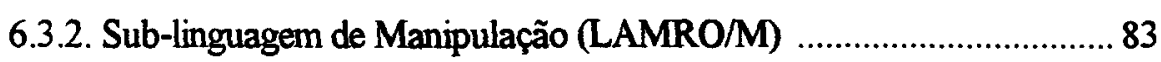

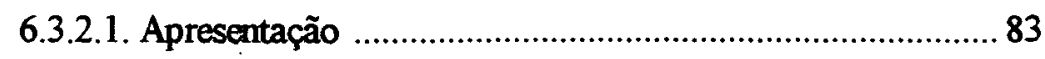

6.3.3. Sub-linguagem de Controle (LAMRO/C) …………........................ 84

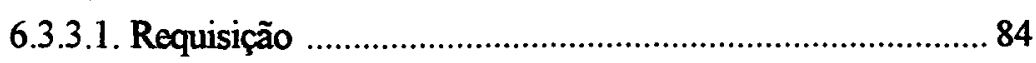

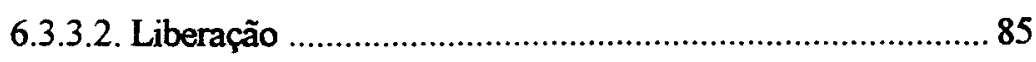

6.3.3.3. Definição de "Default" .......................................................86

6.3.3.4. Estabilização .............................................................. 86

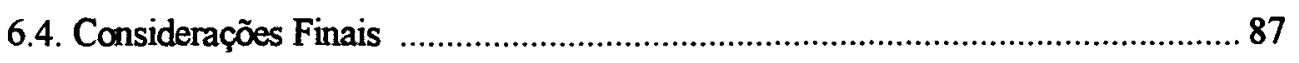

Capitulo 7

ASPECTOS DA IMPLEMENTAÇÃO

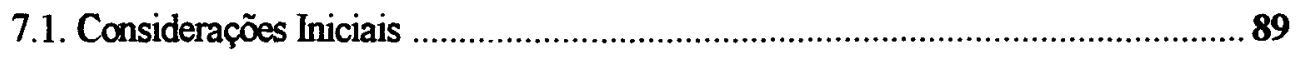

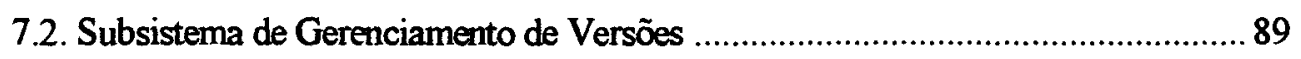

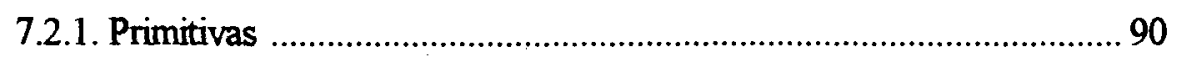

7.2.2. Estruturas de Armazenamento ....................................................... 91

7.2.2.1. Estruturas de Registro em Disco..................................... 91

7.2.2.2. Estruturas de Registro em Memória ................................ 93

7.2.3. Mecanismo de Delta (positivo) ......................................................... 94

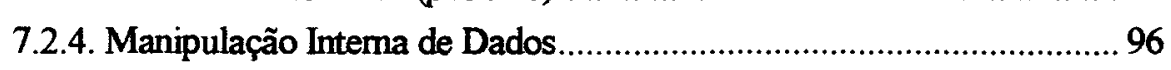

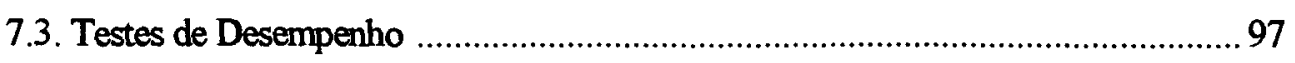

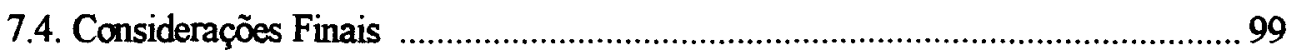

Capitulo 8

8.1. Considerações Iniciais

8.2. Histórico do Trabalho 100 
8.2.2. Fronteiras da Implementação ........................................................ 101

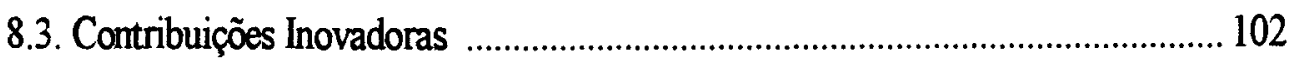

8.3.1. Meta-Modelo de Versões .............................................................. 102

8.3.2. Versões de Objetos Compostos (Colônias) ....................................... 102

8.3.3. Árvores Altemativas de Derivações (AAD) .................................... 103

8.3.4. Comandos Compactos, Robustos e Intuitivos ............................... 103

8.3.5. Objeto Genérico ........................................................................ 104

8.3.6. Modelo de Gerenciamento da Evolução da BD ............................... 104

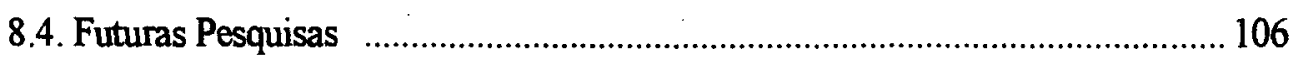

8.4.1. Extensões do Modelo de Versões .................................................. 106

8.4.2. Modelos Relacionados ao Modelo de Versões .................................. 106

8.4.2.1. Modelo de Tempo ......................................................... 106

8.4.2.2. Modelo de Configuraçães ............................................... 107

8.4.2.3. Modelo de Distribuição .................................................. 108

8.4.3. Modelo SIRIUS ......................................................................... 108

8.4.3.1. Incorporação do conceito de Versões ao SIRIUS ............ 108

8.4.3.2. Modelos Simultâneos de Versões...................................... 109

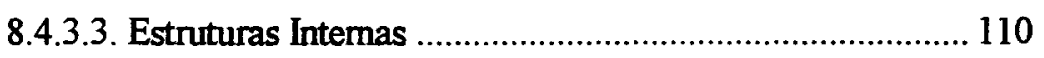

8.4.3.4. Evolução do Esquema de Dados......................................... 111

8.4.3.5. Múltiplos Objetos Genéricos .......................................... 112

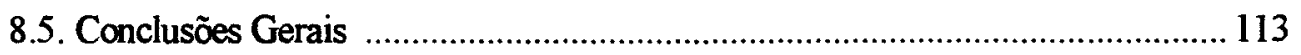

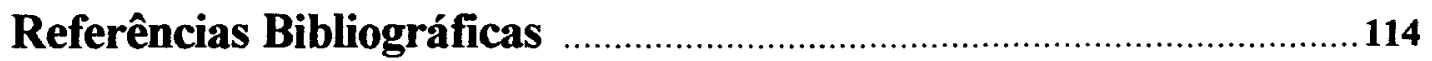

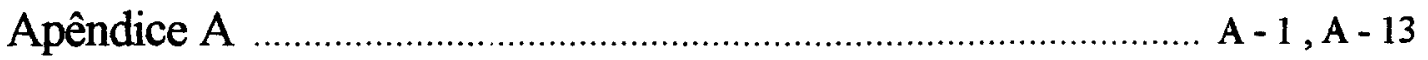

Exemplo de Modelagem de Dados

- Progr. de Campanhas de Produção de Derivados de Petróleo na REPLAN

Apêndice B

Exemplo de Utilização da LAMRO

- Progr. de Campanhas de Produção de Derivados de Petróleo na REPLAN

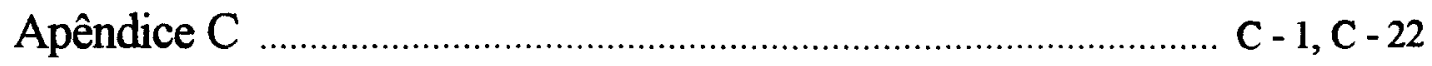

Manual de Referência

- Primitivas envolvendo Versões

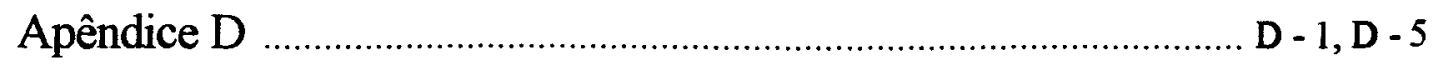

Manual Interno

- Estruturas envolvendo Versões 


\section{LISTA DE FIGURAS}

Figura 1.l - Evolução dos Modelos de Dados ............................................................

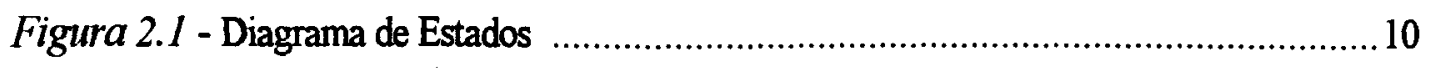

Figura 2.2 - Objeto Genérico ............................................................................. 11

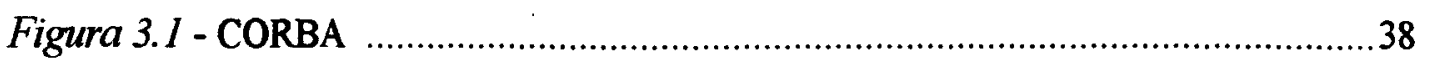

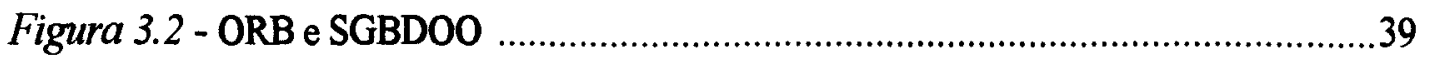

Figura 3.3 - Arquitetura do SGBDOO - ODMG ……................................................ 40

Figura 3.4 - Organização do Padrão STEP ............................................................42

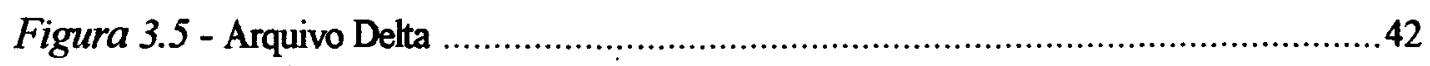

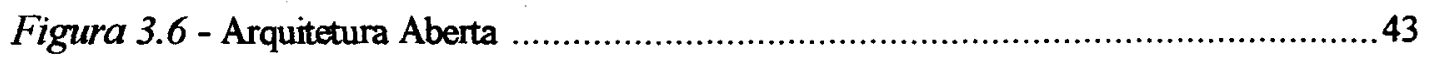

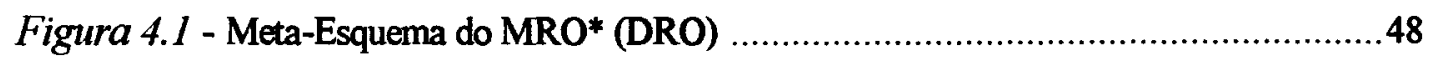

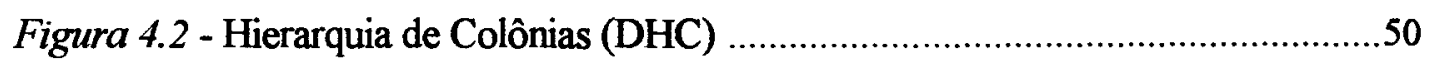

Figura 4.3 - Objetos e Colônias Esquema (DHC) ......................................................5

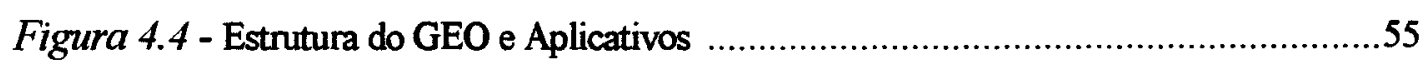

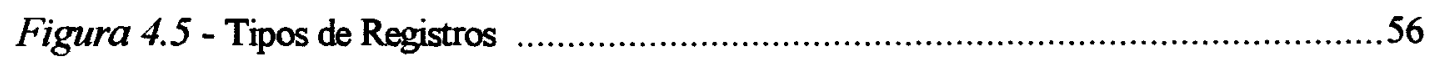

Figura 4.6 - Lista de Colônias Constritas ................................................................57

Figura 5.1 - Parte Modificada do Meta-Esquema do MRO* .............................................64

Figura 5.2 - Exemplo de Objeto Genérico no MRO* ....................................................65

Figura 5.3 - Diagrama de Transição de Estados ........................................................66

Figura 5.4 - Árvores de Derivações em um conjunto AAD ............................................66

Figura 5.5 - Exemplo de Objeto Genérico em uma Árvore de Derivações ..........................68

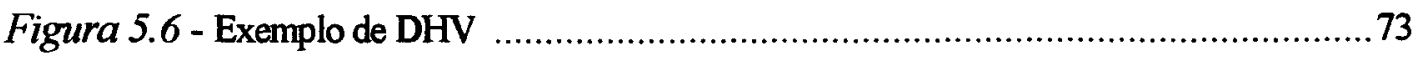

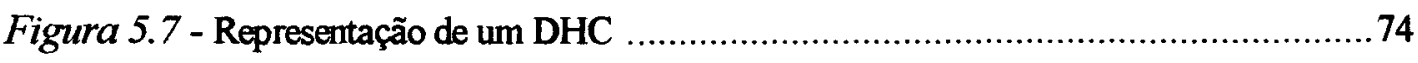

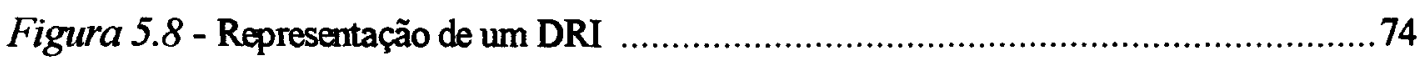

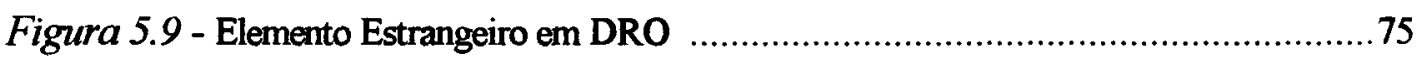

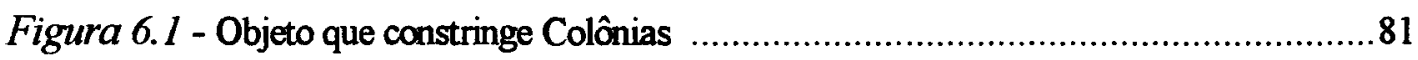

Figura 7.1 - Exemplo Esquematizado de Listas de Colônias e Versões ...............................93

Figura 7.2 - Exemplo Esquematizado de Listas de Atributos e Relacionamentos .................95

Figura 7.3 - Teste de Desempenho .......................................................................98

Figura 8.I - Meta-Esquema para Modelos Simultâneos de Versões ................................. 110

Figura 8.2 - Proposta de Estrutura para Deltas ........................................................ 111

Figura 8.3 - Exemplo de Múltiplos Objetos Genéricos ............................................. 112 


\section{LISTA DE TABELAS}

Tabela 2.1 - Técnicas de Evolução de Esquema vs Estratégias de Propagação …................21

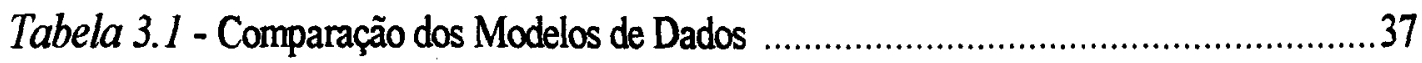

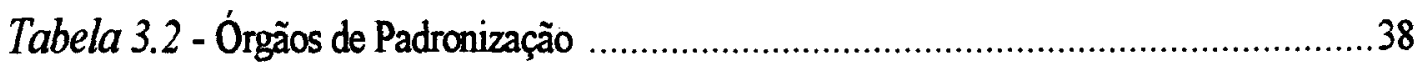

Tabela 8.1 - Os Modelos de Dados no Gerenciamento da Evolução da BD ..................... 105 


\section{RESUMO}

As informações contidas em uma Base de Dados para projeto não são obtidas apenas cumulativamente, mas também através de refinamentos e mudanças sucessivas nas informações já disponíveis. Diversas pesquisas mostram-se preocupadas com este aspecto e propõem conceitos e mecanismos de controle de Versões que podem ser incorporados a Modelos de Bases de Dados Orientadas a Objetos. Alguns destes trabalhos, aqui estudados, focalizam o uso de Versões na evolução não apenas da Base de Dados Extensional (Instâncias), ou seja, nas informações colhidas do mundo real e utilizadas pelas aplicações, mas também sua utilização como um mecanismo eficiente de Evolução do Esquema de Dados (a Base de Dados Intencional).

Com o objetivo principal de constituir um núcleo básico de conceitos e mecanismos que possam atender as mais variadas aplicações, este trabalho estabelece um Modelo de Versões apoiado no conceito de Objeto Composto e que permite uma correlação direta e transparente entre Versões de Instâncias e de Esquemas, ou seja, cada Versão na Base Extensional tem relação direta e única com a Versão da Base Intencional utilizada em sua instanciação. Adicionalmente, este trabalho estabelece um Meta-Modelo de Versões cujas especificações poderão direcionar as pesquisas de futuros Modelos de Versões, no sentido de apoiar a elaboração de Modelos de Versões sofisticados ou simples para aplicações específicas ou gerais, e também poderão ser utilizadas para o estabelecimento de mecanismos para a classificação $\mathrm{e}$ comparação de Modelos de Versões. 


\section{ABSTRACT}

Data stored in project databases are obtained not only through the incorporation of more and more data, but also through the refinements and alterations into the already existent information. There are many works over this subject, studying concepts and control mechanisms to support data versioning in Object-Oriented Database Systems. Some of these works focuses into the support of Version Control in the Extensional Databases, aiming to recognize and control the occurrence of many data versions of the same subject. Other works focuses into the support of Version Control in the Data Schema (Intentional Database), trying to find mechanisms to permit the recovery of different data structured in different ways of the same subject.

This work presents a Version Model, based in the Composite Objets concept, providing a homogeneous support to Version Control in the Extensional and the Intentional Databases. In this model, the Extensional data is partitioned into Composite Objets, and the parts of each Object are interpreted with only one of several possible schemes that are used to instantiate the parts of this kind of Object. This Version Model was conceived to be useful to a broad range of application domains, deriving a set of concepts that had permitted to construct a Version Meta-Model. This Meta-Model is sufficiently generic to aid the construction of elementary or complex Version Models, applied to generic or specific needs, and depicting mechanisms to aid the classification and comparison of existing or proposed Version Model. 


\section{capitulo 1}

\section{1 - Considerações Gerais}

As pesquisas na área de Bases de Dados sempre estiveram sincronizadas com as necessidades dos usuários [BLAKELEY_94a][SILBERSCHATZ_96]. Os objetivos e resultados destas pesquisas, antigamente, eram voltados somente para a aplicação genérica (denominada "convencional"), todavia com o crescimento e diversificação do mercado de "software" para usuários e o conseqüente aumento da complexidade das aplicações, tornaram-se também necessárias as pesquisas para o desenvolvimento de Sistemas de Gerenciamento de Bases de Dados (SGBD's) mais específicos ("não convencionais") [SILBERSCHATZ_91].

Devido às dificuldades tecnológicas que existiam principalmente em relação ao "hardware", apenas recentemente, ao longo dos últimos anos, foram possíveis as pesquisas de diferentes Modelos de Dados e respectivos SGBD's capazes de atingir aplicações específicas. Atualmente as aplicações não convencionais mais visadas pelos grupos de pesquisas em BD envolvem as áreas de engenharia e projeto ("Computer Aided Design" - CAD [MAJUMBER_94], "Computer Aided Software Engineering" CASE [RAMAMOORTHY_90]), automação, administração de escritórios e multimídia, entre outras [CATTELL_94]. 
0 reflexo das necessidades do mercado pode ser cronologicamente visualizado através dos diversos Modelos de Dados desenvolvidos [MCLEOD_91], desde os Modelos Baseados em Registros (Rede, Hierárquico e Relacional) passando pelos Semânticos e Funcionais até os recentes Modelos Orientados a Objetos e seus Sistemas de Gerenciamento de BD's Orientadas a Objetos (SGBDOO's).

Entre os Modelos Orientados a Objetos e as diversas pesquisas realizadas ou em andamento, ainda não foi possível uma coesão de trabalhos que proporcionasse um padrão completo ou norma a ser seguida. 0 que existe como princípio para a pesquisa é um conjunto de conceitos relativamente bem estabelecidos, sobre os quais existem pequenas variações em definições ou formas de implementação [REWINI_95] [VASKEVITCH_94].

\section{2 - Motivação e Escopo}

Atualmente, as empresas têm reavaliado suas estruturas e processos de trabalho de modo a tornarem-se mais eficientes na obtenção da qualidade de seus produtos ou serviços. Nos centros de pesquisa e universidades, a preocupação está em acelerar os processos criativos para a obtenção de resultados reais, fundamentados e diretamente relacionados com os problemas modernos (atuais ou futuros) [DRUCKER_92].

Estas preocupações das instituições levaram à reavaliação do papel da informática nos processos de trabalho [HAMMER_93]. Tradicionalmente entre suas funções, os sistemas computacionais eram responsáveis pelos cálculos, armazenamentos e apresentações das informações, contudo, a atual competitividade do mercado despertou nas instituições um especial interesse pela informatização dos processos de trabalho, em que a criatividade e a cooperação em grupo são indispensáveis.

Entre os processos críticos de trabalho, ao nivel comercial, está o desenvolvimento (projeto) rápido de produtos (ou protótipos) ou a apresentação de resultados que ofereçam inovações para se satisfazer clientes e assim almejar conquistas no mercado consumidor, e ao nível científico, tornou-se fundamental apresentar soluções atuais para os problemas existentes. Tal fato motivou a pesquisa $\mathrm{e}$ o surgimento de diversos sistemas computacionais para o apoio a projetos das mais variadas áreas como, mecânica, elétrica, civil, "software" e outras.

$\mathrm{O}$ apoio a grupos de projetistas, através de ferramentas computacionais, tornou-se indispensável pois oferece segurança, agilidade e diferentes níveis de controle e/ou flexibilidade de trabalho [HENRIKSEN_94]. A utilização e o 
compartilhamento eficiente de informações entre diversas ferramentas exige a utilização de um ambiente cooperativo, centralizador e gerenciador dos trabalhos, onde as informações normalmente são armazenadas em Bases de Dados e controladas por um SGBDOO.

Em conseqüência deste grande interesse comercial e científico pelos SGBDOO's e pela diversidade de aplicações existentes, ainda persistem certos tópicos de relativa preocupação e que geram pesquisas e desdobramento. Entre estes tópicos inclui-se o tema "Versões" [CHEN_96] [LIE_89], cujos respectivos modelos e sistemas de gerenciamento e controle são atualmente alvo de inúmeros trabalhos que retratam esta problemática [RODDICK_95].

Considerando-se os aspectos anteriormente mencionados, este trabalho está particularmente interligado (escopo) ao paradigma de "Orientação a Objetos", representado aqui pelo modelo $\mathrm{MRO}^{*}$ e seu protótipo de SGBDOO denominado GEO (ambos descritos no capítulo 4), tendo como motivação, a demanda por sistemas de gerenciamento/controle de Versões de Objetos de grande complexidade em Bases de Dados (BD) que apoiam ambientes de projeto em engenharia.

\section{3 - Objetivos e Metodologias}

O Grupo de Pesquisa em Base de Dados, estabelecido na USP - São Carlos, foi organizado em meados de 1991 com o propósito de estudar as necessidades dos ambientes de apoio a projetos. Em suas pesquisas, notou-se que as dificuldades atuais da maioria dos grandes projetos devem-se a sua complexidade, que exige um elevado grau de conhecimentos específicos, algumas vezes multi-disciplinares, e grande habilidade no controle das informações. Notadamente, cria-se a necessidade de um desmembramento dos trabalhos correlacionados ao projeto e sua distribuição entre os grupos de projetistas.

Partindo desta premissa, o objetivo principal deste trabalho é oferecer meios para que Modelos Orientados a Objetos suportem características evolutivas, na forma de Versões, possibilitando que SGBDOO's apoiados nestes Modelos possam ser usados em ambientes de projeto na tarefa de armazenamento e acesso das constantes alterações dos dados, de suas estruturas e representações. Desta forma, projetistas poderão realizar modificações no projeto com a elaboração e utilização de Versões dos dados de sua responsabilidade, cabendo aos gerentes de grupo (e administradores da Base de Dados) aplicarem Versões sobre as estruturas do projeto (Esquema de Dados), de modo a alterar as linhas de ação de seus subordinados e contemplar mudanças sugeridas ou impostas. 
Adicionalmente, este trabalho estabelece (no capitulo 5) uma correlação direta e transparente entre Versões nas Bases de Dados Intencional e Extensional, ou seja, cada Versão na Base Extensional terá relação direta e única com a Versão da Base Intencional utilizada em sua instanciação. Em conseqüência, abrem-se novas possibilidades de projetos conceituais e fisicos de Bases de Dados Orientadas a Objetos, como pode ser verificado através do Meta-Modelo de Versões e do Modelo de Versões, criados na aplicação dos conceitos e mecanismos desenvolvidos.

Para constatar as inovações e vantagens oriundas da concretização dos objetivos citados, este trabalho desenvolve um Subsistema de Gerenciamento de Versões (SGV) e uma sub-linguagem de apoio a programação (descritos nos capítulos 6 e 7), que permitem a utilização de Versões de conjuntos de informações como sendo alternativas de projeto.

$\mathrm{Na}$ experimentação deste trabalho, o SGV desenvolvido é integrado ao GEO e os estudos realizados são incorporados ao $\mathrm{MRO}^{*}$, o que permite a utilização prática desta pesquisa em um ambiente para projeto de produtos, além de servir de apoio a novas técnicas dentro das áreas de Bases de Dados e de auxilio no desenvolvimento de projetos científicos ou comerciais.

\section{4 - Histórico Tecnológico}

Nas pesquisas em Bases de Dados surgiram muitos Modelos usados para a descrição das necessidades de dados, cada um proporcionando as características desejadas por suas aplicações. $\mathrm{Na}$ definição de qualquer Modelo de Dados estão seus conceitos fundamentais de modelagem, porém, o tratamento dado individualmente em cada Modelo difere no uso e geralmente na implementação, de acordo com as necessidades ou mesmo por divergências conceituais.

Pelas conseqüentes modificações de mercado e de pesquisa, estabeleceu-se uma sequeencia evolutiva (Figura 1.1) iniciada com os Modelos Baseados em Registros, em resposta às necessidades de processamento da época. Anos depois, surgiram os primeiros Modelos Semânticos e Funcionais, juntamente com o conceito de "Objeto". Posteriormente, iniciou-se os estudos para a conceituação dos Modelos Orientados a Objetos [HURSON_93] e das extensões do Modelo Relacional [JACKSON_90], nos quais reside, atualmente, o maior interesse pela pesquisa.

Os Modelos Orientados a Objetos podem ser classificados em gerações, de acordo com os estágios atuais de pesquisa e desenvolvimento [BERTINO_93]. Desta forma, temos: $1^{\mathrm{a}}$ Geração : são Modelos preocupados com uma linguagem persistente;

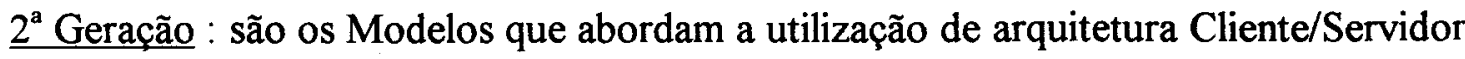




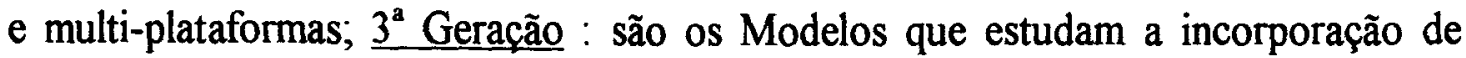
características avançadas, como por exemplo, controle de Versões e a elaboração de DDL/DML completa e orientada a objetos.

Entre os desenvolvedores e usuários, nos últimos anos, tem crescido a preocupação com a "qualidade" (em uma visão ampla) dos SGBD's desenvolvidos comercialmente ou de seus protótipos, o que inclui 0 aspecto do desempenho. Neste sentido, vários estudos e testes têm confrontado gerenciadores, abordando os diferentes aspectos e nuanças que influenciam suas performances. Esta comparação entre

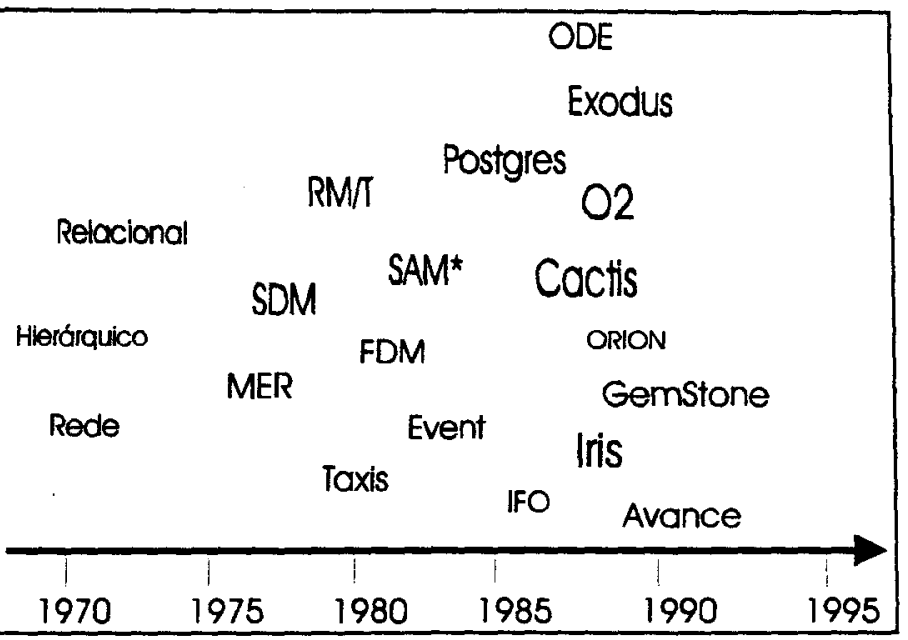

Figura 1.1 - Evolução dos Modelos de Dados gerenciadores, mesmo de paradigmas e modelos diferentes, está se popularizando em "benchmarks" [CHAUDHRI_95] que estabelecem métricas/escalas de desempenho e divulgam problemas ou disparidades expressivas entre os sistemas.

\section{5 - Organização da Tese}

O presente trabalho está organizado em 8 capítulos, sendo seus respectivos conteúdos resumidamente descritos abaixo:

Capítulo 1: apresenta, em linhas gerais, as necessidades que motivaram este estudo, bem como a metodologia utilizada e os objetivos principais atingidos;

Capitulo 2: apresenta diversos Modelos de Versões além das técnicas e estratégias para a utilização de Versões nas Bases de Dados Intencional e Extensional;

Capítulo 3: apresenta um breve estudo sobre os Padrões e Modelos de Dados Orientados a Objetos mais representativos da área, incluindo uma análise comparativa das diversas pesquisas;

Capítulo 4: apresenta um resumo do Modelo de Representação de Objetos MRO* (incluindo o Gerenciador de Objetos - GEO) utilizado para a aplicação dos conceitos e técnicas resultantes deste trabalho; 
Capítulo 5: apresenta um novo Modelo de Versões, apoiado em Objetos Compostos, que pode ser aplicado às BD Intencional e Extensional. Adicionalmente, inclui um Meta-Modelo de Versões elaborado para apoiar o criação de Modelos de Versões adequados para cada problema;

Capítulo 6: apresenta os novos comandos que foram incluídos na Linguagem de Acesso do MRO* para possibilitar a definição, manipulação e controle de Versões na Base de Dados (Intencional e Extensional);

Capítulo 7: apresenta as estruturas de dados e os aspectos funcionais e comportamentais das primitivas que formam o Subsistema de Gerenciamento de Versões (GEO/SGV);

Capítulo 8: apresenta as propostas de linhas de pesquisas que complementam este trabalho, um histórico dos atividades realizadas bem como as contribuições inovadoras desta pesquisa.

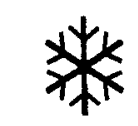




\section{capitulo 2}

\section{VERSÕES \\ EM \\ BASES DE DADOS}

\section{1 - Considerações Iniciais}

Todos os Sistemas de Gerenciamento de Bases de Dados têm a habilidade de adaptação, que permite o reconhecimento de novas situações (internas ou externas), com o intuito de manter um bom desempenho, afinal esta é uma das imposições/requisitos dos usuários. Esta habilidade, pode ser alcançada através de diferentes metodologias e processos de flexibilização da representação e do armazenamento, de modo a manter uma estabilidade relativa da Base de Dados ou para melhorá-la, em determinação e conformidade com os requisitos relacionados ao meio (ou ambiente) e aos usuários.

Entre as metodologias mais empregadas ou de maior interesse atualmente, encontram-se os conceitos que envolvem Versões, pelo fato de várias áreas de aplicação (ex:: CAD, CASE, Automação de Escritórios, etc.) terem processos alternativos de trabalho que são simultaneamente utilizados pelos usuários.

A utilização de Versões permite a organização estruturada de alternativas para a representação de informações em BD's destinadas ao armazenamento de dados 
complexos, indefinidos ou mutáveis. O registro histórico da evolução destas alternativas de informação não deve ter um interesse apenas de controle gerencial (produtividade), mas acima de tudo propiciar flexibilidade de trabalho aos usuários.

Neste capitulo são apresentados diversos Modelos de Versões e descritas as motivações básicas para a utilização de Versões em Bases de Dados Intencionais (Esquema de Dados) e Bases de Dados Extensionais (Instâncias). Adicionalmente, é dada atenção especial a uma classificação original das Técnicas de Evolução de Esquemas de Dados e das Estratégias de Propagação nas Instâncias atingidas pela Evolução, pois ambas podem se utilizar de Versões em seus processos.

\section{2 - Bases de Dados "Versionable"}

As Bases de Dados (Intencionais ou Extensionais) que utilizam-se de Versões, neste trabalho denominadas Bases de Dados "Versionable"1, caracterizam-se pelo armazenamento voluntário (não necessariamente em uma estrutura linear) das informações históricas, de forma explícita se o usuário realizar algum tipo de avaliação e/ou comando, ou de forma implícita, quando o SGBD realiza avaliações e ações com base em Regras estabelecidas anteriormente pelo usuário.

Versões ${ }^{2,3}$ são normalmente utilizadas no apoio a diversos subsistemas do gerenciador da Base de Dados como acontece no Subsistema de Gerenciamento de Transações (SGBD/SGT), onde as Versões são elementos de apoio à recuperação [BAYER_80] e/ou no controle de concorrências de curta ou longa duração [BARGHOUTI_91]. Para isso, utilizam-se operações de "check-out" e de "check-in" para gerar Versões e posteriormente para integrá-las.

Apesar desta função atribuída às Versões, e de outras consolidadas em alguns sistemas, é cada vez mais freqüente a colocação de Versões como sendo individualmente importantes para as aplicações que realizam constantes evoluções de informações e que necessitam mantê-las. Para isso, são desenvolvidos Subsistemas de Gerenciamento de Versões (SGBD/SGV), ou Sistemas de Controle de Versões, que

\footnotetext{
${ }^{1}$ Pelo fato de não existir uma palavra correspondente na língua portuguesa, será utilizado, durante este trabalho, o termo em inglês "versionable" ou "versioning" [KENT_89] para caracterizar um elemento (ou conjunto de elementos) no qual ou do qual é possível originarem-se Versões. No sentido oposto, será utilizado o termo "non-versionable".

${ }^{2}$ Versão é uma descrição do aspecto de um Objeto e que se estabelece no contexto da aplicação, por motivos experimentais, corretivos, adaptativos, ou também por refinamento ou atualização, de modo a definir um marco delimitador do trabalho realizado ou a realizar-se. (definição especifica)

${ }^{3}$ Versão (subs., fem.): cada uma das várias interpretações do mesmo ponto. Ato ou efeito de verter ou de voltar. (definição fonte: Dicionário Aurélio da Lingua Portuguesa)
} 
basicamente são responsáveis pela registro evolutivo da $\mathrm{BD}$, além de colocar-se a serviço de outros subsistema (ex. transação, distribuição [AGRAWAL_93] [FERREIRA_91], configuração [THOMAS_89] e outros).

Para regulamentar ou estruturar o controle de Versões são estabelecidos Modelos de Versões que abordam todos os aspectos conceituais e técnicos desse gerenciamento. Neste sentido, pode-se encontrar, na literatura, menções às estruturas lógicas e/ou fisicas, características especiais das Versões, restrições de operação, instruções de manipulação, diagramas de estados e de transições, bem como, outras especificações para um controle de Versões em situações específicas ou gerais de um problema.

\section{3 - Modelos de Versões}

Existem muitos Modelos de Versões e diversos enfoques [KATZ_90], de acordo com seu(s) autor(es), quanto à aplicação destino e o estágio de desenvolvimento em que se encontram. A seguir são apresentados ${ }^{4}$ alguns destes Modelos de Versões, com atenção especial para as especificações cujos conceitos e técnicas não possuem similares ou semelhanças com outros Modelos de Versões.

\subsection{1 - Klahold, Schlageter \& Wilkes}

Este Modelo propõe a estrutura "Version Graph" para organizar as Versões de um modo mais flexível, possibilitando Relacionamentos de derivação, diretos e explícitos, de forma não necessariamente hierárquica [BERTINO_93].

Opcionalmente, pode-se realizar partições do "Version Graph" em "subárvores", que estabelecem hierarquias de grupos de Versões cujas camadas designam níveis de consistência, ou seja, os níveis mais altos das hierarquias devem passar por verificações de consistências mais rígidas e profundas enquanto as Versões nos níveis mais baixos requerem menos verificações. Estas partições formariam "visões" do "Version Graph" de acordo com critérios especificados pelo usuário.

${ }^{4}$ Os Modelos de Versão não possuem denominações próprias, sendo portanto referenciados pelos nomes de seus autores.

Serão apresentados nesta seção muitos termos e conceitos em suas denominações originais na língua inglesa, evitando-se a tradução, para facilitar o reconhecimento das idéias concebidas pelos autores. 


\subsection{2 - Landis}

Este Modelo trabalha com os conceitos: estrutura histórica não linear, referência dinâmica e "change propagation". As Versões são organizadas em ramos ("branches") ou Alternativas de Derivação, sendo a estrutura histórica organizada em conjuntos de ramos nos quais se estabelecem a Versão corrente e o ramo "default".

A referência a uma Versão pode ser específica ou dinamicamente configurada para selecionar uma Versão. As referências às Versões "antigas" não são alteradas em uma operação de criação de uma Versão "nova", mas somente as referências genéricas passam a reconhecer esta Versão "nova" [BERTINO_93].

O mecanismo de "change propagation" define a criação de uma Versão "nova" de um Objeto como resultado de uma alteração realizada sobre este Objeto. Para manter as mudanças sobre controle e evitar problemas nas Transações, permitese a criação de apenas uma Versão para cada conjunto de alterações realizadas e são utilizados "delta sets" para o armazenamento das operações de modificação executadas em cada derivação.

\subsection{3 - Chou \& Kim}

Este Modelo [KIM_87] estabelece três tipos de Versões (Figura 2.1) além de restrições e comandos específicos para suas manipulações (criação, derivação, promoção, remoção e consulta). Ao nível de restrições, uma Versão "Transient" é manipulada somente pelo seu criador (usuário), as Versões "Working" não podem ser atualizadas, enquanto que, as Versões do tipo "Released" não podem ser atualizadas ou removidas.

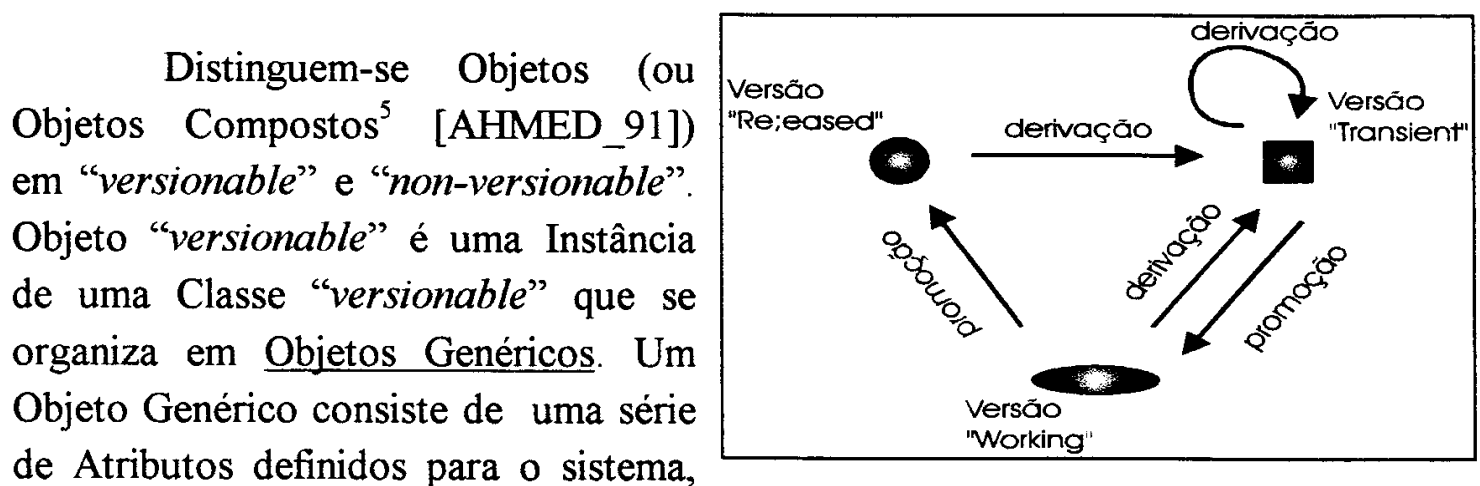
entre os quais: o identificador ("Object

Figura 2.1 - Diagrama de Estados Dentifier" - OID); o contador do total

${ }^{5} \mathrm{O}$ conceito de Objeto Composto estabelece a existência de uma associação entre vários Objetos (de Tipos diferentes) para a composição de um elemento complexo [CIVELLO_93]. 
de Versões no Objeto Genérico; o número incrementado ("Version Number" - VN) que será atribuído à próxima Versão que será criada; o VN da Versão "default" caso seja utilizado a referência genérica; e a estrutura de derivação que contem a árvore dos descritores das Versões, organizados pela ordem das derivações.

No descritor de cada Versão incluem-se o VN e o OID da respectiva Versão, além de sua lista de referências a todos os descritores das Versões derivadas diretamente da Versão focalizada. A cada Versão é atribuído um OID, um VN, um tipo ("Transient", "Working", ou "Released") e o OID de seu Objeto Genérico.

A atribuição de Relacionamentos e/ou Atributos ao Objeto Genérico traduzse fisicamente como a atribuição a todas as Versões representadas. A referência a um Objeto Genérico (Figura 2.2) é solucionada dinamicamente através da escolha de uma Versão entre aquelas que compõem seu conjunto. É permitido ao usuário escolher particularmente uma Versão, porém se não puder identificá-la, lhe é fornecido a Versão ("default") com o "timestamp" mais recente.

\subsection{4 - Dittrich \& Lorie}

Desenvolvido no Centro de Pesquisas da IBM em San Jose, este Modelo [DITTRICH_88] propõe conceitos de uso geral em ambientes de projeto. Para isso, são definidos três elementos básicos: "Design Object" - DO; “environment"; "clusters", além de operações para criar, remover, consultar e estabelecer um estado para as Versões dentro de um Base de Dados SQL.

Cada DO, reconhecido pelo seu OID, é um conjunto de Versões onde cada uma é identificada por um número ("Version Number" - VN) seqüencialmente incrementado e nunca reutilizado dentro do conjunto. O par \{OID-DO, VN\} identifica univocamente cada Versão contida na Base de Dados.

Uma única Versão de cada DO pode ser rotulada como "current", mesmo estando no estado "frozen" ou "thawed". Uma Versão "frozen" é considerada consistente e madura para ser compartilhada pelos usuários e nesse caso, as atualizações ou remoções não são permitidas. Aquelas Versões declaradas "thawed" têm sua restrição de segurança diminuída, devendo ser manipulada com cuidado. Cabe ao usuário, a responsabilidade pela alteração do estado das Versões, não existindo portanto, nenhuma restrição quanto à transformação de uma Versão 
"thawed" para "frozen" ou vice-versa, e muito menos alguma regra quanto a derivação.

A referência a um DO pode ser direta ou genérica, sendo resolvida com a utilização do mecanismo de "environment". Um "environment" é uma estrutura contendo três tipos de informações. A primeira, denominada "direct entries", contêm pares $\{$ OID-DO, VN\} que especificam, para determinados DO's de interesse de um usuário, qual a Versão desejada, através da indicação de seu VN. Para cada usuário existe um único "environment", que é colocado como ativo através de um comando específico e para substituí-lo basta ativar outro "environment".

Os outros tipos de informação permitem ligações de um "environment" na forma de: "Indirect Entries", pares \{OID-DO, E\} que descrevem para determinados DO's em qual "environment" E está especificado o VN da Versão desejada; e "Inclusion Entries", pares $\{\mathrm{E}, \mathrm{p}\}$ que descrevem, para determinados "environment" $\mathrm{E}$, qual a prioridade $\mathrm{p}$ de escolha caso haja conflitos entre "environments" usados.

Um usuário pode agrupar logicamente um conjunto de Versões ("Cluster") de acordo com um critério pessoal. Desta forma, Versões muito usadas de um DO e que encontram-se em situações semelhantes, podem ser agrupadas em um "cluster", para utilização na especificação de um "environment".

\subsection{5 - Katz}

Pesquisas na Universidade da California (Berkeley) e anteriormente na Univ. de Wisconsin (Madison) focalizaram o problema de Base de Dados para apoiar projetos [KATZ_86] [KATZ_87], estabelecendo a organização de Versões em três planos distintos mas que podem estar ortogonalmente associados:

- Plano de Versões: os Objetos são, basicamente, organizados em uma Hierarquia de Derivação Histórica, na qual a associação entre Versões ocorre pela ação de derivação (criação de uma Versão a partir de outra). A utilização de "timestamp" é essencial na representação deste Plano, contudo, é necessária uma indicação explícita das seqüências de derivação utilizando-se Relacionamentos do tipo "Is-a-derivative-of" e de seu oposto "Is-derived-from", visto que várias Versões podem ser derivadas, em paralelo, de um mesmo Objeto (Versão) origem;

- Plano de Equivalência: os Objetos deste Plano, denominados Equivalências, têm o papel de interrelacionar Objetos (Versões ou Equivalências) que semanticamente possuem alguma semelhança ou que focalizem aspectos diferentes (ex. "layouts"). Para isso, as Equivalências se utilizam de 
Relacionamentos explícitos do tipo "Is-Equivalent-to" e do tipo oposto;

- Plano de Configuração: neste Plano, os Objetos são representações das diversas Configurações de um Objeto Composto ("Composite Object" [AHMED_91]) e que podem ser formados agrupando-se uma Versão de cada um dos componentes. Cada Objeto de Configuração é origem de Relacionamentos "Is-composed-from" com Versões, que conseqüentemente possuem Relacionamentos opostos do tipo "Is-acomponent-of" com as Configurações.

Uma forma de referenciar um Objeto armazenado, sem designar alguma Versão em particular, pode ser feita através do Objeto Genérico, o qual sintetiza a estrutura comum à todas as Versões representadas. Outra maneira para uma referência genérica é através de um Objeto Equivalência, que representaria, desta forma, um conjunto de Versões semanticamente envolvidas em um contexto.

Katz estabelece um ciclo de vida para os "Design Files" ou "Design Versions" [KATZ_84]. Nele, um Objeto (arquivo) Versão é criado pelo administrador do projeto e colocado "in-progress". Os projetistas poderão criar Alternativas deste Objeto que serão trabalhadas até que o administrador agrupe ("merge") cada Alternativa com a Versão "in-progress". O passo seguinte é efetivar a Versão, colocando-a "read-only" e posteriormente estabilizando-a como "released" para arquivamento ou restauração. Versões efetivadas podem voltar a tornarem-se "inprogress" e conseqüentemente possibilitar Alternativas para uma restruturação.

\subsection{6 - Batory \& Kim}

Em ambientes CAD, este Modelo [BATORY_85] define "Molecular Objects" como sendo compostos por Objetos e Relacionamentos que possuem dois aspectos visiveis: interface e implementação. É principalmente na implementação que podem ocorrer variações que darão origem às Versões dos Objetos componentes.

Versões (alternativas da implementação ou revisões) são relacionadas aos respectivos tipos através de Relacionamentos especiais denominados "version generalization" . A instanciação de tipos gera uma estrutura histórica para registrar cronologicamente as Versões.

O suporte à configuração dinâmica de "Molecular Objects" é alcançado por meio do mecanismo "parametrized version". Cada Objeto componente de um "Molecular Object" especifica a Versão usada na configuração, exceto quando o Objeto não tem o parâmetro de especificação da Versão, e nesse caso, cabe ao usuário estabelece-la previamente. 


\subsection{7 - Ketabachi \& Berzins}

Este Modelo [KETABACHI_87] reconhece Versões como "refinements" de diferentes descrições de um mesmo Objeto. Existem 3 tipos de "refinements":

1. "Template Refinements" descreve os aspectos de um Objeto;

2. "Explosion Refinements" estabelece as Versões de cada componente que constitui a Versão de um Objeto Composto;

3. "Instance Refinements" descreve as revisões e alternativas de um Objeto.

O histórico das Versões é representado pela conjunção de dois Grafos. 0 primeiro, denominado "refinement graph", descreve os Relacionamentos de derivação entre as várias Versões, e o segundo, chamado "incremental refinements graph" IRG, armazena as diferenças (ou Deltas - $\Delta$ ) entre as Versões e suas respectivas origens.

0 "refinements graph" pode representar: refinamentos dependentes, estabelecendo que as modificações no antecessor de uma Versão serão refletidas na própria Versão; refinamentos independentes, que estabelecem a possibilidade de refinamentos paralelos que não serão refletidos nos sucessores diretos; e refinamentos alternativos independentes, que possibilitam refinamentos paralelos que serão refletidos nos sucessores diretos.

\subsection{8 - Beech \& Mahbod}

Neste Modelo, as Versões possuem seu próprio OID e são organizadas em conjuntos ("version sets") associados a Objetos Genéricos. "Generic" e "Version" são tipos de Objeto que podem ser normalmente utilizados [BERTINO_93].

O Grafo de Versões apresenta a organização das derivações, sendo obtido com o uso de funções pré-definidas ("first, "last", "next version", "preceding version"). A criação de uma Versão nova no Grafo é conseguida através de funções de mutação ou propagação. Na execução de uma mutação, a Versão origem é congelada ("frozen") e uma Versão nova é criada para modificações. Na propagação, a Versão origem é um componente de um Objeto Composto, e nesse caso, cria-se uma Versão deste Objeto e de cada um dos Objetos Compostos que o utilizam.

A referência entre Objetos pode ser "specific" ou "generic" e através de um mecanismo de contexto especifica-se quando e onde as referências genéricas podem ser solucionadas. Este mecanismo pode ser aplicado amplamente se for implementado em Regras especificadas pelo usuário e invocadas pelo SGBD. 


\subsection{9 - Vines, Vines \& King}

Este Modelo define Relacionamentos entre Versões, de modo a especificar a semântica do impacto das alterações entre Objetos. Os Relacionamentos "version sensitive", entre dois Objetos, estabelecem que um Objeto deve ser notificado da alteração (ex. criação de Versão) do outro Objeto, e os Relacionamentos "change sensitive", entre dois Objetos, estabelecem que um Objeto não deve ser notificado da alteração do outro Objeto (não sensivel à alteração), mas se este outro Objeto relacionar-se com um terceiro Objeto, estão este terceiro Objeto deve ser notificado.

Existem Objetos específicos para o controle de modificações. "Change request object" é criado quando requisita-se uma alteração e permanece associado ao Objeto modificado para manter-se uma trilha das alterações estabelecidas. "Change notification object" é criado quando requisita-se uma propagação entre "version sensitive" ou "change sensitive", sendo também criados "Configuration objects" para agruparem as modificações realizadas [BERTINO_93].

\subsubsection{0 - Rumbaugh}

Este Modelo propõe um mecanismo simples para controlar as operações de propagação quando estão envolvidas Versões e também Relacionamentos [RUMBAUGH_88]. Para isso, são utilizados Atributos particulares que podem adquirir um entre 4 valores: "none", quando as operações não se propagam; "propagate", quando a operação pode ser aplicada à Versão e aos seus Relacionamentos; "shallow", quando a operação pode ser propagada ao Relacionamento mas não à Versão; e "inhibit" que reprime a propagação enquanto existirem Relacionamentos no Objeto.

\section{4 - Versões na BD Extensional}

As Versões na Base de Dados Extensional são, na maioria das vezes, motivadas pelo interesse dos usuários em manter e possibilitar a criação e armazenamento de informações alternativas. Tal interesse está relacionado à complexidade do problema representado e pela organização de trabalho dos usuários, ou seja, grandes volumes de informações são normalmente manipulados por diversos usuários, possivelmente ao mesmo tempo, sendo estrategicamente interessante que estes trabalhos não tenham vínculos imediatos. 


\section{5 - Versões na BD Intencional}

As Versões na BD Intencional e mesmo certas Versões na BD Extensional são motivadas pelo processo de Evolução do Esquema de Dados Físico/Conceitual [CAMOLESI_96]. Isto porque, o processo de Evolução do Esquema envolve operações críticas, que podem implicar em alterações das Instâncias envolvidas e modificações nos programas aplicativos que utilizam estas Instâncias [TRESH_93], e para executá-las com segurança, algumas pesquisas propuseram técnicas e estratégias (ambos apresentados nas próximas seções) que se utilizam de Versões.

A estreita relação entre Instância e Esquema e mesmo a associação lógica entre os elementos alterados e inalterados de um Esquema pode gerar, inadvertidamente, alguns agravantes relacionados às incongruências conceituais do Modelo de Dados seguido. Para que isto seja evitado, devem existir regras ou métodos no Meta-Esquema de Dados [TRESH_92] que mantenham o Esquema de Dados integro e, conseqüentemente, as Instâncias consistentes.

Cada Modelo de Dados define os elementos existentes em seu Esquema, uma taxionomia de operações de alterações de Esquemas [KIM_89] e as regras semânticas para a execução das ações evolutivas que geram um Esquema "novo". O conjunto de operações de alteração devem ser definidas semanticamente e, sempre que uma ação ocorrer envolvendo estas operações, ela deve passar por filtros de integridade nos quais a consistência do Esquema "novo" é verificada com base nas invariantes [BANERJEE_87] do Modelo de Dados, ou seja, em um conjunto de condições, restrições e/ou recomendações para cada uma das operações de alteração permitidas.

\subsection{1 - Técnicas de Evolução}

As técnicas de Evolução de Esquema (entre as quais encontra-se "Schema Versioning") não possuem denominações usuais, mesmo porque não havia (até este trabalho) uma classificação exaustiva. A "operação básica", na qual as técnicas fundamentam-se, pode ser usada como critério para uma classificação, mas nenhuma destas técnicas é detalhada ao ponto de ter sua aplicabilidade diminuída. Deste modo, todas são capacitadas para o uso nas mais diferentes aplicações, mesmo porque cada técnica foi aprimorada ou estendida buscando uma compreensão genérica dos problemas.

\subsubsection{1 - "Creating/Modification"}

Esta técnica baseia-se na modificação do Esquema de Dados em uso. Para isso, é criado um Esquema de Dados "novo" utilizando-se ou não de uma cópia do 
Esquema de Dados já implantado. As modificações no Esquema "novo" devem ser de pequena grandeza, ou seja, poucas e pequenas alterações em relação ao Esquema implantado, mesmo que tenham grande influência sobre as Instâncias. Normalmente, as modificações do Esquema de Dados comportam operações simples (ex. "create", "delete" e "change"), descritas em comandos contidos na DDL ("Data Definition Language"), sobre os componentes básicos do Modelo de Dados seguido.

Geralmente o Esquema de Dados "abandonado" é eliminado da BD, contudo, opcionalmente, permite-se mantê-lo armazenado somente para revisões, dependendo do Modelo de Dados e do armazenamento das Instâncias "antigas".

\subsubsection{2 - "Additional"}

Esta técnica de Evolução do Esquema tem como característica a adição de novos elementos ao Esquema de Dados implantado, ou seja, a motivação desta técnica é acrescentar uma quantidade significativa de novos componentes de representação ao Esquema de Dados. A adição de uma grande quantidade de componentes ao Esquema de Dados caracteriza sua extensão para novos contextos de representação do empreendimento.

Aliada a uma abordagem própria para a realização do Projeto da Base de Dados, esta técnica pode oferecer meios para a adição de sub-esquemas (ex.: Esquemas Suplementares [CAMOLESI_93]) ou mesmo para incorporação gradativa do Esquema de Dados em relação às Instâncias que já se encontram armazenadas na Base de Dados (ex.: "approach bottom-up" [ZDONIK_93], "Incomplete Information" [ZICARI_90]). Para isto, requerem-se controles especiais que permitam a adição de novos elementos ao Esquema e que não comprometam nenhum aspecto do processo de manipulação de Instâncias.

\subsubsection{3 - "Schema Versioning"}

Esta técnica propõe a criação de Versões do Esquema como uma forma de realizar sua Evolução. Sua implantação no SGBD deve permitir uma navegação retroativa ou proativa entre as Versões, tanto para a realização de operações lógicas quanto fisicas nas Versões.

Dependendo da implementação e Modelo de Dados, as Versões "antigas" do Esquema de Dados podem ficar inativas indefinida ou momentaneamente, ou podem ter iguais condições de uso, ou seja, a instanciação pode ser realizada em qualquer Versão do Esquema e, neste caso, passa a existir o conceito de Esquema Corrente (ou Esquema Ativo, formado pelas Versões de Esquema requisitadas) e com as 
Instâncias sendo reconhecidas pelo SGBD somente quando sua definição está no Esquema em uso corrente.

As Versões podem ser criadas sobre o Esquema de Dados completo ou sobre uma parte, dependendo do grau de Evolução que sofrerá o Esquema em uso, da granularidade do Modelo de Versões seguido e da implementação (Sistema de Gerenciamento de Versões - SGBD/SGV) do controle de criação de Versões.

Um controle rigoroso deve ser implementado no gerenciamento do Esquema, que permita a criação de Versões coerentes com a taxionomia de operações de alteração do Esquema em relação ao Modelo de Dados. Sendo, talvez, um processo de longa duração e de grande complexidade, pode-se optar pela criação simultânea de Alternativas para uma Versão do Esquema, ou seja, o desenvolvimento paralelo de possíveis Versões do Esquema de Dados.

Ao final do processo de criação, as Alternativas são confrontadas para a escolha daquela que melhor representa o empreendimento em sua nova concepção e que se tornará uma Versão do Esquema. As Alternativas podem passar também por operações de "conversational merging" [ZDONIK_86], onde busca-se aglutinar as melhores soluções ou inovações apresentadas em cada Alternativa para a formação de uma Versão do Esquema.

\subsection{2 - Estratégias de Propagação nas Instâncias}

$\mathrm{Na}$ literatura científica, pode-se encontrar classificações [BJORNERSTEDT_89] aparentemente estabelecidas para as Estratégias de Propagação, que descrevem principalmente a abordagem usada para a utilização do Esquema de Dados "novo". Pode-se encontrar também muitas variações destas estratégias, inclusive daquelas que se utilizam de Versões ("Versioning" e "Materializing"), em adaptações para problemas específicos. No entanto, estas estratégias atualmente enquadram-se em categorias descritas a seguir.

\subsubsection{1 - "Copying"}

A Cópia apresenta uma abordagem simples porém muito utilizada nos SGBD's. Nela, após o estabelecimento de um Esquema "novo", realiza-se de uma única vez a transposição imediata das Instâncias envolvidas na Evolução, ou então, realiza-se a transposição incremental de subconjuntos das Instâncias envolvidas até que todas tenham sido alteradas. A transposição das Instâncias envolvidas é realizada 
através da criação de cópias ${ }^{6}$ de seus dados para a nova situação (do Esquema em uso para o Esquema "novo").

A desvantagem desta abordagem é o tempo consumido para a concretização das cópias de acordo com o Esquema de Dados "novo", o que pode depender da implementação desenvolvida para o sistema de gerenciamento.

\subsubsection{2 - "Updating"}

Nesta estratégia, a passagem para um Esquema "novo" ocorre pela Conversão de suas Instâncias. Quando a conversão das Instâncias envolvidas é realizada imediatamente após a criação do Esquema "novo", a estratégia recebe a denominação de Conversão Imediata ("Immediate update" ou "eager update"). A desvantagem da Conversão Imediata está no tempo consumido para a concretização de todas as conversões em uma única vez, de acordo com o Esquema "novo".

Outra opção consiste em converter as Instâncias durante sua manipulação, através da Conversão Incremental ("Delayed update" ou "Lazy update") [TAN_89]. A cada informação acessada pelo SGBD, é reconhecido seu Esquema de Dados e verificada a existência de alguma indicação de Evolução; caso alguma seja encontrada, o SGBD realiza a conversão da porção acessada da informação para o Esquema "novo".

A desvantagem desta abordagem se estabelece na velocidade de execução das requisições dos dados que não encontram-se convertidos, ou seja, para os pedidos de manipulação de dados ainda não convertidos ocorrerá um certo atraso na apresentação, pois o SGBD deverá realizar a conversão para o Esquema "novo" antes de retornar uma resposta.

\subsubsection{3 - "Screening"}

Mapeamento (ou "Screening") consiste em prorrogar indefinidamente ("deferred-update") a atualização das Instâncias mesmo após o Esquema "novo" ser criado, ou seja, nenhuma alteração fisica é realizada nas informações instanciadas até que a reorganização da BD seja exigida explicitamente por um usuário qualificado.

A cada informação acessada pelo SGBD, faz-se o reconhecimento de seu

\footnotetext{
${ }^{6}$ A cópia original de uma Instância ou de um Esquema é operacionalmente restritiva em sua utilização, ou seja, sobre a origem de uma Cópia pode-se apenas realizar consultas em apoio a operações mais complexas de Evolução. Por outro lado, a Cópia resultante terá as restriçōes de operação originalmente atribuídas ao elemento copiado.
} 
Esquema de Dados e verifica-se a existência de alguma indicação de Evolução. Caso alguma seja encontrada, o SGBD realiza a adaptação lógica da informação segundo o Esquema "novo", que age como um "filtro" para criar a ilusão de Instâncias modificadas.

Esta estratégia compromete a velocidade de execução de qualquer operação de manipulação de dados, uma vez que as informações apresentadas aos usuários devem ser transformadas de acordo com o Esquema "novo" (filtro).

\subsubsection{4 - "Versioning"}

Nesta estratégia, um Esquema de Dados "novo", ao ser instanciado, leva à criação de Versões das Instâncias atingidas, de acordo com a granularidade imposta pelo Modelo de Versões. Dependendo também da implementação, as Versões de Instâncias podem ter diferentes graus de flexibilidade para a manipulação ou podem ter iguais condições de uso.

As Versões de Instâncias podem ser criadas gradativamente pelo usuário, desde que monitoradas pelo SGBD, ou podem ser geradas automaticamente pela cópia/conversão, imediata ou incremental, de uma Versão de Instância para outra, desde que seja utilizado o Esquema de Dados correspondente.

Esta abordagem não apresenta desvantagens significativas, apenas requer um nível maior de controle das Instâncias, normalmente realizado por um Sistema de Gerenciamento de Versões que normalize as atividades de criação, remoção, manipulação e consulta das Versões de Instâncias que podem habitar simultaneamente a Base de Dados.

\subsubsection{5 - "Materializing"}

O objetivo desta estratégia não é atingir as Instâncias já existentes através de operações de cópia, atualização, conversão lógica ou criação de Versões, mas sim realizar novas instanciações ("materialização de Instâncias") de acordo com o Esquema de Dados "novo". As Instâncias já existentes e seu Esquema de Dados permanecem inalterados e possivelmente utilizáveis por qualquer usuário qualificado.

Particularmente, esta estratégia não requer controles especiais e não compromete nenhum aspecto do processo de manipulação de Instâncias, porem exige do SGBD a capacidade de reconhecer o Esquema de Dados de cada Instância dos dados armazenados e a flexibilidade para a "Materialização das Instâncias" em momentos propícios para os usuários. 


\subsection{3 - Técnicas de Evolução versus Estratégias de Propagação}

As Técnicas de Evolução do Esquema de Dados ("Creating/Modification", Additional" e "Schema Versioning") podem conviver em um mesmo sistema, isto porque, são complementares em alguns aspectos de aplicabilidade, tornando-se útil ao DBA em diversas situações evolutivas.

As Estratégias de Propagação apresentam algum tipo de deficiêncial comprometimento da velocidade de execução das operações de manipulação de Instâncias quando é efetivada a propagação da Evolução para a Base de Dados Intencional. Por este motivo, um SGBD não deve apoiar-se exclusivamente em uma única estratégia. A tabela 2.1 mostra as possíveis e impossiveis composições entre as Técnicas de Evolução de Esquema e as Estratégias de Propagação em Instâncias. Não existe um estudo prático sobre estas composições, mesmo porque nunca foram explicitamente apresentadas desta forma.

Tabela 2.1 - Técnicas de Evolução de Esquema versus Estratégias de Propagação

\begin{tabular}{|l|l|l|l|l|l|}
\cline { 2 - 6 } \multicolumn{1}{c|}{} & Copying & Updating & Screening & Versioning & Materializing \\
\hline Creating/Modification & 1 & 2 & 3 & A & 4 \\
\hline Additional & B & C & 5 & D & 6 \\
\hline Schema Versioning & E & 7 & 8 & 9 & 10 \\
\hline
\end{tabular}

As situações não permitidas (indicadas por letras na tabela 2.1) devido aos princípios que regem as Técnicas de Evolução e as Estratégias de Propagação são:

- A - A Técnica de "Creating/Modification" parte do princípio que existirá apenas um único Esquema de Dados ("novo") e considera o Esquema de Dados, que está sendo substituído, como um elemento de apoio para cópia, conversão ou mapeamento e portanto, não há possibilidade ou necessidade de existirem Versões de Instâncias para o Esquema modificado.

- B, C, D - A Técnica "Additional" pratica a adição de componentes "novos" ao Esquema de Dados, e portanto não se enquadra nas Estratégias de "Copying", "Updating" e "Vesioning" pelo fato destas estratégias realizarem a intermediação entre dois estados de cada um dos componente focalizados na Evolução do Esquema. 
- E - A Técnica de "Schema Versioning" propõe a existência de Versões do Esquema de Dados em iguais condições de utilização, e portanto não se pode simplesmente realizar a Cópia das Instâncias de uma Versão para outra, o que restringiria a utilização das Instâncias copiadas.

O conteúdo sintático e semântico das composições permitidas (indicadas por números na Tabela 2.1) entre as Técnicas de Evolução e as Estratégias de Propagação pode sofrer variações, mesmo porque, alguns Modelos de Dados incorporam várias destas composições buscando flexibilizar a Manutenção da Base de Dados. As composições possiveis são:

- 1 - Partindo-se do Esquema "novo", criado e modificado com base no Esquema original, realiza-se a cópia das Instâncias para a nova situação.

- 2 - O Esquema criado é utilizado para a atualização (imediata ou incremental) das Instâncias, de um estado para outro na seqüência evolutiva.

- 3 - O Esquema original da operação de cópia pode ser mantido na BD para uma possivel navegação retroativa (além do mapeamento), desde que restrita apenas à consulta. O SGBD sustenta o armazenamento das Instâncias vinculadas ao Esquema de Dados, mantendo os vínculos entre as Instâncias e os Esquemas ativo e inativo para tornar operacionais as consultas dos usuários com privilégios de acesso.

- 4 - Alguns poucos componentes podem ser alterados ou acrescentados ao Esquema "novo" e deles realiza-se a instanciação.

- 5 - Certos componentes adicionados ao Esquema podem não ser visualizados logicamente pelos usuários, o que caracteriza a estratégia de "Screening".

- 6 - A adição de elementos novos ao Esquema deve provocar a instanciação destes elementos. Assim, Instâncias que já existem podem não ser atingidas e outras podem sofrer o acréscimo de algumas informações (ex.: Relacionamentos, Atributos).

- 7 - Mantêm-se as Versões do Esquema e seus procedimentos de conversão para se realizar todas as alterações. No caso do Modelo de Dados incluir também os procedimentos de restauração [MONK_93], tem-se caracterizado uma Conversão "Direcionada", em que operações "update/backdate" são realizadas de acordo com a demanda de manipulação, utilizando-se Versões de Esquemas escolhidos.

- 8 - Os procedimentos de conversão são mantidos inoperantes até a Reorganização da $\mathrm{BD}$, que pode ser evitada indefinidamente para possibilitar que os usuários tenham diferentes "visões" das Instâncias, pois são mantidas as interrelações (mapeamento) entre as Versões do Esquema. Desta forma, cada informação terá um 
Esquema real (fisico) e poderá adaptar-se a diversas Versões de Esquema (lógico).

- 9 - As Versões de Instâncias dá Base de Dados são criadas de acordo com as Versões de Esquemas, ou seja, no momento em que é estabelecida uma Versão consistente de um Esquema "novo", pode-se iniciar o processo de criação automática (imediata ou incremental) de Versões das Instâncias atingidas pela nova Versão de Esquema. Tanto para as Versões de Esquema que possam existir, quanto para suas respectivas Versões de Instâncias, devem existir meios para flexibilizar seu uso e navegabilidade.

- 10 - As Versões de Instâncias são criadas gradativamente pelo usuário, de acordo com as Versões de Esquema de Dados.

\section{6 - Considerações Finais}

O panorama apresentado neste capitulo demonstra que apesar do tema "Versões em Bases de Dados" ser relativamente intuitivo e bastante discutido, ainda não se consolidou, mesmo sendo de grande importância às necessidades de muitas aplicações. Pelos estudos bibliográficos realizados, pôde-se notar os raros detalhes fornecidos em artigos relatando trabalhos relacionados e os poucos resultados fornecidos, talvez refletindo os estágios atuais das pesquisas e utilização de Versões em problemas reais.

Apesar disso, entre os vários trabalhos apresentados, constatou-se que os Modelos de Versões apoiam-se no paradigma de "orientação a objetos", pois nele encontram-se meios para elaborar estruturas e metodologias que garantem uma consistente implantação/execução.

Esta mesma independência de Modelos de Dados e inclusive de Modelos de Versões existe entre as técnicas e as estratégias que envolvem o processo de Evolução de Esquemas e que particularmente utilizam-se de Versões (Instâncias e Esquemas). Isto permite mesclar Modelos de Dados Orientados a Objetos, Modelos de Versões e técnicas/estratégias de Evolução de Esquema, de acordo com a implementação desejada nos SGBD's. 


\section{capítulo 3}

\section{PADRÕES \\ MODELOS DE DADOS}

\section{1 - Considerações Iniciais}

Os Modelos, de um modo geral, atuam na representação detalhada de componentes e processos de entidades abstratas, fisicas ou fenômenos, possibilitando desta forma suas descrições estruturais e comportamentais. Áreas de ciências exatas, sociais e biológicas empregam seus respectivos Modelos para a visualização, simulação, teste e previsão do comportamento de entidades para fins de compreensão, experimentação e aprendizado de sistemas com grande número de variáveis.

$\mathrm{Na}$ área de BD's surgiu um grande número de Modelos de Dados em que seus conceitos básicos de modelagem e técnicas são diferentes em uso e geralmente na implementação, de acordo com as necessidades ou mesmo por divergências conceituais/filosóficas. O estabelecimento de Padrões envolvendo Bases de Dados surgiu das necessidades mundiais, cada vez mais crescente, de buscar consensos e intercâmbios entre estes trabalhos.

Para elucidarmos as abordagens funcionais e operacionais de alguns Modelos de Dados e Padrões, este capitulo procura formar um conjunto de informações e encontrar 
subsídios para uma análise crítica desta pesquisa. Neste sentido, a atenção ao se analisar as publicações sobre os Modelos e Padrões está basicamente voltada para os conceitos relacionados a esta pesquisa (Versões de Instâncias e Esquemas), que permita, ao final, uma análise comparativa entre este Modelos e Padrões.

A descrição bibliográfica deste capítulo é resumida e contempla determinados trabalhos de pesquisa, não tendo portanto a intenção de apresentar todos os Modelos de Dados e os Padrões existentes, mas apenas alguns dos mais importantes e que encontram-se disponíveis em publicações de grande circulação.

\section{2 - Modelos de Dados}

Segundo o grupo especial de estudos ANSI/X3/SPARC ${ }^{1}$, um Modelo de Base de Dados (ou Modelo de Dados) é genericamente uma ferramenta lógica de representação e descrição abstrata de um problema real ou de uma "imagem" de uma realidade. Para isso, um Modelo de Dados deve possuir uma linguagem de especificação que, utilizando-se de um conjunto de símbolos (gráficos e/ou textuais), formaliza os elementos do mundo real e assim, descreve relacionamentos, semânticas e restrições das informações dispostas em uma Base de Dados.

Tendo enfoques diferenciados para a ação de modelagem, surgiram Modelos de Dados Físicos oferecendo ferramentas de representação usadas na descrição das estruturas de armazenamento de uma BD e Modelos de Dados Conceituais/Lógicos que permitem a representação de dados de uma forma desvinculada de qualquer estrutura fisica.

Apesar das diferenças conceituais e de terminologias, uma classificação dos Modelos de Dados Conceituais/Lógicos, segundo Cattell [CATTELL_94], pode agrupálos em paradigmas, de acordo com suas aplicabilidades e linhas conceituais, e também relacioná-los genealogicamente por suas heranças históricas de definições.

\subsection{1 - Modelos Baseados em Registros}

Até meados dos anos 70 , existiam no mercado um conjunto limitado de aplicações comerciais (atualmente denominadas convencionais) para Base de Dados, porém de grande interesse, cujas características se assemelhavam e cujos problemas se estabeleciam, por exemplo, na manipulação de grandes conjuntos de dados de pequena complexidade.

ANSI - "American National Standands Institute"

X3 - Comitê sobre Computadores e Processamento de Informações

SPARC - "Standards Planning and Requirements Committe" 
Incentivados por esta demanda, pesquisadores desenvolveram diversos Modelos de Dados, dos quais se destacaram o Relacional (IBM) [CODD_70], Rede [CODASYL_71] e Hierárquico [DATE_88a], que possuem em comum a utilização do conceito de Arquivo (Relação ou pseudo-arquivo) como elemento fundamental para a modelagem de aspectos do mundo real e, por esse motivo, este Modelos se tomaram tradicionalmente representações estruturais dos dados.

A popularidade deste paradigma ("Baseado em Registro"), de seus Modelos e respectivos SGBD's, pode ser atribuída ao rigor com que foram criados e fundamentados, e principalmente à simplicidade com que abordam os problemas de modelagem, além de uma divulgação bem estruturada e selecionada. Apesar disto, estes Modelos apresentam limitações quando são direcionados para problemas mais complexos que surgem da crescente necessidade da empresas e usuários.

\subsection{2 - Modelos Semânticos}

Entre os fatores responsáveis pelo destaque do "paradigma semântico", pode-se citar a clareza de suas notações, decorrente das informações derivadas do mundo real serem modeladas explicitamente em Entidades, Relacionamentos e Atributos, e também devido a flexibilidade de seus conceitos que possibilita extensões dos Modelos, como por exemplo, a inclusão de Abstrações de Dados [SMITH_77].

Entre os Modelos de Dados que se destacaram neste paradigma encontram-se: o Modelo Entidade-Relacionamento (ME-R) [BATINI_92], "Semantic Database Model" (SDM) [HAMMER_81], TAXIS [MYLOPOULOS_80] e o "Semantic Association Model" (SAM*) [SU_86].

\subsection{3 - Modelos Funcionais}

Historicamente relacionados com os Modelos Semânticos porém mais adaptados a representar certos problemas, o "paradigma funcional" desenvolvido pelos Modelos Funcionais e seus respectivos SGBDF's (Sistemas de Gerenciamento de Bases de Dados Funcionais) se estabeleceram como técnicas simples de representação baseada em notação matemática, e cujo conceito de Função possibilita a definição de Relacionamentos e Atributos associados a Objetos.

Os Modelos Funcionais, entre os quais temos o FDM [SHIPMAN_81] e o Event (ou INSYDE) [KING_85], não obtiveram grande reconhecimento, todavia ofereceram e atualmente ainda determinam significativas contribuições para seus sucessores, em termos de estrutura, linguagem e na utilização de técnicas de evolução de dados. 


\subsection{4 - Modelos Relacionais Estendidos}

O Modelo Relacional tem grande aceitação nos meios comerciais e científicos pelo fato de ser simples e bem fundamentado. Por esse motivo, gerou-se uma variedade de Modelos "descendentes" do modelo de Codd e dos Modelos Semânticos, como por exemplo, o RM/T [DATE_88b] e o POSTGRES [STONEBRAKER_86]. As pesquisas estão atualmente orientadas para estender os SGBDR's, Sistemas de Gerenciamento de BD Relacionais, de modo a incluir novos elementos estruturais e funcionais necessários às aplicações contemporâneas.

Devido a simultaneidade entre as pesquisas com os SGBDR's Estendidos e a tecnologia do paradigma de "Orientação a Objetos", muitos dos seus conceitos se confundem e fundem-se, o que de certa forma traz beneficios para ambas as linhas de pesquisa.

\subsection{5 - Modelos Orientados a Objetos}

O paradigma da "Orientação a Objetos" originou-se de linguagens de programação como SIMULA-67 e posteriormente SMALLTALK-80, que exploraram e refinaram alguns conceitos na busca de uma técnica eficiente de organização e programação de grandes sistemas. $\mathrm{Na}$ área de Bases de Dados, os Modelos Orientados a Objetos tiveram seus fundamentos apoiados em extensões dos Modelos Semânticos, Funcionais e algumas vezes nos Modelos Relacionais Estendidos.

Apesar de relativamente recentes, as técnicas de modelagem de Bases de Dados Orientadas a Objetos [KIM_92] [NAVATHE_92] têm exercido grande interesse por parte de pesquisadores e empresas de diversas áreas. Por esse mesmo motivo, as várias propostas de Modelo diretamente aplicados a SGBDOO's (Sistemas de Gerenciamento de Base de Dados Orientadas a Objetos) [BERTINO_91] são ainda incompletas e encontram-se na literatura muitas conjecturas e disparidades entre os conceitos envolvidos neste paradigma.

Os SGBDOO's possibilitam o desenvolvimento de ambientes integrados para auxilio a projetos de engenharia (civil, elétrica, mecânica, naval, aeronáutica, espacial entre outras), além de apoiar sistemas de automação de escritório e de multimídia. Incluem-se normalmente entre suas interfaces, diversos "assistentes" gráficos para o apoio ao armazenamento e a navegação/consulta de informações, além de uma ou mais linguagens de programação derivadas da Linguagem $\mathrm{C}++$ para $\mathrm{o}$ desenvolvimento de programas aplicativos. 


\subsubsection{1 - AVANCE}

A universidade de Stockholm e o SISU ("Swedish Institute for Systems Development"), partindo de conceitos experimentais, desenvolveram um protótipo de um sistema de gerenciamento (OPAL, posteriormente denominado AVANCE) para ser aplicado aos sistemas de automação de escritórios, CAD, e CASE, que requeiram uma Base de Dados distribuída.

O AVANCE [BJORNERSTEDT_89] foi projetado em três niveis de abstrações para implementação. $O$ primeiro é um Gerenciador de Objetos que realiza as manipulações de dados, seguido de uma Máquina Virtual que proporciona um interpretador de pseudo-código e por último uma linguagem denominada PAL.

O controle de Versões é um subsistema essencial na realização das funções embutidas no AVANCE. Ao nível de aplicação, as Versões permitem a coexistência de diversas alternativas dos Objetos e a conseqüente geração do grafo histórico de Versões (Modelo de Klahold, Schlageter \& Wilkes - seção 2.3.1), ao passo que, ao nível de sistema, as Versões estão basicamente relacionadas com o controle de concorrência, recuperação de históricos e o gerenciamento de Transações envolvendo o acesso a dados distribuídos.

Na Evolução do Esquema, os Tipos são tratados como Objetos e desta forma, a alteração de suas definições possibilita a criação de Versões que são armazenadas por motivos históricos uma vez que, as Instâncias de cada Tipo são convertidas e mantidas sempre de acordo com Versão mais recente deste Tipo.

\subsubsection{2 - Iris}

Iris [WILKINSON_90] é um modelo de dados desenvolvido pela HP e originário dos modelos semânticos, tendo deles evoluído com a inclusão de três conceitos básicos: Objetos, Tipos e Funções. O OpenODB (um SGBD baseado em Iris) tem como objetivo satisfazer as necessidades dos sistemas de Automação de Escritórios, CAD e CASE.

A arquitetura do Iris [FISHMAN_89] é dividida em interface, Gerenciador de Objetos e Gerenciador de Armazenamento. Na interface, o modelo apresenta mecanismos de acesso interativo, entre os quais estão a linguagem OSQL (Object $\mathrm{SQL}$ ), linguagem $\mathrm{C}$ e editores gráficos. O Gerenciador de Armazenamento é responsável pelos controles de recuperação, indexação, "buffering" e "clustering", enquanto o Gerenciador de Objetos realiza consultas, atualizações e otimizações em Objetos, Funções e Versões.

O controle de Versões do Gerenciador de Objetos considera todos os Objetos 
(ou Objetos Compostos) "non-versionable", podendo deles criarem-se (sem restrições) Versões através de um processo de mutação (Modelo de Beech \& Mahbod - seção 2.3.8) invocado pelo comando "create".

As derivações de Versões são representadas por grafos acíclicos dirigidos, nos quais as Versões podem apresentar-se em três estados: trabalho, estável e congelada (Modelo de Chou \& Kim - seção 2.3.3), de acordo com a situação de uso da aplicação. A duplicação e unificação de Versões é realizada pelos comandos "checkin" e "checkout", onde os usuários restringem o acesso e derivação utilizando "lock key" em um sistema de proteção.

A referência a um Objeto pode especificar uma Versão em particular ou um Objeto Genérico cujas propriedades próprias podem ser herdadas das Versões associadas. $\mathrm{O}$ Objeto Genérico é criado pelo sistema automaticamente quando gerada a primeira Versão do respectivo Objeto e, qualquer referência a ele é solucionada dinamicamente através de um mecanismo baseado em um Objeto especial denominado Contexto.

O Contexto possui regras definidas pelos usuários e que apoiarão a avaliação das referências. As regras são definidas por seqüências de < gatilho, predicado, ação>, onde gatilho especifica a ativação antes ou depois de uma função, predicado é uma expressão lógica para avaliação e a ação é definida por uma linguagem própria.

A evolução do Esquema de Dados é limitada apenas às operações de inserção e remoção de Tipos e Funções, desde que não ocorram conflitos. Todas as modificações de Tipos no Esquema irão acarretar mudanças em todas as Versões de Objetos do Tipo modificado e não apenas em algumas Versões.

\subsubsection{3 - Cactis}

Cactis [HUDSON_87] [HUDSON_88] foi desenvolvido na Universidade do Colorado para auxiliar CAD/CAM e CASE. Para isso, o Cactis [HUDSON_89] suporta a representação de aspectos comportamentais através de Atributos Derivados, atribuindo-lhes Regras, as quais permitem operações sobre Atributos do mesmo Objeto ou de outros Objetos. Desta forma, operações em um Objeto poderão desencadear uma série de ações, desde que estejam de acordo com as Restrições impostas pelo Esquema.

O desencadeamento automático de ações, por meio de Regras, proporciona um eficiente meio de propagação de alterações do Esquema. Estas modificações, quando atingem as definições dos Tipos, geram Versões indicadas por Objetos Delta (Modelo de Ketabachi \& Berzins - seção 2.3.7) que permitem a restauração de estados anteriores dos Tipos e de suas Instâncias. 


\subsubsection{4 - EXODUS / EXTRA}

EXODUS [CAREY_88] é um projeto para criação de SGBD's, desenvolvido pela Universidade de Wisconsin, que apresenta o Modelo de Dados EXTRA e a linguagem de consulta EXCESS, com o objetivo de suportar aplicações cientificas ou que utilizem vozes e imagens, além de auxiliar no desenvolvimento de projetos em engenharia.

Segundo o modelo, os Objetos são organizados fisicamente em unidades de armazenamento ("Storage Objects") [RICHARDSON_87], as quais contêm dados logicamente relacionados (Objeto), independente de serem compostos por poucos "bytes" ou mesmo centenas de "megabytes". Cabe ao usuário, durante a criação de cada Objeto, determinar a permissão de seu desdobramento em Versões. Todo o controle de Versões realizado está baseado em "Storage Object", e assim, caso um Objeto autorizado a ter Versões seja atualizado, este é automaticamente copiado para uma nova unidade de armazenamento, onde se realizarão as alterações. Os conjuntos de Objetos ("Storage Objects"), logicamente ou fisicamente relacionados, são agrupados em "Files".

Para Objetos cujos volumes ultrapassam centenas de "bytes", o gerenciador estabelece o armazenamento em disco somente daquelas informações que foram modificadas. Com a utilização deste mecanismo de Deltas (Modelo de Ketabachi \& Berzins - seção 2.3.7), as Versões compartilharão informações que possuam em comum, o que proporcionará uma economia de memória.

O EXTRA inclui um algoritmo de otimização de Versões [CAREY_89] necessário para uma real utilização do sistema por seus usuários, que consiste basicamente em percorrer o grafo de derivação de Versões para se definirem quais as informações podem ser apagadas das Versões, por não serem usadas por nenhum antecessor ou sucessor.

A relação temporal entre as Versões é determinada utilizando-se o "time stamp" de cada Versão de Objeto em conjunto com seu identificador (oid). Assim, possíveis navegações pelas Versões podem reconhecer associações históricas entre os dados.

O EXODUS não propõe um modelo específico para o tratamento de Versões, pois seu objetivo é oferecer uma estrutura aberta que possa ser adaptada a qualquer aplicação. Portanto, não existem planos definidos para o relacionamento entre Versões e muito menos um diagrama de estados pré-estabelecido.

\subsubsection{5 - GemStone}

O gerenciador GemStone [BRETL_89] é desenvolvido pela Servio Logic Corp. e inicialmente combinava conceitos da linguagem SMALLTALK com funções de gerenciamento de dados. Atualmente, o GemStone trabalha na integração das linguagens 
C++ e OPAL buscando reduzir o tempo de desenvolvimento de aplicações complexas.

O GemStone [BUTTERWORTH_91] está estruturado em dois módulos de processamento, trabalhando em uma rede local na arquitetura cliente/servidor. $\mathbf{O}$ módulo Stone, tipicamente armazenado no servidor, realiza o gerenciamento dos dispositivos de armazenamento bem como os serviços de recuperação, controle de concorrência, transação e autorização. $O$ módulo $\mathrm{Gem}$ reside no cliente e compila/executa os programas aplicativos, possibilitando a intercomunicação com o módulo Stone.

Seguindo a filosofia do modelo, o sistema GemStone não distingui entre Objetos persistentes e não-persistentes, o que proporciona uma visão uniforme e consistente da $\mathrm{BD}$, mesmo para acessos simultâneos de vários usuários. $\mathrm{O}$ controle de concorrência, responsável pela visão integra dos dados, pode ser executado nos métodos otimista ou pessimista, isto é, na execução de Transações concorrentes pode-se optar pela prevenção de conflitos (controle pessimista) ou a exclusão dos conflitos que ocorrerem durante a efetivação das operações (controle otimista).

A perda do trabalho das Transações pelo controle otimista pode ser significativo em alguns casos, dependendo do grau de competitividade dos dados. Para resolver esse problema, uma solução é permitir que cada Transação crie Versões dos Objetos requeridos quando encontrado um conflito, o que adia a escolha entre os Objetos conflitantes até o momento em que o usuário decide por uma das Versões existentes.

Muitas outras características têm sido incluídas no GemStone, das quais se destacam: o "gateway" para BD Relacional Sybase; "Garbage Collection"; e a técnica de Evolução de Esquema que baseia-se em atualizações das definições de Classes com a conseqüente conversão automática destas atualizações nas respectivas Instâncias.

A possibilidade de alterações na estrutura das Classes [PENNEY_87] obriga o controle de concorrência e de autorizações a reverem suas funcionalidades. Em um exemplo, a simultaneidade de manipulação de Objetos e de manipulação da estrutura de suas Classes, por usuários distintos, pode causar a violação de integridade. Noutra situação, é exigida a intervenção nos níveis de acesso e manipulação de modo a permitir a conversão automática das Instâncias e a notificação das mudanças aos usuários credenciados (Modelo de Vines, Vines \& King - seção 2.3.9).

\subsubsection{6 - 02}

O SGBDOO O2 [DEUX_90] [DEUX_91] foi desenvolvido na França por um consórcio de empresas (ALTAIR) [LECLUSE_88] entre 1986 e 1990. Atualmente tem se transformado em um produto cujo desenvolvimento e comercialização estão a cargo da empresa $\mathrm{O} 2$ Technology (sediada em Versailles). 
A arquitetura (O2Engine) é organizada em três níveis: o Gerenciador de Esquema responsável pelo controle de consistência sobre as manipulações dos metadados; o Gerenciador de Objetos que suporta a arquitetura cliente/servidor e os demais controles (transações, "garbage collection" etc); e o O2Store (extensão do WiSS-"Wisconsin Storage Subsystem") que controla os armazenamentos secundários, indexação por B-Tree e proporciona funções de persistência.

Adicionalmente, o sistema O2 agrega ambientes (LOOK - ambiente de geração de interfaces e OOPE - ambiente de programação), ferramentas (processador de linguagens, processador de consultas) e linguagens de programação $(\mathrm{C}, \mathrm{C}+\mathrm{H}, \mathrm{O} 2 \mathrm{C}$ e O2SQL) para apoio aos usuários

A Evolução do Esquema evita qualquer forma de conflito com os dados armazenados. Assim, as modificações não podem ser executadas dinamicamente e as Classes são removidas quando não possuírem Objetos e Classes dependentes. No caso dos Métodos, a remoção ocorre se não são herdados e não estiverem ativos.

Uma forma encontrada para proporcionar flexibilidade à estrutura de Classes são as chamadas Classes Virtuais [ABITEBOUL_91], que consistem em Classes formadas a partir de Visões, dos usuários, definidas em operações da DML. Conceitualmente, um programador pode construir uma Hierarquia de Classes Virtuais tanto na forma "Topdown" (via especialização) quanto "Bottom-up" (via generalização).

Entre as muitas propostas de extensões ao $\mathrm{O} 2$ existe um novo conceito, denominado Especificação Incompleta [ZICARI_90], que tenta abordar as situações encontradas pelos usuários, principalmente na fase de projeto, quando nem todas as informações estão disponíveis. Sua aplicação permite definir Classes (no Esquema de Dados) e até mesmo Objetos de maneira incompleta, ou seja, algumas informações poderão momentaneamente não serem armazenadas na Base de Dados por não estarem disponíveis.

$\mathrm{O}$ encapsulamento proporcionado pelo modelo $\mathrm{O} 2$ permite tratar as Classes de maneira tradicional, agrupá-las em conjuntos de Classes para exportação e importação e também tratá-las como pequenas Bases de Dados para efeito de compartilhamento em aplicações remotas.

\subsubsection{7 - ORION / ITASCA}

O projeto ORION [BANERJEE_87] [KIM_89] [KIM_90] foi lançado no final de 1985 pela Microeletronics and Computer Technology Corporation como um protótipo de Sistema de Gerenciamento de Base de Dados Orientados a Objetos para suportar aplicações em $\mathrm{CAD} / \mathrm{CAM}$ e automação de escritórios. A versão comercial do ORION 
está sendo implementada desde 1989, como ITASCA [CATTELL_94], pela empresa Itasca Systems (sediada em Minneapolis).

O sistema ITASCA possui: um Módulo Manipulador de Mensagens; um Subsistema de Objetos com funções de alto nível incluindo modificações do Esquema e o controle de Versões; um Subsistema de Armazenamento; e um Subsistema de Transações que inclui o gerenciamento de concorrência e recuperação.

Em uma versão recente, o ITASCA adquiriu uma estrutura de suporte à distribuição, onde a Base de Dados é dividida em pública e privada. A BD pública é compartilhada por diversos usuários e pode ser distribuída pelos nós de uma rede local. A BD privada é de conhecimento e exclusividade do usuário que a criou e pode armazenar dados da BD pública (ou vice-versa) usando operações de "checkincheckout".

O modelo de Versões [BERTINO 93] estabelecido no ORION define três estados para os Objetos ou Objetos Compostos (Modelo de Chou \& Kim - seção 2.3.3). Versões Transientes podem ser atualizadas ou removidas pelo seu criador (usuário), sendo armazenadas em sua BD privada. Versões de Trabalho são estáveis podendo ser removidas pelo criador mas não atualizadas, sendo armazenadas na BD privada. Versões "Released" são armazenadas na BD pública não podendo ser atualizadas ou removidas. Pelas regras de transição de estados, um usuário pode promover uma Versão Transiente para Versão de Trabalho e posteriormente para Versão "Released", de acordo com as suas necessidades de trabalho/projeto.

As Versões de Objetos são permitidas apenas para as Classes autorizadas explicitamente. $O$ usuário pode fazer referência a um Objeto específico ou a um Objeto Genérico criado automaticamente pelo sistema e que representa uma Árvore de Derivação. Caso o usuário tenha optado pela referência ao Objeto Genérico, o sistema em tempo de execução selecionará a Versão mais recente.

Uma extensão do modelo, ainda não implementado no ORION ou no ITASCA, permite a Evolução do Esquema através da criação de Versões dos metadados em três granularidades (Esquema, Classe e Visão). Escolhida a granularidade, as Versões são mantidas em igualdade de uso, cabendo ao sistema realizar o mapeamento ou a conversão automática entre as diversas Versões e suas respectivas Instâncias de Objetos.

\subsubsection{8 - ODE}

ODE [AGRAWAL_89] é um SGBD e um ambiente cuja proposta é adicionar funcionalidades às linguagens de programação. Particularmente, o modelo 
propõe a linguagem $\mathrm{OH+}$ que agrega facilidades para a criação de Objetos Persistentes, manipulação de Versões, Controle de Restrições e outras.

As Versões são estabelecidas individualmente para cada Objeto sem alterar a definição dos respectivos Tipos e portanto, não há necessidade de qualquer procedimento de transformação. Tanto para a criação de Versões, que deve ser realizada explicitamente por um comando, quanto para as operações de remoção e modificação, não existem restrições que impeçam as ações dos usuários. Organizados em uma Árvore de Derivação e sem distinções de estados, as Versões podem ser referenciadas especificamente ou através de Objeto Genérico e nesse caso, a referência é dinamicamente direcionada para o Objeto mais recente.

\subsubsection{9 - Outros}

Outros SGBDOO ${ }^{2}$ vêm alcançando robustez e refinamento como é o caso do ObjectStore da Object Design [LAMB_91], ONTOS da Ontos Inc., Objectivity/DB da Objectivity Inc, VERSANT da Versant Object Technology Inc., POET da Poet Software Inc e o GNOMO [FORNARI_93].

\subsection{6 - Análise Comparativa}

Entre os Modelos citados anteriormente, particularmente aqueles que seguem o paradigma "orientação a objetos", percebem-se muitas diferenças [GOLENDZINER_93] [ZAND_95] que abrangem desde conceitos, técnicas, implementações, usos e mesmo as arquiteturas de seus protótipos/produtos.

Tendo como objetivo salientar as diversas propostas para o controle de Versões e a Evolução de Esquemas, registram-se abaixo vários itens cujas especificações estabelecem as características variantes que são normalmente encontradas nos Modelos de Dados:

- [1] Estrutura de Derivação:

as Versões podem ser organizadas e interligadas por Relacionamentos especiais formando uma lista (L), uma árvore (A) ou um grafo acíclico dirigido (G);

2 Outros gerenciadores possuem ou estão em fase de desenvolvendo de um subsistema de controle de Versões, contudo não oferecem inovações em relação àqueles destacados neste capítulo.

Referências às várias Tecnologias Orientadas a Objetos podem ser encontradas na Internet em: http://csalpha.unomaha.edu/object-orientation/ 
- [2] Elemento "versionable":

pode-se criar Versões de Objetos (O), Objetos Compostos (OC) ou de definições do Esquema (E);

- [3] Característica Especial:

a propriedade que indica se um elemento é passível de Versões está sempre presente (SP) ou necessita ser vinculada a cada elemento (0) de forma dinâmica durante a criação, ou de modo estático durante a definição (C);

- [4] Estados:

não existem estados (situações) para as Versões (NE) ou existem e podem variar dentro dos seguintes grupos: Congelada/NãoCongelada $(\mathrm{CN})$, Transitória/Em Trabalho/Liberada (TE), EmTrabalho/Estável/Congelada (EE);

- [5] Objeto Genérico:

a estrutura de derivação de um elemento "versionable" pode não ter representação (NOG) ou ser associada a um Objeto Genérico com Atributos próprios (OAP) ou não (NAP);

- [6] Referência às Versões:

entre as Versões associadas a um Objeto Genérico, pode-se fazer referência especificamente a uma Versão que é escolhida pelo sistema (S), escolhida pelo usuário (U), determinada por alguma função (F), ou sempre é selecionada a Versão mais recente $(\mathrm{R})$;

- [7] Manipulação de Versões:

as operações de criação, modificação e remoção de Versões podem ser realizadas implicitamente pelo sistema (S) ou pelo usuário (U) através de comandos específicos;

- [8] Restrições às Operações:

a manipulação de Versões, pelos usuários, pode ser livre de qualquer impedimento $(\mathrm{L})$ ou oferecer restrições $(\mathrm{R})$ diferenciadas quanto à criação, modificação e exclusão de Versões;

- [9] Utilização de Versões:

as Versões podem ser utilizadas para fins gerais $(G)$, para apoiar o Controle de Concorrência e Transação (CC) ou Controle de Recuperação (CR). 
A Evolução do Esquema [LERNER_90][MONK_93] [RODDICK_92] é um serviço muito pouco explorado pelos Modelos, apesar de mostrar-se útil em todas as aplicações. Mesmo assim, encontram-se diferenças das quais destacam-se:

- [10] Técnica de Evolução:

"Creating/Modification" (CR), "Additional" (AD) e/ou "Schema Versioning"(SV);

- [11] Estratégias de Propagacão:

"Copying" (CO), "Immediate Update" (CM), "Delayed Update" (CN), "Screening" (SC), "Materializing" (MA), "Versioning" de toda a BD Extensional e/ou de uma parte (VE);

- [12] Realização:

a Evolução do Esquema pode ser realizada utilizando-se uma linguagem de definição de dados (LD) e/ou uma interface gráfica/textual amigável (IT) para acompanhamento/monitoramento da concepção do Esquema.

A análise realizada (Tabela 3.1), apenas naqueles Modelos que proporcionam os serviços relacionados com o Controle de Versões e Evolução de Esquemas, demonstra uma relativa variação em certos pontos de algumas pesquisas, que pode estar relacionado com os atuais estágios de desenvolvimento ou com as peculiaridades de cada proposta de trabalho.

\section{3 - Padrões: Gerais e Específicos}

Em todas as áreas tecnológicas encontram-se tópicos de grande interesse e destes originam-se diversas linhas de pesquisa cujas intenções são normalmente enriquecedoras. Todavia, esta busca por inovações traz à discussão as propostas que se apresentam e conseqüentemente, muitos conflitos, ambigüidades e indefinições são geradas tanto em um contexto nacional quanto internacional.

Os Padrões [CATELL_94] surgiram para agrupar, harmonizar e conciliar pesquisadores e empresas com objetivos e idéias (ou ideais) em comum, criando-se meios para tornar viável, aceitável, acessível e consolidado todas as novas tecnologias e deste modo, formar uma base de suporte técnico que assegure seu domínio público.

Pelas inúmeras áreas, sub-áreas ou especialidades que são abordadas pelos diversos Órgãos de Padronização (alguns citados na Tabela 3.2) com seus Padrões formais, legislativos ou governamentais ("de jure"), e mesmo pela existência de sobreposições e simultaneidade entre os trabalhos realizados, há Padrões com 
enfoques gerais e outros específicos mas cujo mapeamento entre eles possibilita a coexistência vinculada de suas contribuições.

Tabela 3.1 - Comparação dos Modelos de Dados

\begin{tabular}{|l|l|l|l|l|l|l|l|l|l|l|l|l|}
\hline $\begin{array}{c}\text { Modelos } \\
\text { de } \\
\text { Dados }\end{array}$ & \multicolumn{9}{|c|}{ Versões na Base de Dados } & \multicolumn{3}{|c|}{$\begin{array}{c}\text { Evolução de } \\
\text { Esquemas }\end{array}$} \\
\cline { 2 - 14 } & {$[1]$} & {$[2]$} & {$[3]$} & {$[4]$} & {$[5]$} & {$[6]$} & {$[7]$} & {$[8]$} & {$[9]$} & {$[10]$} & {$[11]$} & {$[12]$} \\
\hline AVANCE & G & O, & C & CN & OAP & R & U & R & G & SV & CN, & LD \\
& & E & & & & & & & & & SC & \\
\hline Iris & G & O, & O & EE & OAP & F & U & R & G & CR & CO, & LD \\
\hline Cactis & L & O & SP & NE & NOG & I & S & - & CR & CR & CM & LD \\
\hline EXODUS & A & O & O & NE & NOG & I & S & - & G & - & - & - \\
\hline GemStone & - & O & SP & NE & NOG & I & S & - & CC & CR & CO, & - \\
\hline O2 & - & - & - & - & - & - & - & - & - & CR, & - & IT \\
& & & & & & & & & & AD & MA & \\
\hline ORION & A & O, E & C & TE & NAP & R & U & R & G & CR, & SC, & IT \\
& & OC & & & & & & & & SV & VE & \\
\hline ODE & A & O & O & - & NAP & R & U & L & G & - & - & - \\
\hline
\end{tabular}

Legenda

- $\quad$ Desconhecido

SIGLA Referência à opção

Existem também muitos consórcios, associações e grupos de indústrias que promovem Padrões de consenso ("de facto"), alguns dos quais controlam a tecnologia por eles criada e a utilizam em beneficio próprio. Outros consórcios, no entanto, qualificam-se apenas como usuários de uma tecnologia controlada exclusivamente por uma empresa (proprietária/elaboradora do Padrão). 
Especificamente, a informática tem despertado um crescente interesse dos Órgãos de Padronização e de muitos grupos de empresas nos últimos anos [ADLER_95]. Motivados pela necessidades comerciais, estas associações têm abordado diversos escopos que abrangem desde "Hardware", Redes, Linguagens de Dados, Aplicativos Específicos (CAD, CAE, CASE) e Sistemas de Bases de Dados, que é o enfoque das próximas seções.

Tabela 3.2 - Órgãos de Padronização

\begin{tabular}{|l|l|}
\hline Sigla & Nome \\
\hline ANSI & American National Standards Institute \\
\hline CCITT & International Telegraph and Telephone Consultative Committee \\
\hline IEEE & Institute of Electrical and Electronic Engineers \\
\hline ISO & International Standards Organization \\
\hline NIST & U.S. National Institute of Standards an Technology \\
\hline
\end{tabular}

\subsection{1 - OMG}

Formado em 1989 por um consórcio de dezenas de companhias entre as quais estão os maiores desenvolvedores de "software", "hardware" e incluindo usuários, o "Object Management Group" (OMG) iniciou suas atividades tendo como meta padronizar e promover o paradigma de orientação a objetos.

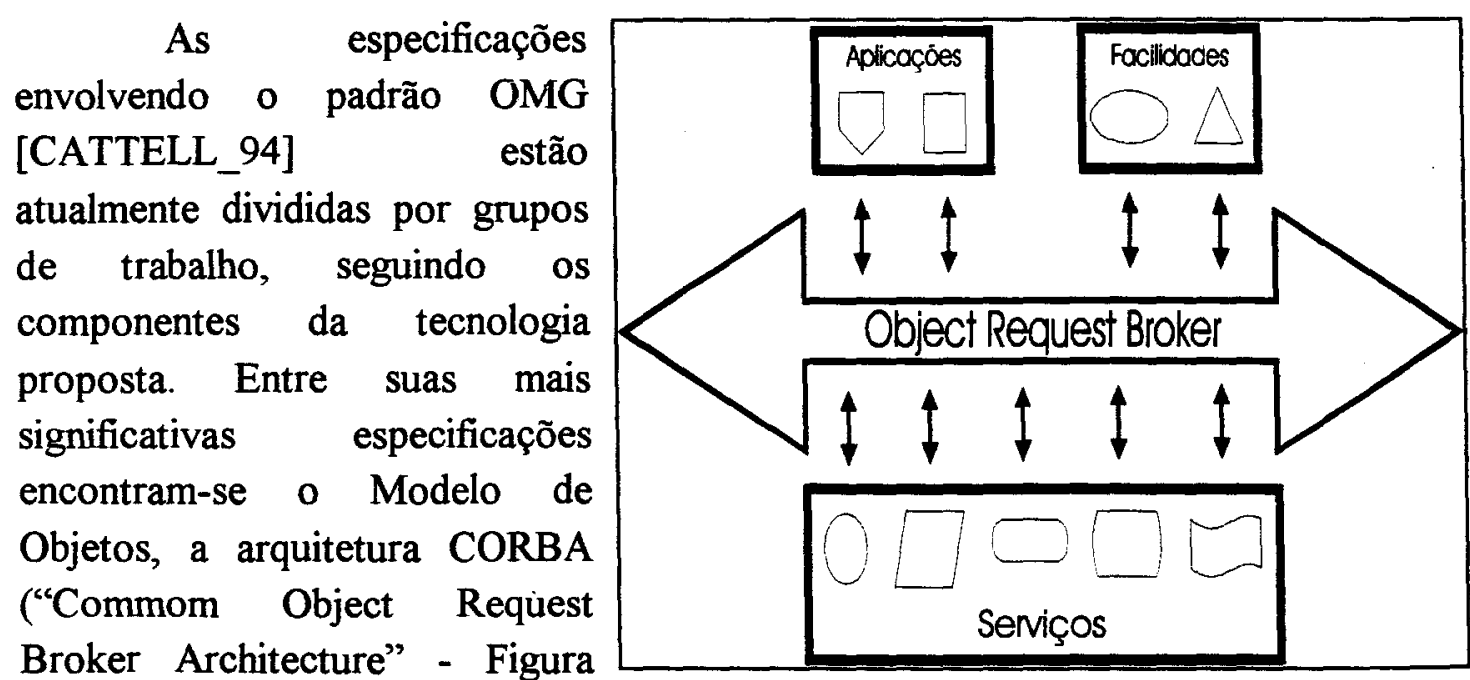

Figura 3.1 -CORBA [CATTELL_94] 3.1) e os "Object Services".

\section{A arquitetura CORBA}

estabelece diversas funcionalidades aos Objetos, entre as quais temos: a distribuição em rede; a localização baseada em identificadores; a invocação remota de métodos, e 
outras que podem ser associadas e comparadas (Figura 3.2) às funcionalidades dos Sistemas de Gerenciamento de Bases de Dados Orientadas a Objetos.

Os Serviços são também funcionalidades dos Objetos, contudo, para tornar o padrão OMG mais flexível, optou-se pela colocação em CORBA (ou simplesmente ORB) apenas da especificação mínima necessária para a comunicação entre Objetos. Assim sendo, por meio da utilização da linguagem de definição de interfaces (IDL), pode-se realizar os vários Serviços que se estendem desde a manipulação convencional de Objetos (criação, remoção,

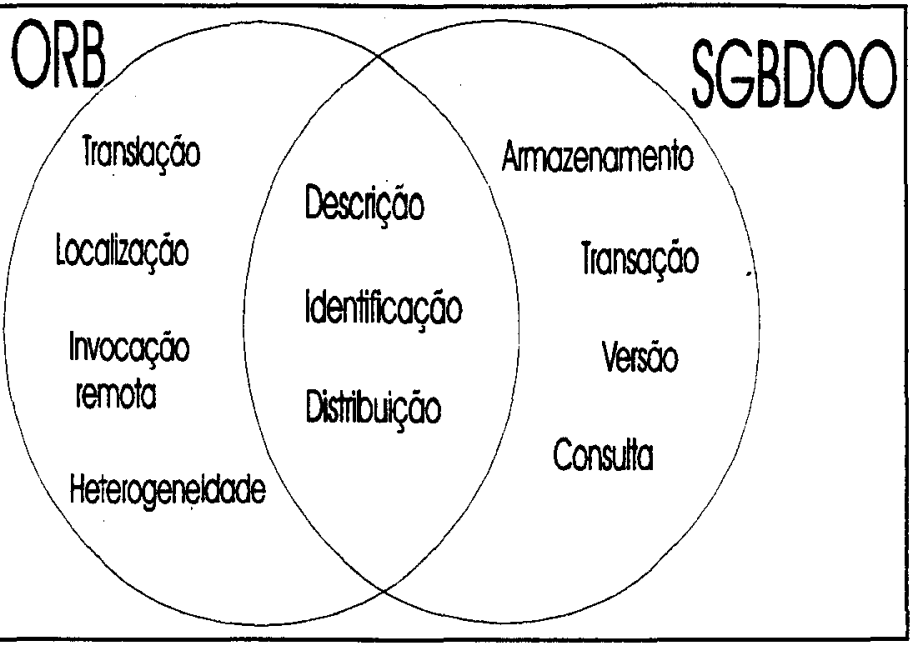

Figura 3.2 - ORB e SGBDOO [CATTELL_94] movimentação e cópia), a definição de integridades referenciais que permite a propagação seletiva de operações, até a colocação de níveis de autorização, consultas em ambiente distribuído, suporte a Versões e Evolução de Esquemas, todos incluídos em planos futuros de extensão.

\subsection{2 - ODMG}

Com o interesse comum por Bases de Dados Orientadas a Objetos, o "Object Database Management Group" (ODMG) foi criado em 1991 e desde então vem agregando membros entre os quais estão pesquisadores e desenvolvedores das seguintes companhias: Ontos, O2 Technology, Objectivity, GemStone Systems, Andersen Consulting, HP, Sybase, Texas Instruments e outras.

Buscando agir sobre a demanda do usuário, o ODMG [CATTELL_94] propôs um padrão de portabilidade cujo objetivo é garantir que programas aplicativos (atuando sobre SGBDOO) possam ser facilmente convertidos para diversas linguagens de programação, possibilitando assim, que uma mesma BD possa ser compartilhada pela utilização de linguagens de programação suportadas pelo Padrão.

Os estudos realizados em conjunto resultaram em um documento revisado (ODMG-93) [BANCILHON_94]. Nele encontram-se as especificações de: uma Arquitetura para SGBDOO's (Figura 3.3); um Modelo de Objetos; uma Linguagem de Definição de Objetos (ODL); uma Linguagem de Consulta de Objetos (OQL) baseada no SQL; uma Linguagem de Manipulação de Objetos (OML) que atua em 
propriedades e operações sobre Objetos persistentes; sintaxes e semânticas dos comandos em ODL, OML e OQL para as linguagens $\mathrm{C}++$ e Smalltalk; e o Mapeamento para a Arquitetura e Modelo OMG.

O Modelo de Objetos suporta os conceitos tradicionais de Classe, Objeto, Atributo, Método, Herança e Abstrações. As linguagens ODL, OML e OQL apresentam-se desvinculadas de qualquer linguagem existente, proporcionando assim um mecanismo de independência. Desta forma, Esquemas de Dados definidos em ODL podem ser transladados para a linguagem de programação desejada. A versão atual
do Padrão ODMG atinge somente as necessidades básicas dos usuários de programas aplicativos orientados a objetos. Particularmente, o conceito de Versões (Objetos ou Classes) e as operações para

Evolução de Figura 3.3 - Arquitetura do SGBDOO - ODMG [CATTELL_94] Esquemas, ainda não são tratados nas Bases de Dados centralizadas e muito menos nas distribuídas.

\subsection{3 - PCTE+}

O PCTE+ ("Portable Common Tool Environment") [BOUDIER_88] é um padrão para ambientes integrados de desenvolvimento de "software" que permite a portabilidade de ambientes CASE para diferentes plataformas de "hardware" e Sistemas Operacionais. O PCTE iniciou-se em outubro de 1983 sendo desenvolvido inicialmente no projeto ESPRIT por um consórcio pan-europeu de empresas como BULL S.A., General Electric Company, OLIVETTI e SIEMENS entre outras.

Entre as coleções integradas de ferramentas e serviços especificados pelo PCTE + [PCTE_89], encontra-se um Sistema de Gerenciamento de Objetos (OMS) composto por um conjunto de primitivas para manipulação de Objetos e mecanismos de execução e comunicação entre processos ou programas. 
Segundo o modelo (extensão do ME-R) utilizado no OMS, todos os Objetos (arquivos) têm suas características descritas por um conjunto de Atributos, um conjunto de Relacionamentos Bidirecionais, e um "Content" que define o conteúdo do Objeto ("file", "message queue", "block device"). A organização do Esquema de Dados é estruturada em conjuntos não disjuntos, chamados de "Schema Definition Sets" (SDS), onde cada um agrupa as definições específicas para um usuário, para uma ferramenta ou para um grupo de usuário de um mesmo projeto. A criação de um "Schema Definition Sets" é realizada definindo-se seus elementos componentes, independentemente de qualquer outro SDS.

Uma característica importante proporcionada pelo padrão PCTE+ é o compartilhamento de definições de dados por diversos usuários. Através da operação de "IMPORT", uma ferramenta ou usuário pode conseguir o compartilhamento de definições de um SDS, desde que the seja permitido o acesso.

Um processo de trabalho poderá necessitar de vários SDS's na definição de sua Visão da BD. A lista formada por SDS's utilizados em um processo é chamada de "Working Schema" (WS). No processo de trabalho é realizada a composição de SDS's do respectivo WS através da união dos conjuntos que não causam inconsistências. Na ocorrência de conflitos de informações, é realizada uma seleção das informações prioritárias, seguindo a ordem da lista de SDS's definidas pelo "Working Schema".

As Versões são estabelecidas sobre Objetos Compostos. A estrutura de derivação entre Versões é um grafo acíclico dirigido (DAG), expresso por relacionamentos do tipo Predecessor-Sucessor que definem, por meio de categorias e cardinalidades, o comportamento dos "links" gerenciados pelo OMS. As alterações são restritas somente às Versões que não possuem predecessores, o que proporciona uma estratégia simples para o controle da integridade das Versões.

\subsection{4 - ISO/STEP}

STEP ("STandard for the Exchange of Product data") [VAGOUN_93] é o nome informal para um conjunto de documentos (ISO ${ }^{3}$ série 10303) estabelecido pelo grupo de trabalho ISO/TC184/SC4. Desde sua primeira versão, publicada em 1992, a organização do padrão (Figura 3.4) se manteve relativamente simples, estruturada em partes correlacionadas e modulares, com o único objetivo de oferecer condições para o compartilhamento de dados usando os recursos integrados (específicos e gerais em engenharia) de representação.

${ }^{3}$ ISO - "International Standards Organization" 


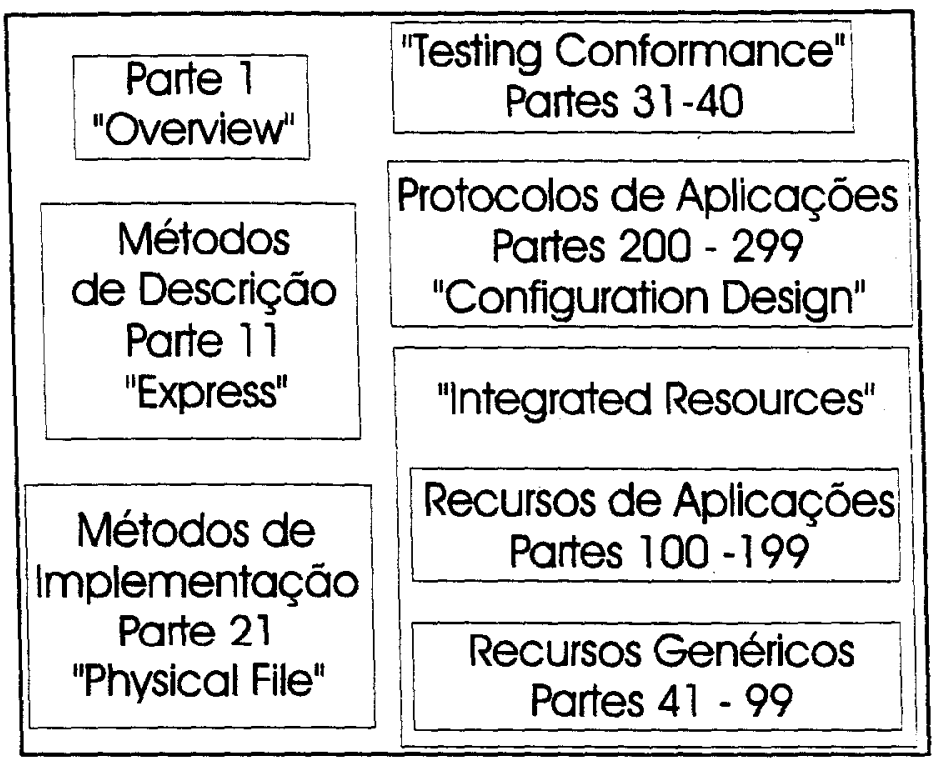

Figura 3.4 - Organização do padrão STEP [VAGOUN_93]
O padrão STEP, em sua Parte 11, apresenta um modelo de dados (EXPRESS) similar ao Modelo E-R, no entanto, mais sofisticado, pois inclui a descrição de estruturas de dados e restrições semânticas através de uma linguagem textual.

Partindo da perspectiva futura de utilização do STEP [DAVIS_91] para diversas aplicações em uma abordagem de "engenharia concorrente" [SHINA_91], uma extensão do padrão inclui ,no modelo EXPRESS, uma série de mecanismos e ferramentas para o reconhecimento de Versões e Deltas. Um conjunto mínimo de operações (Figura 3.5) é usada na definição de arquivos Delta, o que permite um "audit trail" para a reconstrução das mudanças realizadas e de eventos ocorridos.

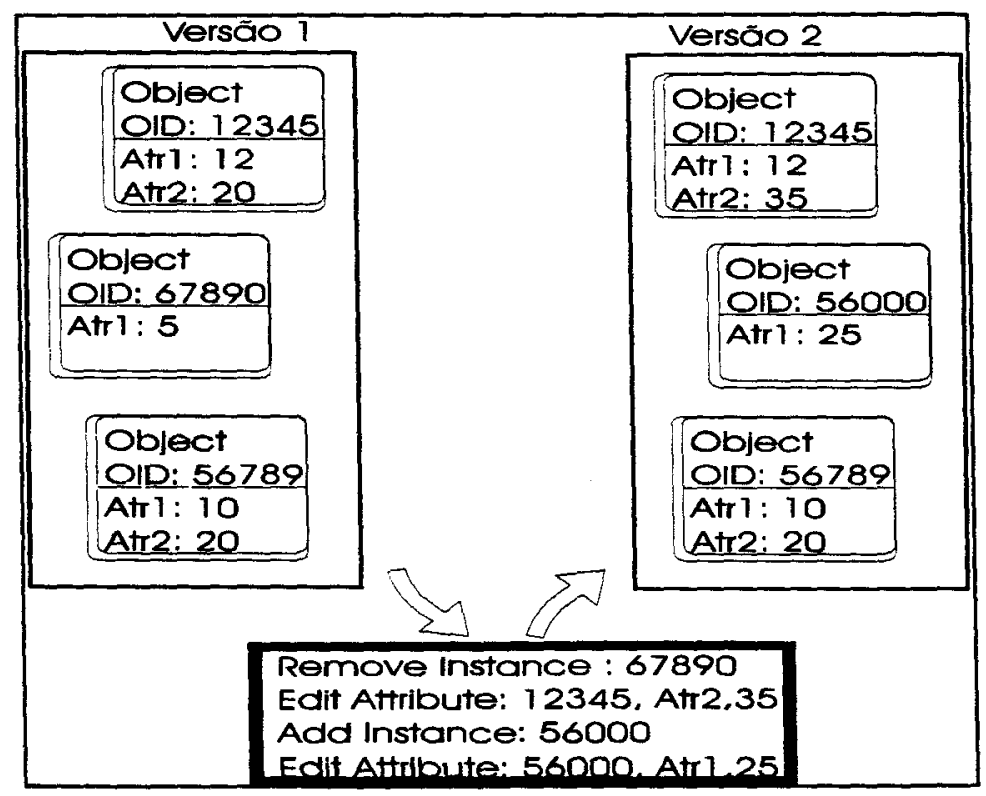

Figura 3.5 - Arquivo Delta [DAVIS_91]

\subsection{5 - Análise Comparativa}

A apresentação anterior, sobre alguns conceitos abordados por alguns Padrões, leva a uma avaliação das tendências futuras e principais preocupações dos especialistas em representação e manipulação de informações. Entre as considerações destes Padrões, encontram-se propostas de arquiteturas para sistemas, modelos, linguagens de dados, e para os "serviços" prestados aos Objetos. 
Até o momento, a ênfase dos estudos e propostas de padronização está em atingir a demanda (no caso, portabilidade e interoperabilidade) dos usuários de BD em sistemas de gerenciamento e em ambientes amigáveis de manipulação. Neste sentido, nota-se a preocupação do ODMG e PCTE+ pela portabilidade de aplicações, enquanto OMG e ISO/STEP salientam soluções para a interoperabilidade de aplicações [MANOLA_94].

Pela compatibilidade de interesses, é possível encontrar muita cooperação entre os grupos de padronização, como é o caso do OMG e ODMG, que possuem membros em comum, o que determinou a compatibilidade de ambos os trabalhos no reaproveitamento de algumas definições, como por exemplo o ODMG ODL e o Modelo de Objetos que são respectivamente extensões do OMG IDL e de seu respectivo Modelo.

A tendência futura é existir uma arquitetura aberta (OSA - "Object Services Architecture") [BLAKELEY_94b] que permitirá integrar um conjunto de "softwares" independentes, obtendose assim, alto grau de portabilidade comunicação entre os aplicativos (sistemas) por meio de um "duto" de passagem de mensagens e com o compartilhamento de modelos e linguagens

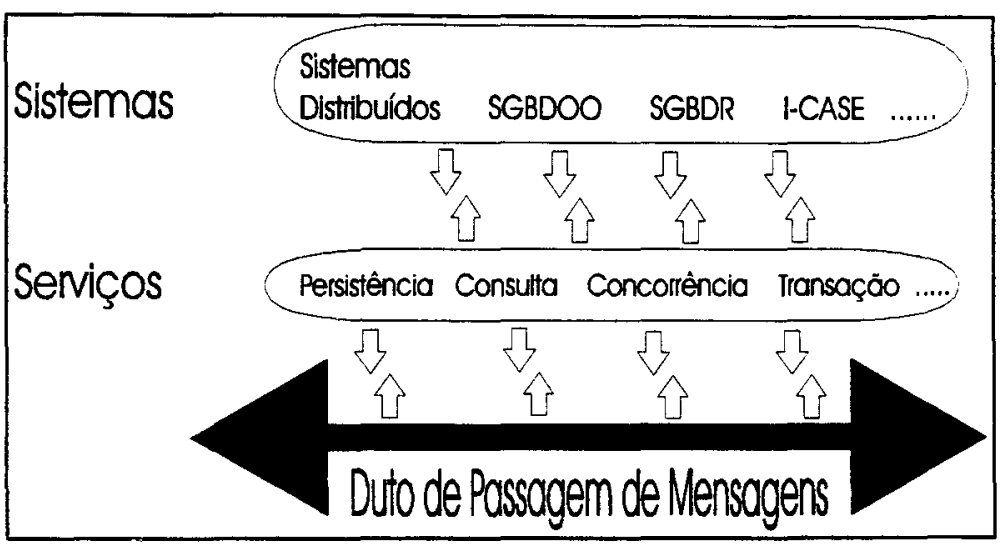

Figura 3.6-Arquitetura Aberta [BLAKELEY_94b] (Figura 3.6).

Pela própria natureza destes Padrões, não existem estimativas ou previsões sobre o futuro de seus trabalhos, pois são ainda incertos os caminhos abertos pelas tecnologias emergentes e muito menos se conhecem as demandas advindas do mercado. As expectativas, no entanto, são promissoras no sentido de que a evolução para arquiteturas abertas e apoiadas na "orientação a objetos" é uma realidade.

Especificamente tratando-se de Versões e Evolução de Esquemas, percebemse que OMG e ODMG ainda não atingiram um estágio de estudo que permita visualizar tais conceitos. No entanto, PCTE+ encontra-se mais adiantado e trata Versões de forma simples porém sustentada e o STEP apenas inicia suas pesquisas neste contexto. 


\section{4 - Considerações Finais}

Este capitulo descreveu e analisou alguns Modelos de Dados, a evolução histórica de vários paradigmas e a heterogeneidade dos Modelos Orientados a Objetos diante de certos conceitos e processos. Em termos de Padrões, pôde-se verificar a preocupação do ODMG e OMG com os problemas das BD [STEIN_94] e suas respectivas linguagens, ao passo que, ISO/STEP está especificamente direcionado a áreas correlacionadas como sistemas $\mathrm{CAD}$ e o $\mathrm{PCTE}+$ para sistemas CASE.

A análise comparativa permitiu constatar os estágios atuais de especificação e desenvolvimento de Modelos e Padrões, em relação aos Modelos de Versões e as técnicas/estratégias para Evolução de Esquemas. Diante desta análise, é possível sustentar as colocaç̃̃es e o trabalho apresentado nos próximos capítulos.

$$
\text { 米 }
$$




\section{capítulo 4}

\section{MODELO DE REPRESENTAÇÃO DE OBJETOS - MRO*}

\section{1 - Considerações Iniciais}

O Modelo de Representação de Objetos - MRO [TRAINA_86] foi elaborado originalmente no Departamento de Ciências de Computação e Estatística do ICMSC-USP em São Carlos no final de 1986 com a colaboração do Instituto de Física de São Carlos (IFSC-USP, na época chamado IFQSC-USP pois incorporava o atual Instituto de Química), tendo como objetivo permitir a construção de Sistemas de Gerenciamento de Bases de Dados que atendessem as necessidades de manipulação de dados e representação de informações dos sistemas de apoio a projetos tradicionais de engenharia [TRAINA_92].

Nos últimos anos, o MRO sofreu atualizações e extensões, decorrente de vários trabalhos de pesquisa (mestrados e doutorados), com o propósito de enriquecer seus conceitos e técnicas de modelagem. Conseqüentemente, recebeu uma nova denominação, MRO* [BIAJIZ_92], e a adesão de vários colaboradores/responsáveis e técnicos que formaram um Grupo de Base de Dados sediado na USP/São Carlos. 
Este capitulo tem por objetivo introduzir os conceitos originais e as extensões que envolvem o MRO*, bem como os subsistema que compõem o GErenciador de Objetos - GEO, um protótipo de SGBDOO apoiado no MRO*.

$\mathrm{Na}$ apresentação do $\mathrm{MRO}^{*}$, são descritos sucintamente seus conceitos e definições, detalhando-se especialmente o conceito de Colônia e de Esquema de Dados, nos quais se baseia este trabalho. A descrição completa de todos os conceitos, bem como o formalismo matemático do MRO*, pode ser encontrada em [BIAJZ_92].

\section{2 - Conceituação}

\subsection{1 - Diagramas de Representação}

Nota-se que os Modelos de Dados, principalmente aqueles que seguem o paradigma de "Orientação a Objetos", não têm uma preocupação, pelo menos aparente, com a representação gráfica de seus dados. Esta preocupação no MRO* é constante, tanto para a representação de Instâncias quanto para representação de Tipos, como pode ser comprovado pela existência dos seguintes diagramas:

- Diagrama de Representacão de Instâncias - DRI: onde pode-se representar os dados (Instâncias de Tipos) que estão ou irão ser armazenados na BD. Sua função é apresentar as informações de interesse de um usuário (ou grupo de usuários) em um certo momento;

- Diagrama de Representacão de Obietos - DRO: onde são representados os Tipos que compõem a BD. Nele pode-se representar o conjunto completo de Tipos contidos na Base de Dados ou apenas uma parte que está inserida ou fará parte da modelagem;

- Diagrama Hierárquico de Colônias - DHC: onde representa-se a Hierarquia de Composição total ou parcial na qual se estrutura os Objetos da BD.

\subsection{2 - Fundamentos}

Seguindo a linha dos Modelos Semânticos, o MRO* modela as entidades do mundo real em Objetos, os quais podem associar-se a outros Objetos através de Relacionamentos. Tanto os Objetos quanto os Relacionamentos possuem Atributos (intrínsecos e extrínsecos). Todo Objeto possui um Código gerado pelo sistema, que o identifica univocamente durante toda a sua existência na Base de Dados. Além disso, um Objeto possui identificadores ou sinônimos fornecidos pelos usuários. 
A semântica de um Atributo pode ser reconhecida através de sua Característica (sinônimo, comentário, tempo, estrutura, gráfico, imagem, visualização, regra, procedimento e propriedade) e de seu Tipo de Dado (byte, int, long, coditipo, float, double, cadeia, 2dcoordenadas, data, hora, valor, etc).

As associações básicas, Relacionamentos Binários, interligam dois Objetos denominados: Objeto Origem e Objeto Destino, através de Modalidades (papéis). Uma associação mais elaborada é chamada Relacionamento Triplo, sendo composta por dois ou mais Relacionamentos Binários que possuem um Objeto em comum.

\subsection{3 - Esquema e Meta-Esquema de Dados}

Pode-se descrever um esquema genérico do MRO* através de um MetaEsquema de Dados (Figura 4.1), onde cada elemento pode ser encarado como um MetaTipo. A existência de um Meta-Esquema permite definir um Esquema de Dados de uma aplicação como um conjunto de informações representada em uma estrutura sintática idêntica à usada na representação das Instâncias. Portanto, o Esquema de Dados (ou Base Intencional) e a Base de Dados propriamente dita (Base Extensional) podem ser armazenados em uma organização lógica semelhante.

\subsection{4 - Abstrações de Dados}

\section{- Generalização/Especialização}

Objetos, Relacionamentos e Atributos são classificados em Tipos. Tipos de Objetos e Tipos de Relacionamentos podem ser especializados em Subtipos. Um Subtipo é especificado através da indicação de um Tipo ou Subtipo anteriormente definido, chamado Tipo Mestre e de um Predicado, que estabelece o critério de escolha dos elementos do Tipo Mestre que constituirão o subconjunto de elementos daquele Subtipo. Tipos e Subtipos são mantidos em Hierarquias de Generalização/Especialização através de relacionamentos intrínsecos (IS-A). 


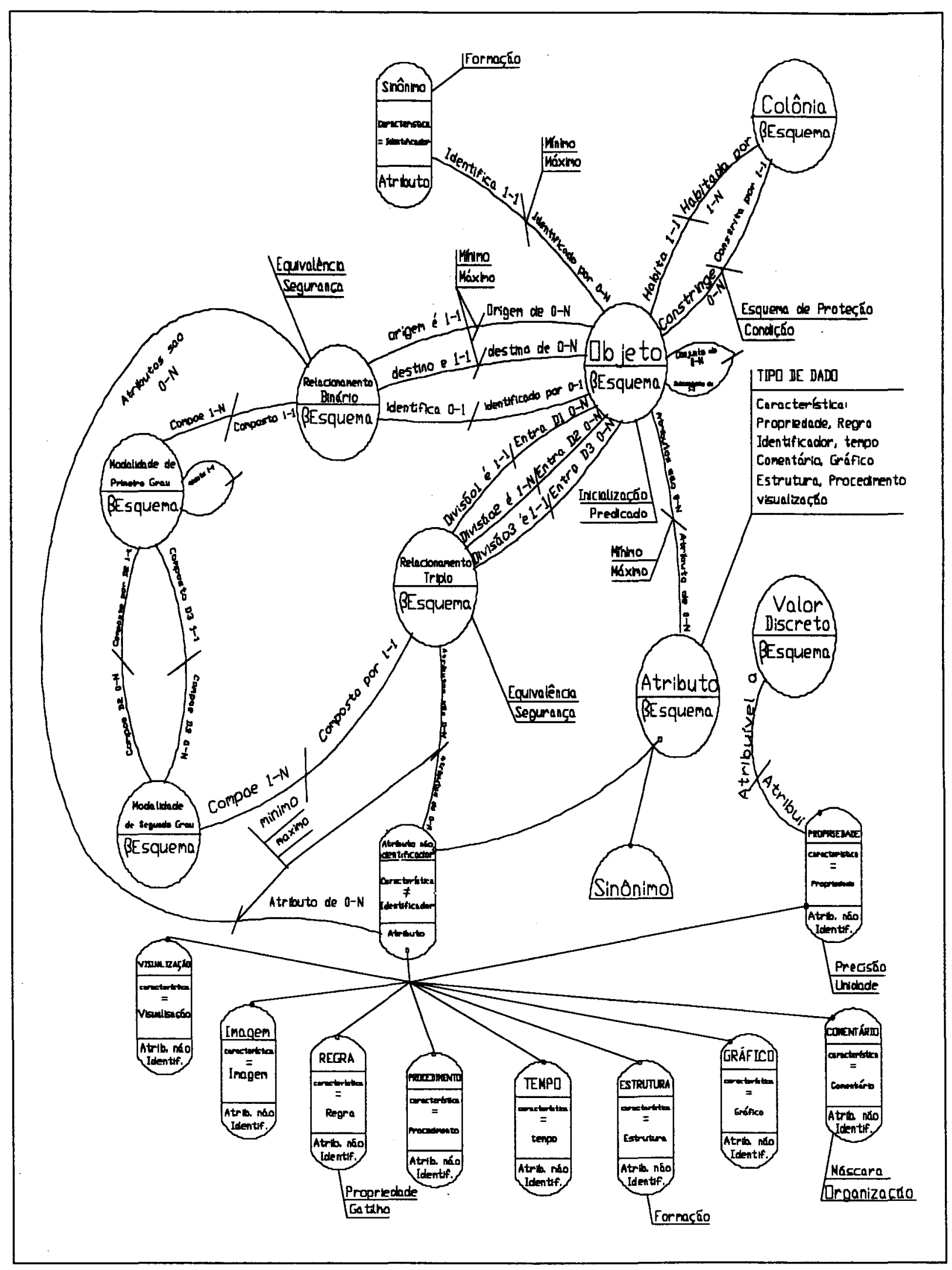

Figura 4.1-Meta-Esquema do MRO* (DRO) 


\section{- Composição/Decomposição (Colônias de Objetos)}

Colônias são partições do conjunto de Objetos da BD, ou de outra forma, são as representações propositadamente obrigatórias dos Objetos Compostos, sendo portanto, cada Colônia constituída de um grupo de Objetos de diversos Tipos, chamados de objetos habitantes da colônia, e de Relacionamentos e Atributos associados. Define-se também, que cada Colônia de Objetos é a consolidação da modelagem de um determinado aspecto de interesse da aplicação.

Para uma maior abrangência do MRO*, além da partição do conjunto de Objetos em Tipos de Objetos com as mesmas propriedades, percebeu-se que os Objetos de uma BD devem ser classificados segundo outros aspectos, de acordo com os seus Tipos. Considerando-se que cada Objeto habita exatamente uma Colônia, estabelecemos uma partição no conjunto de Tipos de Objetos, sendo cada parte denominada Tipo de Colônia. Deste modo, cada Tipo de Colônia determina um conjunto de Tipos de Objeto e, assim, Objetos de um certo Tipo somente habitam Colônias de um único Tipo.

$\mathrm{O}$ conceito de Colônia estabelece relacionamentos intrínsecos (IS-PART-OF) entre os Objetos da Base de Dados e, conseqüentemente, a formação de uma Hierarquia de Composição, ou seja, um Objeto $O_{1}$ qualquer, através de um relacionamento de composição estabelecido pelo gerenciador, possibilita o acesso ou a definição de uma Colônia cujos Objetos habitantes são componentes de $\mathrm{O}_{1}$. Cada Objeto componente pode, por sua vez, ter relacionamentos de composição com Objetos de outras Colônias.

Isto possibilita aumentar ou diminuir a especificidade de um Objeto, como se a "visão" que se tem da informação pudesse ser mais ou menos detalhada, a critério do próprio usuário. Sendo assim, quando vista de maneira global, a Base de Dados é apresentada com um pequeno grau de detalhe, com Objetos pertencentes a uma Colônia criada pelo sistema, chamada Colônia Global. Se o interesse recair em um dos componentes visíveis, o grau de detalhe deste componente aumenta.

Em termos de acesso a Objetos, isso corresponde a se ter poucos Objetos acessíveis enquanto se manipula a BD de um ponto de vista global. Quando indicado ao sistema para considerar (refinar) um destes Objetos, aponta-se um novo grupo de Objetos (nova Colônia) do qual se deseja manipular informações, e assim tornam-se acessiveis os novos Objetos. $O$ procedimento de refinamento pode ser repetido sucessivamente, indicando-se para consideração um dos novos Objetos disponiveis, o que aumenta gradativamente o nivel de detalhe e, conseqüentemente, a quantidade de Objetos a que se tem acesso através de seus sinônimos. Com o refinamento de um determinado Objeto, os demais, em um mesmo nível de detalhe (mesma Colônia), não deixam de estar acessiveis, mas não são também refinados. Desta forma, torna-se mais "natural" para o usuário indicar o escopo de percepção ou de identificação dos dados, especificando-se o nivel de 
detalhe desejado através da navegação pela Hierarquia de Composição, restringindo-se assim, o grupo de Objetos passíveis de serem acessados pelo usuário.

Indicar um Objeto para consideração (ou refinamento) caracteriza a operação de requisitar e abrir uma Colônia para acesso, de modo que os Objetos habitantes daquela Colônia tomam-se acessíveis para consulta e modificação ou apenas para consulta. Desta forma, Colônias possibilitam o controle e a abrangência (granularidade) do gerenciamento de acesso à Base de Dados. A indicação de um Objeto pode abrir mais de uma Colônia de Tipos diferentes. O Objeto Considerado é definido como um Objeto que se tem presentemente disponivel e que se indica para refinamento, fazendo com que a Colônia que contenha os Objetos que o especificam com um maior grau de detalhe (Colônia Constrita pelo Objeto Considerado) seja aberta.

Colônias organizam-se segundo uma Hierarquia de Colônias (ex: Figura 4.2), em que a Colônia Global é o topo da hierarquia (ex: armazena Instâncias do Tipo de Objeto CARRO e outros) e o nível imediatamente subordinado é constituido pelas Colônias (ex: Instâncias do Tipo de Colônia PROJETO) constritas por Objetos (ex: Instâncias de CARRO) que habitam a Colônia Global e assim sucessivamente. Esta hierarquia indica a existência de um relacionamento intrínseco de composição entre os Objetos que consideram as Colônias e os Objetos que as habitam.

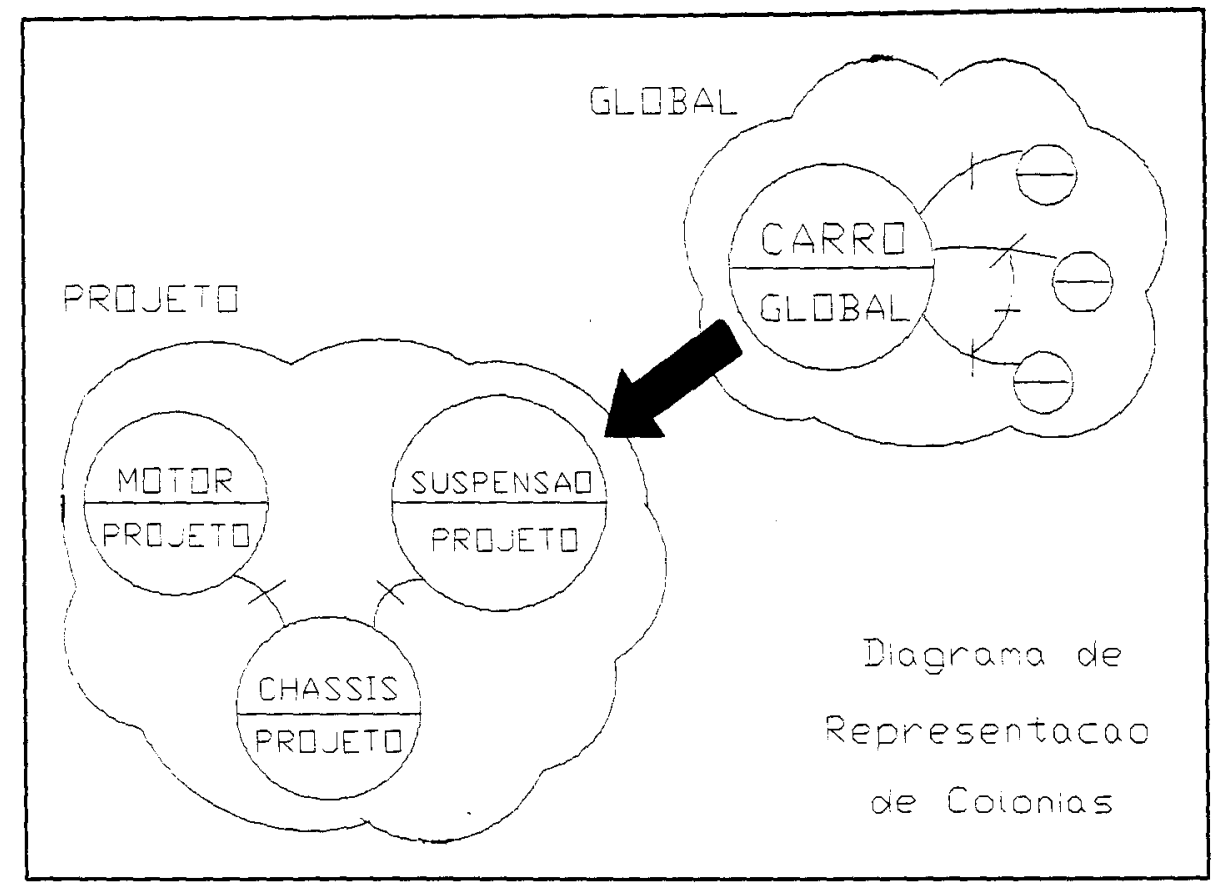

Figura 4.2 - Hierarquia de Colônias (DHC) 


\section{3 - Formalismo}

A definição completa do formalismo dos conceitos citados anteriormente (ex: Esquema de Dados ${ }^{1}$ e Colônias ${ }^{2}$ ) é bastante abrangente e este trabalho não tem a intenção de apresentar esta formalização pois exigiria uma complexa e extensa apresentação de várias Definições e Teoremas.

\section{4 - Extensões ao MRO*}

\subsection{1 - Características}

Exceto pelas características básicas (sinônimo e propriedade) que foram prontamente definidas, as demais características de Atributo foram somente previstas no início do MRO* (Figura 4.1). Estas características mais sofisticadas são parte da extensão do Modelo pois necessitaram ou necessitarão de pesquisas específicas e criteriosas, pois normalmente envolvem interrelacionamentos com os outros aspectos do Modelo de Representação.

Referente à Característica Tempo, as dimensões temporais Tempo Válido e Tempo de Transação são pré-definidas e adicionalmente permite-se a colocação do Tempo Definido pelo Usuário. A representação do Tempo, ao nível de Atributo [SILVA_93], possibilita o estabelecimento temporal de Objetos e Relacionamentos em Instâncias e em Tipos.

No MRO*, os Atributos de Objeto ou Relacionamento que possuem Característica de Regra [SANTOS_92] são definidos com a descrição de dois componentes fundamentais: Condição e Ação. A Condição é composta de duas partes (Evento e Predicado) e determina quando a Ação poderá ser executada. O Evento é qualquer situação (Operação na BD, Passagem do Tempo ou Disparo de outra Regra) envolvendo Objetos ou Relacionamentos que exigem algum controle. Predicado é uma expressão lógica para verificar as questões aplicadas sobre o elemento envolvido. Através dos comandos da Ação é definida a abrangência da Regra, ou seja, quais elementos são afetados pela execução.

${ }^{1}$ Definição 68: Um Esquema é um conjunto $C E s q u(\lambda)$ cujos componentes são os conjuntos $\operatorname{CTr}(\lambda), C T c o(\lambda), C T a(\lambda), C T o b(\lambda)$ definidos para um empreendimento $\lambda$, onde estes conjuntos são respectivamente o conjunto de Relacionamentos, Colônias, Atributos e Objetos. [BIAJIZ_92]

2 Definição 45: Uma Colônia $C o$ é representada por uma tupla $\operatorname{Co}(\lambda)=\langle C$ habita,objConstr, tco> onde C-habita é o conjunto de Objetos que habitam Co, objConstr é o Objeto que constringe $C o$ e tco é um Tipo de Colônia e que pertence ao conjunto CTco( $\lambda$ ). [BIAJIZ_92] 
Cada comando da Ação pode realizar operações simples sobre os valores dos Atributos de Objetos e de Relacionamentos. Regras (Atributos) também podem ser associadas a Tipos e neste caso, são avaliadas sempre que as respectivas Instâncias forem acessadas.

Os Atributos com Características Gráficas [TAKAI_93] são estruturas complexas de armazenamento que devem especificar: a forma gráfica em termos de elementos primitivos (ponto, linha, arco, etc); as Matrizes de Transformação que são usadas nas modificação geométricas (escala, rotação e translação); e "Bundles" que especificam espessuras, estilos e outras características dos elementos primitivos.

\subsection{2 - Distribuição}

A distribuição no $\mathrm{MRO}^{*}$ caracteriza-se por disponibilizar Objetos de uma "BD original" em uma "BD cópia" através de relacionamentos que refletem semanticamente as associações entre os Objetos e suas cópias [FERREIRA_91].

\subsection{3 - Linguagem}

Para facilitar a especificação de operações com dados (Instâncias e Tipos) foi definido uma linguagem de comandos denominada LAMRO (Linguagem de Acesso do MRO*) [PIZZIGATTI_92], cuja sintaxe esta intimamente relacionada ao Modelo.

Na elaboração da LAMRO, o mapeamento entre comandos e conceitos do MRO* levou à simplicidade, facilidade de utilização e disponibilidade do interpretador no ambiente operacional desejado. Mas, para isso, sua elaboração exigiu a definição de um conjunto de palavras-chaves (ou palavras-reservadas) e de sintaxes pouco flexíveis para os comandos. Para ilustrar as características da LAMRO são apresentados a seguir exemplos de utilização de alguns comandos.

Exemplo 1: Criar no Esquema de Dados um Tipo de Objeto Equipamento cujas Instâncias habitarão a (ou seja, estarão contidas na) Colônia Global.

\section{DEFINE OBJETO Equipamento \\ HABITA Global;}

Exemplo 2: Criar no Esquema de Dados um Tipo de Colônia Projeto cujas Instâncias serão constritas por (ou seja, poderão ser acessadas através das respectivas) Instâncias do Tipo de Objeto Equipamento.

DEFINE COLÔNIA Projeto

CONSTRITA POR Esquipamento; 


\subsection{4 - Esquemas Suplementares}

Com base no trabalho sobre Esquemas de Dados [CAMOLESI_92b], demonstrou-se a interrelação entre as Hierarquias de Generalização e de Composição em modelagens para ambientes de projetos. Pôde-se, com isso, incorporar à BD Intencional a capacidade de divisão ou particionamento em conjuntos complementares. A BD Intencional, desta forma, estabelece-se como sendo composta: por um Esquema Inicial que contem o conjunto de informações gerais da modelagem do empreendimento, podendo ser utilizada por qualquer usuário da Base Extensional; e por quantos Esquemas Suplementares forem necessários, onde cada um armazena as definições de Tipos destinadas a certos usuários.

Em cada Esquema Suplementar encontram-se informações específicas de uma área de conhecimento, que devem ser utilizadas apenas pelos usuários interessados em um domínio de informações de um aspecto do projeto [CAMOLESI_92a]; ou em um domínio de informações de um grupo de projeto que trabalhará, concorrentemente ou não, para a finalização do projeto; ou em um domínio de informações de um usuário específico; ou em um domínio de informações de uma alternativa de projeto. Para isso, um Esquema Suplementar pode conter quantos e quaisquer Objetos (Tipos de Colônia, Tipos de Objeto, Tipos de Atributo, Tipos de Relacionamento) que se façam necessários para estender a modelagem.

Sendo

Colônia, em sua definição mais genérica, uma partição da Base de Dados e portanto um conjunto de Objetos, pode-se usá-la na composição de Objetos e conseqüentemente na criação de Objetos Compostos, mas também armazenamento dos Esquemas (Inicial e Suplementares). Estas Colônias contendo partes do Esquema, denominadas

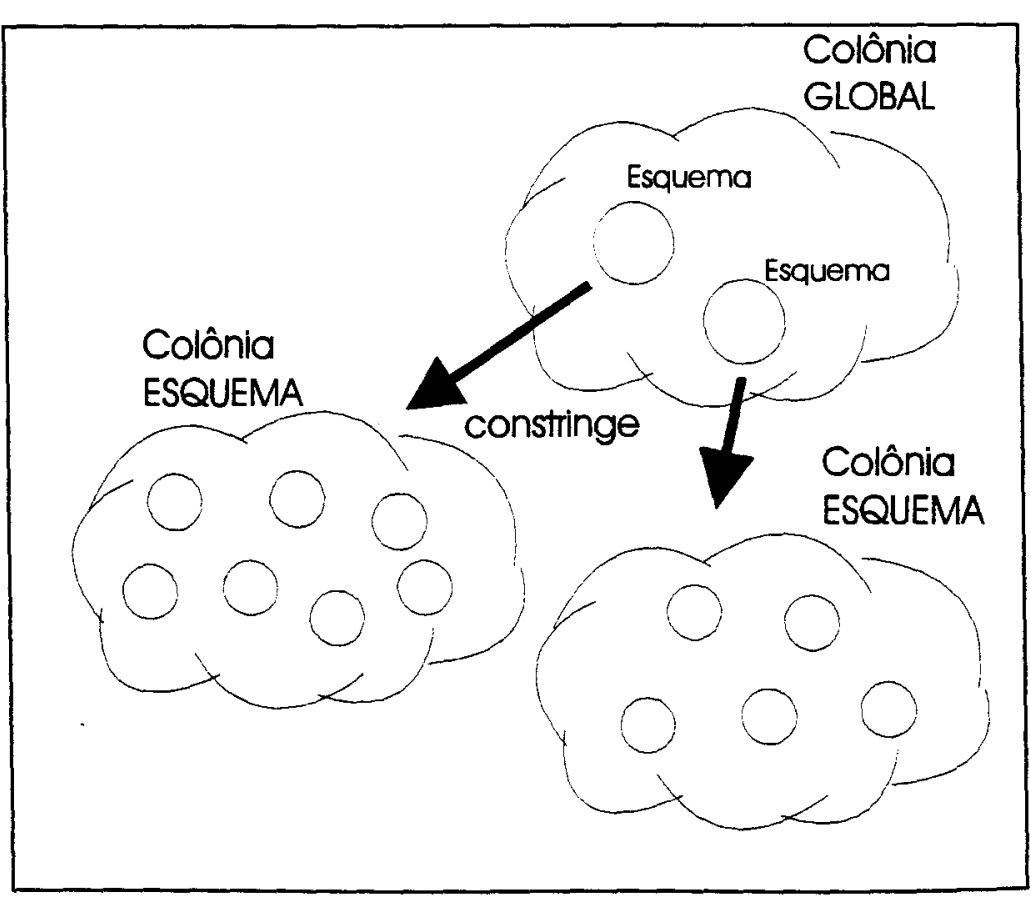

Figura 4.3 - Objetos e Colônias Esquema (DHC) simplemente Colônias Esquema, são constritas por Objetos (do Tipo Esquema - pré- 
definido pelo SGBD) cujos nomes são definidos pelo projetista da Base de Dados Intencional e que habitam somente a Colônia Global (Figura 4.3).

Diferente de muitos Modelos de Dados Orientados a Objetos, que tratam o Esquema de Dados como um "monolito", o MRO* tem um Esquema de Dados Ativo [CAMOLESI_93] (ou EDA) formado por um agrupamento da Colônia Esquema Inicial com as Colônias Esquemas Suplementares requisitadas explicitamente.

Este agrupamento é realizado instantaneamente para atender as necessidades momentâneas dos usuários no acesso às informações, o que impõe ao Esquema de Dados Ativo as seguintes características: único e individual para cada usuário da Base Extensional e portanto o SGBD deve controlar vários Esquemas de Dados Ativos (semelhantes ou não) no acesso concorrente à $\mathrm{BD}$; transitório, pois é mantido em memória principal; dinâmico porque sua definição (ativação de Esquemas Suplementares para agruparem-se ao Esquema Inicial) é realizada somente para o acesso à BD durante uma seção de trabalho do usuário; e flexível uma vez que pode ser alterado facilmente através das operações de requisição e liberação de Esquemas Suplementares.

\section{5 - GErenciador de Objetos - GEO}

Em meados de 1988, iniciou-se o desenvolvimento de um protótipo de SGBDOO denominado GErenciador de Objetos [TRAINA_91], o qual está gradativamente incorporando os conceitos do MRO*, a medida que o próprio modelo evolui. Um dos objetivos deste protótipo é a validação prática e o estudo de como os conceitos do MRO* (e de Sistemas Orientados a Objetos em geral) podem ser implantados em ferramentas reais.

\subsection{1 - Organização das Camadas}

Em sua atual implementação para manipular eficientemente a Base Extensional e a Base Intencional, o GEO está dividido em 3 camadas (figura 4.4):

Núcleo: é composto pelo Subsistema de Gerenciamento de Registros Lógicos (SG-Log), Subsistema de Gerenciamento de Registros Físicos (SG-Fis) e Subsistema de Gerenciamento de Memória Cache (SG-Cac);

GEO-Básico: é composto por primitivas responsáveis pelas operações de acesso efetivo à $\mathrm{BD}$, tal como criar ou eliminar Objetos, Relacionamentos, etc; 
GEO-Semântico: é composto por primitivas responsáveis pelas operações complementares ao GEO-Básico, através da avaliação de regras sintáticas estáticas e também das regras semânticas.

\begin{tabular}{|c|c|c|c|}
\hline \multicolumn{4}{|c|}{ Aplicativos } \\
\hline $\begin{array}{l}\text { Editor de } \\
\text { Esquemas }\end{array}$ & $\begin{array}{l}\text { Editor de } \\
\text { Consultas }\end{array}$ & $\begin{array}{l}\text { Aplicativos } \\
\text { Específicos }\end{array}$ & outros \\
\hline \multicolumn{4}{|c|}{ GEO-Semântico } \\
\hline \multicolumn{4}{|c|}{ GEO-Básico } \\
\hline \multicolumn{4}{|c|}{ Núcleo } \\
\hline \multicolumn{4}{|c|}{ Subsistema de Gerenciamento de Registros Lógicos (SG-Log) } \\
\hline \multicolumn{4}{|c|}{ Subsistema de Gerenciamento de Registros Físicos (SG-Fis) } \\
\hline \multicolumn{4}{|c|}{ Subsistema de Gerenciamento de Memória Cache (SG-Cac) } \\
\hline
\end{tabular}

Figura 4.4 - Estrutura do GEO e Aplicativos

\subsection{2 - Subsistemas de Gerenciamento}

O GErenciador de Objetos pode também ser visto como um conjunto de subsistemas interrelacionados que se apoiam mutuamente no controle da Base de Dados. Estes subsistemas são compostos por um conjunto de rotinas/primitivas e estruturas de apoio com finalidades específicas, de acordo com suas funções básicas:

1.) Subsistema de Gerenciamento de Transações (GEO/SGT): apoia-se no subsistema de Gerenciamento de Memória Cache (GEO/SG-Cac) em que cada "página" da memória está vinculada a uma Transação e a uma operação (exclusiva ou compartilhada);

2.) Subsistema de Gerenciamento de Objetos : possibilita a manipulação de Objetos sem restrições de ordem semântica. Envolve o tratamento de Identificadores de Objetos, manipulação de Composições de Objetos, contexto e navegação na Base de.Dados;

3.) Subsistema de Gerenciamento de Relacionamentos : permite a manipulação de Relacionamentos definidos pelo usuário. O GEO gerencia Relacionamentos Intrínsecos e Extrínsecos: os intrínsecos têm semântica é conhecida pelo Gerenciador, tal como as Hierarquias de Generalização e Composição; os extrínsecos são aqueles cuja semântica é definida e reconhecida pelo usuário; 
4.) Subsistema de Gerenciamento de Atributos : permite a manipulação de Atributos com características de Propriedade e Comentário, tanto para Objetos quanto para Relacionamentos;

5.) Gerenciador de Esquemas de Dados (GEO/GED): permite realizar operações relacionadas ao Esquema de Dados, sendo composto de primitivas de manipulação, acesso e verificação, que são utilizadas pelos demais subsistemas de gerenciamento [TRAINA_93].0 GEO/GED existe em duas versões: GED/Mono-Esquema para operações com um Esquema de Dados único; e GED/Multi-Esquema para operações com o Esquema Inicial e Esquemas Suplementares.

Pelo fato de existirem duas versões do Gerenciador de Esquemas de Dados, o GEO pode ser criado nas versões GEO/Mono-Esquema ou GEO/Multi-Esquema, de acordo com o respectivo GED, para as necessidades simples ou mais complexas de representatividade da Base de Dados.

\subsection{3 - Tipos de Registros}

O SG-Log, SG-Fis e SG-Cac trabalham internamente no GEO, realizando o gerenciamento das informações em três estruturas integradas (Figura 4.5):

- Registros Lógicos:

são as unidades de armazenamento onde registramse todos os Objetos, Colônias, Atributos, Relacionamentos, etc.;

- Registros Virtuais: são coleções de Registros Lógicos agrupados por possuírem alguma relação (ex: pertencerem a mesma Colônia);

- Registros Físicos: são as unidades de leitura $e$ gravação do GEO, onde

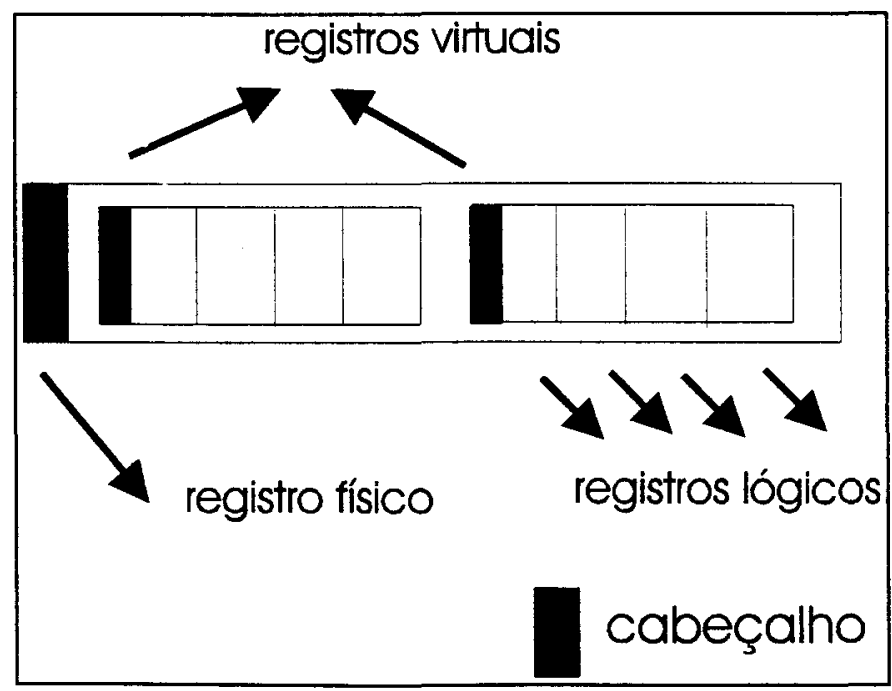

Figura 4.5 - Tipos de Registros armazenam-se os Registros Virtuais. 


\subsection{4 - Arquivos Lógicos}

Os conjuntos de Registros Lógicos de um mesmo tipo são denominados Arquivos Lógicos. Existem atualmente os seguintes Arquivos Lógicos internamente sustentados em uma BD do GEO: Colônias; Identificadores; Objetos; Relacionamentos Binários $\mathrm{e}$ Triplos; Regras; Atributos e Propriedades; Comentários; Gráficos; Tempos e nós de Árvore-B.

\section{Todos os Registros}

Lógicos são interligados através de listas encadeadas, de acordo com as associações estabelecidas pelos usuários ou pelo sistema (em alguns casos). Um exemplo esquematizado pode ser visto na Figura 4.6, onde de cada Registro Lógico de Objeto pode-se ter o endereço do início de uma lista encadeada de Registros Lógicos de Colônias que são constritas pelo Objeto indicado.

\section{6 - Considerações Finais}

Este capitulo descreveu o MRO* e suas extensões, que capacitam-no para utilização em CASE, além de MCAD ("Mechanical Computer-Aided Design"), ECAD ("Eletronic Computer-Aided Design") e CAP ("Computer-Aided Publishing").

Um exemplo comprovado, da aplicação do MRO* e do GEO para uma ambiente CASE, é o Editor Genérico Sensível à Sintaxe (EGSS) [VALÊNCIO_93] desenvolvido inicialmente para suportar subconjuntos de comandos das linguagens Pascal, C e FORTRAN. No EGSS, os programas são construidos sintaticamente corretos pela utilização de gabaritos de comandos e expressões. A representação interna dos programas editados é única e na forma de símbolos pré-definidos no 
Esquema de Dados, o que permite a tradução de qualquer programa para uma das linguagem contempladas pelo EGSS.

Mesmo com todas as extensões para o $\mathrm{MRO}^{*}$, ainda existem muitos conceitos a serem desenvolvidos e que, ao serem incorporados ao GEO, viabilizarão sua utilização em vários ambientes de projeto.

$$
\text { 茨 }
$$




\section{capítulo 5}

\section{META-MODELO \\ MODELO DE VERSÕES}

\section{1 - Considerações Iniciais}

Uma análise geral dos capítulos de estudos bibliográficos (capítulos 2 e 3) permite constatar a complexidade e a variabilidade intrínseca que envolvem a pesquisa e implementação de um gerenciador de Versões. Obviamente, os ambientes de aplicação (ex: CASE, MCAD, ECAD) contribuem muito para agravar os problemas e dificuldades destas pesquisas, devido às particularidades destas aplicações.

Esta complexidade e variabilidade não podem ser reduzidas mas podem ser dominadas pela organização ponderada de suas variantes. Acompanhando este princípio, este capítulo inova ao descrever, de forma estruturada seguindo um MetaModelo de Versões, algumas contribuições para os Modelos de Dados Orientados a Objetos em termos de modelagem, representação (conceitual e fisica) e controle de Versões. Estas contribuições são experimentadas em uma situação prática através da criação do Modelo de Versões (destinado ao $\mathrm{MRO}^{*}$ ) que é aqui apresentado. 
capitulo $5-60$

\section{2 - Meta-Modelo de Versões}

A análise realizada anteriormente (capítulo 2) sobre os Modelos de Versões em Bases de Dados mostra, em suma, que existem poucas variações e muitas lacunas nestas pesquisas. No geral, notam-se itens de especificações que ocorrem em vários Modelos de Versões e itens apenas citados em alguns destes Modelos..

A escolha de um SGBD, utilizando-se como parâmetro de comparação o Modelo de Versões suportado, pode trazer muitas dúvidas ao usuário, pois não existe nenhum estudo de avaliação das características dos Modelos de Versões em termos de complexidade, completeza e adequação a um problema.

No sentido de apoiar a escolha, o estudo e/ou a experimentação de um Modelo de Versões, ou mesmo para indicar os caminhos para o desenvolvimento de um Modelo específico de um problema ou genérico de uma área, desenvolveu-se um Meta-Modelo de Versões que normatiza/padroniza as especificações relevantes, imprescindíveis e opcionais de um Modelo de Versões.

A amostragem dos Modelos de Versões, apresentado no capítulo 2, possibilitou verificar e relacionar a existência de vários itens de especificação que no Meta-Modelo de Versões foram divididos em dois grupos:

- Fundamentais: são especificações (16 itens) imprescindíveis para um Modelo de Versões pelo fato de apresentarem definições e detalhes cruciais para o entendimento de suas características funcionais. A inexistência de uma especificação fundamental, em um Modelo de Versão, fatalmente leva a incompreensão deste Modelo e até mesmo à total desestruturação ou desorganização de seus princípios;

- Complementares: são especificações (4 itens) opcionais para um Modelo de Versões, que incluem referências a tópicos relacionados como por exemplo, linguagens, modelos físicos e outros modelos (parceiros com relação a dependências/restrições ou até funcionalidades). A ausência de uma especificação complementar não afetará o entendimento básico do Modelo de Versões a não ser que o usuário esteja interessado em se aprofundar nos detalhes específicos do Modelo de Versões.

Seguindo o Meta-Modelo, uma classificação dos Modelos de Versões pode denominá-los: "básicos" quando estabelecem especificações mínimas que não chegam a incluir todos os itens fundamentais; e "plenos" quando relatam todos os itens fundamentais e opcionalmente os complementares em sua especificação. 


\subsection{1 - Fundamentais}

Independentemente do Modelo de Dados, o Meta-Modelo de Versões define os seguintes itens fundamentais para um Modelo de Versões:

1. Alvo: descreve-se qual Base de Dados (Intencional e/ou Extensional) é abordada pelo Modelo de Versões (texto ${ }^{1}$ );

2. Granularidade: descreve-se sobre qual elemento (Objeto, Objeto Composto, Classe, Esquema, etc) são realizadas as Versões;

3. Condição Versão: descreve-se como é colocada e/ou retirada a condição que estabelece a permissão de operações com Versões (por comandos ou automaticamente pelo sistema);

4. Transição de Estados: descrevem-se quais as possíveis alterações de estados que podem ocorrer durante o "ciclo de vida" de uma Versão;

5. Restrições de Acesso: descrevem-se quais os níveis de acesso (leitura, escrita) para cada tipo de usuário (ex: criador da Versão, grupo de usuário, todos) em cada estado. Deve sempre existir uma preocupação com o intercâmbio ou interrelação entre as Restrições de Acesso estabelecidas pelo Modelo de Versões e pelos outros Modelos (Autorização, Distribuição, Transação, etc.) utilizados, para que não ocorram impedimentos ou permissões indevidas;

6. Estado Inicial: descreve-se qual é o estado de uma Versão no momento em que é criada, a partir de uma Versão ou de um elemento que não é considerado Versão;

7. Motivação: descreve-se o motivo pelo qual um usuário ou o sistema irá criar, remover e/ou alterar o estado de uma Versão, ou seja, em quais situações (ex.: criação de certos elementos ou de uma quantidade de elementos) uma Versão é criada, removida ou tem seu estado alterado;

8. Estruturas de Dependência: descreve-se qual ou quais são as organizações estruturais que interrelacionam as Versões, independentemente de seus estados. Como exemplo, temos as formações estruturais para Derivação na forma de Lista, Árvore, Grafo ou outras variações;

${ }^{1}$ O Meta-Modelo de Versð̃es define seus itens fundamentais e complementares em uma estrutura informal, que pode ser composta por: texto descritivo do item; figura, diagrama; estrutura (matriz, grafo, etc); ou outra forma de linguagem descritiva. 
9. Restrições de Manipulação: descreve-se para qual tipo de usuário é permitida a criação, remoção de Versões e mudança de estado. A criação pode ser permitida a todos os usuários e ao SGBD (sem a ação direta de um usuário), que neste caso também se compromete com a remoção;

10.Procedimentos de Alteração de Estados: descrevem-se, caso existam, as condições em que são permitidas cada alteração de estado e as ações que eventualmente devem ser realizadas após cada alteração;

11. Conjuntos Lógicos: descreve-se como as Versões são agrupadas e apresentadas logicamente aos usuários;

12. Referências: descrevem-se de que forma as Versões podem ser referenciadas pelos usuários e pelo SGBD (referência dinâmica ou estática). No caso de referência dinâmica, descreve-se como é escolhida uma Versão específica entre as Versões agrupadas em um Conjunto Lógico;

13.Elementos Especiais: descrevem-se quais elementos especiais (Objetos, Atributos ou Relacionamentos), que independente do Modelo de Dados, são necessários para a representação de Versões;

14.Propagação e Notificação: descreve-se como ocorrem as propagações de alteração de uma Versão para os seus dependentes (diretos ou indiretos) e que notificações devem ser enviadas aos usuários;

15. Reaproveitamento: descreve-se qual a liberdade permitida pelo Modelo para a reutilização de Versões, ou seja, em quais momentos/situações ou estados são permitidas as consultas, acessos e manipulações de Versões inativas (se existirem), ou também, em quais momentos/situações ou estados são permitidas as exportações de Versões para outras BD's;

16.Aplicação: descreve-se qual a utilização para o Modelo de Versões. Pode ser de uso geral (genérico), atuando em qualquer aplicação, ser destinado a problemas de áreas específicas (mecânica, civil, elétrica, etc), ou servir de apoio a uma funcionalidade (controle de transação, distribuição, etc).

\subsection{2 - Complementares}

O complemento do Meta-Modelo de Versões é composto por itens que podem acompanhar um Modelo de Versões mas que não são essenciais, pelo fato de não estarem diretamente relacionados ao seu aspecto de modelagem conceitual. A função do Complemento é melhorar a especificação e aumentar a compreensão do Modelo de Versões e, neste sentido, podemos relatar os seguintes itens: 
1. Estruturas Físicas: descrevem-se quais as estruturas de armazenamento de Versões, do Conjunto Lógico, dos Procedimentos de Alteração de Estado, das Restrições (Manipulação/Acesso), das Estruturas de Dependência, etc;

2. Mecanismos Especiais: descrevem-se os mecanismos usados e/ou procedimentos especificos de armazenamento das Versões;

3. Comandos para Utilizacão: descrevem-se quais são os comandos, ao nivel de usuário e de DBA (administração), para acesso, criação, remoção, navegação pelas Estruturas de Dependências de Versões, etc.;

4. Modelos Relacionados: descrevem-se outros Modelos (ex.: Configuração, Tempo, Distribuição, Transações) que tenham alguma correlação estrutural, funcional ou semântica com o Modelo de Versões.

Para o Meta-Modelo de Versões, deve-se observar que: a) alguns itens podem oferecer redundâncias de informação, no entanto estas colocações reafirmam o Modelo de Versões e aumentam sua compreensão; b) dependendo da semântica de uma Aplicação, alguns itens poderão simplesmente definir a inexistência de certos aspectos, mas mesmo assim estes itens devem ser explicitamente documentados; c) não há, entre os itens, uma ordem a ser seguida para a criação de um Modelo de Versões.

\section{3 - Modelo de Versões do MRO*}

O Modelo de Versões do MRO* tem sua Granularidade determinada pelos Objetos Compostos [AHMED_91], contudo apresenta diferenças em relação à forma como é tratado no Modelo de Chou e Kim (seção 2.3.3), o único estudo que contempla com propriedade o problema de modelagem de Versões em Objetos Compostos. As diferenças devem-se basicamente aos princípios que regem os Modelos de Dados seguidos (MRO* e ORION).

O ORION, como a maioria dos Modelos Orientados a Objetos, estabelece a Hierarquia de Composição como uma (mais uma) organização de Objetos definida por relacionamentos "is-part-of", tratados de maneira semântica e internamente diferente de outros relacionamentos. O MRO*, por sua vez, estrutura toda a Base de Dados na Hierarquia de Composição em que os Objetos Compostos (denominados Colônias) estão relacionados aos seus componentes, através de relacionamentos implícitos e naturalmente reconhecidos pelo SGBD e pelos usuários.

A escolha de Colônias, no Modelo de Representação de Objetos, como Granularidade do Modelo de Versões apoia-se na larga utilização de Objetos 
Compostos, que foi várias vezes ressaltada em Modelos de Dados que suportam Abstrações de Composição/Decomposição.

O fato do MRO* ter um tratamento uniforme para Colônias de Tipos (BD Intencional) e Colônias de Instâncias (BD Extensional), permite que o Modelo de Versões seja aplicado a toda a Base de Dados, determinando assim seu Alvo: BD Intencional e Extensional. Neste caso, ambas as Bases de Dados exigem uma especificação individualizada de alguns itens para cada Alvo pois, apesar do Modelo de Versões ter um tratamento único para estas Bases de Dados, existem algumas variações e peculiaridades que devem ser explicitadas.

Para comportar o Modelo de Versões, o Meta-Esquema de Dados do MRO* sofreu algumas alterações associadas às Colônias e aos Objetos (Figura 5.1). O MetaEsquema de Dados modificado inclui os seguintes Elementos Especiais:

\section{- Meta-Atributo Versão}

no Meta-Tipo Colônia, o que permite estabelecer Tipos de Colônia "non-versionable" e Tipos de Colônia "versionable". Assim, em cada definição de um Tipo de Colônia, o projetista da aplicação tem que estabelecer (autorizar ao nível de gerenciador) a possibilidade de criação de Versões como Instâncias;

\section{- Meta-Atributo Genérico}

no Meta-Tipo Objeto, o que permite estabelecer os Tipos de Objeto Genérico e os Tipos de Objeto Não-Genérico, ou seja, o projetista do Esquema da aplicação tem obrigatoriamente de estabelecer em cada Tipo de Objeto, se suas Instâncias (Objetos) poderão (ou não) ser

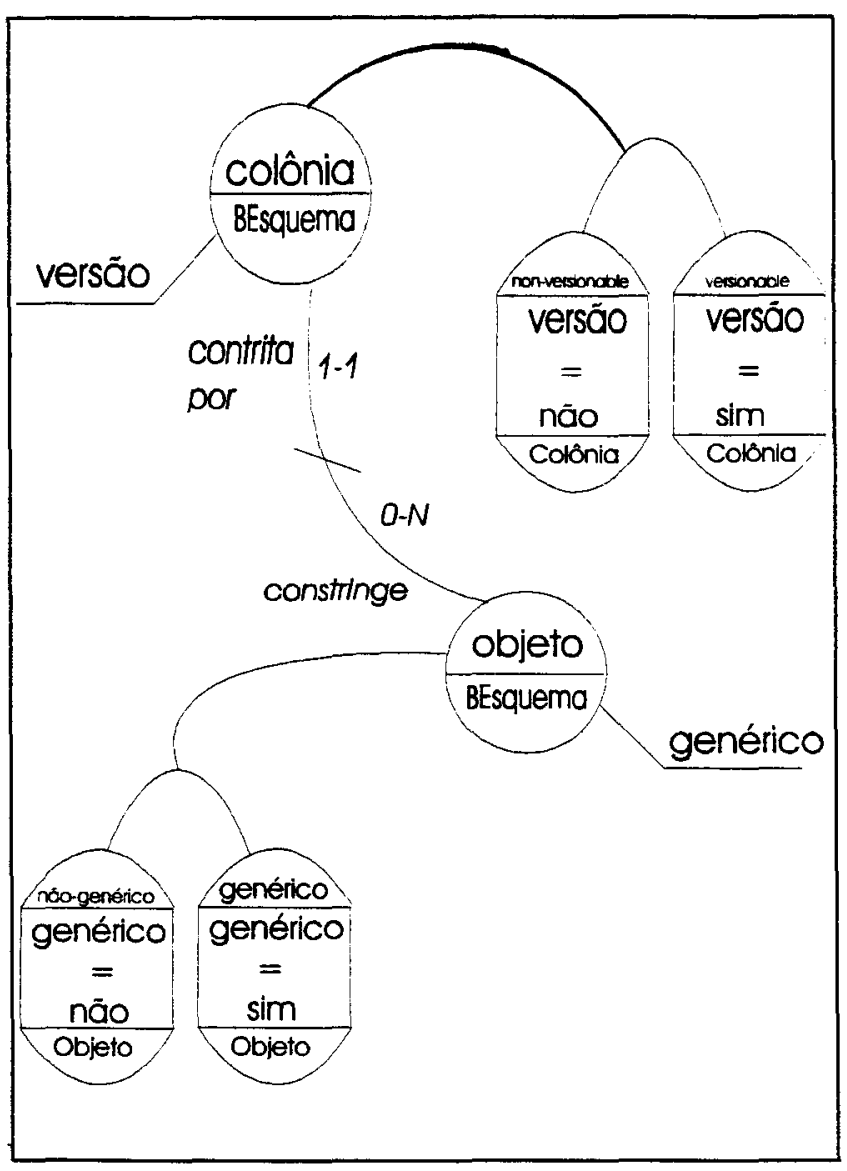

Objetos Genéricos de um conjunto Figura 5.1 - Parte Modificada do Meta-Esquema do MRO* de Objetos da Base de Dados².

\footnotetext{
${ }^{2}$ A flexibilidade para definir Objeto Genérico para as Instâncias somente dos Tipos de
} 
Particularmente neste trabalho, um Obieto Genérico ${ }^{3}$ é um Objeto que segue a definição "tradicional" do paradigma de "orientação a objetos", sendo criado explicitamente pelo usuário em um operação de instanciação (como a maioria dos Objetos da BD), mas destaca-se por estar vinculado a vários Objetos de seu Tipo. Cada um destes Objetos foi instanciado para ter os mesmos Atributos e Relacionamentos do Objeto Genérico. Eventualmente, estes Objetos terão seus próprios Atributos e Relacionamentos e, todos ou parte dos Atributos e

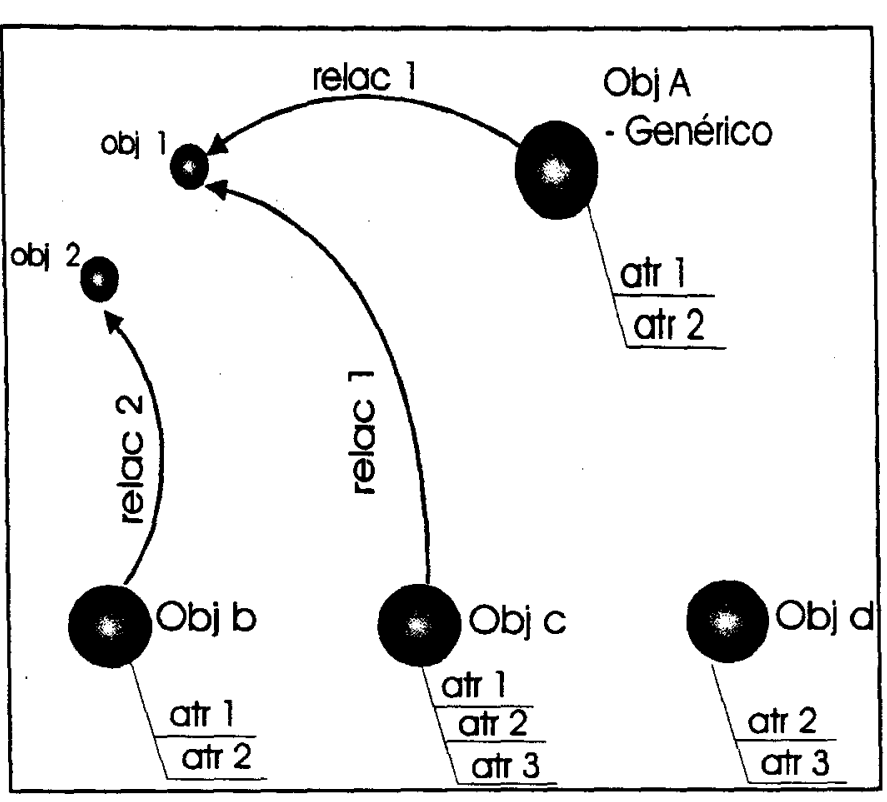

Figura 5.2 - Exemplo de Objeto Genérico no MRO* Relacionamentos que pertencem ao Objeto Genérico podem ser removidos, como mostra a Figura 5.2 (Obj $a$ é Genérico de $b, c, d$ ). O vínculo de um Objeto com o seu Objeto Genérico pode ser retirado e, neste caso, deixa de existir o "compartilhamento" de informações (valores de Atributos e Relacionamentos) entre o Objeto e o respectivo Genérico.

A Transicão de Estados estabelece duas situações para uma Versão (Figura 5.3), nomeadas estável e instável. Na alteração de estados, uma Colônia Instável pode tornar-se Colônia Estável pela utilização explícita de um comando do usuário, mas a operação inversa não é permitida pois Colônias Estáveis estão sendo utilizadas e portanto não podem ser alteradas. Uma Versão de Colônia é sempre criada no estado instóvel (Estado Inicial) independente de ser uma Versão gerada a partir de uma Colônia Instável ou Estável.

Objeto escolhidos pelo projetista do Esquema é uma inovação do Modelo de Versões do MRO*.

${ }^{3}$ Objeto Genérico, na definição deste trabalho, é um Objeto com semântica estabelecida pela aplicação e portanto, tendo Atributos de representação do empreendimento, e que estruturalmente interrelaciona-se com outros Objetos por meio de associações implícitas particularmente estratégica para o gerenciador. Desta forma, esta definição difere nos aspectos estrutural e semântico do Objeto Genérico estabelecido por Chou e Kim [Kim_87], onde conceitua-se Objeto Genérico como um elemento criado "artificialmente", apenas com Atributos para apoiar o controle de versões, e que engloba um conjunto de Versões de um mesmo Objeto.

Pode-se referenciar um Objeto Genérico no MRO* da mesma forma que aos Objetos interrelacionados ao Genérico, ao passo que, referenciar um Objeto Genérico no ORION é dinamicamente estabelecido como uma referência a uma Versão representada pelo Genérico. 
As Versões de uma Colônia são organizadas em um conjunto denominado Árvores Alternativas de Derivações ${ }^{4}$ - AAD (Estrutura de Dependência), onde as interrelações entre Versões registram a seqüência de derivações, o que permite uma consulta e navegação entre dependências de Versões de uma mesma Colônia da Base de Dados (Figura 5.4).

O conjunto AAD é composto por Árvores de Derivações onde cada Versão de Colônia ("pai") possui uma interligação com uma Versão "filha" derivada/gerada do "pai" e uma interligação com uma Versão "irmã" que possui a mesma origem da Versão "pai". As Versões "filha"

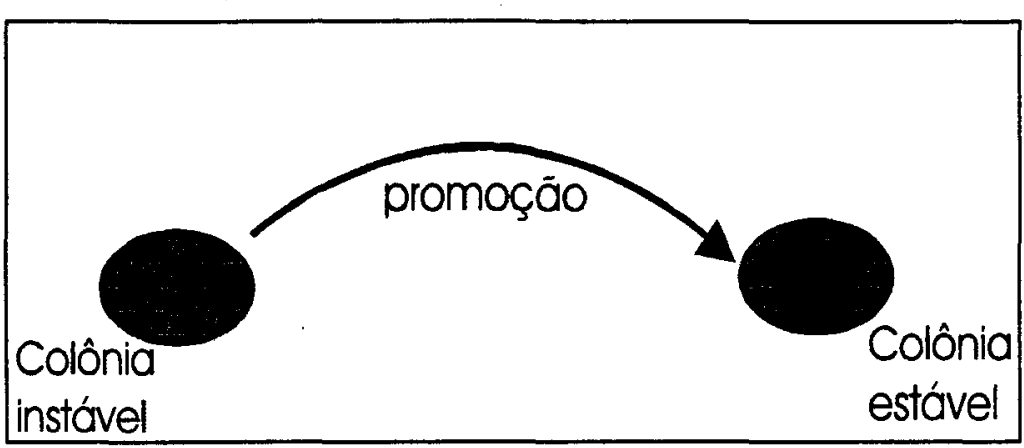
possuem os mesmos

Figura 5.3 - Diagrama de Transição de Estados

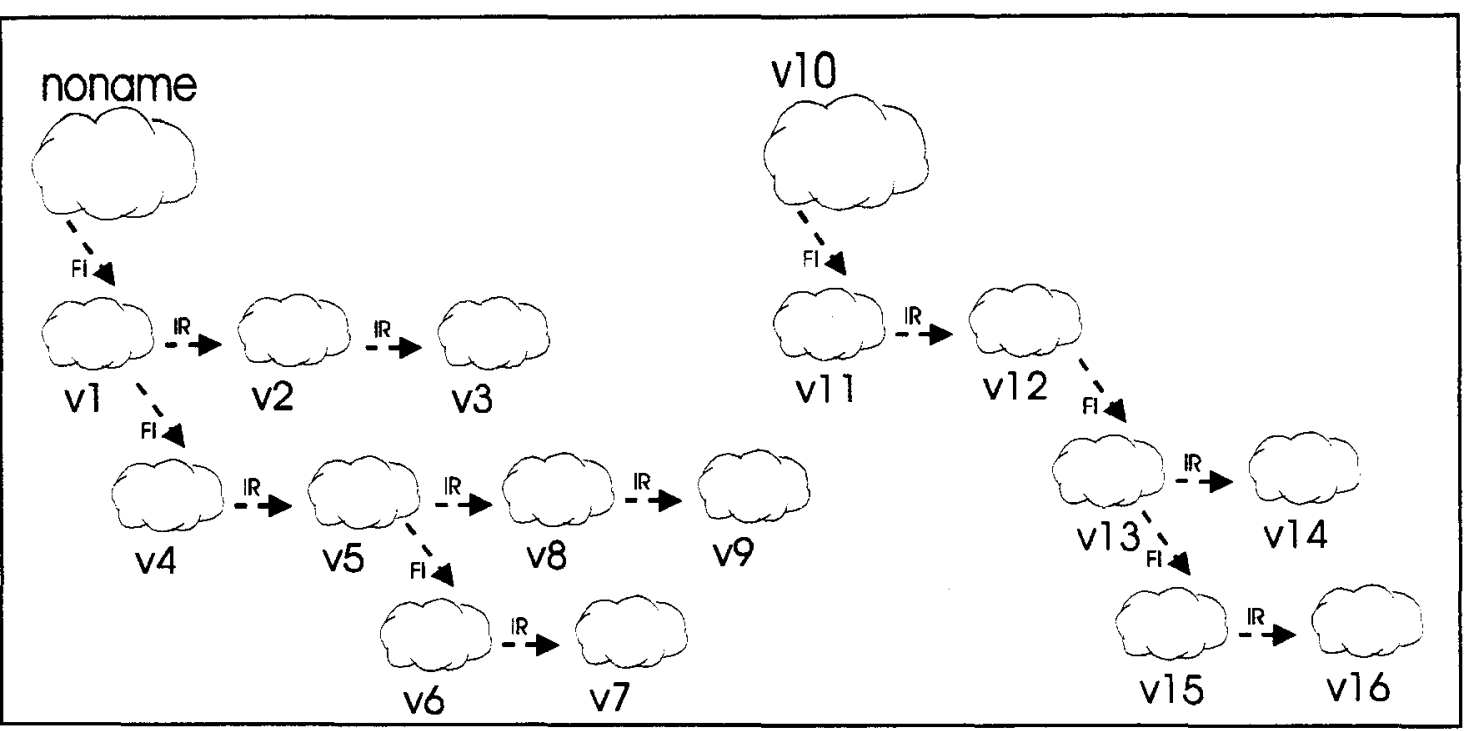

Figura 5.4 - Árvores de Derivações em um conjunto AAD

${ }^{4} \mathrm{O}$ conceito de Árvores Alternativas de Derivações é uma contribuição deste trabalho pelo fato de estender a aplicação comumente usada de Árvore de Derivação, permitindo a ampliação dos limites e possibilidades de estabelecimento e geração de Versões.

Em Modelos de Dados como o EXODUS e ORION, cada Objeto "versionable" possui uma única Árvore de Derivação para organizar suas Versões e isto, conseqüentemente, limita a origem das Versões de um mesmo Objeto a uma única Versão ("raiz"). 
Objetos de sua Versão "pai”, exceto as "raízes" das Árvores de Derivações que foram criadas vazias. Uma Versão possui quantas Versões "filha" e Versões "irmã" forem necessárias, pois na criação de Versões não existem limitantes que restrinjam as necessidades dos usuários.

As várias Árvores de Derivações, que formam o conjunto $\mathrm{AAD}$, são independentes entre si, pois os Objetos de uma Versão de Colônia ("pai") podem ser Objetos Genéricos apenas de outros Objetos de Versões "filha" da mesma Árvore de Derivações. Desta forma, duas Versões de Árvores de Derivações distintas, denominadas Versões de $2^{a}$ Ordem, normalmente possuem composições de Objetos potencialmente diferentes se comparadas a duas Versões de uma mesma Árvore de Derivações (Versões de $1^{\text {a. }}$ Ordem).

Na criação de uma Versão "nova", os Objetos contidos na Versão "pai" são definidos também para a Versão "nova". Nesta criação, cada Objeto (do Tipo Genérico) da Versão "pai" torna-se um Objeto Genérico ${ }^{5}$ vinculado ao respectivo Objeto na Versão "nova". Caso um Objeto (do Tipo Genérico) na Versão "pai" possua um vínculo com um Genérico de outra Versão já existente, então, o respectivo Objeto na Versão "nova" terá vínculo com o Genérico desta outra Versão (Figura 5.5). Os Objetos Não-Genéricos ${ }^{6}$ de uma Versão "pai" são também repassados fielmente (em termos de Atributos e Relacionamentos) para a Versão "nova", contudo após este repasse nenhum vinculo permanece entre os Objetos e assim, qualquer atribuição a um Objeto Não-Genérico não terá efeito sobre outros Objeto.

A identificação de uma Versão específica ocorre pelo seu nome, atribuido pelo usuário na operação de criação da Versão, que é único entre as Versões da mesma Colônia que estão organizadas em um conjunto de Árvores Alternativas de Derivações. A primeira Versão de cada Colônia "versionable" é a única que não tem um nome definido pelo usuário, sendo denominada "noname".

A utilização prática de AAD's permitirá (opcionalmente), a um usuário da $\mathrm{BD}$, iniciar um processo de criação de Versões não tendo que apoiar-se em Versões já existentes (nem mesmo em seus Esquemas de Dados), ou seja, um usuário, no desejo de elaborar Versões completamente novas, diferentes daquelas já estabelecidas, pode criar uma Versão (sem conteúdo - vazia) como uma "raiz" de uma nova Árvore de Derivações, a qual fará parte do conjunto de AAD da Colônia (da Base de Dados Intencional ou Extensional) focalizada.

\footnotetext{
${ }^{5}$ Os Objetos Genéricos existem apenas em Versões de Colônias que possuem "filhas".

${ }^{6}$ Objetos Não-Genéricos são Objetos do Tipo Não-Genérico e portanto não são utilizados como Genéricos na BD.
} 


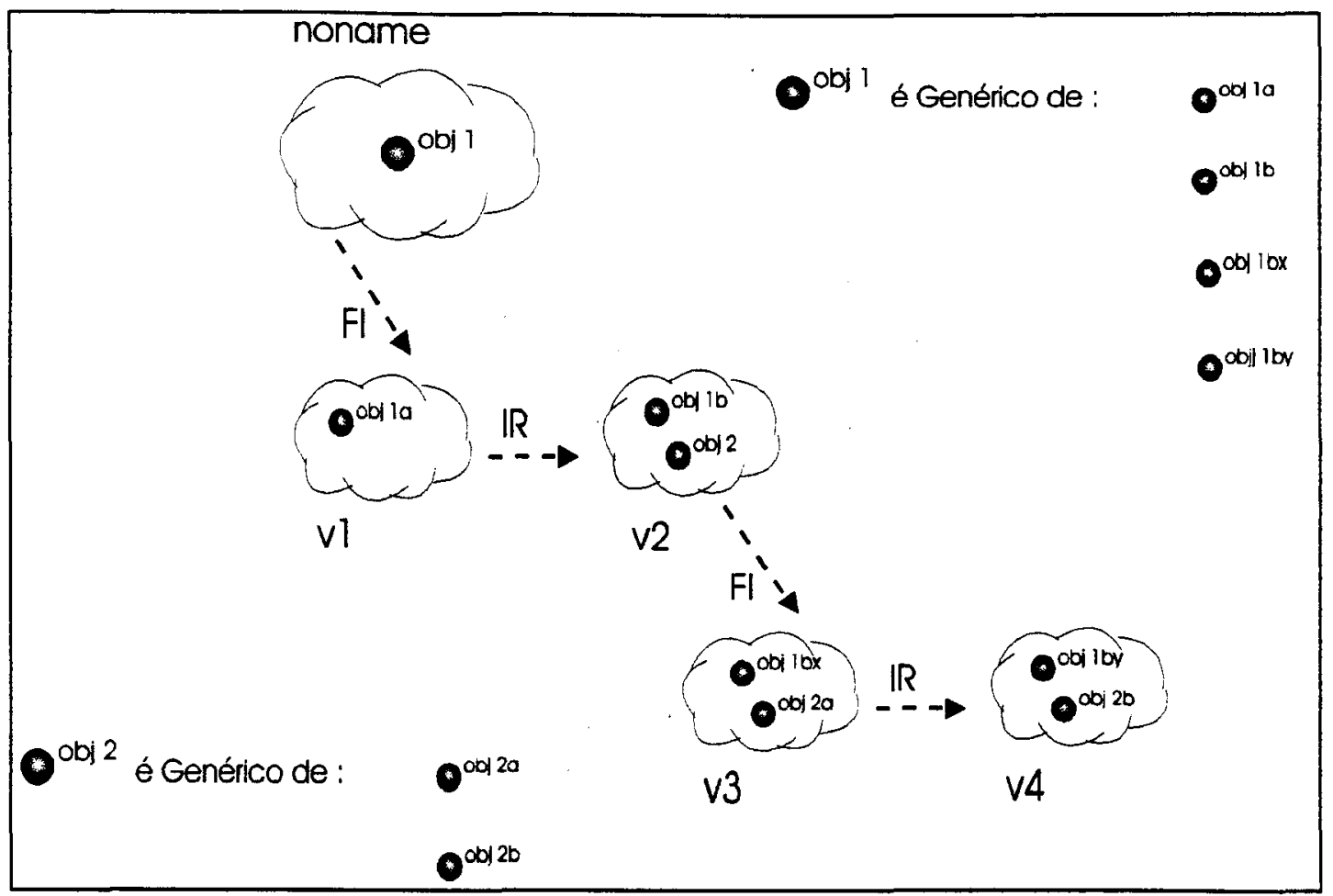

Figura 5.5 - Exemplo de Objeto Genérico em uma Árvore de Derivações

Para cada conjunto $\mathrm{AAD}$ em cada objeto da $\mathrm{BD}$, todos os usuários têm individualmente disponíveis para Referência (dependendo do nível de autorização de cada um): uma Versão Corrente correspondendo àquela em que o usuário está no presente momento posicionado e acessando; e uma Versão Default correspondendo àquela em que o usuário determinou como mais rotineira. Igualmente, para cada conjunto $\mathrm{AAD}$ em cada Objeto da $\mathrm{BD}$, existem as Versões Correntes do ambiente gerenciador e suas Versões Default designadas por serem normalmente utilizadas pelos usuários menos preocupados com a identificação de Versões.

Uma Colônia Estável (consolidada) pode ser somente consultada ou então utilizada na instanciação se for uma Colônia Esquema Suplementar, enquanto uma Colônia Instável pode ser consultada e alterada (leitura e escrita) por qualquer usuário. Estas Restricões de Acesso são muito simples, de forma a permitir a utilização deste Modelo de Versões individualmente ou em conjunto com outros Modelos (Autorização, Transação, Distribuição, etc.) que também colaboram com suas próprias restrições de acesso.

As Mudanças de estado ou remoções de Versões de Colônias (Restricões de Manipulacão) são operações exclusivas dos DBA's ou de gerentes de projeto (se existirem), isto porque, são atividades normalmente gerenciais e decisivas para um projeto, pois envolvem consolidações/aceitações de dados para utilização efetiva nos próximos processos de trabalho ou, no caso de remoção, se esta realizando o 
abandono/descarte de Versões que não se mostram promissoras. A criação de Versões de Colônias do Tipo "versionable" é permitida a qualquer usuário, porém o Modelo de Autorização poderá impedir criações de Versões de Colônias protegidas.

Sobre o aspecto dos Procedimentos de Alteracão de Estados, não existem ações especiais para a mudança de estado instóvel para estável, com exceção da exigência de consistência (sintática e semântica em relação ao MRO*) das Colônias Instáveis para torná-las Colônias Estáveis. A condição de consistência para alteração de estados pode aparentemente ser simples, contudo envolve muitas verificações de relativa complexidade e são absolutamente necessárias apesar dos Modelos de Versões normalmente não mencionarem tais condiç̃es.

Cada Instância é permanentemente associada ao seu respectivo Tipo e conseqüentemente à sua correspondente Versão (Estável) de Colônia Esquema Suplementar. Portanto, nenhuma Versão usada pelas Instâncias pode ser alterada o que, neste aspecto, torna inexistente a preocupação com relação a Propagacão e Notificacão.

Entre as Versões de uma Colônia, ocorre a Propagação apenas na criação de Objetos, ou seja, quando um Objeto (do Tipo Genérico ou Não-Genérico) é criado em uma Versão Instável de Colônia, todas as suas Versões "descendentes" também recebem o Objeto, exceto as Versões Estáveis e suas derivações. O Objeto criado inicialmente na Versão Instável torna-se Objeto Genérico dos respectivos Objetos nas Versões "descendentes". Opcionalmente, os usuários daquelas Colônias Estáveis que não foram atingidas por alguma Propagação, podem receber uma Notificação (mensagem) de aviso apresentando a Propagação não efetuada.

Seguindo os caminhos definidos para o MRO*, que é um modelo muito amplo em representação e aplicabilidade de suas teorias e conceitos, este Modelo de Versões se propõe a ser genérico (Aplicacão) em suas definições, o que não o impede de ser modificado, em alguns itens, para direcioná-lo a uma área específica.

\subsection{1 - Versões na Base Intencional}

A criação de uma Versão de Colônia Esquema Suplementar não está condicionada a nenhuma regra ou elemento da BD, sendo assim, a Condicão Versão é implicita, constante e sempre favorável a geração de Versões para qualquer Colônia Esquema Suplementar, mesmo porque, é praticamente impossível e desnecessário para um DBA determinar previamente a inexistência de Versões do Esquema.

Uma restrição semântica do $\mathrm{MRO}^{*}$ não permite a criação de Versões da Colônia Esquema Inicial porque nela estão armazenados apenas os elementos iniciais 
e básicos de representação de uma aplicação. Havendo a perspectiva de necessidade de criação de Versões na BD Intencional, a Colônia Esquema Inicial deve ser mantida apenas com as informações que nunca deverão ter Versões.

A existência de uma Versão de Colônia Esquema Inicial representaria outra aplicação ou outro enfoque da mesma aplicação que, para o MRO*, significa outra Base de Dados. Assim, diante da necessidade de criação de um Esquema Inicial novo, o projetista de modelagem deve optar pela modificação do Esquema Inicial já existente, se não forem alterações significativas que descaracterizem o problema, ou optar pela criação de uma outra Base de Dados para o Esquema Inicial novo.

A Motivacão de um projetista da BD em criar uma Colônia Esquema Suplementar deve estar basicamente orientada no sentido da complementação de informações, sem descartar outras, mas apenas incrementando (independente da quantidade) a modelagem, enquanto a criação de um Versão de Colônia Esquema Suplementar deve ser voltada à experimentação, correção, adaptação, atualização ou refinamento de uma quantidade indeterminada de informações do Esquema Suplementar origem.

Como mencionado anteriormente no item Restricões de Acesso, aos usuários autorizados da BD são permitidas somente consultas às Versões Estáveis, mas particularmente nas Versões Estáveis de Esquemas Suplementares, a atividade de consulta se estende ao SGBD, que neste caso, realiza consultas às Versões Estáveis de (Colônias) Esquemas Suplementares, escolhidas pelo usuário, para a montagem do Esquema de Dados Ativo.

Uma Versão Instável de Colônia Esquema Suplementar pode tornar-se uma Versão Estável pela utilização explícita de um comando do usuário, já a operação inversa é impedida pois Versões Estáveis de Esquemas Suplementares são utilizadas na instanciação e não devem ser alteradas. O Esquema de Dados Ativo (Conjuntos Lógicos) é a composição de Versões Estáveis, não sendo permitida a requisição de Versões Instáveis de Esquemas Suplementares para comporem o Esquema Ativo, pelo fato de poderem ser alteradas, o que causaria inconsistências se fossem utilizadas na instanciação.

Uma forma mais persistente de associação entre as Versões de Esquemas Suplementares é estabelecida pelos Objetos Esquema (Elemento Especial), que são criados exclusivamente para se associarem às Versões de Colônia Esquema, não tendo a função de representação de dados dentro do contexto de uma aplicação, como acontece normalmente com os Objetos. Os Objetos Esquema são armazenados na (habitam a) Colônia Global e cada um agrupa as Versões de uma mesma Colônia Esquema Suplementar. 
A criação de uma Colônia Esquema Suplementar exige inicialmente a geração de um Objeto Esquema, que terá a função específica de relacioná-lo, bem como agrupar suas Versões. Esta é uma exigência do MRO* que determina, para qualquer Colônia (Esquema ou Instância), a existência de um Objeto que a constringe (Figura 4.3) e pelo qual é possível acessar a Colônia.

A Referência a qualquer Colônia Esquema Suplementar deve explicitamente indicar o respectivo nome do Objeto Esquema e o nome de uma Versão de Colônia Esquema Suplementar específica, ou então optar pela escolha dinâmica de uma Versão entre as Versões existentes no conjunto AAD.

$\mathrm{Na}$ Base Intencional não existem Versões consideradas inativas, uma vez que qualquer Versão de Colônia Esquema Suplementar, desde que seja Estável, pode ser instanciada quando necessário e a critério do usuário. Assim, o Reaproveitamento se aplica somente à exportação de Versões de Esquemas Suplementares para outras Bases de Dados, pois a representatividade de um Esquema Suplementar, por depender de contextos normalmente técnicos (ex: componentes de um motor, componentes elétricos de uma construção), facilita sua aplicação em diversos problemas.

\subsection{2 - Versões na Base Extensional}

Para a definição de Tipos de Colônias nas Colônias Esquema, os projetistas devem indicar explicitamente o valor de Atributo Sim (para Tipo de Colônia "versionable") ou Não (para Tipo de Colônia "non-versionable") para a Condicão Versão, como indicado na Figura 5.1. A alteração da Condição Versão de um Tipo de Colônia "versionable" para "non-versionable" (ou vice-versa) é possivel somente quando este Tipo estiver contido em uma Versão Instável de Colônia Esquema.

Não existem quaisquer regras para a criação de Versões de Colônias de Instâncias, porém uma restrição semântica do $\mathrm{MRO}^{*}$ não permite a criação de Versões da Colônia Global, uma vez que nela são armazenados as informações iniciais de toda a instanciação. Os Objetos da Colônia Global são pontos de partida para as Hierarquias de Colônias e de Versões.

Cada (Versão de) Colônia de Instâncias, exceto a Global, está vinculada à um Objeto pertencente a uma Colônia em um nivel superior da Hierarquia de Composição (Hierarquia de Colônias). Independente do nível de uma Colônia de Instâncias dentro da Hierarquia de Colônias, pode-se criar Versões dependendo da Condição Versão de seu Tipo. Contudo, a remoção de Versões de Colônia de Instâncias depende do nível de autorização oferecido ao usuário e da existência de Colônias de Instâncias dependentes na Hierarquia de Colônias e no conjunto AAD. 
A Motivacão de um usuário, para a criação ou remoção de uma Versão de Colônia de Instâncias, varia dependendo do ambiente de projeto utilizado, e neste caso, para tornar o Modelo de Versões proposto mais genérico, não se estabelecem normas de conduta específicas para as ações de criação e remoção destas Versões e mesmo para as mudanças de seus estados, ficando a cargo dos usuários (engenheiros/projetistas) a estipulação de seus limites em relação a este item.

A ligação intrínseca (Estrutura de Dependência) entre as Versões de Colônias Esquema e as Versões de Colônias de Instâncias é estabelecida pela associação entre cada Instância e seu respectivo Tipo, uma vez que existe homogeneidade de tratamento para as Versões em ambas as Bases de Dados (Intencional e Extensional).

A relação de dependências estabelece uma cardinalidade $\mathrm{N}: \mathrm{M}$ entre as Versões (Estáveis) de Esquemas Suplementares e as Versões (Estáveis ou Instáveis) de Colônias de Instâncias, ou seja, uma Versão Estável de Colônia Esquema Suplementar pode ter seus Tipos instanciados em várias Versões de Colônias de Instâncias, e estas Versões (contendo muitas Instâncias) podem ser instanciação de várias Versões Estáveis de Esquemas Suplementares, desde que, cada Instância esteja vinculada apenas a um Tipo de uma única Versão de Esquema Suplementar.

Impor limites de representação das Versões de Esquemas Suplementares resultaria em restrições que reduziriam o poder de representação do Modelo. Portanto, para flexibilizar o Modelo de Versões proposto, em uma Versão de Colônia Esquema Suplementar podem estar definidos quantos Tipos de Colônia de Instâncias ("versionable" e "non-versionable) forem desejados para a modelagem.

Nos conjuntos de $\mathrm{AAD}$ na BD Extensional, cada Árvore de Derivações pode ter suas Versões instanciadas a partir de diferentes Esquemas Ativos, ou seja, cada Árvore de Derivações no conjunto de AAD pode ser instanciada por diferentes Versões de Esquemas Suplementares. Desta forma, um usuário, ao criar uma Versão "vazia" e "raiz" de uma Árvore de Derivações nova, tem a possibilidade de instanciar esta Versão com elementos novos que sigam as Versões de Esquemas Suplementares desejadas.

A Referência a qualquer Instância existente deve vir precedida pela requisição da respectiva Versão Estável de Colônia Esquema Suplementar para incorporá-la ao Esquema de Dados Ativo. No caso de um pedido de acesso a uma Colônia de Instâncias, é necessário também a indicação de uma Versão específica (se existir) ou pode-se optar pela escolha dinâmica de uma Versão. 


\section{4 - Representação Gráfica}

Os novos conceitos deste trabalho exigem a adição de elementos de representação gráfica para a visualização da modelagem, pois a apresentação de trabalhos realizados ou em estágios de criação são imprescindiveis para projetistas e administradores da BD e a representação é uma das preocupações sempre presentes nas pesquisas com o MRO*.

\subsection{1 - Diagrama Hierárquico de Versões (DHV)}

O conjunto AAD de cada Colônia Esquema Suplementar ou Colônia "versionable" de Instâncias pode ser visualizado em um Diagrama Hierárquico de Versões (ou DHV), onde as interligações de "parentesco" são explicitamente declaradas por setas tracejadas nomeadas FI (entre Versão "pai" e Versão "filha") ou IR (entre duas Versões "irmãs"), como é exemplificada na Figura 5.6.

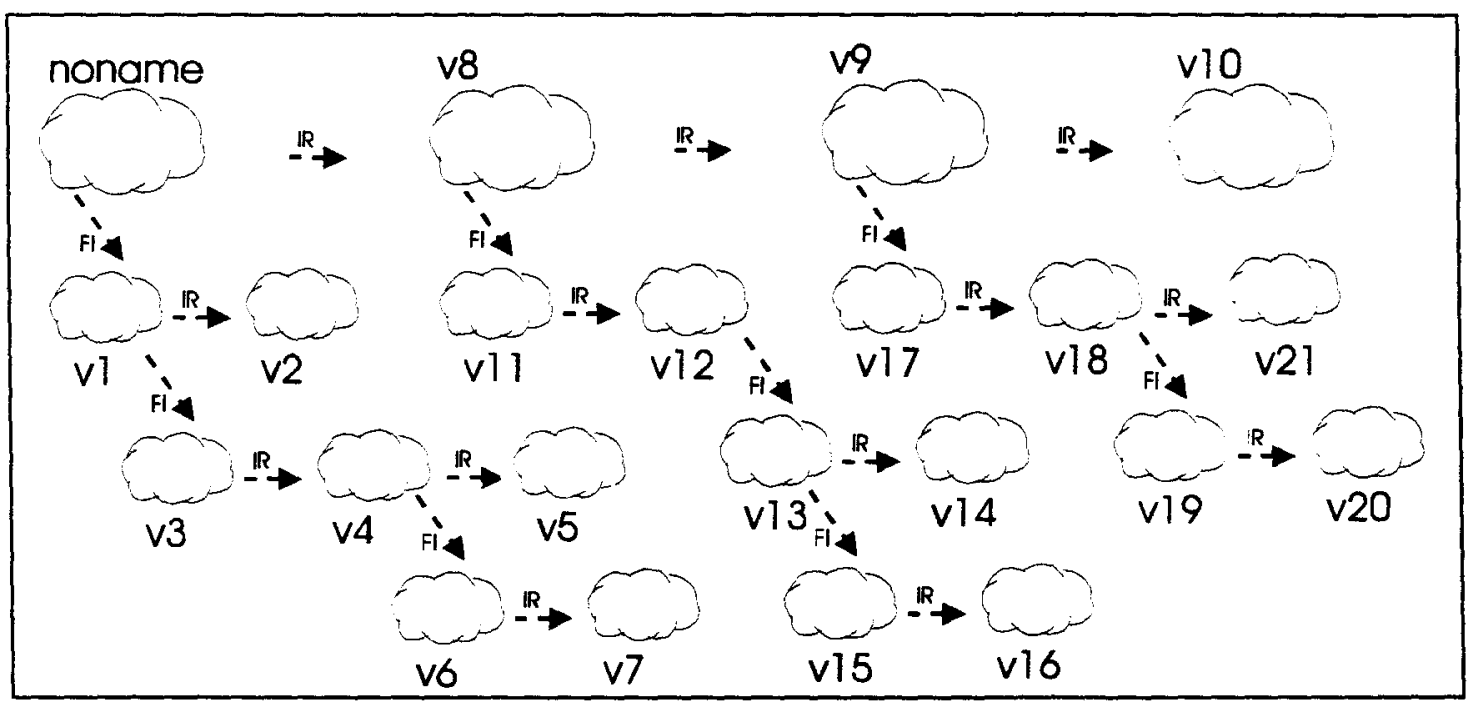

Figura 5.6 - Exemplo de DHV

As "raizes" das Árvores de Derivações de um mesmo conjunto AAD são interligadas por setas tracejadas do tipo IR. O DHV também inclui o nome de todas as Versões existentes, exceto a primeira Colônia criada que não possui um nome, sendo genericamente denominada "raiz" ou "noname".

Adicionalmente, o conteúdo (Instâncias) de cada Versão do conjunto AAD pode ser apresentado no DHV, embora neste caso, as Versões devam ser simples (contendo poucos elementos) para não prejudicar a clareza do diagrama. 


\subsection{2 - Diagrama Hierárquico de Colônias (DHC)}

No DHC (de Tipos), além da representação tradicional, deve-se acrescentar junto ao Tipo de Colônia (como esquematizado na Figura 5.7a) um retângulo em volta do nome do Tipo de Colônia "versionable" e as denominações das Colônias Esquemas Suplementares usadas para sua instanciação (em retângulos internos ao Tipo de Colônia).

No DHC, quando apresentando Instâncias (Objeto e Colônias), deve-se acrescentar (Figura 5.7b) junto à Colônia de Instâncias, um retângulo em volta do nome do Tipo de Colônia "versionable" e, caso

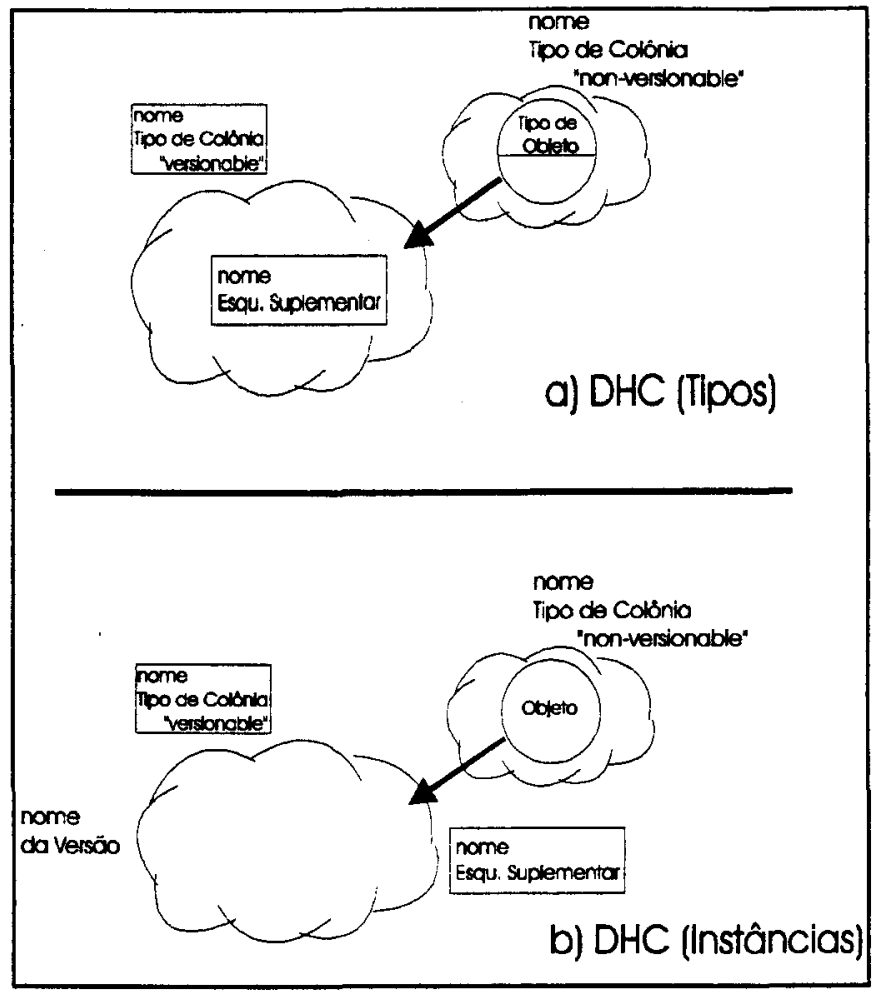

Figura 5.7-Representação de um DHC inclua uma Versão específica, é obrigatório a colocação do nome desta Versão e dos nomes dos Esquemas Suplementares usados na instanciação (em retângulos posicionados abaixo da Colônia de Instâncias).

\subsection{3 - Diagrama de Representação de Instâncias (DRI)}

$\mathrm{Na}$ representação de uma Versão de Colônia de Instâncias em um DRI e, mesmo em um DHV ou DHC, é necessário indicar (esquematizado na Figura 5.8) em um retângulo com 0 nome da Versão de Colônia Esquema Suplementar utilizada na instanciação de cada Objeto (Relacionamento e Atributo).

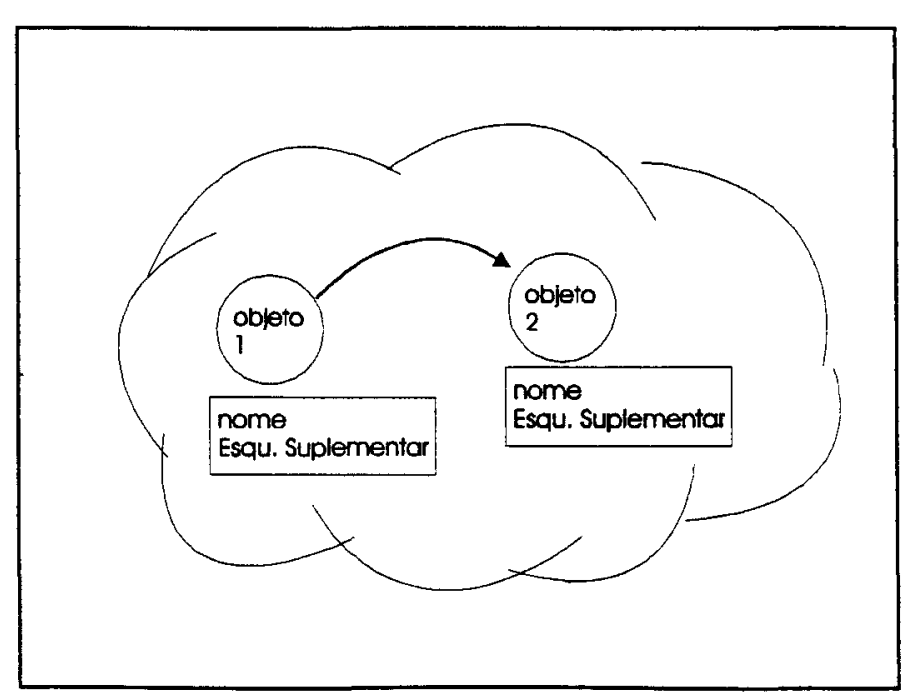

Figura 5.8 - Representação de um DRI 


\subsection{4 - Diagrama de Representação de Objetos (DRO)}

$\mathrm{Na}$ representação de uma Versão de Colônia Esquema, em um DRO e mesmo em um DHV ou $\mathrm{DHC}$, podem existir Relacionamentos com elementos contidos em Versões de outras Colônias Esquemas Suplementares. Estes elementos (chamados Estrangeiros ${ }^{7}$ ) são diferenciados e destacados dos demais, declarando-se as Colonias que os contêm, como está esquematizado na Figura 5.9 onde $o$ "Tipo de Objeto 2" não pertence à Colônia Esquema Suplementar

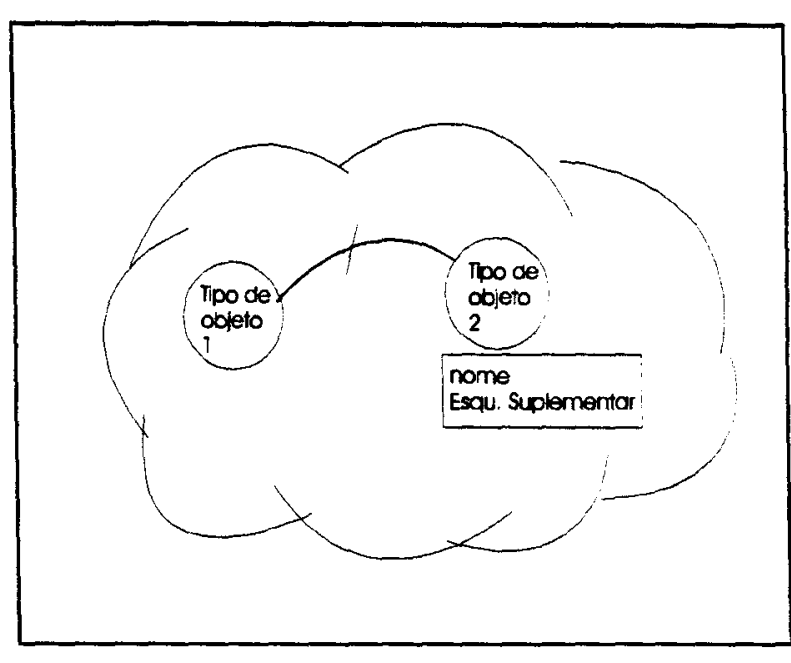

Figura 5.9 - Elemento Estrangeiro em DRO indicada.

\section{5 - Considerações Finais}

Seguindo a homogeneidade em que o MRO* aborda as Instâncias e os Tipos, o Modelo de Versões (ilustrado em um exemplo real de modelagem no Apêndice A) estabelece uma atuação uniforme em ambas as Bases de Dados (Intencional e Extensional) mas para isso, apresenta uma grande complexidade e um conjunto de conceitos que o diferencia de todos os Modelos de Versões anteriormente estudados. Além disso, destaca-se pela completeza de suas especificações, pois aborda em detalhes todos os aspectos obrigatórios de um Modelo de Versões que o qualificam para uma variedade de aplicações.

Em relação ao Meta-Modelo de Versões, elaborado exclusivamente neste trabalho, não existe uma especificação "definitiva" de seus itens, pois podem ainda surgir conceitos novos com a evolução (refinamentos) dos Modelos de Versões existentes. Os futuros Modelos de Versões deverão ser avaliados para o reconhecimento de itens novos, fundamentais ou complementares, no Meta-Modelo de Versões.

\section{米}

${ }^{7}$ Elementos Estrangeiros também podem ser encontrados em DRI's. 


\section{LINGUAGEM DE ACESSO DO MRO* (extensão)}

\section{1 - Considerações Iniciais}

As pessoas envolvidas com a BD são classificadas em: Gerentes/projetistas (ou Administradores - DBA), responsáveis pela definição/criação do Esquema de Dados (Inicial e Suplementares); Programadores de Aplicativos, que baseiam-se no Esquema para o desenvolvimento de aplicativos; e os Usuários Comuns, que realizam as definições/criações de Instâncias utilizando-se do Esquema de forma transparente.

Para as diversas operações que envolvem uma Base de Dados no GEO, tanto por parte dos gerentes/projetistas quanto pelos programadores e usuários, foi desenvolvida uma linguagem baseada em comandos (LAMRO) para a especificação dos Objetos que compõem a BD e das "variáveis" do ambiente de desenvolvimento. O conjunto mínimo de comandos da LAMRO (Linguagem de Acesso do MRO*) foi inicialmente proposto em um trabalho de pesquisa anterior [PIZZIGATTI_92].

No sentido de enriquecer o Modelo de Versões, em relação ao item (Complementar) Comandos para Utilização estalececido no Meta-Modelo de Versões (capítulo 5), foram realizados estudos para modificações e extensões à LAMRO, que 
conduziram a: reclassificação de todos os comandos; alterações na sintaxe de alguns comandos envolvendo Objeto e Colônias; e a criação de novos comandos.

Este capítulo tem por objetivo apresentar os resultados deste trabalho dentro do contexto da LAMRO, não tendo a intenção de descrever todos os comandos que fazem parte desta linguagem, mas somente os novos comandos e aqueles que passaram por alguma alteração na sua concepção original.

\section{2 - Especificações da LAMRO}

A LAMRO foi concebida de modo a refletir a uniformidade do MRO* no tratamento de Instâncias e Tipos na forma de Objetos. Assim, não existe nesta linguagem a clássica divisão (ex. SQL) entre os comandos que atuam sobre Tipos e os comandos que atuam sobre Instâncias.

\subsection{1 - Classificação dos Comandos}

Os comandos da LAMRO são divididos em três conjuntos (D - Definição, M Manipulação e $\mathbf{C}$ - Controle), de acordo com suas funcionalidades e independentemente de seu contexto de atuação (BD Intencional ou BD Extensional):

- LAMRO/D: comandos de definição (criação, remoção, atualização, etc) de dados (Instância e Tipos);

- LAMRO/M: comandos de manipulação (consulta, apresentação, transferência, etc) de dados (Instâncias e Tipos);

- LAMRO/C: comandos de controle e de estabelecimento de ambientes (p/ o "Database Administrator" - DBA ou usuários) na Base de Dados.

\subsection{2 - Notação Utilizada}

$\mathrm{Na}$ definição sintática dos comandos foi utilizada a seguinte notação:

- palavras reservadas ou palavras chaves aparecem em letras maiúsculas;

- argumentos fornecidos pelo usuário em letras minúsculas;

- $<$ delimitam um símbolo definido pelo usuário;

- I I delimitam um conjunto de símbolos opcionais;

- ()+ delimitam um conjunto de símbolos que podem aparecer uma ou mais vezes;

- / delimita um conjunto de símbolos dos quais ao menos um deve aparecer;

- ; finaliza um comando;

- $I^{*} * /$ delimitam um comentário. 


\section{3 - Comandos}

Os comandos relacionados a seguir estão apoiados no novo Meta-Esquema (Figura 5.1). Entre estes comandos, alguns foram adaptações baseadas em sintaxes predecessoras e outros foram criados para comportarem as principais operações sobre Versões envolvendo: Tipos de Colônia, Tipos de Objeto, Instâncias de Colônias do Tipo Esquema (ou Colônias Esquema) e Instâncias de Tipos de Colônia (Colônias).

\subsection{1 - Sub-linguagem de Definição (LAMRO/D)}

\subsubsection{1 - Inserção}

\section{Tipos de Colônia}

O comando de criação de um Tipo de Colônia foi alterado ${ }^{1}$ devido ao Modelo de Versões e desta forma, é possível especificar em que Tipos é permitido ao usuário a criação de Versões de Colônia.

Para este fim, adicionou-se ao comando, como apresentado abaixo, a cláusula VERSÃO onde estabelece-se a permissão para criação de Versões do Tipo de Colônia (VERSÃo SIM para "versionable") ou caso contrário proibe-se o surgimento de Versões deste Tipo (VERSÃO NÃO para "nonversionable"). Caso a cláusula VERSÃO não seja mencionada no comando, é reconhecido o valor SIM.

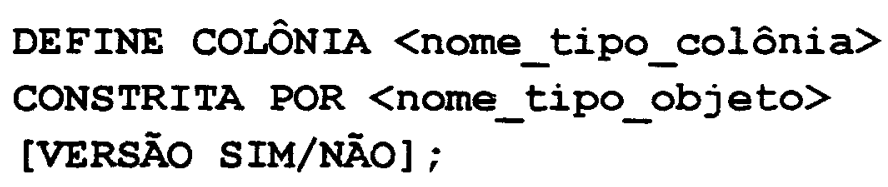

\section{Tipos de Objeto}

$$
/ * \text { default SIM */ }
$$

A alteração no comando de criação de um Tipo de Objeto $^{2}$, como apresentado a seguir, permite especificar em que Tipos existirá o mecanismo de Objeto Genérico para suas Instâncias (Objetos). Desta forma, estabelece-se a possibilidade do projetista do Esquema de Dados evitar (GENÉRICO NÃO), ou permitir (GENÉRICO SIM), que Objetos de um determinado Tipo possam agir semanticamente como Genéricos de outros Objetos do mesmo Tipo. Caso a cláusula GENÉRICO não seja mencionada, o interpretador ou compilador da linguagem reconhece o valor "default" SIM.

\footnotetext{
${ }^{1}$ A antiga sintaxe do comando DEFINE COLÔNIA foi exemplificada no capítulo 4.
}

${ }^{2}$ A antiga sintaxe do comando DEFINE OBJETO foi exemplificada no capítulo 4. 
DEFINE OBJETO (<nome_tipo_objeto $)+$

HABITA <nome_tipo_colônia>

[GENÉRICO SIM/NÃO] /* default SIM */

\section{Colônias e Colônias Esquema ${ }^{3}$}

A criação de Versões de uma Colônia é realizado pelo comando a seguir. Nele especifica-se primeiramente o nome do Tipo de Colônia a ser instanciada (Tipo ESQUEMA pré-definido pelo gerenciador para aquelas Colônias pertencentes à BD Intencional ou um <nome_tipo_colônia> definido pelo projetista no Esquema de Dados) e o nome que terá esta Versão. O Tipo de Colônia deve ter sua condição VERSÃO valendo SIM, e em sua primeira instanciação, o nome da Versão é opcional sendo que o gerenciador automaticamente nomeia esta Versão como "NONAME". Neste caso, a cláusula FILHA/IRMÃ não deve ser utilizada.

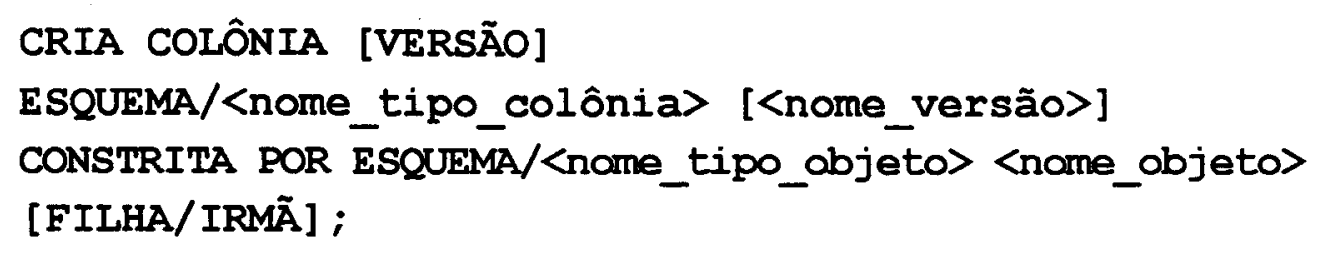

Na cláusula CONSTRITA POR, o usuário deve referenciar o Objeto, representado pelo seu Tipo e nome, que irá constringir a Versão criada, ou em outras palavras, deve-se especificar o Objeto que permitirá acesso à Versão criada pelo comando, desde que o Tipo de Colônia instanciada e o Tipo de Objeto que constringe tenham o relacionamento "constrita por" previamente declarado no Esquema (Figura 6.1b). Caso a Versão criada faça parte da Base Intencional, então o Tipo do Objeto deve ser declarado ESQUEMA (tipo pré-definido), o que especifica um Objeto especialmente criado (apenas na primeira instanciação desta Colônia) para constringir Colônias da BD Intencional (Figura 6.1a).

Uma Versão é sempre criada a partir de uma Colônia existente e correntemente aberta para manipulação (leitura/escrita). Para especificar qual será a correlação entre a Colônia original e sua Versão, o usuário dispõe ao final do comando de duas alternativas que permitem especificar a relação de "parentesco" (FILHA ou IRMÃ), de modo a construir as Árvores Alternativas de Derivações entre as Versões de uma mesma Colônia. É necessário a declaração explícita de uma das alternativas para indicar ao gerenciador como proceder a criação ${ }^{4}$ da Versão.

\footnotetext{
${ }^{3}$ Os comandos p/ Colônias Esquema podem ser utilizados apenas no GEO/Multi-Esquema.

${ }^{4}$ O Modelo de Versões estabelece que:

- uma Versão "filha" ou "irmã" é criada a semelhança de sua Versão "pai";

- uma Versão "irmã" é criada "vazia" caso não possua Versão "pai".
} 
Uma aplicação alternativa do comando anterior, para que não reconheça Versões, é apresentado abaixo e pode ser utilizado pelos usuários que não possuem/trabalhem com as Versões em sua Base de Dados (Intencional ou Extensional), ou então pode ser empregado na instanciação de Tipos de Colônia "non-versionable", ou seja, que não permitem a criação de Versões (condição VERSÃO é NÃO).

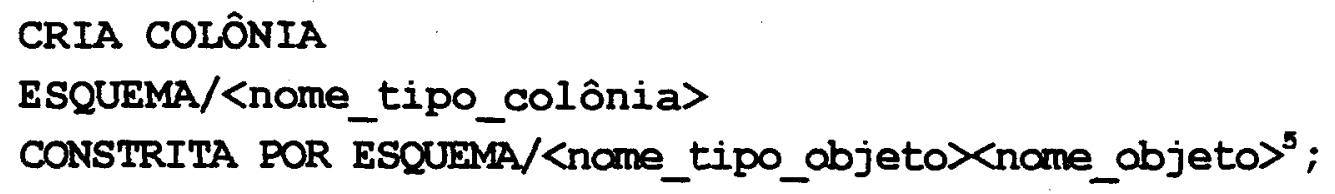

A inexistência da palavra VERSÃO no comando indica ao gerenciador a execução de procedimentos para a instanciação de uma Colônia da Base de Dados Intencional ou Extensional que não é considerada Versão, por ser a única de seu Tipo sendo constrita pelo Objeto indicado.

A utilização do comando anterior em Tipos de Colônias que possuem Versões acarretará em impedimento de execução e/ou relato de um erro ${ }^{6}$, pois o gerenciador não tem meios para se responsabilizar pela colocação de um nome na Versão de Colônia a ser criada.

\subsubsection{2 - Remoção}

O comando para a retirada de uma Colônia é apresentado abaixo seguindo basicamente a mesma organização do comando de instanciação mostrado na seção anterior. Intencionalmente as sintaxes são semelhantes, com poucas variações em palavras-chaves, para facilitar a memorização e utilização dos diferentes comandos.

Realizar a remoção de uma Versão de Colônia da BD Intencional envolve: a especificação de ESQUEMA como nome do Tipo de Colônia; a colocação do nome da Versão que deseja-se eliminar; na cláusula CONSTRITA POR, declarar ESQUEMA como nome do Tipo de Objeto; e em seguida, especificar o nome do Objeto que permite acesso a esta Versão.

${ }^{5}$ O Objeto, que constringe uma Colônia de Tipo definido pelo projetista, deve previamente existir quando referenciado pelo comando CRIA.

Também pelo mesmo comando, o Objeto que constringe uma Colônia Esquema será criado (caso não exista) junto com a primeira Versão de Colônia Esquema deste Objeto e será inserido apenas na Colônia Global.

${ }^{6}$ O objetivo deste capítulo não é a apresentação dos critérios para verificação de comandos inconsistentes, suas respectivas respostas ao usuário e as decorrente ações do gerenciador. 
Possivelmente uma utilização mais freqüente deste comando será na eliminação de Versões de Colônias da BD Extensional que não são mais de interesse dos usuários. Para isso, basta especificar (como mostrado a seguir) o nome e o Tipo de Colônia da Versão desejada e, na cláusula CONSTRITA POR, incluir o nome e o Tipo do Objeto que constringe esta Versão.

\section{ELIMINA COLÔNIA [VERSÃO] \\ ESQUEMA/<nome_tipo_colônia> [<nome_versão>] CONSTRITA POR ESQUEMA/<nome_tipo_abjeto><nome_objeto>;}

Para a operação de remoção existe uma alternativa do comando anterior que não reconhece Versões. Em sua forma reduzida, como é apresentado abaixo, pode ser utilizado pelos usuários que não possuem/trabalhem com as Versões em sua Base de Dados (Intencional ou Extensional), ou pode ser empregado na remoção de Colônias que não possuem Versões.

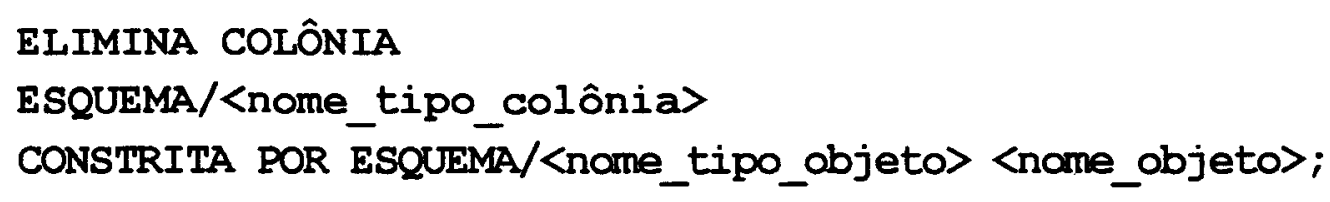

\begin{abstract}
A simples inexistência da palavra VERSÃO no comando indica, ao gerenciador, que trata-se da remoção de uma Colônia da BD (Intencional ou Extensional) que não é considerada Versão, por ser a única de seu Tipo sendo constrita pelo Objeto indicado.
\end{abstract}

A utilização deste comando, em Tipos de Colônias que possuem Versões, acarretará em impedimento de execução e o relato de um erro, pois o gerenciador não tem meios de identificar, entre as Versões existentes, aquela que o usuário deseja retirar da Base de Dados.

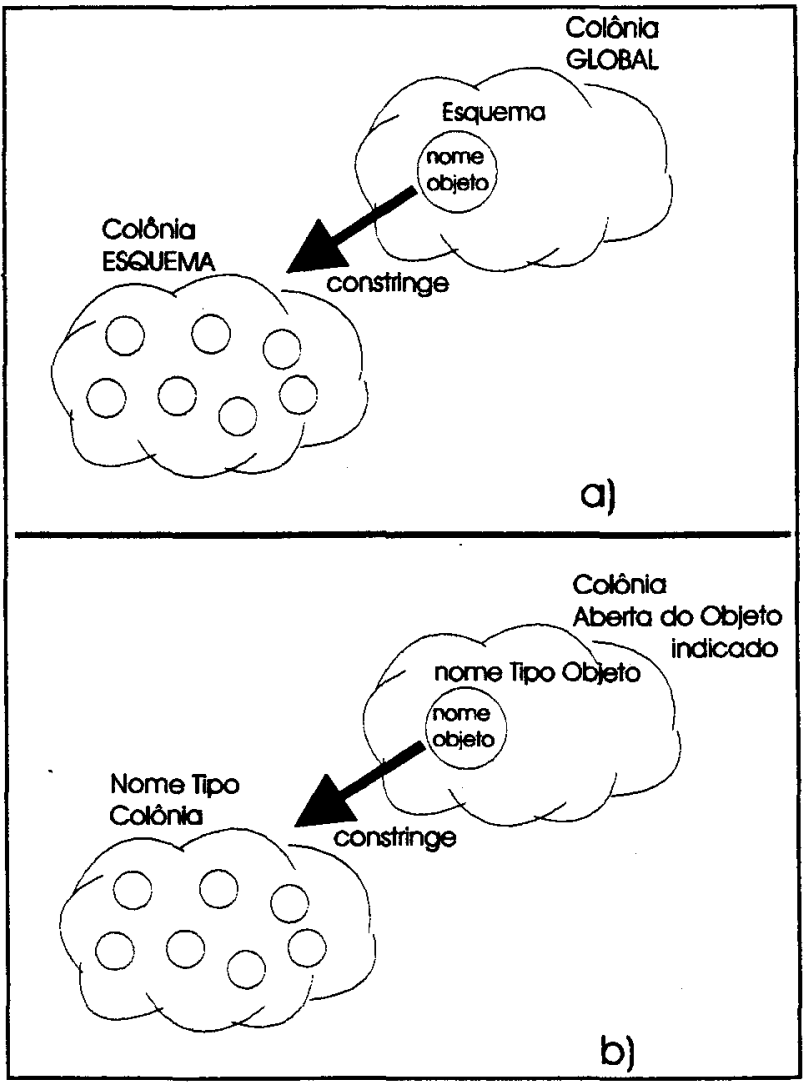

Figura 6.1 - Objeto que constringe Colônias 


\subsubsection{3 - Alteração}

A alteração de definição de um Tipo de Colônia pode envolver a mudança da Condição estabelecida pelo cláusula VERSÃO, mas esta alteração é permitida apenas aos Tipos de Colônia não instanciados, ou seja, um certo Tipo de Colônia, que não tenha sido instanciado, pode ter sua condição VERSÃO alterada de SIM para NÃO e vice-versa ${ }^{7}$.

Esta flexibilidade é motivada pelo fato que, em uma decisão dos usuários comuns ao nível de gerência, certos conjuntos de informações (Colônias) que pensava-se que iriam requerer trabalhos alternativos (criação de Versões), não serão necessários e neste caso, altera-se a condição VERSÃO destes conjuntos de SIM para NÃO. Por outro lado, também pode-se determinar que conjuntos de informações, que não seriam foco de atenção para estudos de alternativas, terão importantes variações e neste caso, altera-se a condição VERSÃO destes conjuntos de NÃO para SIM.

\section{SUBSTITUI COLÔNIA <nome_tipo_colônia> \\ [PARA CONSTRITA POR <nome_tipo_objeto>] \\ [PARA VERSÃO SIM/NÃO];}

A flexibilidade alcançada pelo comando anterior é a razão para a existência do comando de alteração de Tipos de Objeto. Modificar a condição GENÉRICO de um Tipo de Objeto pode ser uma ação gerencial no sentido de inibir ou permitir referência a um Objeto Genérico.

Se a condição GENÉRICO de um Tipo de Objeto tem valor NÃO, tende a influenciar os usuários a criarem novos Objetos (sem os mesmos Atributos e Relacionamentos do Objeto Genérico), podendo ser um meio de "impulsionar" a criatividade de cada um. Noutra possibilidade, a condição GENÉRICO valendo SIM leva os usuários a reaproveitarem informações armazenadas (Atributos e Relacionamentos) em Objetos Genéricos.

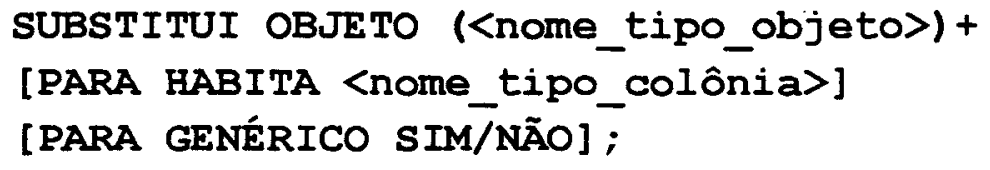

\footnotetext{
${ }^{7}$ Alterações nas definições de Tipos (Colônias, Objetos, Atributos e Relacionamentos) são permitidas apenas em Versð̃es Instáveis de Colônias Esquema.
} 


\subsection{2 - Sub-linguagem de Manipulação (LAMRO/M)}

\subsubsection{1 - Apresentação ${ }^{8}$}

Uma operação simples porém muito útil aos usuários e a apresentação do conteúdo (os Objetos seus Atributos e Relacionamentos) de uma Colônia da BD. Para isso foi criado o comando abaixo, em que pode-se especificar qual a Colônia que deseja-se visualizar, desde que existam condições favoráveis (acesso permitido).

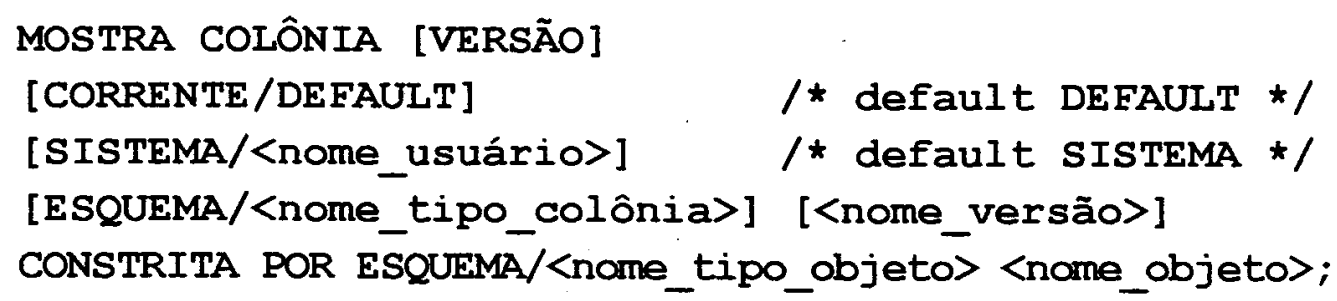

Para especificar qual a Versão desejada, o usuário pode definir o Tipo de Colônia que se deseja, especificar o nome e Tipo do Objeto que a constringe e optar entre a Versão Corrente ou "default" de um usuário ou do gerenciador. Caso nenhuma opção seja especificada, o gerenciador reconhecerá a Versão padrão (DEFAULT e SISTEMA) como aquela a ser mostrada ao usuário.

Mesmo optando pelo apresentação padrão ou outra opção, a não colocação do <nome_tipo_colônia> resultará na apresentação do conteúdo de uma Versão de Colônia de cada um dos Tipos de Colônia constritas pelo Objeto especificado, de acordo com a opção declarada. Independente da escolha ou não de alguma das opções, ao se declarar o Tipo e nome de uma Versão, como apresentado a abaixo, será apresentado esta Versão específica.

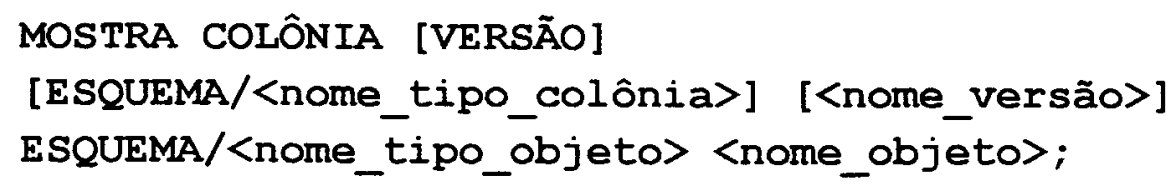

A ausência da palavra-chave VERSÃO e da cláusula <nome_versão> indica sua aplicação apenas em Base de Dados que não possuem Versões ou em Tipos de Colônia "nonversionable".

${ }^{8}$ Apresentação é uma consulta geral em que não especifica-se condições (ex. o que, como) que permitiriam parametrizar um desejo específico de informações. 
A utilização deste mesmo comando em um Tipo "versionable" acarretará na apresentação apenas da Colônia "NONAME" do Tipo especificado. Caso o Tipo não seja especificado, serão apresentadas todas as Colônias "NONAME" que são constritas pelo Objeto declarado.

\subsection{3 - Sub-linguagem de Controle (LAMRO/C)}

\subsubsection{1 - Requisição}

Semelhante aos comandos anteriores, REQUISITA age na BD Intencional e na BD Extencional (caso especifique-se <nome_tipo_colônia $>$ e $<$ nome_tipo_objeto $>$ previamente definidos no Esquema) de maneiras semanticamente diferentes, de acordo com as variações permitidas por sua sintaxe apresentada abaixo.

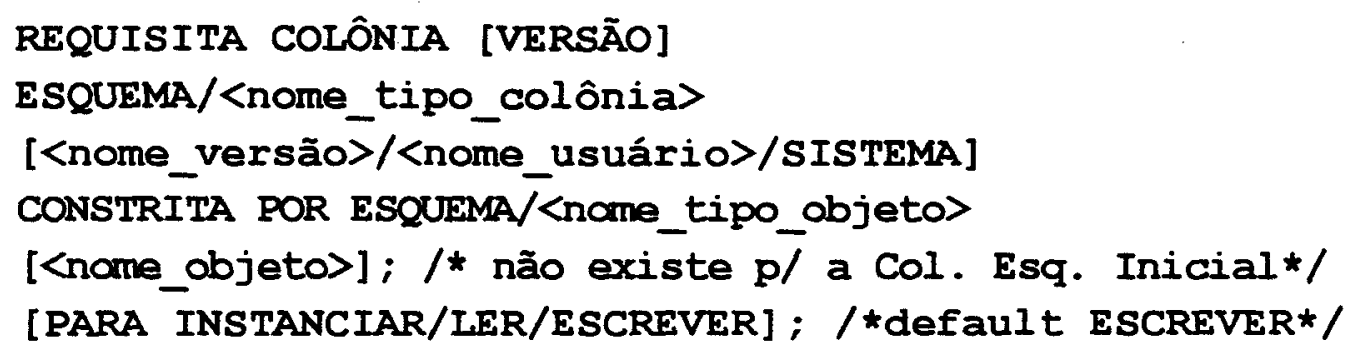

Basicamente, é na cláusula PARA que especifica-se o objetivo do comando através da palavra-chave: INSTANCIAR para incluir a Colônia do Tipo ESQUEMA no Esquema de Dados Ativo e utilizá-la na instanciação da BD Extensional; LER quando deseja-se apenas o acesso a Colônia para um consulta; ou ESCREVER para realizar operações de inserção ou alteração na Colônia especificada ${ }^{9}$.

A requisição de uma Versão da BD Intencional envolve: a especificação de ESQUEMA como do Tipo de Colônia; a colocação do nome da Versão que se deseja trabalhar; na cláusula CONSTRITA POR, declarar ESQUEMA como Tipo de Objeto; e em seguida, o nome do Objeto que permite acesso a esta Versão ${ }^{10}$.

Onde não existem Versões, pode-se requisitar a única Colônia do tipo indicado associada ao Objeto especificado. Para isso, a palavra-chave VERSÃO e a especificação de <nome_versão>, <nome_usuário> ou SISTEMA devem ser evitadas, como mostra o comando abaixo. Erroneamente, se este comando for aplicado em uma Colônia "versionable", a requisição agirá na Colônia "NONAME" do Objeto.

${ }^{9}$ A requisição para leitura ou leitura/escrita de uma Colônia envolve o pedido de acesso correspondente e a abertura da Colônia (veja rotinas de acesso no Apêndice $\mathrm{C}$ ).

10 Opcionalmente, o nome da Versão pode ser substituído pelo <nome_usuário> ou SISTEMA, o que especifica a Versão "default" respectiva 


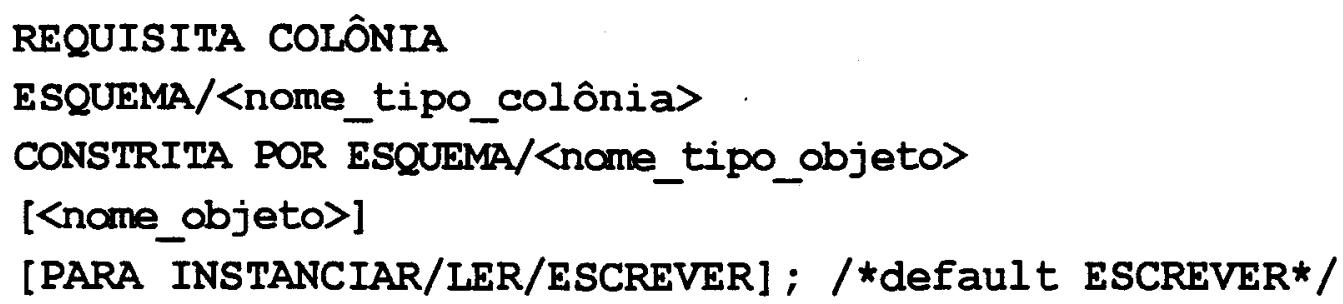

\subsubsection{2 - Liberação}

Dependendo da requisição feita por um usuário, uma Colônia pode permanecer inacessível para outros usuários. A função do comando abaixo é liberar ${ }^{11}$ a Colônia e assim possibilitar sua requisição e utilização por outras pessoas.

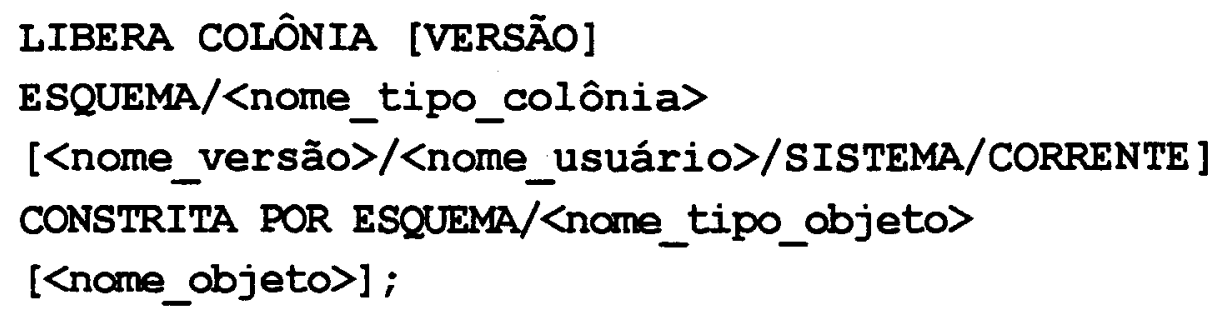

A liberação de uma Colônia é realizada de acordo com a respectiva requisição feita pelo usuário. Por exemplo, uma Colônia Esquema incluída no Esquema de Dados Ativo (EDA - visto no capítulo 4), através da requisição para instanciação, será retirada do EDA caso não gere inconsistências para o próprio EDA, ou em outro exemplo, uma Colônia (qualquer) requisitada para leitura e escrita será imediatamente liberada para outros usuários que estiverem interessados.

Particularmente na BD Intencional, a liberação e mesmo a requisição de Colônias Esquema junto ao EDA podem causar inconsistências, como por exemplo, especificações incompletas de Tipos (referências indevidas). Portanto, deve-se ficar atento para as respostas (avisos e cancelamento da operação) dadas pelo gerenciador após a requisição ou liberação de uma Colônia Esquema.

Um usuário pode ter simultaneamente a requisição de várias Colônias de mesmo Tipo, portanto é imprescindivel que ao fazer uma liberação especifique-se, através do <nome_versão>, <nome_usuário>, da palavra-chave SISTEMA ou CORRENTE, qual a Colônia que se deseja liberar.

Em uma situação em que não existem Versões, este comando libera a única Colônia do Tipo indicado existente no Objeto especificado. Para isso, a palavra-chave VERSÃO e as especificações de <nome_versão>, <nome_usuário> ou SISTEMA,

"A liberação de uma Colônia de Instâncias envolve o fechamento e liberação de acesso de acordo com o pedido/requisição existente (veja rotinas de acesso no apêndice C). 
devem ser evitadas como mostra o comando abaixo.

Erroneamente, se o usuário aplicar o comando a seguir em uma Colônia "versionable", nenhuma ação será tomada pelo fato do gerenciador não poder identificar uma Colônia para liberação.

LIBERA COLÔNIA

ESQUEMA/<nome_tipo_colônia>

CONSTRITA POR ESQUEMA/<nome_tipo_objeto>

[<name_objeto>];

\subsubsection{3 - Definição de "Default"}

Todos os usuários possuem uma Versão "default" para cada Tipo de Colônia em cada Objeto que constringe Colônias. Mesmo assim, existem Versões "default" destas Colônias para o sistema gerenciador e que são utilizadas quando o usuário explicitamente especifica uma Colônia ("genérica") para seu uso, ou quando o usuário fizer referência a sua Versão "default" que não foi definida ou foi apagada.

O comando abaixo apresenta a sintaxe para a definição das Versões "default" de Colônias, mas em caso de Tipos "non-versionable" este comando não é utilizado pois, o sistema gerenciador automaticamente estabelece a respectiva Versão "NONAME" (a primeira e única deste tipo para o Objeto que a constringe) como "default" do sistema e conseqüentemente de todos os usuário da Base de Dados.

DEFINE DEFAULT SISTEMA/<nome usuário>

ESQUEMA/<nome_tipo_colônia> <nome_versão>

CONSTRITA POR ESQUEMA/<nome_tipo_objeto><nome_objeto>;

\subsubsection{4 - Estabilização}

Seguindo o Modelo de Versões, uma Colônia inicialmente é criada (pelo comando CRIA) no estado de instabilidade e posteriormente pode ter seu estado alterado para estável com a utilização do comando abaixo. As Versões estabilizadas não podem ser requisitadas para escrita.

ESTABILIZA COLÔNIA [VERSÃO]

ESQUEMA/<nome_tipo_colônia> [<nome_versão>]

CONSTRITA POR ESQUEMA/<nome_tipo_objeto><nome_objeto>; 
A estabilização em Versões de Colônias do Tipo Esquema é necessária pois apenas Versões estáveis podem compor o EDA, enquanto que, as Versões de Colônias de Tipos definidos pelo projetista passam pela estabilização para assegurar aos usuários a finalização da Versão.

O comando de estabilização pode ser utilizado para "imobilizar" um Colônia de um Tipo "non-versionable" bastando que, a palavra-chave VERSÃO e a cláusula <nome_versão> não sejam incluídas no comando, como é mostrado abaixo.

\section{ESTABILIZA COLÔNIA}

ESQUEMA/<nome_tipo_colônia>

CONSTRITA POR ESQUEMA/<nome_tipo_objeto><name_objeto>;

\section{4 - Considerações Finais}

Este capitulo apresenta os comandos envolvendo Versões no $\mathrm{MRO}^{*}$ (um ilustração completa e real de utilização deste comandos encontra-se no Apêndice B) e portanto não contempla todos os comandos existentes na LAMRO, mas apenas aqueles criados ou modificados em sintaxe e semântica para incorporarem os conceitos do Modelo de Versões.

Mesmo alguns comandos apresentados (ex. DEFINE OBJETO) não foram plenamente expostos por terem variações não relacionadas com o tema deste trabalho $^{12}$. Além disso, as composições de cláusulas que não foram explicitamente citadas podem ser consideradas inconcebíveis semanticamente e portanto, devem causar a interrupção de execução do comando correspondente e o relato do erro.

A concepção dos comandos apresentados exigiu uma profunda avaliação das necessidades dos usuários bem como uma ponderada elaboração das sintaxes, visualizando dois aspectos estreitamente relacionados: expressividade e simplicidade. Intencionalmente, os comandos são muito expressivos, ou seja, a semântica de cada comando tem funções correspondentes na BD Intencional e na BD Extensional. Aparentemente, isto pode dificultar o aprendizado e a conseqüente disseminação da LAMRO, mas em compensação, as sintaxes dos comandos são simples e semelhantes, com poucas variações em palavras-chaves para facilitar a memorização e utilização dos comandos.

Os usuários (projetistas, programadores e usuários comuns) devem ter consciência de que grande porcentagem da carga semântica dos comandos é devido à

${ }^{12}$ A especificação completa dos comandos da LAMRO encontra-se em [PIZZIGATTI_92]. 
manutenção da consistência da Base de Dados, que exige procedimentos de verificação (não estudados) cujos critérios estão relacionados a redundâncias de informações, inconsistências diretas ou indiretas e demais problemas particulares de cada operação.

$$
\text { 获 }
$$




\section{capítulo 7}

\section{ASPECTOS \\ DA \\ IMPLEMENTAÇÃO}

\section{1 - Considerações Iniciais}

Neste capítulo são abordados os aspectos da implementação realizada para a validação dos conceitos e do Modelo de Versões definidos neste trabalho. A implementação utiliza-se do GErenciador de Objetos (GEO), desenvolvido na USP/São Carlos, como um protótipo para modificações e para incorporação do Subsistema de Gerenciamento de Versões (GEO/SGV).

Especificamente, são apresentados os procedimentos que compõem o $\mathrm{GEO} / \mathrm{SGV}$, as Estruturas Físicas e o Mecanismo Especial de Delta $(\Delta)$, ambos definidos pelo Meta-Modelo de Versões como itens complementares.

\section{2 - Subsistema de Gerenciamento de Versões}

O GEO/SGV é a denominação para um conjunto de procedimentos (ou primitivas), estruturas (não necessariamente disjuntas de outros subsistemas) e adicionalmente um mecanismo de Delta. Na organização em camadas do GEO, o 
Subsistema de Gerenciamento de Versões se aloja no GEO-Básico, pois sua funcionalidade principal resume-se em operações de acesso lógico à Base de Dados.

\subsection{1 - Primitivas ${ }^{1}$}

O conjunto de primitivas do GEO/SVG foi elaborado segundo algumas experiências reais e simuladas que foram realizadas e levando-se em consideração as necessidades básicas dos programadores de aplicativos, que utilizarão diretamente as primitivas no desenvolvimento, e as necessidades internas do SGBD para a execução das operações "requeridas" pelos comandos da LAMRO (capítulo 6).

As primitivas (nomeadas segundo os padrões estabelecidos no GEO) enquadram-se na seguinte classificação:

- Acesso:

- Requisita acesso a uma Versão (ANVER)

- Libera acesso a uma Versão (ZNVER)

- Abre acesso corrente a uma Versão (PNVER)

- Fecha acesso corrente a uma Versão (XNVER)

- Busca:

- Inicia busca pelas “irmãs” de uma Versão (TBVER)

- Inicia busca pelas "filhas" de uma Versão (TCVER)

- Avança a busca para a próxima Versão (VNVER)

- Identificação:

- Colocar o nome principal de uma Versão (NAVER)

- Muda o nome principal de uma Versão (MNVER)

- Manipulação:

- Cria uma Versão (CTVER)

1 O Apêndice $\mathbf{C}$ apresenta o Manual de Referência com a descrição completa das primitivas. A implementação destas primitivas somam aproximadamente 1500 linhas de código e documentação interna. 
- Copia uma Versão (CPVER)

- Remove uma Versão Aberta (RNVER)

- Miscelânea:

- Retira referência ao Genérico (GEVER)

- Estabiliza uma Versão (ESVER)

- Obter Dados:

- Obtém o código da primeira Versão (BAVER)

- Obtém o código de uma Versão (BCVER)

- Obtém o código do Tipo de uma Versão (BDVER)

- Obtém o estado e o nome de uma Versão (BFVER)

- Obtém o código de uma Versão Aberta (BNVER)

Obter Informações Sintáticas: ${ }^{2}$

- Obtém a "Condição Versão" de um Tipo de Colônia (VerCOL)

- Obtém a "Condição Genérico" de um Tipo de Objeto (GenOBJ)

\subsection{2 - Estruturas de Armazenamento ${ }^{3}$}

\subsubsection{1 - Estruturas de Registro em Disco}

Internamente no GEO, duas estruturas de Registro Lógico foram alteradas. O Registro Lógico de Colônias (MROColonia - Apêndice D) recebeu adicionalmente quatro campos, de modo que cada Colônia possui:

- col_pai indicando o Registro Lógico da Colônia origem;

- col_irmãs indicando o Registro Lógico de uma Colônia "irmã";

- col filhas indicando o Registro Lógico de uma Colônia "filha"; e

- estado $v$ indicando o estado atual da Colônia.

${ }^{2}$ São também primitivas do GEO/GED (Gerenciador de Esquemas de Dados).

${ }^{3} \mathrm{O}$ Apêndice D apresenta o Manual Interno como a descrição completa das duas Estruturas de Registro em Disco e as duas Estruturas de Registro em Memória que foram alteradas neste trabalho. 
Desta forma, não houve a necessidade de elaboração de uma estrutura adicional (veja exemplo na figura 7.1) para registrar os conjuntos de AAD's das Colônias (como ocorre normalmente em muitos gerenciadores), uma vez que a estrutura (compacta) de Registro Lógico de Colônias recebeu novos campos e incorporou a função de apoiar a navegabilidade entre as Versões derivadas .

A conseqüência desta implementação é a agilidade (eficiência) do processo de busca por Versões, pois ao mesmo tempo em que se percorre um conjunto AAD para a procura de uma determinada Versão, tem-se disponivel demais informações das Versões como por exemplo, os valores de seu controle de acesso e o ponteiro para o conjunto de Objetos desta Versão. Desta forma, tem-se uma estrutura compacta, eficiente e ainda flexível pois futuras implementações poderão utiliza-la.

Ao Registro Lógico de Objetos (MROObjeto - Apêndice D) foi adicionado o campo genérico que indica o endereço do Objeto Genérico (se existir) em cada Objeto da Base de Dados. Desta forma, qualquer Objeto pode ser utilizado como Objeto Genérico ${ }^{4}$ (desde que permitido pelo Esquema), onde o campo genérico é utilizado para indicar o Objeto Genérico em cada Objeto da Base de Dados.

0 exemplo esquematizado da figura 7.1 mostra a interrelação entre um Objeto e seu Genérico. Nota-se que o Objeto Genérico possui o endereço do início de uma lista de Colônias que são constritas pelo respectivo Objeto Genérico, ao passo que, o Objeto "comum" não possui está lista uma vez que pertence ao seu Genérico. Alcança-se desta forma, uma redução das redundâncias pois evita-se a repetição de informações (lista de Colônias, lista de Atributos e lista de Relacionamentos) entre um Objeto e seu Genérico, pelo fato dos dados estabelecidos em um Objeto Genérico estarem disponiveis para os Objetos interrelacionados a ele.

Um detalhe apresentado na Figura 7.1 é o fato da lista de Colônias constritas pelo Objeto (Genérico) ter Tipos de Colônias diferentes. Esta é a forma do MRO* permitir a Composição de Objetos sobre diferentes aspectos (Equivalências). Esta flexibilidade do MRO*, na definição de Colônias de diferentes Tipos para a Composição de Objetos, enriquece o Modelo de Versões pois cada Colônia constrita pelo Objeto pode dar origem a um conjunto AAD com suas Versões.

\footnotetext{
${ }^{4} \mathrm{O}$ fato de qualquer Objeto da Base de Dados poder ser utilizado como Objeto Genérico é uma solução inovadora e vantajosa que pode ser implementada em qualquer SGBDOO.
} 


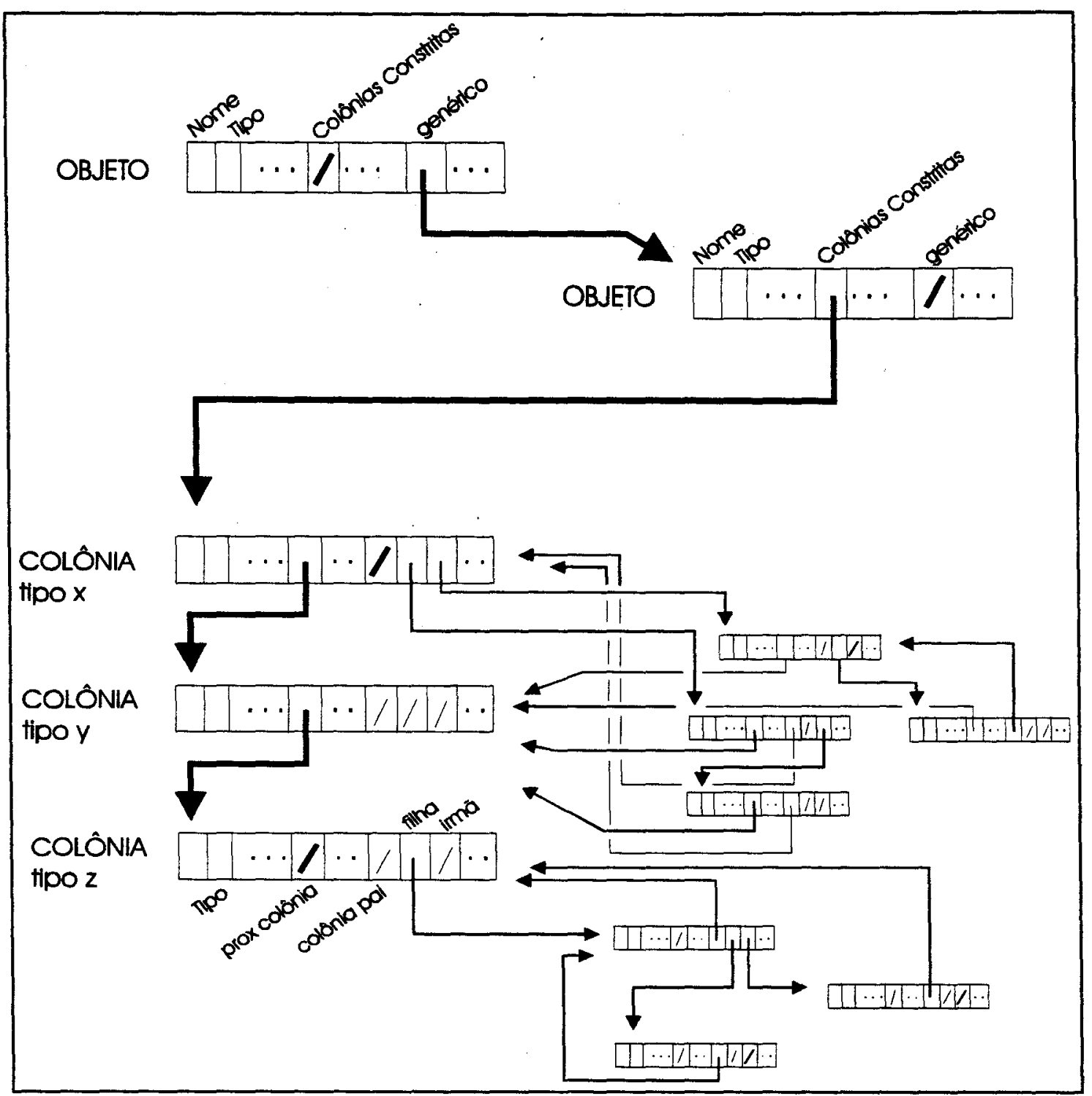

Figura 7.1 - Exemplo Esquematizado de Listas de Colônias e Versões

\subsubsection{2 - Estruturas de Registro em Memória}

No GEO existem duas estruturas básicas para o registro em memória das Colônias solicitadas por cada usuário. A estrutura IColonia_Corrente armazena a indicação das Colônias que estão sendo acessadas pelo usuário (Colônias Abertas) e a estrutura IColacessível armazena a indicação das Colônias requisitas pelo usuário (Colônias Acessíveis).

Nas duas estruturas foi necessário a adição do campo código para o armazenamento do código da Versão da Colônia (aberta ou acessível). Em ambas as estruturas, as Colônias eram identificadas pela raiz (indicação do primeiro Objeto da 
Colônia) e no caso da IColacessível também era utilizado o tipocol. Com a possibilidade de existirem várias Versões acessíveis de mesma Colônia (apenas uma delas pode estar aberta), estes campos poderiam ter valores semelhantes, o que fez necessário a utilização do código da (Versão) Colônia.

\subsection{3 - Mecanismo de Delta (positivo)}

As implementações de SGBDOO invariavelmente representam Deltas e Objetos Genérico em estruturas distintas e vinculadas aos Objetos da Base de Dados. Esta forma de implementação aumenta a complexidade do processamento interno devido as diversas estruturas que devem ser gerenciadas em operações simples ou complexas (ex.: consultas e criações de Versões).

Outro aspecto negativo dos gerenciadores existentes decorre da maior utilização dos dispositivos de armazenamento (disco e memória), pois o crescimento da Base de Dados é bem mais acelerado em virtude do surgimento de inúmeras Versões que são representadas por diversas estruturas de dados.

A busca de uma solução para os aspectos negativos (processamento e armazenamento) presentes nas atuais implementações levou à elaboração de uma estrutura única (o Registro Lógico de Objetos com adição do campo genérico) que permitiu: aumentar o poder semântico dos Objetos da Base de Dados; sustentar a representação de Objetos Genéricos e Deltas; e alcançar um bom desempenho no processamento sem a necessidade de criação de novas estruturas.

A implementação de Objeto Genérico, segundo o Modelo de Versões estabelecido, reduziu a redundância de dados nos Objetos das Versões de Colônias, pois todos os Objetos que possuem um Objeto Genérico utilizam-se das listas de Atributos, Relacionamentos e Colônias associadas ao Genérico. Esta economia de memória de armazenamento é transparente aos usuários pois a origem das informações consultadas e/ou manipuladas não é explícita.

A inclusão de Atributos, Relacionamentos e/ou Colônias especificamente em um Objeto (não em um Genérico) é possível, como mostra a Figura 7.2, onde um Objeto possui um Relacionamento associado (além dos três interligados ao seu Genérico). Desta forma, um Objeto pode ter informações atribuidas diretamente a ele (utilizando-se das respectivas primitivas de inclusão), além daquelas associadas ao Objeto Genérico relacionado.

A inclusão de informações (Atributos, Relacionamentos ou Colônias) em Objetos Genéricos é a concretização do Mecanismo que foi denominado de Delta Positivo, o qual possibilita que Versões correlacionadas (pertencentes a uma mesma 
seqüência de derivações) não armazenem fisicamente dados redundantes mas apenas aqueles adicionalmente atribuidos ${ }^{5}$.

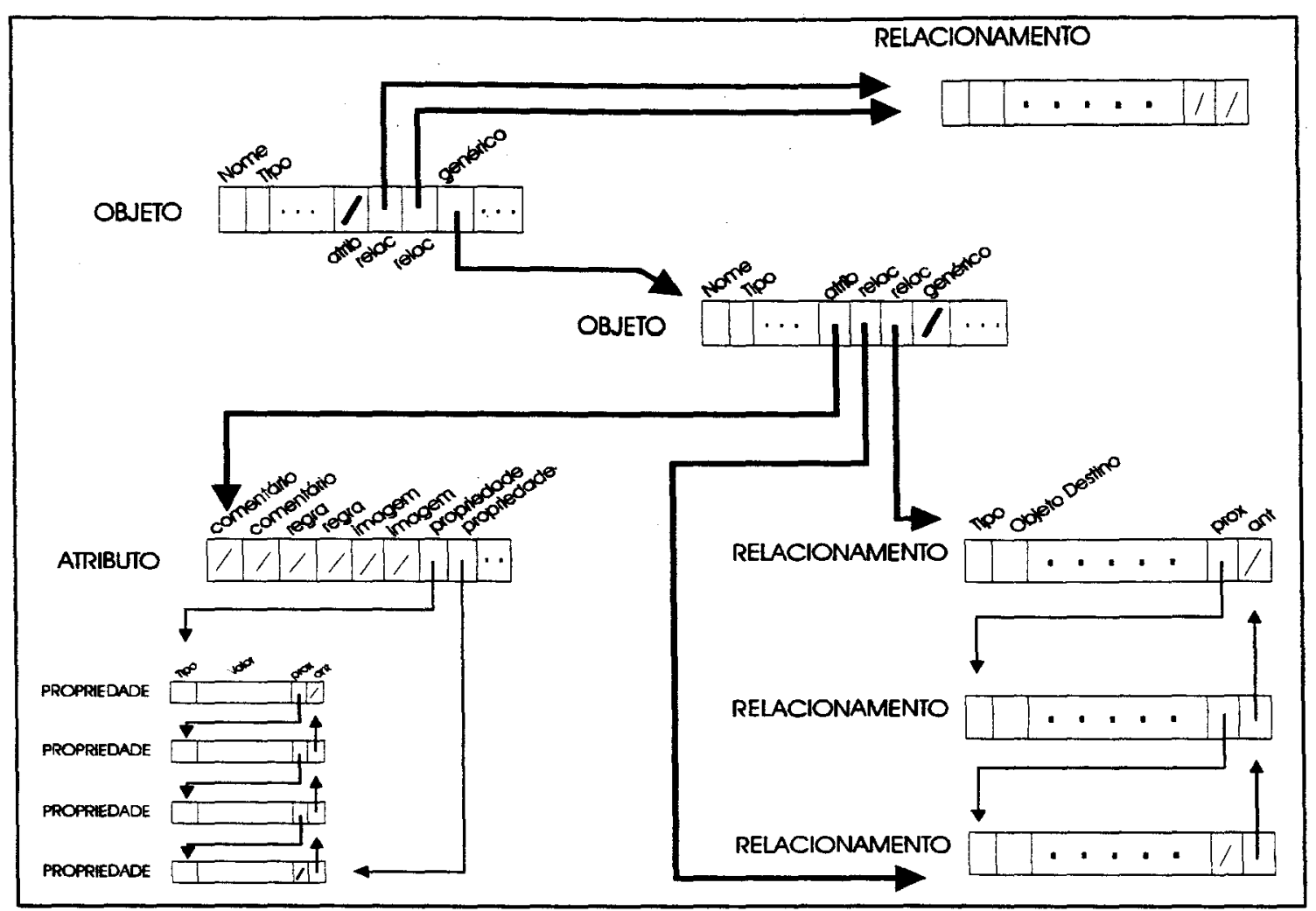

Figura 7.2 - Exemplo Esquematizado de Listas de Atributos e Relacionamentos

O Mecanismo de Delta Positivo utiliza efetivamente as associações internas entre as informações para viabilizar o conceito de Objeto Genérico. A vinculação entre os Objetos Genéricos e o Mecanismo de Delta Positivo é uma das inovações deste trabalho, pois nos Modelos de Versões, o Objeto Genérico não tem esta funcionalidade adicional pois sua estrutura interna é voltada para a representação de um conjunto de Versões e de algumas propriedades comuns ${ }^{6}$.

${ }^{5}$ O Mecanismo de Delta Negativo, em que um Objeto pode ter informações retiradas em relação ao seu Objeto Genérico, não foi implementado devido a problemas na concepção das estruturas fundamentais da Base de Dados do GEO que necessitarão estudos futuros.

${ }^{6}$ Os Modelos de Versões (ex: Landis - seção 2.3.2, Ketabachi \& Berzins - seção 2.3.7), o padrão ISO/STEP (seção 3.3.4) e as implementações comumente encontradas nos SGBD's, utilizamse de estruturas auxiliares para armazenar as diferenças entre as Versões ou para representar as diferenças na forma de operações. 


\subsection{4 - Manipulação Interna de Dados}

Três aspectos internos de execução devem ser ressaltados :

- Criação de Versões: toda Versão é criada pela primitiva CTVER, com a execução do comando CRIA COLÔNIA VERSÃO, a partir de uma Colônia "origem" obrigatoriamente indicada na estrutura IColonia_Corrente. A primitiva CTVER basicamente cria um registro lógico para a Versão "nova" e o interliga (diretamente pela associação FI entre Versão "nova" e Versão "origem" ou indiretamente pela associação IR entre Versão "nova" e uma Versão "filha" da Versão “origem" - Figura 5.6) com o registro lógico da Versão "origem", estabelecendo uma relação de derivação (utilizando-se dos novos campos de MROColonia) representada por uma Árvore de Derivações em um respectivo conjunto AAD.

Junto a primitiva de criação é executada a primitiva de cópia (CPVER) que reconhece os registros lógicos de todos os Objetos da Versão "origem" e os "reproduz" (cria) na Versão "nova". A "reprodução" não é fiel, ou seja, apenas alguns aspectos são duplicados (os campos: tipo, nome, mestre, estado e quem_criou estrutura MROObjeto) e outros são inicializados (valores nulos para os ponteiro das lista encadeadas de Atributos, Colônias Constritas e Relacionamentos).

Além disso, cada um dos Objetos criados recebe uma ligação com o seu respectivo Objeto "original" que terá o papel de Objeto Genérico, mas caso o Objeto "original" tenha um Objeto Genérico então este Objeto Genérico é ligado ao Objeto criado;

- Inclusão de elementos nas Versões: Nas Versões (Colônias) poderão ser incluídos Objetos normalmente, pois para o Subsistema de Gerenciamento de Objetos é indiferente o tratamento dado às Colônias pelo SGV. Em uma Versão, seus Objetos ("reproduzidos" a partir de outra Versão) poderão receber Relacionamentos e Atributos novos, os quais terão seus respectivos registros lógicos associados à listas encadeadas dos próprios Objetos (estas listas foram inicializadas na "reprodução");

- Reconhecimento do conteúdo das Versões: a consulta a cada Objeto de uma Versão, quando orientada a apresentação de Relacionamentos e Atributos, é realizada em duas partes:

- obtendo-se os Relacionamentos e Atributos indicados nas listas encadeadas vinculadas ao próprio registro lógico de cada Objeto, ou seja, pode-se consultar (e inclusive criar, remover, alterar) quaisquer ou todos os Atributos e Relacionamentos diretamente inseridos nos Objetos de uma Versão; 
- obtendo-se os Relacionamentos e Atributos indicados nas listas encadeadas vinculadas ao registro lógico do Objeto Genérico que é referenciado no registro lógico de cada Objeto através do campo genérico (em MROObjeto), ou seja, as primitivas de consulta são direcionadas para obter as listas de Atributos e Relacionamentos pertencentes ao Objeto Genérico relacionado (quando existir).

\section{3 - Testes de Desempenho}

A preocupação quanto ao desempenho dos SGBD's (protótipos e comerciais), demonstrado nos vários "benchmarks" [CHAUDHRI 95] publicados, estabelece-se como uma das grandes preocupaçðes dos desenvolvedores e pesquisadores.

Dependendo da métrica ou aspecto analisado, inúmeros fatores podem estar relacionados à performance dos gerenciadores, porém normalmente são causados pelo Modelo (estrutura, linguagem, etc) utilizado ou pela arquitetura (método de acesso/indexação, etc) empregada. De um modo geral, todos os elementos do sistema gerenciador devem ser analisados segundo suas conformidades estruturais, funcionais e comportamentais diante das expectativas do mercado.

Em virtude desta preocupação com o desempenho, realizou-se testes de performance sobre o Subsistema de Gerenciamento de Versões (GEO/SGV) implementado, obtendo-se os resultados apresentados na Figura 7.3.

As duas Bases de Dados utilizadas nos testes de desempenho estão estruturadas da seguinte forma:

- BD 1 : possui a Colônia Esquema Inicial ${ }^{\top}$, a Colônia Global e uma Colônia C1 "Versionable" subordinada. A Colônia $\mathrm{C} 1$ é composta por 50 Objetos (de 5 Tipos distintos), cada um possuindo 5 Atributos (de 5 Tipos distintos) e 2 Relacionamentos (de Tipos distintos);

- BD 2 : possui a Colônia Esquema Inicial, a Colônia Global e uma Colônia C1 "Versionable" subordinada. A Colônia $\mathrm{C} 1$ é composta por 100 Objetos (de 5 Tipos distintos), cada um possuindo 5 Atributos (de 5 Tipos distintos) e 2 Relacionamentos (de Tipos distintos).

7 Operações envolvendo Versões de Colônias Esquema Suplementar não foram completamente implementadas e portanto não puderam ser testadas. 


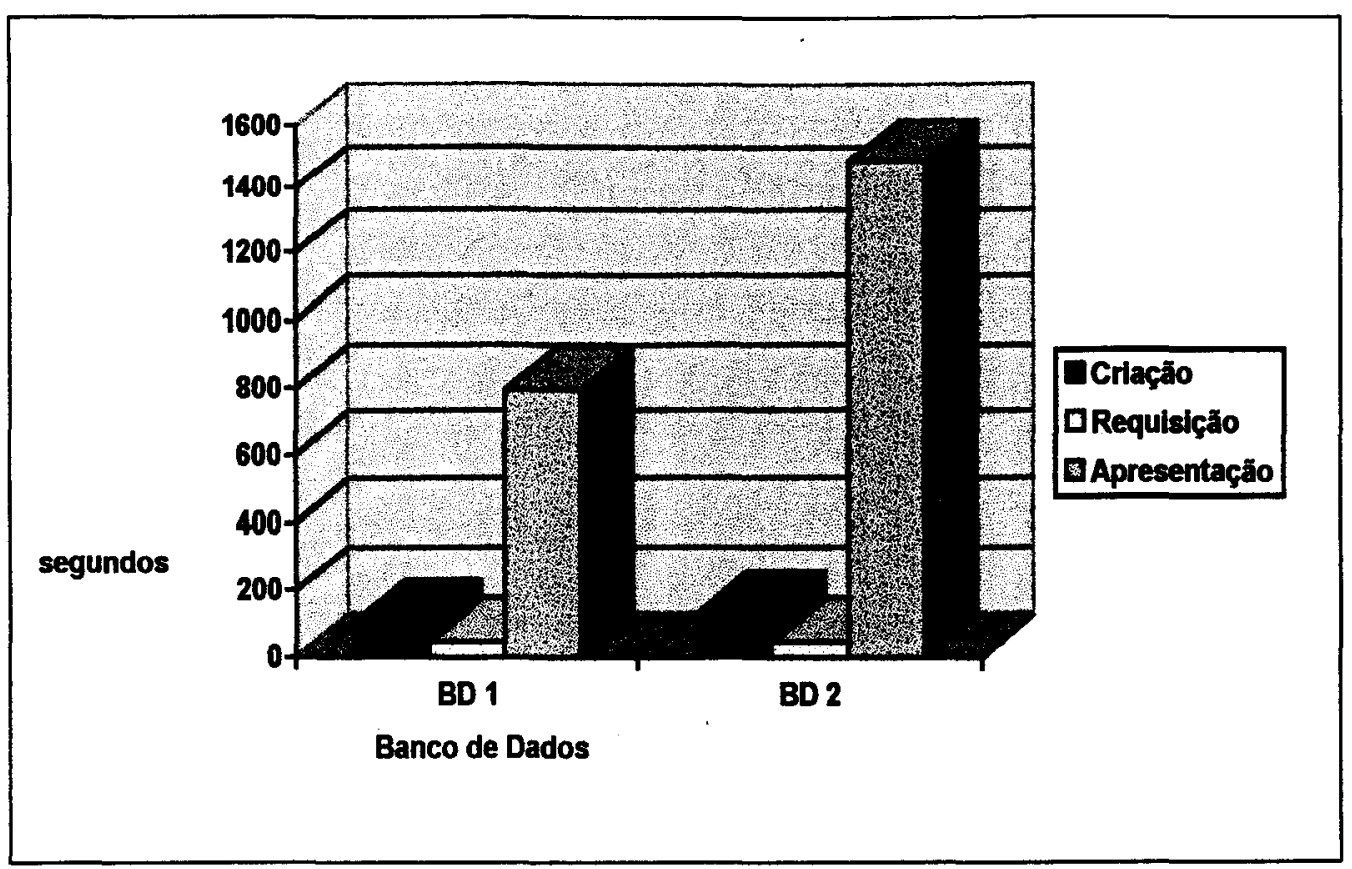

Figura 7.3 - Testes de Desempenho

Os testes realizados em um microcomputador Pentium (Intel), $100 \mathrm{MHz}$ e com $16 \mathrm{Mb}$ RAM, proporcionaram medições aproximadas do tempo (em segundo) referentes as seguintes operações:

- Criação: criação de 30 Versões da Colônia Cl em uma única Árvore de Derivações de 4 níveis;

- Requisição: pedido de acesso e abertura das 30 Versões da Colônia C1;

- Apresentação: pedido de acesso, abertura e apresentação do conteúdo completo (Objetos, Atributos e Relacionamentos) das 30 Versões da Colônia C1.

Notam-se nos testes que as operações de Criação e de Requisição de Versões são relativamente rápidas se comparadas a operação de Apresentação, independentemente da quantidade de Objetos nas Versões. Esta grande diferença no tempo de execução é causada pelas rotinas de busca e apresentação dos Objetos e portanto não deve ser atribuida as rotinas do GEO/SGV.

Outra constatação dos testes realizados demonstra não ser significativo a quantidade de Objetos de uma Colônia em relação ao tempo de execução das operações de Criação e Requisição. Pode-se observar que a Requisição das 30 Versões, em ambas as Bases de Dados, foi realizada em aproximadamente 45 segundos enquanto, a Criação das 30 Versões nas duas Bases de Dados tiveram um diferença de 20 segundos (100 segundos para a BD1 e 120 segundos para a BD2). 
Os resultados alcançados pelo GEO, como um todo, ainda estão longe de merecerem elogios, contudo, este é o primeiro passo para a busca de um melhor desempenho que deverá ser decorrente de restruturações internas dos arquivos lógicos e das implementações.

\section{4 - Considerações Finais}

Este capítulo mostrou uma visão geral da implementação realizada para provar a validade e o desempenho do Modelo de Versões estabelecido e de suas inovações. Aspectos de Implementação normalmente não são detalhados nas descrições dos Modelos de Versões disponíveis para estudo e pesquisa. Alguns destes Modelos de Versões, ao serem incorporados em um Modelo de Dados, deixam de ser especificamente focalizados e passam a compor um aglutinado de conceitos, o que pode dificultar o entendimento e avaliação particular do Modelo de Versões.

É importante ressaltar a transparência (para o usuário) da utilização do mecanismo de Delta Positivo e da navegação pelas listas encadeadas que compõem a Base de Dados. Na prática, um usuário ao consultar as informações de um Objeto terá a sua disposição (desde que permitido pelo controle de acesso) todos os Atributos, Relacionamentos e Colônias constritas, indiferente de estarem vinculadas ao próprio Objeto ou ao seu Genérico (caso exista). 


\section{capítulo 8}

\section{CONCLUSÕES \\ FUTURAS PESQUISAS}

\section{1 - Considerações Iniciais}

Motivado pelas necessidade atuais dos ambientes de desenvolvimento que apoiam-se em SGBDOO para o armazenamento e controle de informações, o Modelo de Versões foi definido de modo a sustentar o trabalho concorrente e cooperativo [HENRIKSEN_94] entre grupos de trabalho, buscando conduzir este processo de uma forma amigável e coerente com o regras determinadas pelos gerentes de projeto.

Este capítulo finaliza a exposição do Modelo de Versões com o relato descritivo das contribuições deste trabalho, além da enumeração e discussão de futuros trabalhos e pesquisas.

\section{2 - Histórico do Trabalho}

Tendo em mente a motivação e objetivos gerais deste trabalho, realizou-se uma pesquisa bibliográfica abrangente envolvendo o estudo de diversos Modelos de Versões, aplicações de Versões nas Técnicas de Evolução de Esquema de Dados, 
aplicações de Versões nas Estratégias de Propagação nas Instâncias, Modelos de Dados que empregam Modelo de Versões, e também pesquisou-se as especificações existentes atualmente sobre Versões em Padrões específicos e gerais.

Deste estudo bibliográfico, com a intenção de dominar o problema, iniciouse a elaboração do Modelo de Versões e posteriormente, o projeto e desenvolvimento do Subsistema de Gerenciamento de Versões que foi incorporado ao GErenciador de Objetos (GEO). A utilização do Modelo de Versões em um problema real (modelagem de campanhas de produção de derivados de petróleo) e também os testes no GEO/SGV (para medição do desempenho do protótipo) permitiram comprovar as expectativas de aplicabilidade teórica e prática do Modelo e de sua transparência, para os usuários, na execução do gerenciador.

\subsection{1 - Domínio do Problema}

Após a leitura técnica especializada, foi notada a ausência de diretrizes que conduzissem ao desenvolvimento de um Modelo de Versões, tanto para uma aplicação específica quanto geral. Por isso, a partir de uma necessidade real percebida neste trabalho, definiu-se um Meta-Modelo de Versões que serviu para direcionar este trabalho e conduzi-lo a resultados compreensiveis e desejados.

\subsection{2 - Fronteiras da Implementação}

A implementação foi uma etapa deste trabalho que proporcionou uma série de dificuldades, pois o GErenciador de Objetos, apesar de subdividido em camadas, apresenta subsistemas estreitamente interrelacionados. Desta forma, 0 desenvolvimento do SGV exigiu alterações em diversos subsistemas do GEO:

- no Subsistema de Gerenciamento de Registros Lógicos (SG-Log) foram alteradas as estruturas dos registros lógicos de Colônias e Objetos;

- no Subsistema de Gerenciamento de Objetos foram alteradas as primitivas de manipulação dos registros lógicos de Objetos e Colônias;

- no Subsistema de Gerenciamento de Atributos e no Subsistema de Gerenciamento de Relac. foram alteradas algumas primitivas de busca;

- no Gerenciador de Esquemas de Dados foram alteradas as estruturas internas do Esquema de Dados e algumas primitivas.

O GEO é utilizado como bancada para testes em todas as pesquisas envolvendo o MRO*. Conseqüentemente, algumas funcionalidades do GEO não estão disponíveis devido aos estados atuais de suas pesquisas. Desta forma, a 
implementação do GEO/SGV não pôde contemplar todos os itens especificados no Modelo de Versões e assim, a implementação realizada: restringe-se ao GEO/MonoEsquema (que utiliza um Esquema de Dados único); não registra quais são as Versões "default"; não controla as Restrições de Acesso e de Manipulação; e não realiza a Propagação da criação de Objetos entre Versões dependentes.

\section{3 - Contribuições Inovadoras}

\subsection{1 - Meta-Modelo de Versões}

Pelos estudos bibliográficos realizados, percebe-se não haver a preocupação com a completeza dos Modelos de Versão definidos, mas à medida que as aplicações tornar-se-ão mais sofisticadas, novos e pormenorizados Modelos de Versão terão que ser elaborados em conformidade com as necessidades vigentes.

No sentido de apoiar a elaboração de Modelos de Versões sofisticados ou simples para aplicações específicas ou gerais, este trabalho estabeleceu um MetaModelo de Versões, cujas especificações poderão direcionar o projetista do Modelo, sendo composto pelos seguintes itens:

Fundamentais: Alvo; Granularidade; Condição Versão, Transição de Estados; Restrições de Acesso; Estado Inicial; Motivação; Estruturas de Dependência; Restrições de Manipulação; Procedimentos de Alteração de Estados; Conjuntos Lógicos; Referências; Elementos Especiais; Propagação e Notificação; Reaproveitamento; Aplicação.

Complementares: Estruturas Físicas; Mecanismos Especiais; Comandos para Utilização; Modelos Relacionados.

Os itens fundamentais e complementares não estão limitados apenas àqueles apresentados. Pelo fato dos Modelos de Versões ainda estarem incompletos e terem sido pouco explorados, é de se esperar que suas evoluções façam com que o MetaModelo de Versões se adapte para permanecer uma ferramenta útil.

\subsection{2 - Versões de Objetos Compostos (Colônias)}

O Modelo de Versões do MRO* apoia-se no conceito de Objetos Compostos, contudo apresenta diferenças em relação à forma como é tratado no Modelo do ORION, o único estudo que aborda com profundidade o problema de modelagem de Versões em Objetos Compostos. As diferenças devem-se basicamente aos principios que regem estes dois Modelos de Dados seguidos: 
- ORION, como a maioria dos Modelos Orientados a Objetos, estabelece a Hierarquia de Composição como uma (mais uma) organização de Objetos definido por relacionamentos "is-part-of' tratados de maneira semanticamente e internamente diferente de outros relacionamentos;

- MRO*, por sua vez, estrutura toda a Base de Dados na Hierarquia de Composição em que os Objetos Compostos (denominados Colônias) estão relacionados aos seus componentes, através de relacionamentos implícitos e naturalmente reconhecidos pelos usuários.

Pelo fato do MRO* ter um tratamento uniforme para Colônias de Tipos (BD Intencional) e Colônias de Instâncias (BD Extensional), o Modelo de Versões é especificado para toda a Base de Dados, com uma abrangência e homogeneidade não alcançadas por nenhum outro Modelo de. Versões com o mesmo Alvo (BD Intencional e Extensional) pois, primitivas, estruturas de dados, comandos de uma linguagem de programação (LAMRO), itens fundamentais de especificação e elementos de representação gráfica, são igualmente utilizados para Versões de Colônias (Objetos Compostos) que armazenam Tipos ou Instâncias.

\subsection{3 - Árvores Alternativas de Derivações (AAD)}

A organização das Versões de um mesmo elemento em várias Árvores de Derivações, formando um conjunto denominado AAD (Árvores Alternativas de Derivações), é uma extensão significativa em relação aos Modelos de Versões que suportam apenas uma única Árvore de Derivação para as Versões de um mesmo elemento, como é o caso do EXODUS e do ORION.

Uma única Árvore de Derivações limita a origem das Versões de um mesmo elemento a uma única Versão ("raiz"), ao passo que, em um conjunto AAD, amplia-se a liberdade de criação do usuário com a possibilidade de se estabelecerem sequeências de Versões completamente diferentes, ao iniciar-se uma Árvore de Derivações nova com uma Versão "raiz" (inicialmente vazia) que pode originar Versões alternativas.

\subsection{4 - Comandos Compactos, Robustos e Intuitivos}

Os comandos desenvolvidos para a LAMRO são expressivos e com semânticas correspondentes na BD Intencional e na Extensional. A estrutura sintática dos comandos é simples e claramente retrata o MRO*, em estreita relação com seus conceitos, apesar das operações complexas envolvidas em suas execuções. Muitas possibilidades de operações são atingidas com uma estrutura sintática reduzida. 
Os usuários (projetistas, programadores e usuários comuns) poderão ter dificuldades no aprendizado e memorização destes comandos da LAMRO, porém este problema é reduzido devido as poucas palavras-chaves existentes e a pequena quantidade de comandos necessários para a manipulação da Base de Dados.

\subsection{5 - Objeto Genérico}

Objeto Genérico, na definição deste trabalho, é um Objeto com semântica estabelecida pela aplicação, portanto tendo Atributos de representação do mundo real, e que estruturalmente interrelaciona-se com outros Objetos por meio de associações implícitas particularmente estratégicas para o gerenciador.

Esta definição difere nos aspectos estrutural e semântico do Objeto Genérico estabelecido por Chou e Kim [KIM_87] para o ORION, que o conceitua como um elemento criado "artificialmente", apenas com Atributos para apoiar o controle de Versões, e que engloba um conjunto de Versões de um mesmo Objeto.

Além disso, referenciar (por acesso de um usuário ou do sistema) um Objeto Genérico no ORION é dinamicamente estabelecido como uma referência a uma Versão do Objeto representado pelo Objeto Genérico, contudo, a referência a um Objeto Genérico no MRO* é o acesso ao próprio Objeto e não aos Objetos interrelacionados ao Genérico, a menos que esta referência esteja internamente envolvida em algum processamento do SGV.

Adicionalmente, uma inovação no Modelo de Versões é a flexibilidade para permitir ou não, no Esquema de Dados, o "papel" de Objeto Genérico para as Instâncias somente dos Tipos de Objeto escolhidos pelo projetista do Esquema. Além disso, a transparência de um Objeto Genérico não permite que um usuário reconheçao entre os outros Objetos de uma Versão de Colônia, e o vínculo de um Objeto com o seu Objeto Genérico pode ser retirado a qualquer momento, sem prejuízos, perda de informações ou lentidão no processamento de consultas.

\subsection{6 - Modelo de Gerenciamento da Evolução da BD}

Todas as especificações envolvendo modificações em elementos de um SBD podem ser reunidas em um conjunto denominado Modelo de Gerenciamento da Evolução da $\mathrm{BD}$, sendo composto pelos seguintes itens:

Evolucão do Esquema de Dados - que corresponde aos operadores e operações de modificação sobre os elementos do Esquema de Dados; 
Técnica de Evolução do Esquema - que corresponde ao conjunto de técnicas que possibilitam as modificações do Esquema;

Evolução de Instâncias - que corresponde aos operadores e operações de modificação das Instâncias;

Estratégia de Propagacão nas Instâncias - que corresponde a abordagem usada para repassar as modificações do Esquema para as Instâncias; e

Adaptação dos Aplicativos [AJILA_95] - que corresponde a abordagem para alterar os aplicativos atingidos com as alterações do Esquema.

Decorrente de trabalho anterior [CAMOLESI_93], o MRO* adquiriu a capacidade de realizar a Técnica "Additional" para Evolução do Esquema em conjunto com a Estratégia de Propagação "Materializing". Neste corrente trabalho, o Modelo de Versões definido estabelece a utilização em conjunto de "Schema Versioning" (Técnica de Evolução do Esquema) e "Materializing" (Estratégia de Propagação nas Instâncias).

Embora a utilização conjunta de "Schema Versioning" e "Materializing" seja bastante flexivel e poderosa dentro da classificação, o levantamento bibliográfico realizado mostrou que nenhum outro Modelo de Dados (Tabela 8.1) estabeleceu a utilização unificada destas duas abordagens e ainda empregar Objeto Composto como elemento básico para o controle de Versões.

As vantagens para o projetista do Esquema estão relacionadas à autonomia e flexibilidade de trabalho, pois as alterações na $\mathrm{BD}$ não necessitam envolver todo o Esquema de Dados mas podem ser concentradas em pequenos conjuntos (Esquemas Suplementares) onde são montadas as Versões. Para o usuário comum, a Evolução é transparente pois a BD permanece ativa e os dados já existentes inalterados.

Tabela 8.1 - Os Modelos de Dados no Gerenciamento da Evolução da BD

\begin{tabular}{|l|l|l|l|l|l|}
\cline { 2 - 6 } & Copying & Updating & Screening & Versioning & Materializing \\
\hline Creating/Modification & $\begin{array}{l}\text { Iris } \\
\text { GemStone }\end{array}$ & $\begin{array}{l}\text { Iris } \\
\text { Cactis } \\
\text { GemStone }\end{array}$ & ORION & & O2 \\
\hline Additional & & AVANCE & $\begin{array}{l}\text { AVANCE } \\
\text { ORION }\end{array}$ & ORION & $\begin{array}{l}\text { O2 } \\
\text { MRO* }\end{array}$ \\
\hline Schema Versioning & & MRO * \\
\hline
\end{tabular}




\section{4 - Futuras Pesquisas}

\subsection{1 - Extensões do Modelo de Versões}

Entre as possíveis extensões do Modelo de Versão, algumas colocam-se particularmente atraentes, como é o caso de:

- Estudo e implementação de primitivas para a execução de "merging" entre Versões, o que possibilitará o confronto entre Versões, provavelmente com a intervenção do usuário, aglutinar as melhores informações registradas;

- Estudo da viabilidade da representação e implementação de "Relacionamento Genérico", em que os Relacionamentos poderiam ter o mesmo "status" dos Objetos Genéricos, ou seja, Objetos e Relacionamentos seriam criados em uma operação de criação de Versão e os Atributos seriam as unidades para diferenciação entre as Versões, bem como o apoio do mecanismo de Delta;

- Estudo e implementação de Sinônimos para a identificação de Versões em um conjunto de Árvores Alternativas de Derivações, que possibilitará uma Versão ter vários nomes que a identifique em seu conjunto $\mathrm{AAD}$. Um usuário terá facilidade em identificar Versões específicas pois poderá atribuir-lhes nomes (Sinônimos) que facilitem a memorização e o reconhecimento de seus conteúdos;

- Estender a Técnica de Evolução "Schema Versioning", estabelecida no Modelo de Versões para o MRO*, de forma a atuar sobre as seguintes Estratégias de Propagação nas Instâncias: "Updating", "Screening" e "Versioning".

\subsection{2 - Modelos Relacionados ao Modelo de Versões}

A relação entre Versões e os Modelos, mostrados a seguir, é tão estreita que em certas situações se confundem ou se completam, contudo ainda não existem trabalhos que os correlacionem em uma coexistência clara.

\subsubsection{1 - Modelo de Tempo}

O Tempo ${ }^{1,2}$ é uma parte essencial e determinante dos dados em função da constante mutação envolvendo o mundo real [SNODGRASS_92]. Algumas pesquisas

\footnotetext{
${ }^{1}$ Tempo é a variação continua de um característica dos objetos, que pode ser simbolizado por números reais ou inteiros, extraídos de uma seqüência eqüidistante de valores representativos da unidade de tempo escolhida. (definição específica)

2 Tempo (subs., masc.): sucessão dos anos, dos dias, das horas, etc., que envolvem a noção de presente, passado e futuro (definição fonte: Dicionário Aurélio da Lingua Portuguesa)
} 
estabelecem Tempo como uma característica de ligação entre as Versões, de modo a manter um histórico dos dados armazenados [SOO_?1].

Todavia, a colaboração mútua entre um Modelo de Tempo e um Modelo de Versões não pode limitar-se ao registro evolutivo/histórico de dados. $\mathrm{O}$ Modelo de Tempo do $\mathrm{MRO}^{*}$, que permite a temporização de Atributos de Objetos e Relacionamentos em parâmetro temporal mensurável (Tempo de Transação, Tempo Válido, Tempo Real), deve futuramente sincronizar-se com o Modelo de Versões.

Em conjunto, o Modelo de Tempo e o Modelo de Versões poderão permitir em trabalhos futuros: a colocação dinâmica de parâmetros temporais em Versões (temporização de Versões); a avaliação temporal de Versões de Colônia Esquema Suplementar segundo valores de tempo específicos ou dentro de um intervalo de tempo; a requisição e liberação de Versões (principalmente de Esquemas Suplementares) em tempos definidos e; outras funcionalidades.

\subsubsection{2 - Modelo de Configurações}

Estabelecer um Modelo de Configurações ${ }^{3}$ envolve definir estruturas de armazenamento, primitivas de manipulação, comandos em uma linguagem de programação e outros itens[ MAHLER_90]. Cada usuário, poderia definir diferentes Configurações, dando-lhes nomes (e até Sinônimos) para identificação e cada um teria internamente uma estrutura, onde seriam registrados os ponteiros para as Versões que comporiam a Configuração estabelecida. Configurações poderiam ser Objetos no MRO* com uma semântica peculiar e provavelmente armazenados em um Colônia particularmente criada com este objetivo.

A estreita ligação entre o futuro Modelo de Configurações do $\mathrm{MRO}^{*}$ e o Modelo de Versões [AMBRIOLA_90] é percebida quando questionam-se aspectos de ambos os Modelos, como por exemplo:

- Quais os efeitos em uma Configuração na remoção de uma Versão?

- Versões em quais estados podem compor uma Configuração?

- Uma Versão pode ser removida a partir da Configuração que a compõe?

- O estabelecimento de uma Configuração seguirá as Restrições de Acesso do Modelo de Versões?

${ }^{3}$ Configuração é uma coleção de Versões (de tipos distintos) que estabelece um Objeto Complexo [ELMASRI_94]. 


\subsubsection{3 - Modelo de Distribuição}

0 Modelo de Distribuição do MRO* [FERREIRA_96] estabelece a Colônia como a unidade de distribuição. Dependendo da relação entre a "BD original" e a "BD cópia", as Colônias da "BD cópia" terão ligações intrínsecas e fortes com as Colônias da "BD original". Estas ligações podem estabelecer-se em um processo de derivação, ou seja, uma Versão da "BD cópia" pode ser gerada pela derivação de uma Versão de Colônia da "BD origem".

A complexidade de ambos os Modelos, Distribuição e Versões, abre inúmeras questões para futuras pesquisas, entre as quais:

- Na criação de Versões em um "BD cópia", como estabelecer quais as Versões de Esquema Suplementar devem ser também levadas para a "BD cópia" ?

- Se Colônias Instáveis puderem ser distribuídas, como gerenciar o processo de propagação entre as Versões da "BD origem" e da "BD cópia" ?

\subsection{3 - Modelo SIRIUS}

O MRO* está atualmente sendo reavaliado pelo Grupo de Pesquisas em Base de Dados da USP/São Carlos, buscando ponderar sobre todas as pesquisas realizadas sobre o MRO* nos últimos anos. Deste trabalho de reavaliação, está se desenvolvendo um novo Modelo de Dados fundamentado em parametrização de Abstrações de Dados e que difere do MRO* tanto em conceitos quanto em capacidade de representação.

Este novo Modelo de Dados, denominado SIRIUS [BIAJIZ_96], também apoia-se no conceito de Colônia e portanto o Modelo de Versões estabelecido neste trabalho pode ser migrado para o Modelo SIRIUS. Todavia, o GErenciador de Objetos (GEO) sofrerá profundas alterações em sua organização em camadas, nas estruturas de dados internamente utilizadas, nas próprias primitivas dos subsistemas $\mathrm{e}$ conseqüentemente, a implementação do GEO/SGV deverá ser reestudada.

\subsubsection{1 - Incorporação do conceito de Versões ao SIRIUS}

O Modelo SIRIUS apoia-se totalmente na identificação das Abstrações relevantes, as quais são parametrizadas e especializadas para a elaboração de construtores semânticos. Seguindo a formalização adotada no SIRIUS [BIAJZ_96] , a representação de Versões poderá ser enquadrada como uma Abstração, denominada Abstração de "versionamento", permitindo a integração total e ortogonal dos demais conceitos já existentes e do conceito de Versões. 


\subsubsection{2 - Modelos Simultâneos de Versões}

O estudo de vários Modelos de Versões, bem como a criação do Modelo de Versões do MRO*, permitiu notar as restrições que os Modelos impõem as aplicações, ou seja, uma aplicação e mesmo um grupo de pessoas usuárias desta aplicação são obrigadas a trabalhar com as Versões segundo as definições "rígidas" do Modelo de Versões. Isto evidentemente, não é um beneficio no sentido de direcionar ou regularizar o trabalho dos usuários mas é uma restrição que impõe regras nas quais os usuários podem não desejar, mas são obrigados a respeitar.

Permitir que os usuários estabeleçam suas próprias estruturas de trabalhos e desenvolvimento é uma flexibilidade que os Modelos devem almejar. Neste sentido, o SIRIUS permitirá o estabelecimento dinâmico de um Modelo de Versões para as Colônias de Instâncias de uma Base de Dados, ou até o estabelecimento de múltiplos Modelos de Versões que podem, dinamicamente e individualmente, ser colocados para diferentes Tipos de Colônias.

Alguns itens fundamentais dos Modelos de Versões, simultaneamente atuantes em uma mesma BD, terão especificações iguais (ex: Granularidade, Condição Versão e outros), contudo, itens importantes e diferenciados poderão ser estabelecidos diretamente no Esquema, cabendo ao DBA defini-los.

A Figura 8.1 apresenta a proposta para o Meta-Esquema do SIRIUS que permite definir Modelos de Versões e relacioná-los aos Tipos de Colônias. Alcança-se desta forma, a flexibilidade para estabelecer o Estado Inicial, Transições de Estados, e no formato de Regras (condição e ação) definir: as Restrições de Acesso e de Manipulação para cada Tipo de Usuário; Procedimentos de Alteração de Estados; e a Motivação automatizada para a criação e para remoção de Versões em cada estado.

O estabelecimento de Modelos de Versões, ao nível de Esquema, permite aos desenvolvedores e usuários a adaptação do gerenciador de Versões à estrutura de trabalho implantada e utilizada. Para isso, o gerenciador de Versões terá que ser modificado para se apoiar muito mais no Esquema de Dados do que se desenvolveu em sua implementação atual, em que o GEO/SGV apenas consulta o Esquema para identificar quais são os Tipos de Colônia "versionable" e Tipos de Objeto "genéricos". 


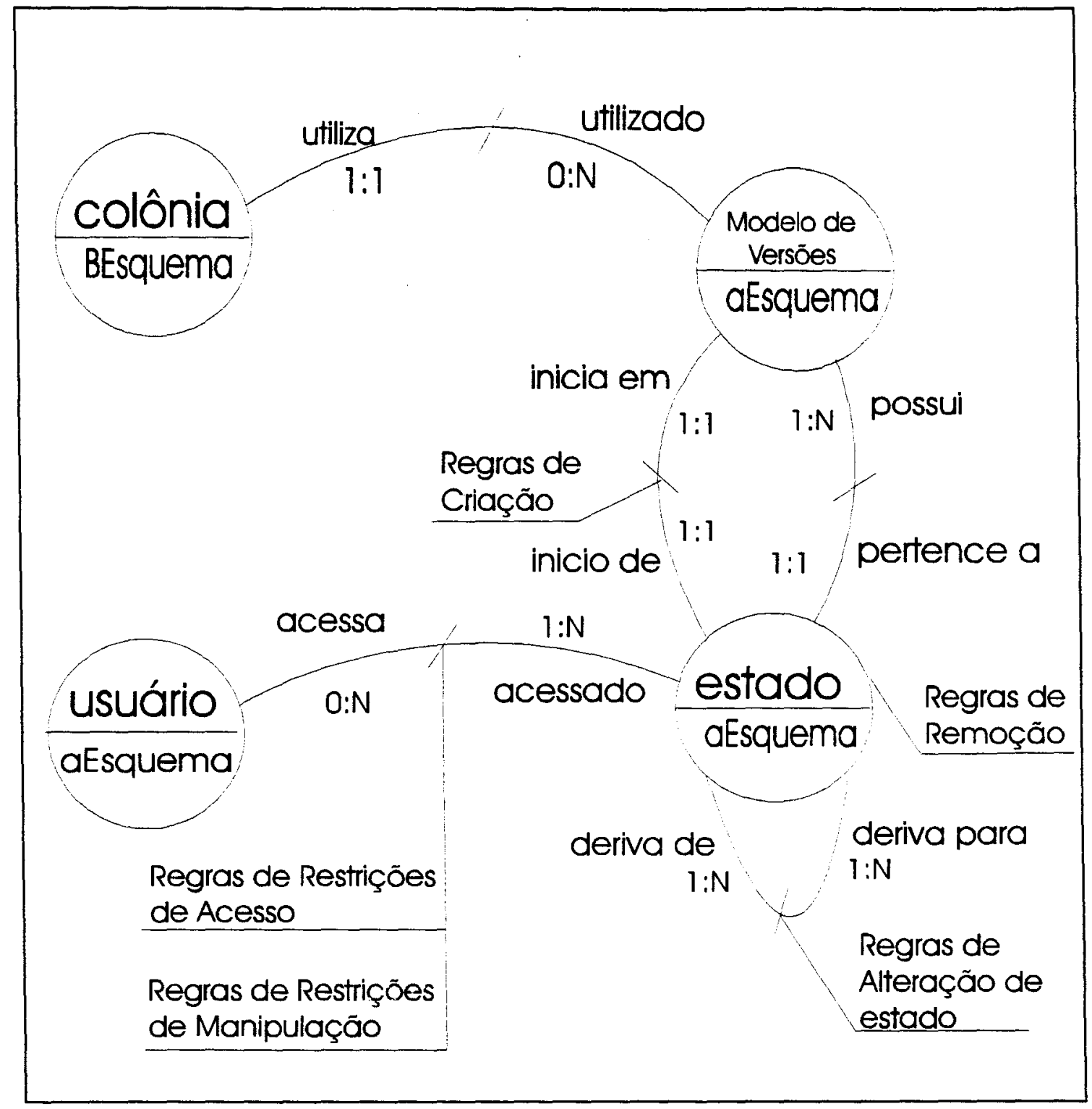

Figura 8.1-Meta-Esquema para Modelos Simultâneos de Versões

\subsubsection{3 - Estruturas Internas}

Duas estruturas de dados devem ser pesquisadas e implementadas objetivando complementar o Modelo de Versões do SIRIUS e melhorar o desempenho do gerenciador:

- estrutura para compactação: o conteúdo das Versões Estáveis não pode ser alterado, portanto os Objetos, Relacionamentos e Atributos poderão ser armazenados em registros próximos (até consecutivos) com o propósito de otimizar consultas. 
- estruturas de Objetos: a representação de Delta Negativo exigirá a elaboração de um nova estrutura para o registro lógico de Objetos. A proposta inicial, apresentada na Figura 8.2, estabelece um campo no registro lógico de Objetos que endereça um registro lógico de Atributos, o qual aponta apenas para aqueles Atributos que existem no Objeto Genérico endereçado mas que foram retirados do Objeto específico. Esta proposta ainda deve ser estudada para estabelecer o tratamento que será dado aos Atributos multi-valorados que organizam-se em estruturas de dados (vetores, listas, matrizes e etc.).

\subsubsection{4 - Evolução do Esquema de Dados}

Uma vez que é permitida a criação de uma Versão (Instável) a partir de uma Versão Estável de Colônia Esquema Suplementar, é necessário especificar claramente quais operações de alteração do conteúdo de um Esquema Suplementar são possiveis e também, em que situações podese realizar a remoção de Versões Estáveis de Colônia Esquema Suplementar, pois a

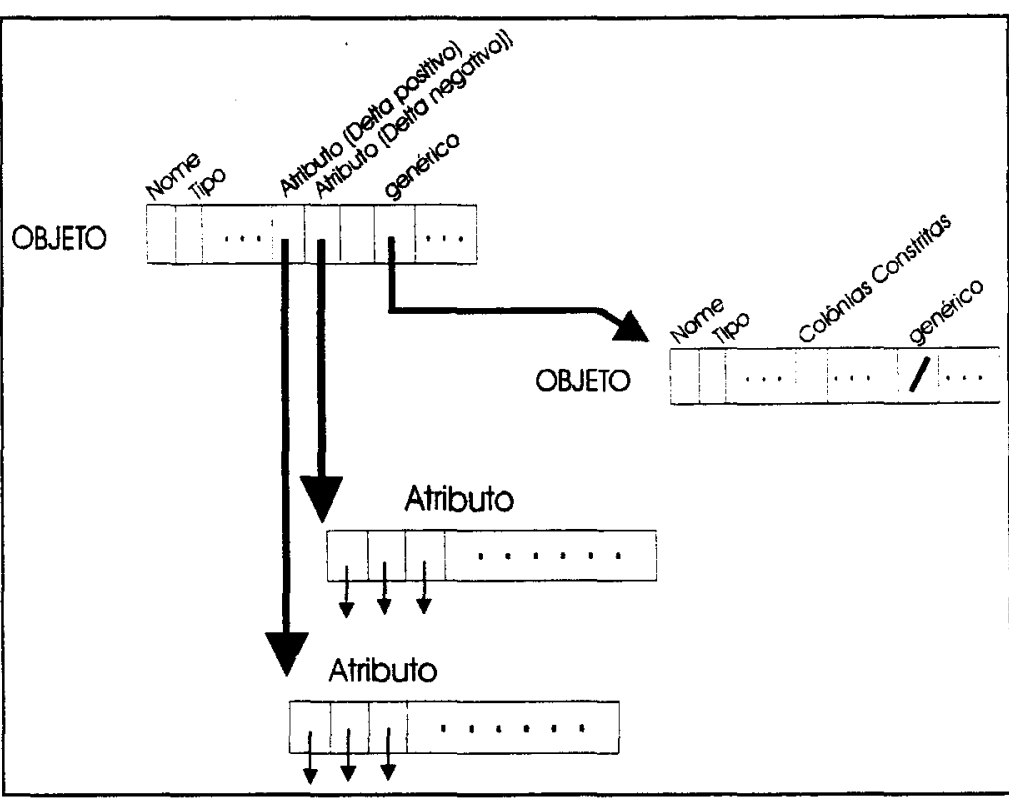

Figura 8.2 - Proposta de Estrutura para Deltas eliminação inconseqüente de um Esquema Suplementar pode levar a indefinição de Instâncias da Base de Dados.

A importância destas especificações (Evolução do Esquema) deve-se principalmente ao fato do Esquema de Dados Ativo (EDA) poder ser constituído de Versões do mesmo Esquema Suplementar, o que podem causar inconsistência ao EDA, caso uma série de verificações de consistência e um controle rígido sobre as alterações de Versões não sejam realizadas pelo sistema Gerenciador de Esquemas.

Portanto, a especificação conceitual destas operações e suas restrições são necessárias para a redefinição do GED para suportar Versões de Colônias Esquemas Suplementares no EDA. Um estudo destas operações já foi iniciado para viabilizar rapidamente a requisição/liberação de Versões de Esquemas Suplementares no EDA. 


\subsubsection{5 - Múltiplos Objetos Genéricos}

O Modelo de Versões estabeleceu que cada Objeto da Base de Dados pode estar associado a apenas um Objeto Genérico (Figura 5.5). Esta restrição pode confrontar-se diretamente com os interesses de trabalho de alguns usuários que desejam associar um Objeto a diversos Genéricos de uma mesma Árvore de Derivações. A Figura 8.3 mostra o mesmo exemplo da Figura 5.5 mas com os Objetos "obj lbx" e "obj lby" tendo dois Objetos Genéricos ("obj 1" e "obj lb").

A possibilidade de associação de vários Objetos Genéricos com um Objeto permitirá que os Objetos utilizem-se das várias listas encadeadas de Atributos, Colônias Constritas e Relacionamentos que pertencem aos seus Objetos Genéricos. Para isso, a estrutura de registro lógico de Objetos deverá ser alterada para suportar uma lista encadeada de registros lógicos de Objetos Genéricos. Além disso, várias primitivas do GEO terão que ser alteradas para suportarem e reconhecerem as lista encadeadas de Objetos Genéricos. Adicionalmente, pode-se incluir um Meta-Atributo no Meta-Tipo Objeto que permita definir, para cada Tipo de Objeto, se suas Instâncias terão apenas um Genérico ou poderão ter Múltiplos Objetos Genéricos.

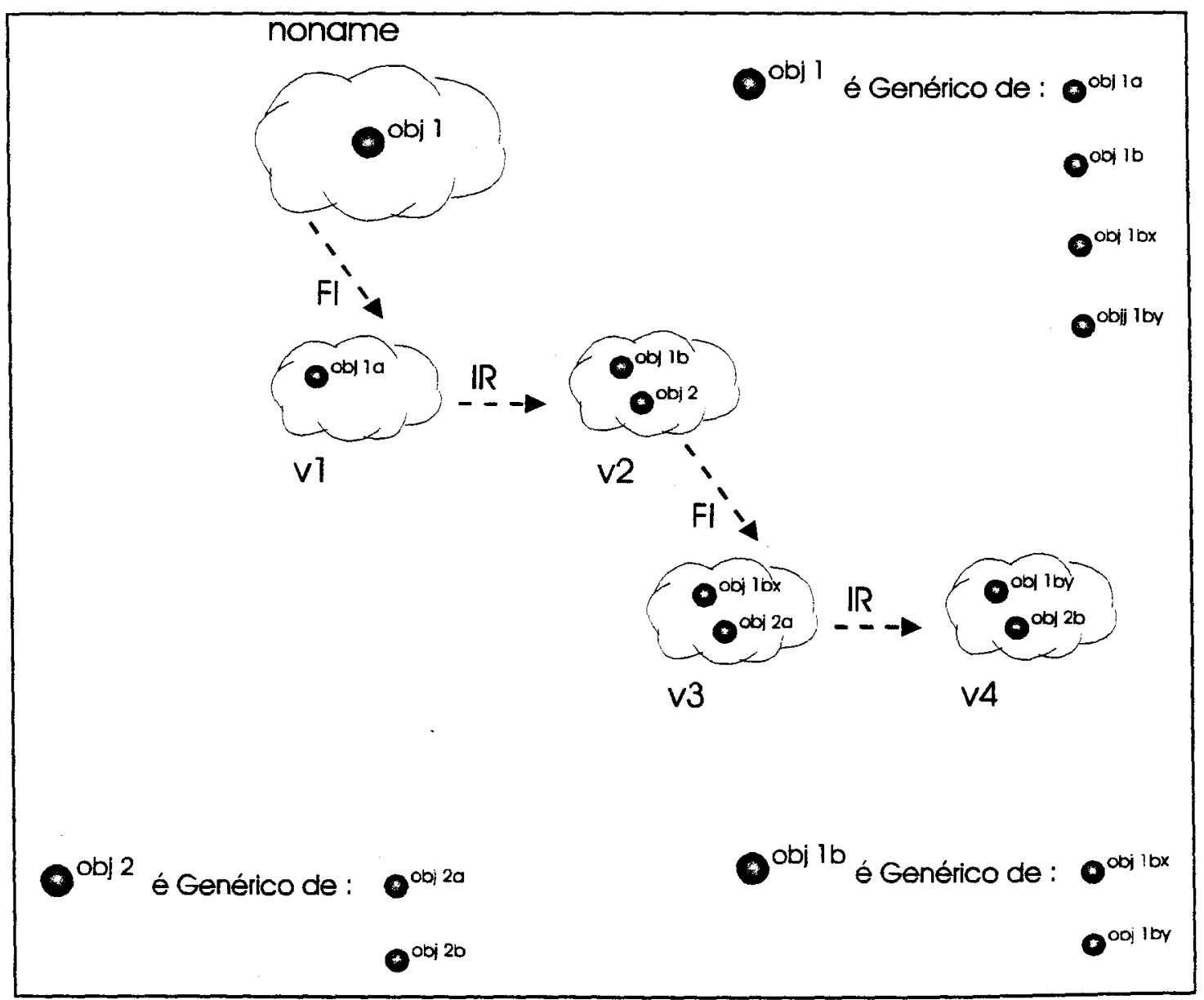

Figura 8.3 - Exemplo de Múltiplos Objetos Genéricos 


\section{5 - Conclusões Gerais}

A existência de um Controle de Versão dos projetos tem se tornado um dos principais interesses dos desenvolvedores de ferramentas computacionais, por ser um dos fatores determinantes da aceitação de seus produtos no mercado consumidor. Diversas pesquisas buscam incorporar este conceito aos Gerenciadores e Modelos de Orientados a Objetos, de modo a oferecerem meios de representação de Objetos passíveis de mutações estruturais, funcionais ou comportamentais ao longo do tempo.

A colocação do Modelo de Versões de forma transparente aos usuários, e a generalidade de suas especificações, credencia sua aplicação em várias áreas (ex. CASE [DEWAN_93], CAD/CAM [REMBOLD_86]) cujos problemas de desenvolvimento caracterizam-se pela concorrência de criação e/ou elaboração ("Simultaneous Engineering" [SPRAGUE_91]) de elementos de projeto e pela existência de alternativas durante o processo de desenvolvimento.

Independente dos aspectos teóricos ou práticos, comerciais ou científicos, o Modelo de Versões definido neste trabalho busca flexibilizar ao máximo o processo de criação e manipulação de Versões. $O$ objetivo principal foi alcançado com a possibilidade de desenvolvimento de Versões de projeto ou sub-projeto, de forma paralela e independente, porém interrelacionada logicamente.

$$
\text { * }
$$




\section{REFERÊNCIAS BIBLIOGRÁFICAS}

\section{[ABITEBOUL_91]}

ABITEBOUL S.; BONNER, A. - Object and Views, In: ACM SIGMOD Conference, Denver (Colorado-EUA), 1991, Anais, p. 238-247.

\section{[ADLER_95]}

ADLER, R. M. - Emerging Standards for Component Software, IEEE Computer, v. 28, n. 3, p. $68-77,1995$.

\section{[AGRAWAL_89]}

AGRAWAL, R.; GEHANI, N. H. - ODE (Object Database and Environment): The Language and the Data Model, In: ACM SIGMOD Conference, s.1., 1989, Anais, p. 36-45.

\section{[AGRAWAL_93]}

AGRAWAL, D.; SENGUPTA, S. - Modular Synchronization in Distributed, Multiversion Databases: Version Control and Concurrency Control, IEEE Transactions on Knowledge and Data Engineering, v. 5, n. 1, p. 126-137, 1993.

\section{[AHMED_91]}

AHMED, R; NAVATHE, S. B. - Version Management of Composite Objects in CAD Databases, In: ACM SIGMOD Conference, Denver (CO-EUA), 1991, Anais, p. 218-227.

\section{[AJILA_95]}

AJllA, S. - Software Maintenance: An Approach to Impact Analysis of Object Change, Software - Practice and Experience, v. 25, n. 10, p. 1155-1181, 1995.

\section{[AMBRIOLA_90]}

AMBRIOLA, V.; BENDIX, L.; CIANCARINI, P. - The Evolution of Configuration Management and Version Control, Software Engineering Journal, p. 303-310, Nov., 1990.

\section{[BANCILHON_94]}

BANCILHON, F.; FERRAN, G. - ODMG-93: The Object Database Standard, IEEE Computer, v. 17, n. 4, p. 3-14, 1994. (Bulletin Tech. Committee on Data Engineering) 
[BANERJEE_87]

BANERJEE, J.; KIM, W.; KIM, H. J.; KORTH, H. F. - Semactic and Implementation of Schema Evolution in Object-Oriented Databases, In: ACM SIGMOD Conference. San Francisco (California-EUA), 1987, Anais, p. 311-322.

[BARGHOUTI_91]

BARGHOUTI, N. S.; KAISER, G. E. - Concurrency Control in Advanced Database Applications, ACM Computing Surveys, v. 23, n. 3, p. 269-317, 1991.

\section{[BATINI_86]}

BATINI, C.; LENZERINI, M.; NAVATHE, S. B. - A Comparative Analysis of Methodologies for Database Schema Integration, ACM Computing Surveys, v. 18, n. 4. p. 323-364, 1986.

[BATINI_92]

BATINI, C.; CERI, S.; NAVATHE, S. B. - Conceptual Database Design, Ed. Benjamin/ Cummings, 1992.

[BATORY_85]

BATORY, D. S.; KIM, W. - Modeling Concepts for VLSI CAD Objects, ACM Transactions on Database Systems, v. 10., n. 3, p. 322-346, 1985.

[BAYER_80]

BAYER, R.; HELLER, H., REISER, A. - Parallelism and Recovery in Database System, ACM Transactions on Database Systems, v. 5, n. 2, p. 139-156, 1980.

\section{[BERTINO_91]}

BERTINO, E.; MARTINO, L. - Object-Oriented Database Management Systems: Concepts and Issues, IEEE Computer, v. 24, n. 4, p. 33-47, 1991.

\section{[BERTINO_93]}

BERTINO, E.; MARTINO, L. - Object-Oriented Database Systems, Ed. Addison-Weslev, 1993.

\section{[BIAJIZ_92]}

BIAJZ, M. - MRO: Uma Atualização do Modelo de Representação de Objetos e uma Abordagem Funcional, São Carlos, 1992, Dissertação (Mestrado) - ICMSC, Universidade de São Paulo.

[BIAJIZ_96]

BIAJIZ, M. - Representação de Modelos de Dados Orientados a Objetos Através da Parametrização de Abstrações, São Carlos, 1996, Tese (Doutorado) - IFSC, Universidade de São Paulo.

\section{[BJORNERSTEDT_89]}

BJORNERSTEDT, A.; HULTEN, C. - Version Control in a Object-Oriented Architecture, In: KIM, W.; LOCHOVSKY, F. H. - Object-Oriented Concepts, Databases and Applications, Ed. Addison-Wesley, 1989, Cap. 18, p 451-485.

\section{[BLAKELEY_94a]}

BLAKELEY, J. A. et al. - The Impact of Database Research on Industrial Products, SIGMOD RECORD, v. 23, n. 2, pp. 35-40, 1994.

\section{[BLAKELEY_94b]}

BLAKELEY, J. A. - Open Object Database Management Systems, SIGMOD RECORD. v. 23, n. 2, pp. 520, 1994. 


\section{[BOUDIER_88]}

BOUDIER, G. et al. - An Overview of PCTE and PCTE+, In: ACM SIGMOD Conference, Chicago (Illinois-EUA), 1988, Anais, p. 248-257.

\section{[BRETL_89]}

BRETL, R. et al. - The GemStone Data Management Systems, In: KIM, W.; LOCHOVSKY, F. H. - Object-Oriented Concepts, Databases and Applications, Ed. Addison-Wesley, 1989, Cap. 12, p. 283-308

\section{[BUTTERWORTH_91]}

BUTTERWORTH, P. et al. - The GemStone Object Database Management System, Communications of the ACM, v. 34, n. 10, p. 50-63, 1991.

\section{[CAMOLESI_92a]}

CAMOLESI JR., L.; TRAINA JR., C. - Construção de Ferramentas de Apoio a Projetos Utilizando um Gerenciador de Bases de Dados com Suporte de Esquemas Suplementares, In: Simpósio Brasileiro de Engenharia de Software, 6, Gramado (RS-Brasil), 1992, Anais, p. 259-274.

\section{[CAMOLESI_92b]}

CAMOLESI JR., L. - Suporte a Acesso Multi-Usuário em Bases de Dados Orientadas a Objetos Através de Esquemas Suplementares, São Carlos, 1992, Dissertação (Mestrado) ICMSC, Universidade de São Paulo.

\section{[CAMOLESI_93]}

CAMOLESI JR., L.; TRAINA JR, C. - Tratamento de Múltiplos Aspectos de Projeto Através de um Gerenciador de Esquemas de Dados para Modelos Orientados a Objetos, In: Simpósio Brasileiro de BD, 8, Campina Grande (PB-Brasil), 1993, Anais, p. 283-296.

\section{[CAMOLESI_96]}

CAMOLESI JR., L.; TRAINA JR., C. - Evolução de Esquemas de Dados: Um Panorama Amplo de Aspectos Técnicos e Gerenciais, In: Simpósio Brasileiro de Banco de Dados, 11, São Carlos (SP-Brasil), 1996, Anais, p. 1-19.

\section{[CAREY_88]}

CAREY, M. J. et al. - A Data Model and Query Language for EXODUS, In: ACM SIGMOD Conference, Chicago (Illinois-EUA), 1988, Anais, p. 413-423.

\section{[CAREY_89]}

CAREY, M. J. et al - Storage Management for Object in EXODUS, In: KIM, W.; LOCHOVSKY, F. H. - Object-Oriented Concepts, Databases and Applications, Ed. Addison-Wesley, 1989, Cap. 14, p 351-369.

\section{[CATTELL_94]}

CATELL, R.G.G. - Object Data Management, Ed. Addison-Wesley, 1994.

\section{[CHAUDHRI_95]}

CHAUDHRI, A. B. - An Annotated Bibliography of Benchmarks for Object Databases, SIGMOD RECORD, v. 24, n. 1, p. 50-57, 1995.

\section{[CHEN_96]}

CHEN, I-M. A; MARKOWITZ, V. M. - Version Management for Scientific Databases, In: International Conference on Extenging Database Technology, Avegnon (FRA), 1996, Anais, Lecture Notes in Computer Science, n. 1057, p. 289-306.

\section{[CIVELLO_93]}

CIVELLO, F. - Roles for Composite Objects in Object-Oriented Analysis and Design, SIGPLAN NOTICES, v. 28, n. 10, p. 376-393, 1993. 
[CODASYL_71]

CODASYL Database Task Group, ACM Report, Abril 1971.

[CODD_70]

CODD, E. F. - A Relational Model for Large Shared Data Banks, Communications of the ACM, v. 13, n. 6, p. 377-387, 1970.

\section{[DATE_88a]}

DATE, C. J. - Introdução a Sistemas de Bancos de Dados, Ed. Campus, 1988.

\section{[DATE_88b]}

DATE, C. J. - Bancos de Dados: Tópicos Avançados, Ed. Campus, 1988.

\section{[DAVIS_91]}

DAVIS, T. A.; TRAPP, G. - Advancing Concurrent Engineering using STEP, West Virginia University (WV-EUA), 1991. (Relatório Técnico do Concurrent Engineering Research Center - CERC, 12)

\section{[DEUX_90]}

DEUX, O. et al - The Story of O2, IEEE Transactions on Knowledge and Data Engineering, v. 2 , n. 1, p. 91-108, 1990.

\section{[DEUX 91]}

DEUX, O. et al - The O2 System, Communications of the ACM, v. 34, n. 10, p. 30-33, 1991.

\section{[DEWAN_93]}

DEWAN, P.; RIEDL, J. - Toward Computer-Supported Concurrent Software Engineering, IEEE Computer, v. 26, n. 1, p. 17-27, 1993.

\section{[DITTRICH_88]}

DITTRICH, K. R.; LORIE, R. A. - Version Support for Engineering Database Systems, IEEE Transactions on Software Engineering, v. 14, n. 4, p. 429-437, 1988.

\section{[DRUCKER_92]}

DRUCKER, P. F. - Administrando para o Futuro: Os anos 90 e a virada do século, Ed. Pioneira, 1992.

\section{[ELMASRI_94]}

ELMASRI, R.; NAVATHE, S. B. - Fundamentals of Database Systems, Ed. Benjamin/ Cummings, 1994.

\section{[FERREIRA_91]}

FERREIRA, J. E. - Estudo da Distribuição de Bases de Dados Orientadas a Objetos, São Carlos, 1991, Dissertação (Mestrado) - IFSC, Universidade de São Paulo.

\section{[FERREIRA_96]}

FERREIRA, J. E. - Compartilhamento de Objetos Compostos entre BD Orientadas a Objetos, São Carlos, 1996, Tese (Doutorado) - IFSC, Universidade de São Paulo.

\section{[FISHMAN_89]}

FISHMAN, D. H. et al. - Overview of the Iris DBMS, In: KIM, W.; LOCHOVSKY, F. H. Object-Oriented Concepts, Databases and Applications, Ed. Addison-Wesley, 1989, Cap. 10, p. $219-250$.

\section{[FORNARI_93]}

FORNARI, M. R.; GOLENDZINER, L. - Evolução de Esquemas de Dados Utilizando Versões em BD Orientados a Objetos, In: Simpósio Brasileiro de Banco de Dados, 8, Campina Grande (PB-Brasil), 1993, p. 113-127. 
[GOLENDZINER_93]

GOLENDZINER, L. G.; SANTOS, C. S. dos - Versões em BD Orientados a Objetos, In: Simpósio Brasileiro de BD, 8, Campina Grande (PB-Brasil), 1993, Anais, p. 7-23.

[HAMMER_81]

HAMMER, M.; MCLEOD, D. - Database Description with SDM: A Semantic Database Model, ACM Transactions on Database Systems, v. 6., n. 3, p. 351-386, 1981

\section{[HAMMER_93]}

HAMMER, M.; CHAMPY, J. - Rengineering the Corporation, a Manifesto for Business Revolution, Ed. Harper Collins, 1993.

\section{[HENRIKSEN_94]}

HENRIKSEN, L. W. - Structuring and Planning of Interoperable Workgroup, In: International Conference on System Integration, 3, São Paulo (SP-Brasil), 1994, Anais, v. 2, p. 1211-1219.

\section{[HUDSON_87]}

HUDSON, S. E.; KING, R. - Object-Oriented Database Support for Software Environments", In: ACM SIGMOD Conference, San Francisco (California-EUA), 1987, Anais, p. 491-503.

\section{[HUDSON_88]}

HUDSON, S. E.; KING, R. - Cactis Project: Database Support for Softwaare Environments", IEEE Transactions on Software Engineering, v. 14, n. 6, p. 709-719, 1988.

\section{[HUDSON_89]}

HUDSON, S. E.; KING, R. - Cactis: A Self-Adaptive, Concurrent Implementation of an Object-Oriented Database Management Systems, ACM Transactions on Database Systems, v. 14, n. 3, p. 291-32, 1989.

\section{[HURSON_93]}

HURSON, A. R. et al. - Object-Oriented Database Management Systems: Evolution and Performance Issues, IEEE Computer, v. 26, n. 2, p. 48-61, 1993.

\section{[JACKSON_90]}

JACKSON, M. S. - Beyond Relational Databases, Information and Software Technology, v. 33, n. 1, p. 4-12, 1991.

\section{[KATZ_84]}

KATZ, R. H.; LEHMAN, T. J. - Database Support for Versions and Alternatives of Large Design Files, IEEE Transactions on Software Engineering, v. 10, n. 2, p. 191-200, 1984.

[KATZ_86]

KATZ, R. H. et al. - Version Modeling Concepts for Computer-Aided Design Files, In: ACM SIGMOD Conference, Washington (D.C.-EUA), 1986, Anais, p. 379-386.

\section{[KATZ_87]}

KATZ, R. H. et al - Design Version Management, IEEE Design \& Test, v. 4, n. 1, p. 12-22, 1987.

\section{[KATZ_90]}

KATZ, R. H. - Toward a Unified Framework for Version Modeling in Engineering Databases, ACM Computing Survey, v. 22, n. 4, p. 375-408, 1990.

\section{[KENT_89]}

KENT, W. - Panel: An Overview of the Versioning Problem, SIGMOD RECORD, v. 18, $n$. 2, p. 5-7, 1989. 


\section{[KETABACHI_87]}

KETABACHI, M. V.; BERZINS, V. - Modeling and Managing CAD Databases, IEEE Computer, v. 20, n. 2, p. 93-102, 1987.

[KIM_87]

KIM, W. et al. - Composite Object Support in an Object-Oriented Database System, In: OOPSLA, Orlando (Florida-EUA), 1987, Anais, p. 118-125.

\section{[KIM_89]}

KIM, W. et al. - Features of the ORION Object-Oriented Database Systems, In: : KIM, W.; LOCHOVSKY, F. H. - Object-Oriented Concepts, Databases and Applications, Ed. Addison-Wesley, 1989, Cap. 11, p 251-281.

[KIM_90]

KIM, W. et al. - Architecture of the ORION Next-Generation Database System, IEEE Transactions on Knowledge and Data Engineering, v. 2, n. 1, p. 109-124, 1990.

[KIM_92]

KIM, W. et al. - Object-Oriented Databases for New Apllications, Future Generation Computer System, v. 7, p. 317-327, 1992.

[KING_85]

KING, R.; MCLEOD, D. - A Database Design Methodology and Tool for Information Systems, ACM Transactions on Office Information Systems, v. 3, n. 1, p. 2-21, 1985.

[LAMB_91]

LAMB, C. et al. - The ObjectSore Database System, Communications of the ACM, v. 34, n. 10, p. $34-49,1991$.

\section{[LECLUSE_88]}

LECLUSE, C. et al. - O2, an Object Data Model, In: ACM SIGMOD Conference, Chicago (Illinois-EUA), 1988, Anais, p. 424-433.

\section{[LERNER_90]}

LERNER, B. S.; HABERMANN, A. N. - Beyond Schema Evolution to Database Reorganization, In: ECOOP/OOPSLA Conference, s.1., 1990, Anais, p. 67-76.

[LIE_89]

LIE, A. et al. - Change Oriented Versioning in a Software Engineering Database, In: Internacional Workshop on Software Configuration Management, 2, Princenton (New Jersey-EUA), 1989, Anais, ACM SIGSOFT, v. 14, n. 7, p. 23-25.

[MAHLER_90]

MAHLER, A.; LAMPEN, A. - Integrating Configuration Management into a Generic Environment, In: Symposium on Software Development Environments, 4, Washington (D.C.-EUA), 1990, Anais. ACM SIGSOFT, v. 15, n. 6, p. 229-237.

\section{[MAJUMBER_94]}

MAJUMBER, D.; RANGAN, R. M.; FULTON, R. E. - Information Management for Integrated Design Environmets, Engineering with Computer, v. 11, n. 4, p. 227-245, 1994.

\section{[MANOLA_94]}

MAN̄OLA, F.; MITCHELL, G. - A Comparation of Object Models in ODBMS-Related Standards, IEEE Computer Society, v. 17, n. 4, p. 27-35, 1994. (Bulletin of the Technical Committee on Data Engineering) 


\section{[MCKENZIE_90]}

MCKENZIE, E.; SNODGRASS, R. - Schema Evolution and the Relacional Algebra, Information Systems, v. 15, n. 2, p. 207-232, 1990.

[MCLEOD_91]

MCLEOD, D. - Perspective in Object Databases, , Information and Software Technology, v. 33, n. 1, p. 13-21, 1991.

\section{[MONK_93]}

MONK, S., SOMMERVILLE, I .- Schema Evolution in OODBs Using Class Versioning. SIGMOD RECORD, v. 22, n. 3, p. 16-22, 1993.

\section{[MYLOPOULOS_80]}

MYLOPOULOS, J. et al. - A Language facility for designing Database Intensive Applications, ACM Transactions on Database Systems, v. 5, n. 2. p. 185-207, 1980.

[NAVATHE_92]

NAVATHE, S. B. - Evolution of Data Modeling for Databases. Communications of the ACM, v. 35, n. 9. p. 112-123, 1992.

\section{[PCTE_89]}

Commission of The European Communities: DG XIIV/A4 ESPRIT - PCTE: A Basic for a Portable Commom Tool Environment, C Volume 1, Versão 1.5, , Junho 1989.

\section{[PENNEY_87]}

PENNEY, D. J.; STEIN, J. - Class Modification in the GemStone Object-Oriented DBMS, In: OOPSLA Conference, Orlando (Florida-EUA), 1987, Anais. p. 111-117.

\section{[PIZZIGATTI_92]}

PIZZIGATTI, P. L. - Uma Linguagem para o Gerenciador de Objetos baseada no Modelo de Representação de Objetos, São Carlos. 1992, Dissertação (Mestrado) - ICMSC, Universidade de São Paulo.

\section{[RAMAMOORTHY_90]}

RAMAMOORTHY, C. V. et al. - The Evolution Support Environment System, IEEE Transactions on Software Engineering, v. 16. n. 11, p. 1225-1234. 1990.

\section{[REMBOLD_86]}

REMBOLD, U.; DILLMANN. R. - Computer-Aided Design and Manufacturing, Ed. Springer-Verlag, 1986, Cap. 1, p. 3-27.

\section{[REWINI_95]}

REWINI, E. EL - Object-Technologv: A Virtual Roundtable, IEEE Computer, v. 28, n. 10 , p. 58-72, 1995.

\section{[RICHARDSON_87]}

RICHARDSON. J. E.; CAREY, M. J. - Programming Constructs for Databases Systems Implementations in EXODUS, In: ACM SIGMOD Conference. San Francisco (CaliforniaEUA), 1987, Anais, p. 208-219.

\section{[RODDICK_92]}

RODDICK, J. F. - Schema Evolution in Database Systems - An Annotated Bibliography, SIGMOD RECORD, v. 21, n. 4, p. 35-40. 1992.

\section{[RODDICK_95]}

RODDICK, J. F. - A Survey of Schema Versioning Issues for Database Systems, Information and Software Technology, v. 37, n. 7, p. 383-393. 1995. 


\section{[RUMBAUGH_88]}

RUMBAUGH, J. - Controlling Propagation of Operations Using Attributes on Relations, In: OOPSLA Conference, San Diego (CA-EUA), 1988, Anais, p.285-296.

[SANTOS_92]

SANTOS, R. R. dos - Um Sistema de Gerenciamento de Regras para o Modelo de Representação de Objetos, São Carlos, 1992, Dissertação (Mestrado) - ICMSC, Universidade de São Paulo.

\section{[SCIORE_91]}

SCIORE, E. - Multidimensional Versioning for Object-Oriented Databases, Lecture Notes in Computer Science, n. 566, p. 355-370, 1991.

\section{[SHINA 91]}

SHINA, S. G. et al. - Concurrent Engineering, IEEE Spectrum, p. 22-37, Julho 1991.

\section{[SHIPMAN_81]}

SHIPMAN, D. W. - The Funtional Data Model and the Data Language DAPLEX, ACM Transactions on Database Systems, v. 6, n. 1, p. 140-173, 1981.

\section{[SILBERSCHATZ_91]}

SILBERSCHATZ, A;; STONEBRAKER, M.; ULLMAN, J. - Database Systems: Achievements and Opportunities, Communications of the ACM, v. 34, n. 10, p. 110-120, 1991.

\section{[SILBERSCHATZ_96]}

SILBERSCHATZ, A.; STONEBRAKER, M.; ULLMAN, J. - Database Research: Achievements and Opportunities into the 21st Century, SIGMOD RECORD, v. 25, n. 1, p. 52-63, 1996.

\section{[SILVA_93]}

SILVA, R. C. da - Armazenagem e Gerenciamento de Informaç̃̃es Temporais em um Modelo de Base de Dados Orientado a Objetos, São Carlos, 1993, Dissertação (Mestrado) ICMSC, Universidade de São Paulo.

\section{[SMITH_77]}

SMITH, J. M.; SMITH, D. C. P. - Database Abstrations: Aggregation and Generalization, ACM Transactions on Database Systems, v. 2, n. 2, p. 105-133, 1977.

\section{[SNODGRASS_92]}

SNODGRASS, R. T. - Temporal Databases,Lecture Notes in Computer Science, n. 639, p. 22-64, 1992.

\section{[SOO_91]}

SOO, M. D. - Bibliography on Temporal Databases, SIGMOD RECORD, v. 20, n. 1, p. 1423, 1991.

\section{[SPRAGUE_91]}

SPRAGUE, R. A.; SINGH, K. J.; WOOD, R. T. - Concurrent Engineering in Product Development, IEEE Desing \& Test of Computer, v. 8, n. 1, p. 6-13, 1991.

\section{[STEIN_94]}

STEIN, R. M. - Objects Databases, Byte, v. 19, n. 4, p. 74-104, 1994.

\section{[STONEBRAKER_86]}

STONEBRAKER, M.; ROWE, L. A. - The Design of POSTGRES, In: ACM SIGMOD Conference, Washington (D.C.-EUA), 1986, Anais, p. 340-355. 


\section{[SU_86]}

SU, S. Y. W. - Modeling Integrated Manufacturing Data with SAM*, Computer, v. 19, n. 1, p. 34-49, 1986.

\section{[TAKAI_93]}

TAKAI, O. K. - Representação de Atributos com Características Gráficas em uma Base de Dados Orientada a Objetos, São Carlos, 1993, Dissertação (Mestrado) - ICMSC, Universidade de São Paulo.

\section{[TAN_89]}

TAN, L.; KATAYAMA, T. - Meta Operations for Type Management in Object-Oriented Databases - A Lazy Mechanism for Schema Evolution, In: International Conf. on Deductive and Object-Oriented Databases, Kyoto (Japão), Anais, p. 241-258.

\section{[THOMAS_89]}

THOMAS, I. - Version and Configuration Management on a Software Engineering Database, In: Internacional Workshop on Software Configuration Management, 2, Princenton (New Jersey-EUA), 1989, Anais, ACM SIGSOFT, v. 14, n. 7, p. 23-25.

\section{[TRAINA_86]}

TRAINA JR., C. - Máquina e Modelo de Dados Dedicados para aplicações de Engenharia, São Carlos, 1986, Tese (Doutorado), IFSC, Universidade de São Paulo.

\section{[TRAINA_91]}

TRAINA JR., C. - GEO: Um Sistema de Grenciamento de Bases de Dados Orientados a Objetos - Estado Atual de Desenvolvimento e Implementação, In: Simpósio Brasileiro de Banco de Dados, 7, Manaus (AM-Brasil), 1991, Anais, p. 193-207.

\section{[TRAINA_92]}

TRAINA JR., C.; SLAETS, J. F. W. - MRO: Um Modelo de Representação de Objetos, São Carlos, ICMSC, 1992. (Notas Internas do ICMSC-USP, 104)

\section{[TRAINA_93]}

TRAINA JR., C.; CAMOLESI JR., L. - Primitivas do Núcleo do Gerenciador de Esquema de Dados no MRO*, São Carlos, ICMSC, 1993. (Relatório Técnico ICMSC-USP, 10)

\section{[TRESCH_92]}

TRESCH, M.; SCHOLL, M. H. - Meta Object Management and its Application to Database Evolution, In: International Conference on Entity-Relationship Approach, s.1., 1992, Anais, Leature Notes in Computer Science, n. 645, p. 299-321.

\section{[TRESH_93]}

TRESCH, M.; SCHOLL, M. H. - Schema Transformation Without Database Reorganization, SIGMOD RECORD, v. 22, n. 1, p. 21-27, 1993.

\section{[VAGOUN_93]}

VAGGOUN, T. - Standard for Exchange of Product Data (STEP) Technology, In: CE \& CALS Conference and Exposition, Washington (D.C.-EUA), 1993, s.p..

\section{[VALENCIO_93]}

VALENCIO, C. R. - Um Editor Genérico Sensivel à Sintaxe Armazenada numa Base de Dados, São Carlos, 1993, Dissertação (Mestrado) - ICMSC, Universidade de São Paulo.

\section{[VASKEVITCH_94]}

VASKEVTTCH, D. - Database in Crisis and Transition: A Technical Agenda for the Year 2001, SIGMOD RECORD, v. 23, n. 2, p. 484-489, 1994. 


\section{[WILKINSON_90]}

WILKINSON, $\mathrm{K}$. et al. - The Iris Architecture and Implementation, IEEE Transactions on Knowledge and Data Engineering, v. 2. n. 1, p. 63-75. 1990.

\section{[ZAND_95]}

ZAND, M. et al. - A Survey of Current Object-Oriented Databases, Database Advances. v. 26, n. 1, p. 14-29, 1995.

\section{[ZDONIK_86]}

ZDONIK, S. B. - Version Management in an Object-Oriented Databases, Lecture Notes in Computer Science, n. 244, p. 405-422. 1986.

\section{[ZDONIK_93]}

ZDONIK. S. B. - Incremental Database Systems: Databases from the Ground Up, SIGMOD RECORD, v. 22, n. 2, p. 408-412, 1993.

\section{[ZICARI_90]}

ZICARI, R. - Incomplete Information in Object-Oriented Databases, SIGMOD RECORD. v. 19, n. 3. p. 5-16, 1990. 


\section{APÊNDICE A}

\section{Exemplo de Modelagem de Dados \\ - Programação de Campanhas -}

Nota:

Este exemplo de modelagem, utilizando-se dos conceitos e representações criadas neste trabalho, retrata simplificadamente o problema da programaçāo (anual e mensal) das campanhas de produção de derivados de petróleo na REPLAN (refinaria) PETROBRÁS em Paulínia (cidade do estado de São Paulo).

Sendo a maior refinaria da PETROBRÁS em refino de petróleo (cerca de 301.920 Barris/dia), a REPLAN tem entre seus problemas a programação das campanhas de produção de derivados de petróleo, de acordo com a demanda de mercado e a configuração e disponibilidade de seus equipamentos (dutos, tanques, unidades de processamento e etc.).

A programação de campanha corresponde à uma especificação do trabalho de produção de derivados de petróleo, durante um certo periodo (dias), de maneira que determinada quantidade de matéria-prima (petróleo) seja refinada em determinadas 
quantidades de produtos (gasolina, nafta, querosene, diesel, etc.).

$\mathrm{Na}$ REPLAN, os responsáoeis pela programação das campanhas são os engenheiros e técnicos do Departamento de Produção (COPROD) em cooperação com outras divisōes que gerenciam dados e processos operacionais.

O problema da programação de uma campanha consiste basicamente em detalhar:

- o armazenamento de petróleo em tanques disponíveis de acordo com o recebimento de petróleo pelos oleodutos (OSPLAN e OPASA);

- o armazenamento de derivados de petróleo em tanques e esferas de acordo com o processamento/produção de derivados nas unidades (destilação atmosférica, destilação à vácuo e craqueamento catalítico - a REPLAN possui duas de cada);

- o processamento das unidades de acordo com a demanda das distribuidoras (BR, TEXACO, SHELL, ESSO, etc.).

Os armazenamentos e processamentos são definidos em Transferências (de petróleo, subprodutos ou derivados) entre tanques, tanques $e$ unidades, unidades $e$ tanques, unidades e esferas, e oleodutos e tanques, por meio de dutos que os interligam. Estas Transferências são definidas em termos de: equipamento origem, equipamento destino, horário inicio, horário final, data e volume para transferência.

A medida que uma campanha é aprovada pelos departamentos competentes, os operadores nos oleodutos, dutos, tanques, esferas e unidades seguem sua programação como um roteiro de trabalho que não pode sofrer muitas alteraçōes, exceto quando algum equipamento fica inoperante.

O armazenamento da programação de campanhas de produção pode ser realizado em uma Base de Dados que permita a representação e controle de versões em dois níveis:

- Esquema de Dados, pois a configuração dos equipamentos na refinaria não é sempre a mesma. A PETROBRÁS está constantemente realizando a manutenção $e$ atualização de tanques, dutos e unidades, $e$ isto pode alterar campanhas definidas ou em definição. Desta forma, Versões da configuração de equipamentos da REPLAN podem ser utilizadas pelos engenheiros e técnicos de programaşão de campanhas para simularem campanhas/situaçöes futuras e/ou emergenciais da existência de novos equipamentos ou impossibilidade de uso dos equipamentos inoperantes; 
- Instâncias, pois as campanhas são estudadas e elaboradas por vários engenheiros e técricos simultaneamente, de acordo com a configuração dos equipamentos disponíveis, buscando várias soluções dentre as quais é escolhida a mais otimizada e que será efetivamente realizada. As Versöes são os meios para o armazenamento das campanhas enquanto são alternativas não definidas.

A modelagem apresentada a seguir, uma simplificação do problema de programação de campanhas, descreve (em 10 folhas de diagramas):

- a Base de Dados Intencional: possui dois Esquemas Suplementares, deniminados A e B, e suas Versões. As Versões do Esquema Suplementar A possuem a representação dos tipos de tanques e do tipo de oleoduto, sendo que a Versão "Raiz" e a Versão "v1"são semelhantes e a Versão "v2"possui adicionalmente a especificação de um tipo de tanque com teto móvel (TanqM_Petr). As Versões do Esquema Suplementar $B$ possuem a representação dos tipos de unidades, sendo que a Versão "Raiz" e a Versão "vl"são semelhantes e a Versão "v2"possui adicionalmente a especificação de um relacionamento (transferido) entre o tipo de unidade Unid_ATM e o tipo de tanque com teto móvel (TanqM_Petr, especificado na Versão "v2" do Esquema Suplementar A); e

- a Base de Dados Extensional: possui três Tipos de Colônias para a representação dos dados de uma campanha:

- a Colônia Global, onde são armazenados os dois Objetos Esquema associados aos Esquemas Suplementares $A$ e B, além do Objeto (Tipo Programação) que registra o ano correspondente da campanha;

- a Colônia Sistemas, onde registram-se os Objetos referentes aos meses correspondentes da campanha; $e$

- a Colônia Plano Bandeira (do tipo "versionable") que armazena as campanhas propriamente ditas. São representadas 4 Versões da Colônia Plano Bandeira que se destacam pelo registro de tanques e/ou unidades diferentes que são utilizadas em transferências distintas (em relação ao tempo ou ao volume). 
Mostra a Hierarquia de Colônias da BD Extensional que está definida no Esquema Inicial (BD Intencional). Na Colônia GLOBAL, um Objeto (Tipo Programação) constringe a Colônia SISTEMAS. Na Colônia SISTEMAS, um Objeto (Tipo Produção) constringe a Versões da Col. PLANO_BANDEIRA que são definidas por Versões dos Esqu. Suplementares $A$ e $B$.

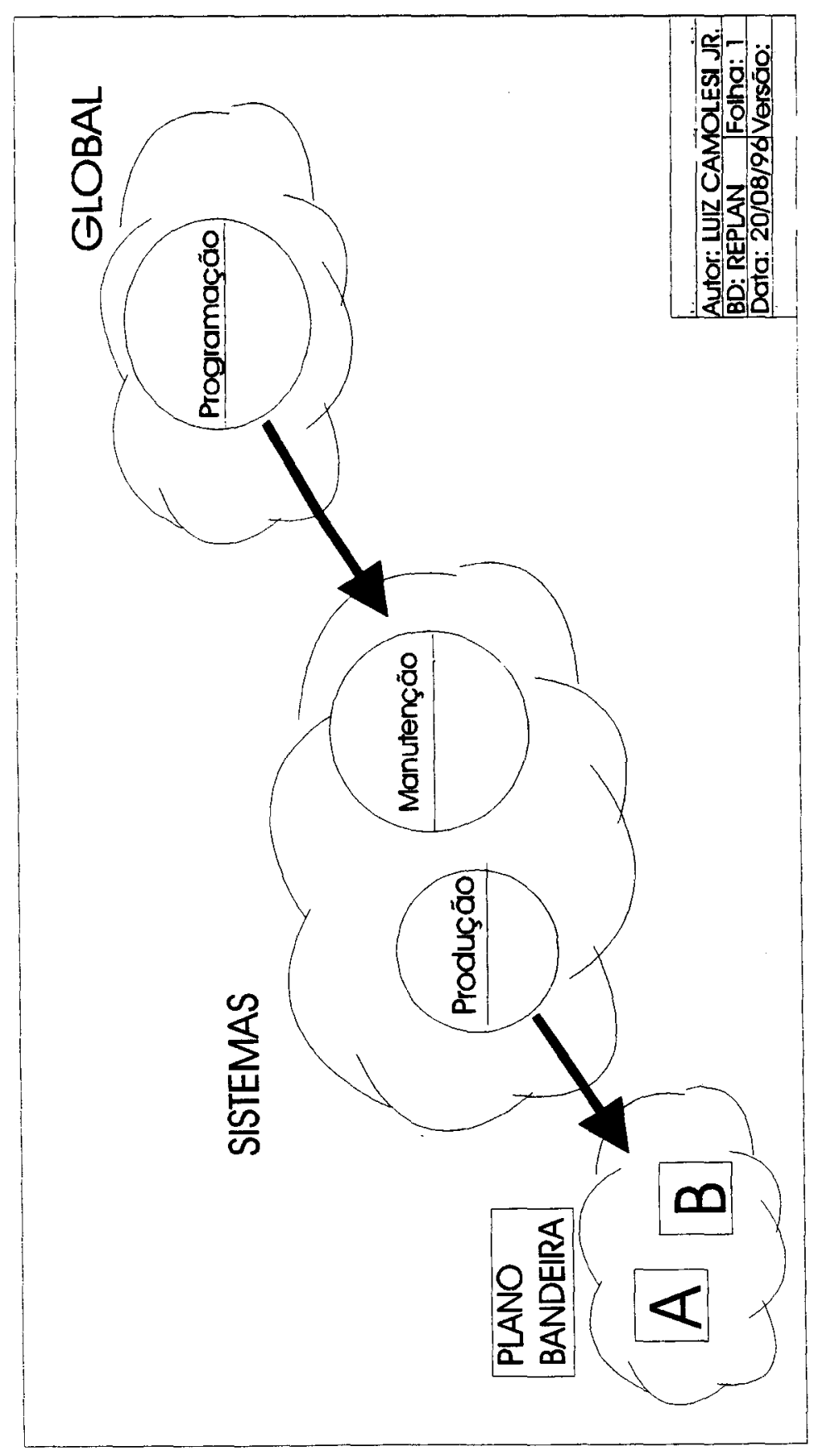


A -5

FOLHA 2 -:

DHC - Inicial

Mostra a Hierarquia de Colônias da BD Extensional. Na Colônia GLOBAL; o Objeto 1996 (Tipo Programação) constringe a Colônia SISTEMAS, o Objeto Área_Tanques (Tipo Esquema) constringe Versões da Colônia Esquema Suplementar A e o Objeto Área_Unidades (Tipo Esquema) constringe Versões da Colônia Esquema Suplementar $B . \mathrm{Na}$ Colônia SISTEMAS, o Objeto Outubro (Tipo Produção) constringe a Versões da Colônia PLANO_BANDEIRA.

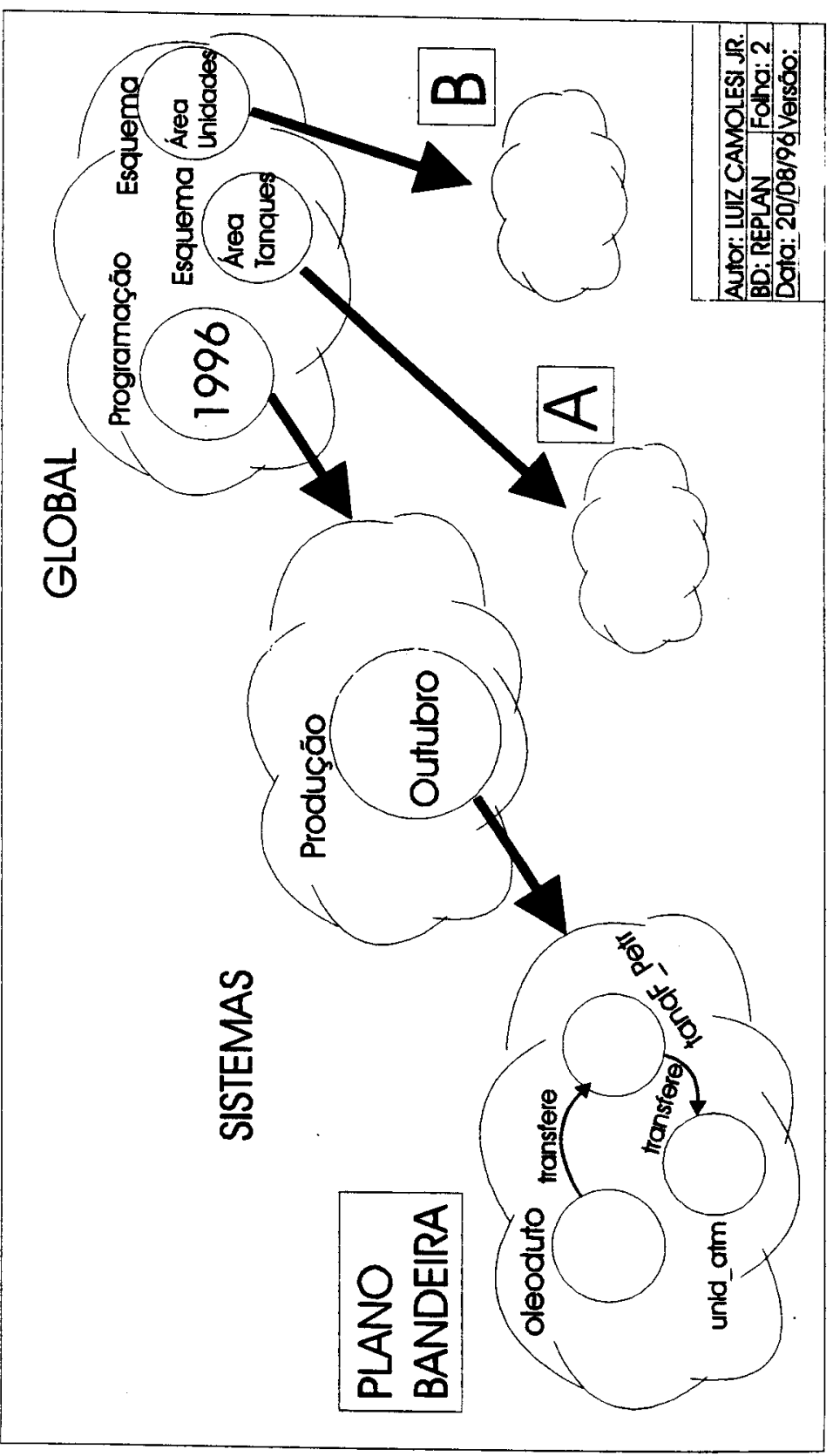


Mostra a Hierarquia de derivação de Versões da Colônia PLANO_BANDEIRA. Adicionalmente o conteúdo de cada Versão (raiz, v1, v2, v3) da Colônia pode ser visualizado. Os Objetos de todas as Versões foram instanciados dos genéricos de seus respectivos tipos.

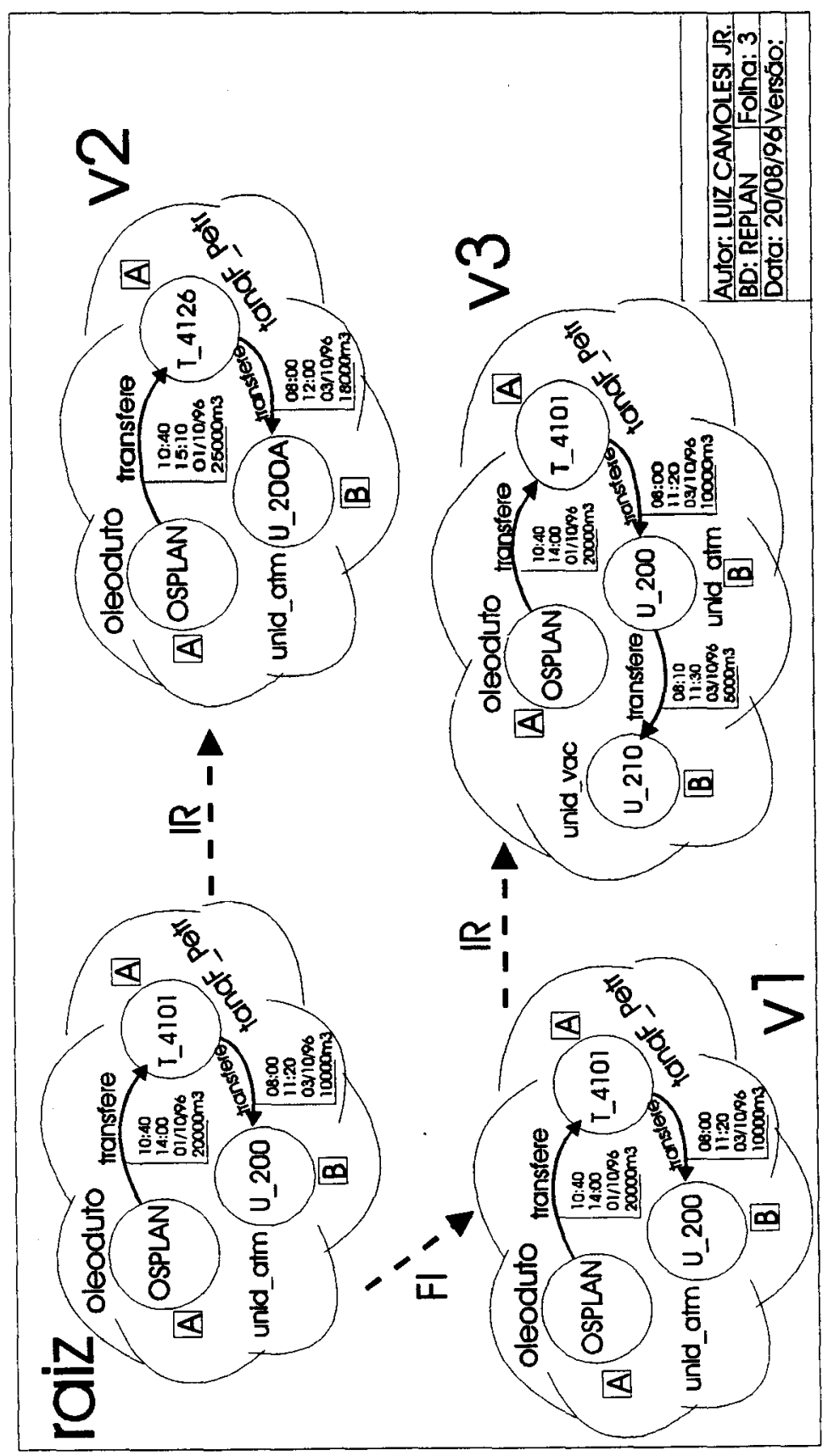


FOLHA 4 -: DHV - Colônias Esqu. Suplementar A e B

Mostra a Hierarquia de derivação de Versões das Colônias Suplementar A e B. O conteúdo de cada Versão (raiz, v1, v2) destas Colônias não é apresentado pelo fato das Versões serem complexas. Cada Versão das Colônias Esquema Suplementar pode ser visto separadamente nos próximos diagramas.

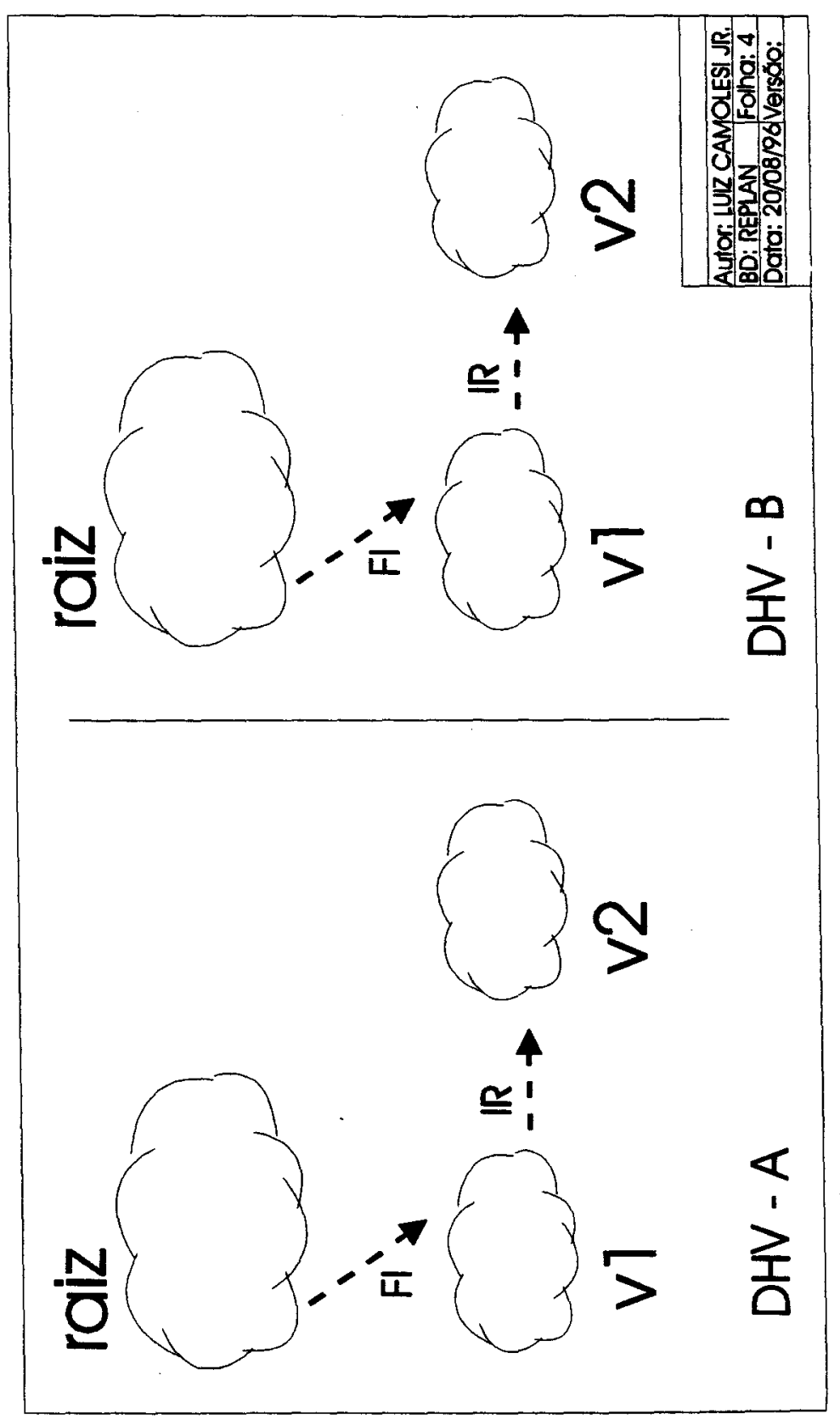


FOLHA 5 -:

DRO - Versão "Raiz" da Col. Suplementar A

Mostra a primeira Versão (raiz ou "noname") da Colônia Esquema Suplementar A. No diagrama desta versão, os Tipos Unid_ATM, Unid_VAC e Unid_CRA são referências aos seus genéricos na Colônia Esquema Suplementar $B$.

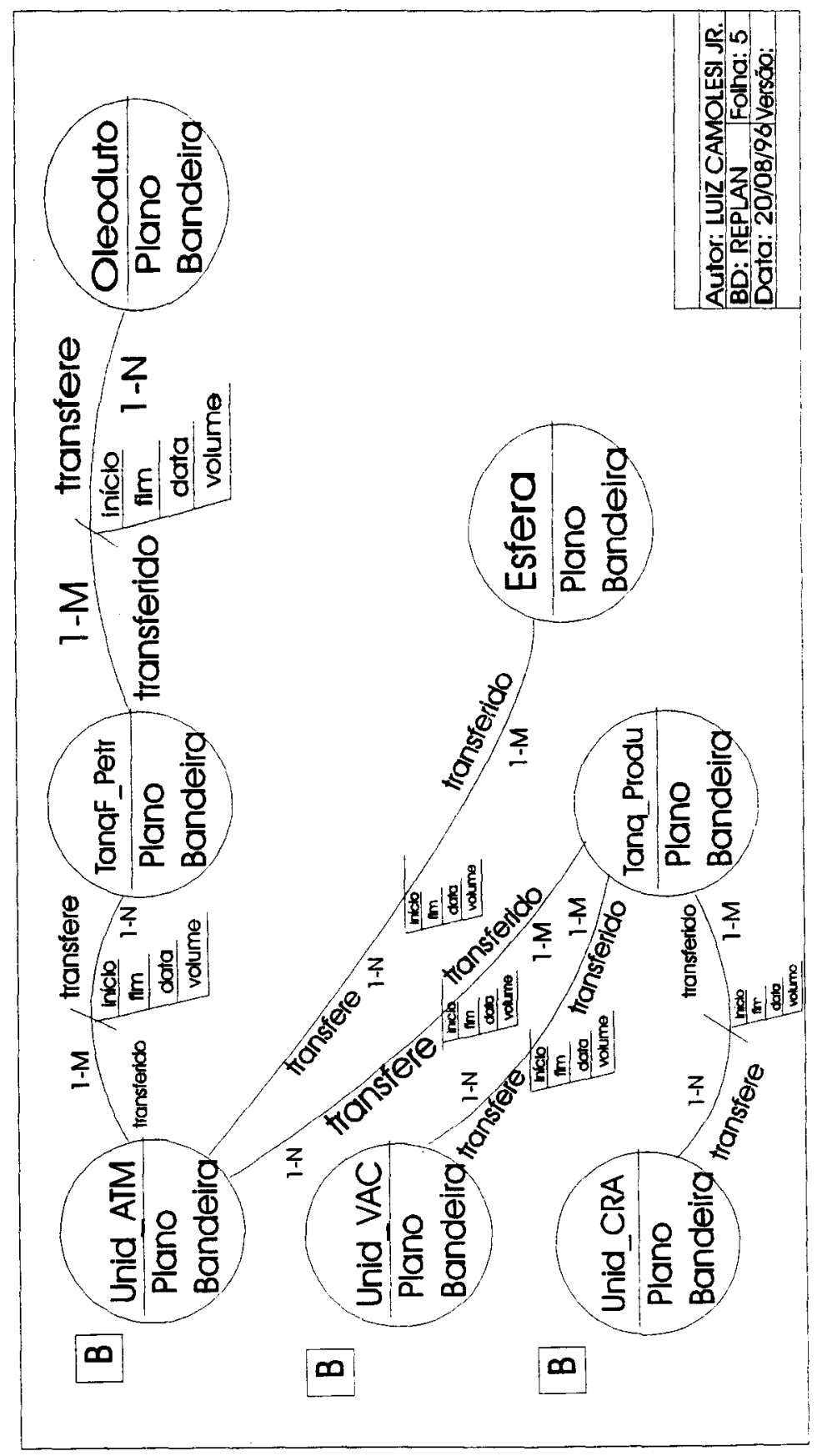



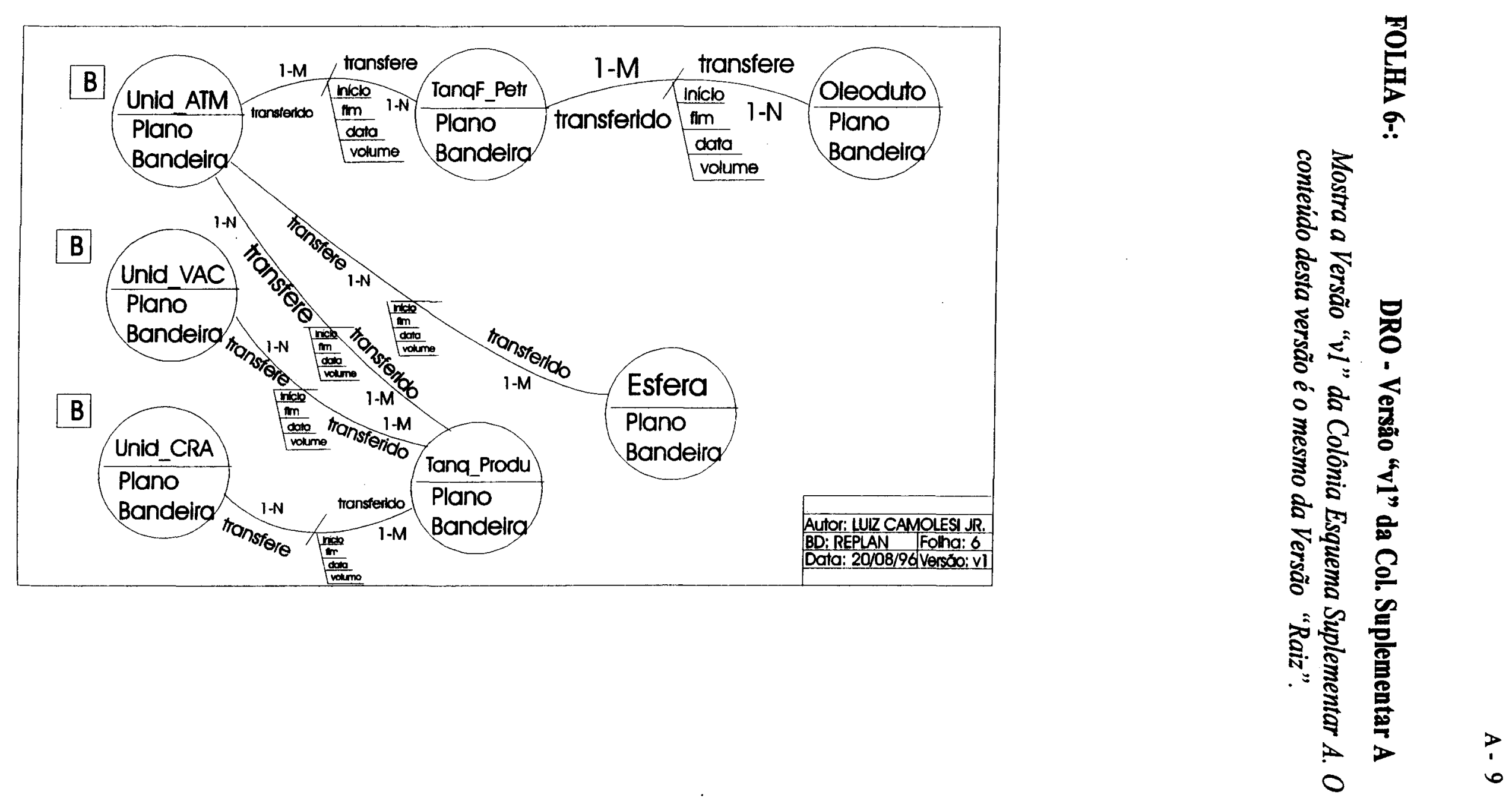
FOLHA 7-:

DRO - Versão "v2" da Col. Suplementar A

Mostra a Versão "v2" da Colônia Esquema Suplementar A. $O$ conteúdo desta versão difere da Versão " $v 1$ " pelo fato de conter o Tipo de Objeto TanquM_Petr (Tanques de petróleo com teto móvel) e seus relacionamentos.

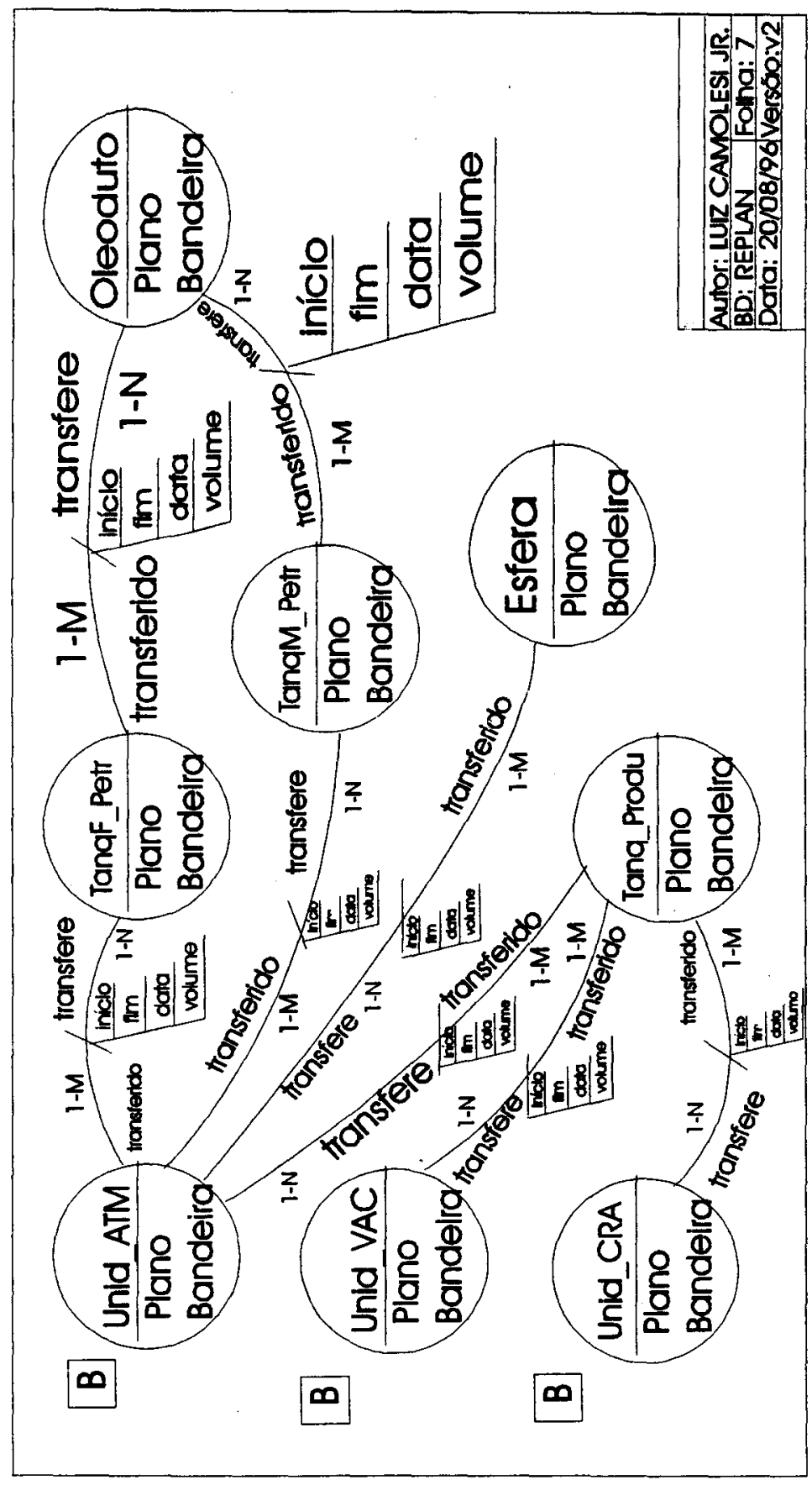


FOLHA 8-: DRO - Versão "Raiz" da Col. Suplementar B

Mostra a primeira Versão (raiz ou "noname") da Colônia Esquema Suplementar B. No diagrama desta versão, os Tipos Unid_ATM, Unid_VAC e Unid_CRA possuem relacionamentos entre si e existem referências a genéricos da Colônia Esquema Suplementar $A$.

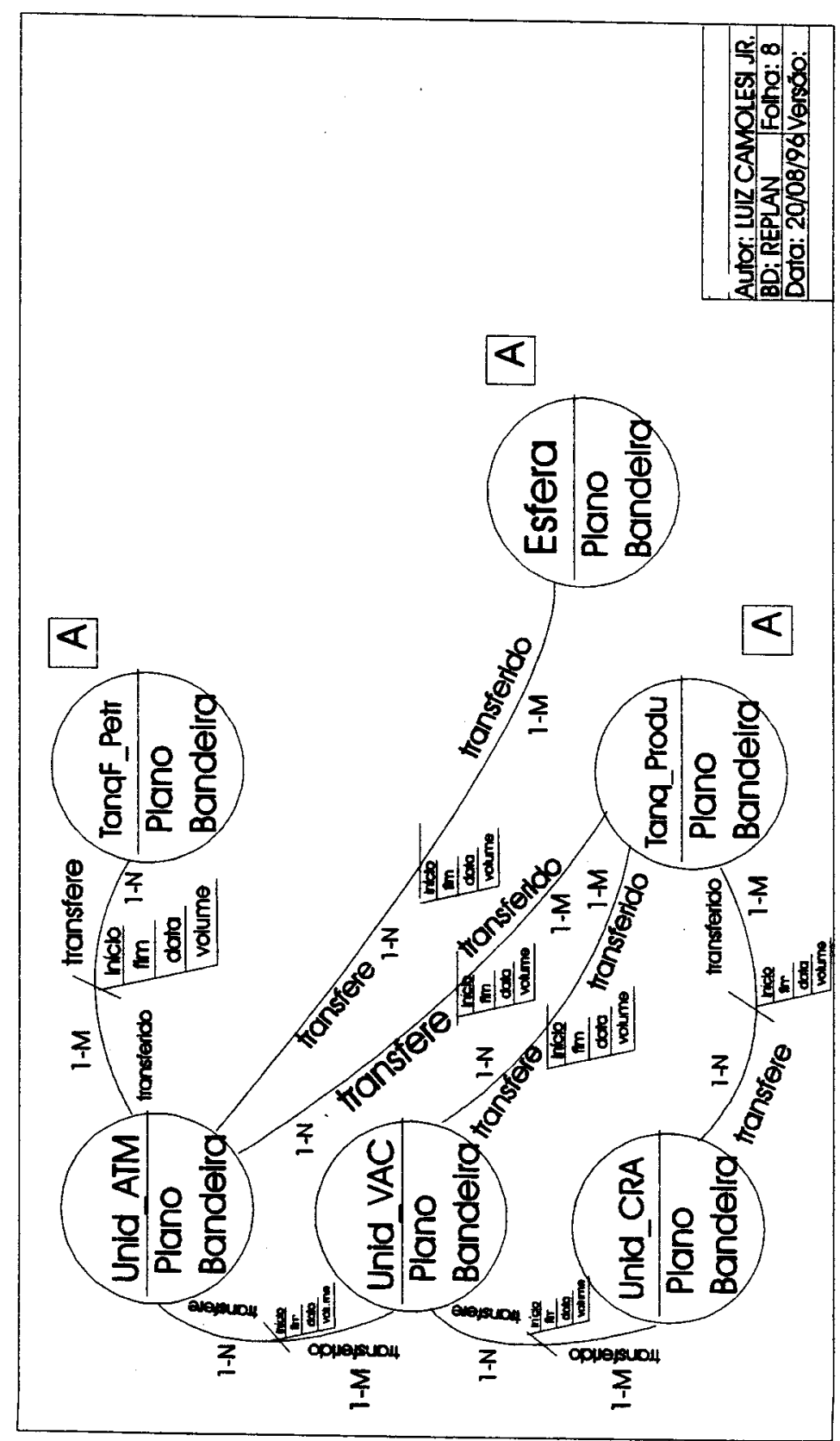




\section{FOLHA 9-: $\quad$ DRO - Versão "v1" da Col. Suplementar B}

Mostra a Versão "v1" da Colônia Esquema Suplementar B. $O$ conteúdo desta versão é o mesmo da Versão "Raiz".

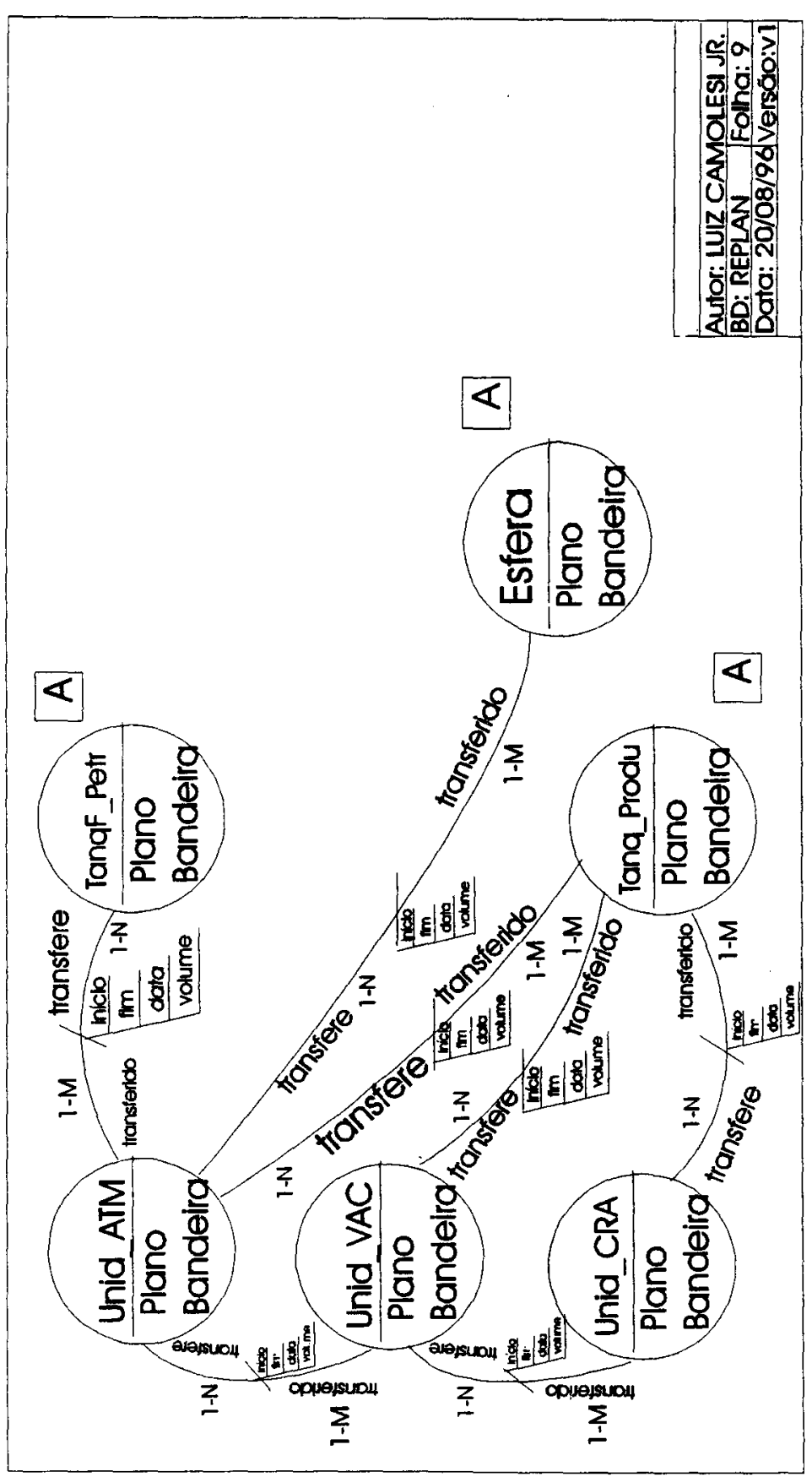




\section{FOLHA 10-: $\quad$ DRO - Versão "v2" da Col. Suplementar B}

Mostra a Versão "v2" da Colônia Esquema Suplementar B. O conteúdo desta versão difere da Versão "v1" pelo fato de existir um relacionamento com o Tipo de Objeto TanquM_Petr (Tanques de petróleo com teto móvel) definido na Versão "v2" da Colônia Esquema Suplementar A.

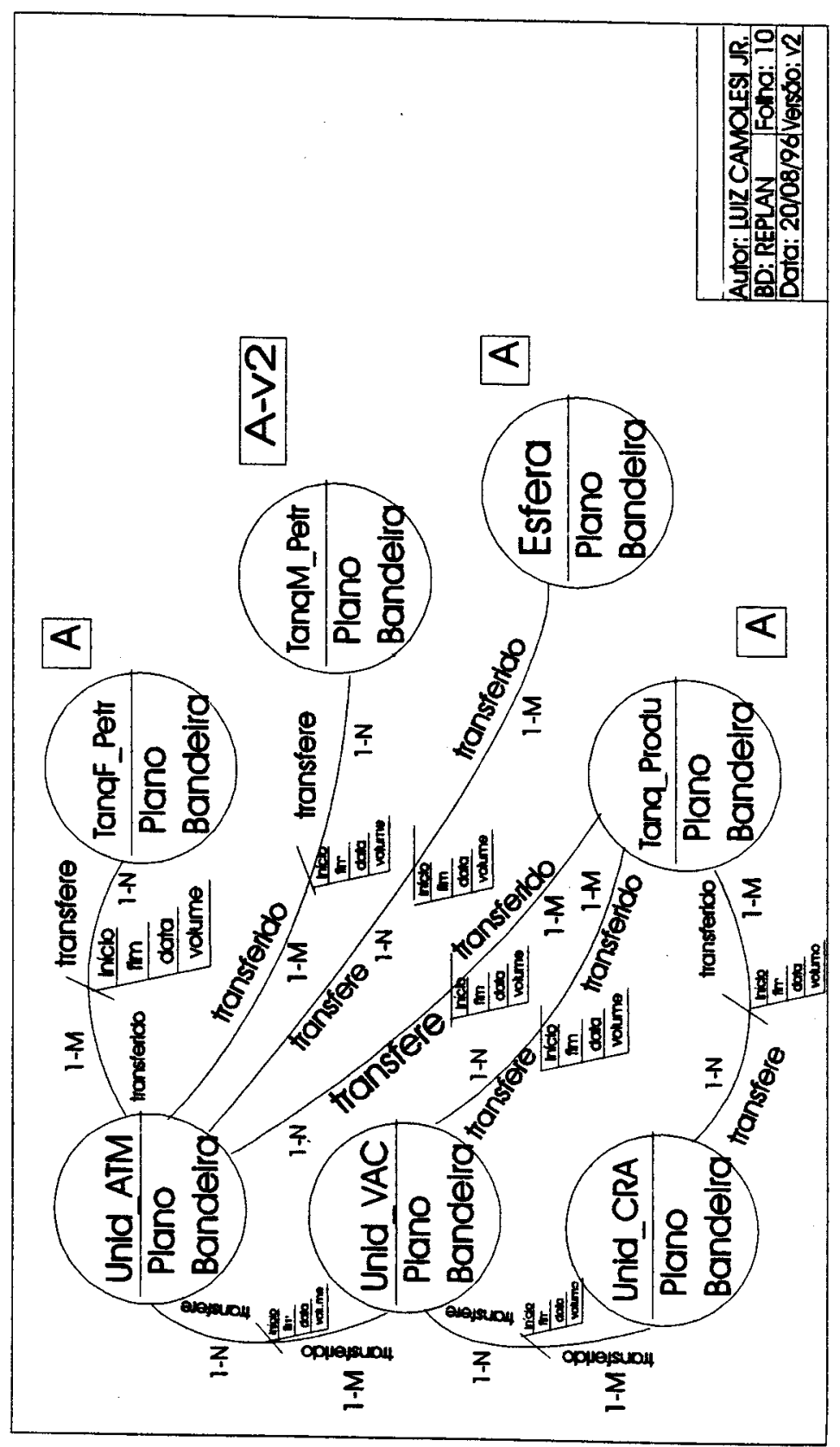




\section{APÊNDICE B}

\section{Exemplo de Utilização da LAMRO \\ - Programação de Campanhas -}

Nota:

Este apêndice mostra a utilização dos comandos da LAMRO para definição e manipulação de Versōes de Colônias. Os comandos apresentam-se agrupados e seguindo os diagramas do apêndice A que contém a representação de um exemplo de modelagem (programação de campanhas de produção de derivados de petróleo na REPLAN/ PETROBRÁS). 


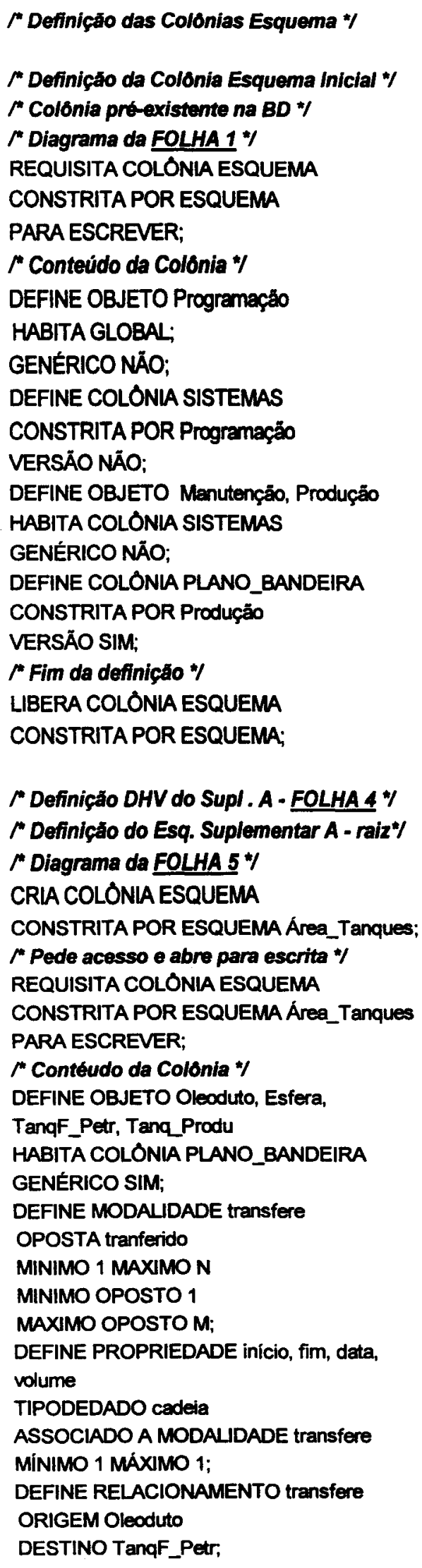

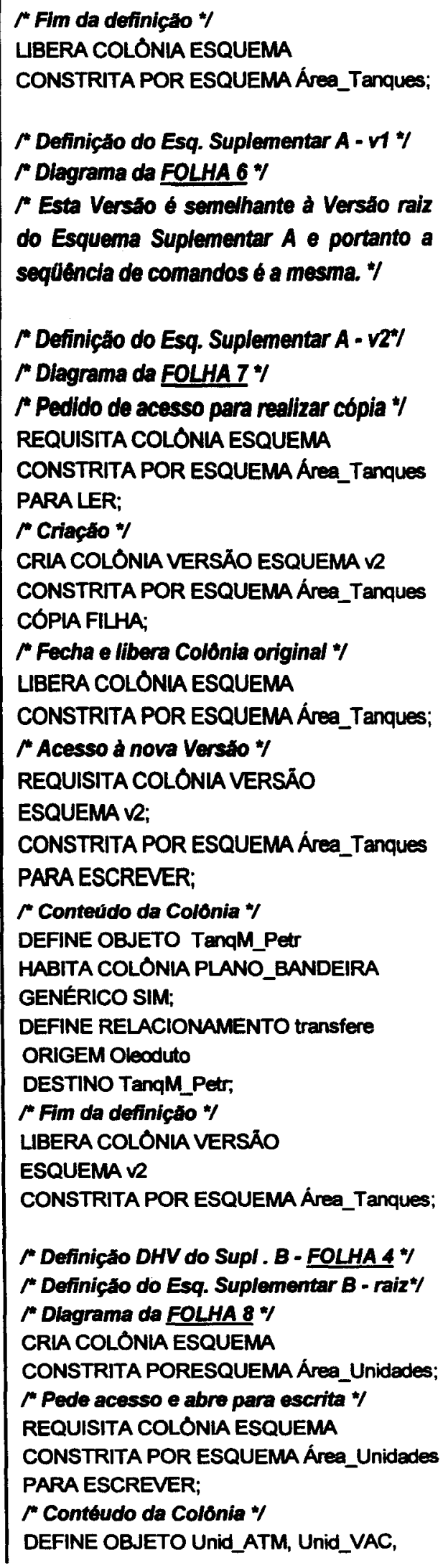


Unid_CRA

HABITA COLÓNIA PLANO_BANDEIRA

GENÉRICO SIM;

DEFINE RELACIONAMENTO transfere

ORIGEM TanqF_Petr

DESTINO Unid_ATM;

DEFINE RELACIONAMENTO transfere

ORIGEM Unid_ATM

DESTINO Esfere:

DEFINE RELACIONAMENTO transfere

ORIGEM Unid_ATM

DESTINO Tanqu_Produ;

DEFINE RELACIONAMENTO transfere

ORIGEM Unid ATM

DESTINO Unid VAC;

DEFINE RELACIONAMENTO transfere

ORIGEM Unid_VAC

DESTINO Unid_CRA:

DEFINE RELACIONAMENTO transfere

ORIGEM Unid_VAC

DESTINO Tanqu_Produ;

DEFINE RELACIONAMENTO transfere

ORIGEM Unid_CRA

DESTINO Tanqu_Produ;

" Fim da definiçáo"y

LIBERA COLÓNIA ESQUEMA

CONSTRITA PORESQUEMA Área_Unidades;

" Definicato do Esq. Suplementar B - v1 *

" Diagrama da FOLHA 9 "\%

* Esta Versto é semelhante à Versato raiz do Esquema Suplementar B a portanto a seqüencia de comandos 8 a mesma. */

" Definicăo do Esq. Suplementar B - V2"/

" Diagrama da FOLHA 10 \%

* Pedido de acesso para realizar cópia "/ REQUISITA COLONIA ESQUEMA

CONSTRITA POR ESQUEMA Area_Unidades

PARA LER;

"Crlaça *

CRIA COLÓNIA VERSAOO ESQUEMA $\checkmark$

CONSTRITA POR ESQUEMA Área_Unidades

CÓPIA FILHA;

"Focha e llbera Colonia original "/

LIBERA COLONIA ESQUEMA

CONSTRITA POR ESQUEMA Área_Unidades

" Acesso a nova Versato "\%

REQUISITA COLONIA VERSÄO

ESQUEMA V;

CONSTRITA POR ESQUEMA Áree_Unidades

PARA ESCREVER;
" Acesso a Versăo de A correlacionada " REQUISITA COLÓNIA VERSÄO

ESQUEMA R;

CONSTRITA POR ESQUEMA Área_Tanques

PARA ESCREVER;

DEFINE RELACIONAMENTO transfere

ORIGEM TanqM_Petr

DESTINO Unid_ATM;

* Fecha e llbera Versao do Supl. A *

UIBERA COLÓNIA VERSÄO

ESQUEMA V2

CONSTRITA POR ESQUEMAÁrea_Tanques;

F Fim da definiço *

LIBERA COLONIA VERSÃO

ESQUEMA 2

CONSTRITA PORESQUEMA Área_Unidades;

Pe Definicajo das Instancias "/

"Dlagrama da FOLHA $2 \%$

"Criacto de Objetos a Colonias */

CRLA OBJETO Programação 1996;

CRIA COLONIA SISTEMAS

CONSTRITA POR Programaçăo 1996:

REQUISITA COLÓNIA SISTEMAS

CONSTRITA POR Programação 1996

PARA ESCREVER;

CRIA OBJETO Produção Outubro;

CRIA COLÓNIA VERSÃO

PLANO BANDEIRA

CONSTRITA POR Produçäo Outubro:

" Diagrama da FOLHA 3 */

"* Utilizaça de Supl. p instanciaço */

REQUISITA COLONIA ESQUEMA

CONSTRITA POR ESQUEMAÁrea_Tanques

PARA INSTANCLAR;

- Utilizacto de Supl. para instanciaça "y REQUISITA COLONIA ESQUEMA

CONSTRITA POR ESQUEMA Area_Unidades PARA INSTANCLAR;

"Acessa a abre para inserir instancias"/ REQUISITA COLONIA PLANO_BANDEIRA CONSTRITA POR Produçăo Outubro PARA ESCREVER;

"Cria Versato raiz de PLANO_BANDEIRA *

CRIA OBJETO Unid_ATM U 200;

CRIA OBJETO TanqF_Petr T_4101;

INCLUI RELACIONAMENTO transfere

OBJETO Unid ATM U 200;

INCLUI ATRIBUTO inicio 08:00; 
INCLUI ATRIBUTO fim 11:20; INCLUI ATRIBUTO data 03/10/96; INCLUI ATRIBUTO volume 10000; CRIA OBJETO Oleoduto OSPLAN; INCLUI RELACIONAMENTO transfere OBJETO TanqF_Pet T_4101; INCLUI ATRIBUTO início 10:40; INCLUI ATRIBUTO fim 14:00; INCLUI ATRIBUTO data 01/10196; INCLUI ATRIBUTO volume 20000;

" Fim da instanciacto "\% LIBERA COLONIA PLANO_BANDEIRA CONSTRITA POR Produçăo Outubro;

"Cria Versaso "vi" de PLANO_BANDEIRA/ r Esta Versto é semelhante à Versto raiz da Colónia Plano_Bandeira e portanto a sequiência de comandos é a mesma. */

"Cria Versào "V2" de PLANO_BANDEIRA / "Pedido de acesso p/ realizar criagá * REQUISITA COLONIA PLANO_BANDEIRA CONSTRITA POR Produçāo Outubro PARA LER; " Crlaçáo de uma "Irmă" que năo é cópja */ CRIA COLONIA VERSÃO PLANO_BANDEIRA 2 CONSTRITA POR Produçāo Outubro IRMA;

F Fecha e libera Colonia original */ LBERA COLONIA PLANO_BANDEIRA CONSTRITA POR Produção Outubro;

P Acesso à nova Versto *y REQUISITA COLONIA VERSÃO PLANO_BANDEIRA V2; CONSTRITA POR Produçăo Outubro PARA ESCREVER;

"Crlaçáo de Objetos, atr. e relac. "y CRIA OBJETO Unid_ATM U_200A; CRIA OBJETO TanqF_Petr T_4126; INCLUI RELACIONAMENTO transfere OBJETO Unid_ATM U_200A. INCLUI ATRIBUTO início 08:00; INCLUI ATRIBUTO fim 12:00; INCLUI ATRIBUTO data 03/10/96; INCLUI ATRIBUTO volume 18000; CRIA OBJETO Oleoduto OSPLAN; INCLUI RELACIONAMENTO transfere OBJETO TanqF_Petr T_4126; INCLUI ATRIBUTO início 10:40; INCLUI ATRIBUTO fim 15:10; INCLUI ATRIBUTO data 01/10/96;
INCLUI ATRIBUTO volume 25000;

* Fim da instanciacho * UBERA COLONIA PLANO_BANDEIRA CONSTRITA POR Produçăo Outubro;

"Cria Versao "v3" de PLANO_BANDERA I

F Pedido de acesso para realizar copia */ REQUISITA COLONIA PLANO_BANDEIRA CONSTRITA POR Produçęo Outubro PARA LER;

"Criacto de uma "filha" * CRIA COLONIA VERSÃo

PLANO_BANDEIRA 3 CONSTRITA POR Produçāo Outubro CÓPIA FILHA;

" Fecha e libera Colonia original "\% LIBERA COLONIA PLANO_BANDEIRA CONSTRITA POR Produção Outubro; F Acesso à nova Versto * REQUISITA COLÓNIA VERSÃO PLANO BANDEIRA B; CONSTRITA POR Produçāo Outubro PARA ESCREVER;

"Criaçáo de Objetos, atr. a relac. "/ CRIA OBJETO Unid_VAC U_210; LOCALIZA OBJETO Unid_ATM U_200; INCLUI RELACIONAMENTO transfere OBJETO Unid_VAC U_210; INCLUI ATRIBUTO inicio 08:10; INCLUI ATRIBUTO fim 11:30; INCLUI ATRIBUTO data 03/10/96; INCLUI ATRIBUTO volume 5000; LIBERA COLONIA PLANO_BANDEIRA CONSTRITA POR Produçăo Outubro; " Libera Suplementar em uso * LIBERA COLONIA ESQUEMA CONSTRITA POR ESQUEMA Área_Tanques; "Libera Suplementar em uso * LIBERA COLONIA ESQUEMA CONSTRITA PORESQUEMA Área_Unidades; F Fim da instanclaçăo *I

/" Fim do comandos */ 


\section{APÊNDICE C}

\section{Manual de Referência \\ - Primitivas envolvendo Versões -}

\section{Nota:}

Este apêndice apresenta o manual das primitivas que envolvem Versões de Colônias em Bases de Dados criadas no GEO. Tais primitivas são executadas em comandos da Linguagem de Acesso do MRO* (LAMRO) e/ou podem ser utilizadas para desenvolvimento de aplicatioos.

As páginas deste manual seguem um padrĩo estabelecido pelo Grupo de Pesquisa do GEO. No cabeçalho de cada página, apresenta-se no canto superior esquerdo a funcionalidade geral da primitiva e no canto superior direito aparece ROTINA/Versão indicando a parte do manual do núcleo do GEO que corresponde às primitivas de atuação sobre Versões, ou ROTINA/Esquema indicando a parte do manual que corresponde às primitivas de consulta ao Esquema de Dados. 
NOME

ANVER - Requisita acesso a uma Versão

\section{SINOPSE}

pal2 ANVER (codver, tcol, pedido, concede)

codicol cod ver;

coditipo tcol.

pal2 pedido, ${ }^{*}$ concede;

\section{DESCRIÇÃO}

Esta rotina requisita o acesso de uma Versão de Colônia para uso posterior do usuário.

\section{RETORNO}

. concede indica concessão de acesso (vide NOTA). . erro (vide ERROS).

\section{RESTRIÇÕES}

deve existir um Objeto corrente constringindo a Colônia.

. deve existir a Versão de Colônia do tipo indicado.

. Não deve-se exceder o número máximo de requisiç̃̃es

\section{NOTA}

O valor de "pedido" pode ser:

GEO LE

0x0040

GEO LE ESCREVE

OxOFFF ou uma combinação de:

GEO CRIA OBJETO

$0 \times 0800$

GEO APAGA OBJETO

0x0400

GEO_CRIA_RELACIONAMENTO 0x0020

GEO_APAGA_RELACIONAMENTO 0x0010

GEO CRIA ATRIBUTO 0x0004

GEO_APAGA_ATRIBUTO 0x0002

\section{ERROS}

0 - obtido o acesso.

5 - código de tipo de Colônia é inválido.

6 - pedido de acesso não reconhecido.

7 - não existe objeto corrente.

39 - Colônia já está acessível.

40 - Objeto corrente não constringe esta Colônia.

300 - código de Versão de Colônia não existe.

501 - excedido o máximo de Colônias acessíveis.

711 - Problema com o gerenciador.

\section{VEJA TAMBÉM}

ZNVER, PNVER, XNVER em (ROTINA/Versão).

\section{EXEMPLO}

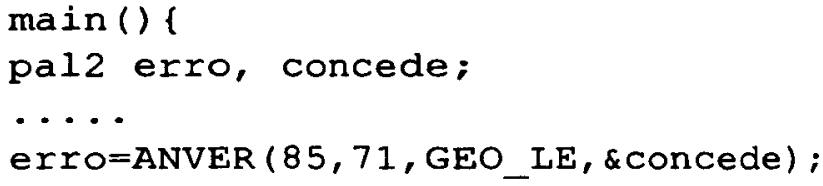


NOME

ZNVER - Libera acesso a uma Versão.

\section{SINOPSE}

pal2 ZNVER (co, tcol, codver)

codiobjeto co;

coditipo tcol;

codicol codver;

\section{DESCRIÇÃO}

Esta rotina libera o acesso de uma Versão de Colônia em uso pelo usuário.

\section{RETORNO}

. erro (vide ERROS).

\section{RESTRIÇÕES}

. a Versão deve estar fechada.

. a Versão deve estar acessível.

- deve existir a Versão de Colônia do tipo indicado.

. Objeto indicado deve constringir a Colônia indicada.

\section{NOTA}

Uma Versão para ser liberada deve ter sido requisitada para acesso anteriormente e estar fechada (não utilizada no presente momento)

\section{ERROS}

0 - liberação bem sucedida.

5 - código de tipo de Colônia é inválido.

27 - Versão não está acessível.

41 - Versão está aberta.

711 - Problema com o gerenciador.

\section{VEJA TAMBÉM}

ANVER, PNVER e XNVER em (ROTINA/Versăo).

\section{EXEMPLO}

$\operatorname{main}()$

1

pal2 erro, concede;

coditipo tcol;

codiobjeto co;

codicol codver;

.....

codver $=85$

/*Requisita Versão 85 */

erro=ANVER (codver, 71, GEO_LE, \&concede);

....$$
\cdots \cdots
$$

/*Liberar Versão 85 do obj. corrente*/

erro $=\operatorname{BNOBJ}(\& \mathrm{CO})$;

erro= BDVER (codver, \& tcol);

erro $=\operatorname{ZNVER}(\mathrm{co}, \mathrm{tcol}, \mathrm{codver})$

… 
NOME

PNVER - Abre acesso corrente a uma Versão.

\section{SINOPSE}

pal2 PNVER (co, tcol, codver)

codiobjeto $\mathrm{co}$.

coditipo tcol;

codicol codver;

\section{DESCRIÇÃO}

Esta rotina abre uma Versão de Colônia para utilização corrente de um usuário.

\section{RETORNO}

. erro (vide ERROS).

\section{RESTRIÇÕES}

. a Versão deve estar acessível.

deve existir a Versão de Colônia do tipo indicado.

. Objeto indicado deve constringir a Colônia indicada.

\section{NOTA}

Apenas uma Versão de cada Tipo de Colônia pode estar aberta ao mesmo tempo. Qualquer Versão de mesmo tipo ou hierarquicamente dependente será automaticamente fechada.

\section{ERROS}

0 - abertura bem sucedida.

5 - código de tipo de Colônia é inválido.

27 - Versão não está acessível.

711 - Problema com o gerenciador.

\section{VEJA TAMBÉM}

ANVER, ZNVER e XNVER em (ROTINA/Versão).

\section{EXEMPLO}

main ()

pal2 erro, concede;

coditipo tcol;

codiobjeto co;

codicol codver;

.....

codver $=85$

/*Requisita Versão $85 * /$

erro=ANVER (codver, 71, GEO_LE, \&concede) :

….

/*Abrir Versão 85 do objeto corrente*/

erro $=$ BNOBJ $(\& C O)$;

erro= BDVER (codver, \&tcol);

erro $=\operatorname{PNVER}(c o$, tcol, codver $)$; 
NOME

XNVER - Fecha acesso corrente a uma Versão.

\section{SINOPSE}

pal2 XNVER (tcol)

coditipo tcol;

\section{DESCRIÇÃO}

Esta rotina fecha uma Versão de Colônia em utilização corrente por um usuário.

\section{RETORNO}

. erro (vide ERROS).

\section{RESTRIÇÕES}

. deve existir a Versão aberta de Colônia do tipo indicado.

\section{NOTA}

Todas as Versð̋es hierarquicamente dependente serão automaticamente fechada.

\section{ERROS}

0 - fechamento bem sucedido.

5 - código de tipo de Colônia é inválido.

28 - não existe Versão aberta deste tipo.

711 - Problema com o gerenciador.

\section{VEJA TAMBÉM}

ANVER, ZNVER e PNVER em (ROTINA/Versão).

\section{EXEMPLO}

$\operatorname{main}()$

1

pal2 erro, concede;

coditipo tcol:

codiobjeto co:

codicol codver;

......

codver $=85$;

$/{ }^{*}$ Requisita Versão $85 * /$

erro=ANVER (codver, 71, GEO LE, \& concede) ;

$\ldots$

/*Abrir Versão 85 do objeto corrente*/

erro $=\mathrm{BNOBJ}(\& \mathrm{CO})$;

erro= BDVER (codver, \& tcol);

erro $=\operatorname{PNVER}(\mathrm{co}, \mathrm{tcol}, \mathrm{codver})$;

$\ldots$

(*Fechar Versão 85*/

erro $=\operatorname{XNVER}($ tcol $)$;

$\ldots \ldots$

/*Liberar Versão 85 */

erro $=$ ZNVER $(c o$, tcol, codver $)$; 
NOME

TBVER - Inicia busca pelas "irmãs" de uma Versão.

\section{SINOPSE}

pal2 TBVER (ccol, tcol, co,bccol)

coditipo tcol

codiobjeto co

codicol ccol, *bccol;

\section{DESCRIÇÃO}

Esta rotina inicia a busca pela “irmãs" da Colônia indicada.

\section{RETORNO}

. bccol - código da primeira "irmã” da Versão indicada. . erro (vide ERROS).

\section{RESTRIÇÕES}

. o Objeto indicado deve constringir a Versão indicada.

\section{NOTA}

Uma Árvore de Derivação se estabelece através de relaç̃̃es de dependência, denominadas "irmã" ou "filha", entre as Versões de uma certa Colônia.

O início da busca pelas 'irmãs" de uma Versão representa o interesse em percorrer todos os relacionamento implícitos deste tipo da Versão indicada.
A "irmã" retornada em bccol pode não existir como pode ser a primeira de uma seqüência.

\section{ERROS}

0 - busca bem sucedida.

5 - código de tipo de Colônia é inválido.

30 - código de Objeto inválido

40 - Objeto não constringe esta Colônia.

300 - código de Versão inicial não existe

711 - Problema com o gerenciador.

\section{VEJA TAMBÉM}

TCVER e VNVER em (ROTINA/Versão).

\section{EXEMPLO}

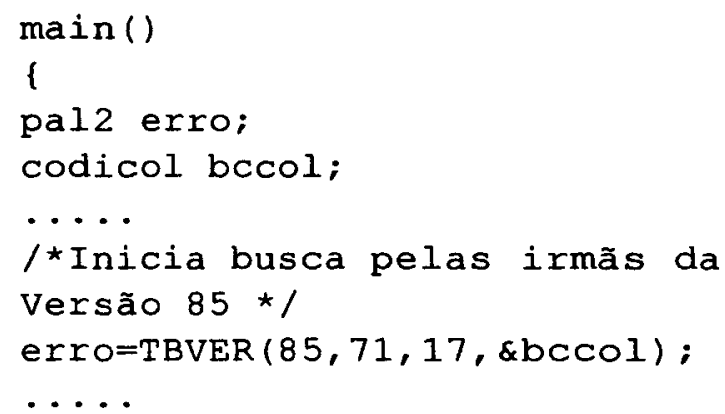




\section{NOME}

TCVER - Inicia busca pelas "filhas" de uma Versão.

\section{SINOPSE}

pal2 TCVER (ccol, tcol, co, bccol)

coditipo tcol;

codiobjeto co;

codicol ccol, ${ }^{\star b}$ bcol;

\section{DESCRIÇÃO}

Esta rotina inicia a busca pela "filhas" da Colônia indicada.

\section{RETORNO}

. bccol - código da primeira "filha" da Versão indicada. . erro (vide ERROS).

\section{RESTRIÇÕES}

. o Objeto indicado deve constringir a Versão indicada.

NOTA

Uma Árvore de Derivação se estabelece através de relações de dependência, denominadas "irmã" ou "filha", entre as Versões de uma certa Colônia.

O início da busca pelas "filhas" de uma Versão representa o interesse em percorrer todos os relacionamento implícitos deste tipo da Versão indicada.
A "filha" retornada em bccol pode não existir como pode ser a primeira de uma sequiência.

\section{ERROS}

0 - busca bem sucedida.

5 - código de tipo de Colônia é inválido.

30 - código de Objeto inválido

40 - Objeto não constringe esta Colônia.

300 - código de Versão inicial não existe

711 - Problema com o gerenciador.

\section{VEJA TAMBÉM}

TBVER e VNVER em (ROTINA/Versão).

\section{EXEMPLO}

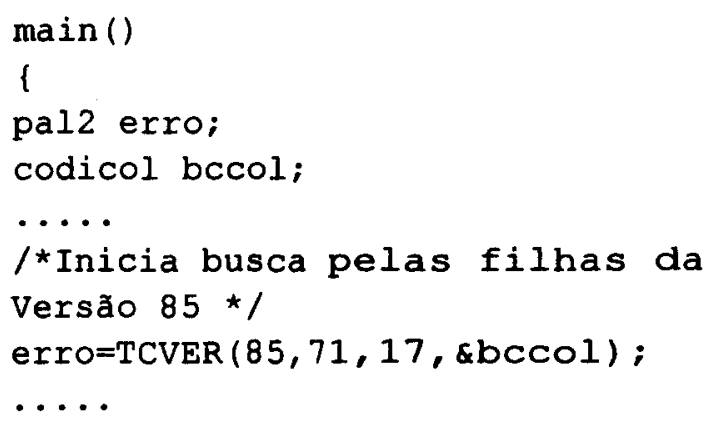


NOME

VNVER - Avança a busca para a próxima Versão.

\section{SINOPSE}

pal2 VNVER (ccol, tcol, bccol)

coditipo tcol;

codicol ccol, ${ }^{\star b c c o l}$

\section{DESCRIÇÃO}

Esta rotina avança na busca da próxima Versão (filha ou irmã) daquela indicada.

\section{RETORNO}

bccol - código da próxima Versão.

erro (vide ERROS)

\section{RESTRIÇÕES}

\section{NOTA}

Uma Árvore de Derivação se estabelece através de relações de dependência, denominadas "irmã" ou "filha", entre as Versões de uma certa Colônia.

A próxima Versão, retornada em bccol, será "irmã" ou "filha" da Colônia inicialmente indicada em TBVER ou TCVER, respectivamente.

\section{ERROS}

O - busca bem sucedida.

5 - código de tipo de Colônia é inválido.

300 - código de Versão inicial não existe

711 - Problema com o gerenciador.

\section{VEJA TAMBÉM}

TBVER e TCVER em (ROTINA/Versão).

\section{EXEMPLO}

main()

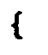

pal2 erro;

codicol ccol, bccol;

…

*Inicia busca pelas filhas da

Versão $85 * 1$

$\mathrm{CCOl}=85$;

erro=TCVER (ccol, 71, 17, \&bccol);

do 1

....

ccol=bccol ;

/* Avança p/ próxima filha da

Versão $85 \star /$

VNVER (ccol, 71, \&bccol);

\} while (erro $=0)$ ) 
NOME

NAVER - Colocar o nome principal de uma Versão.

\section{SINOPSE}

pal2 NAVER (codver, tcol, co, nome)

coditipo tcol;

codiobjeto co:

codicol codver;

cadeia nome;

\section{DESCRIÇÃO}

Esta rotina estabelece o nome principal de uma Versão.

\section{RETORNO}

erro (vide ERROS)

\section{RESTRIÇÕES}

. O Objeto indicado deve constringir a Versão indicada.

\section{NOTA}

O nome de uma Versão é composto de 6 caracteres e pode ser tanto uma cadeia normal (formato padrão CCMX\&CO - cadeia com campo tamanho máximo e corrente) quanto uma cadeia formato "-.".

Mesmo a Versão já tendo um nome, este será substituído pelo novo nome indicado.

\section{ERROS}

0 - operação bem sucedida.

5 - código de tipo de Colônia é inválido.

30 - código de Objeto inválido

40 - Objeto nã̀o constringe esta Colônia.

300 - código de Versão não existe

303 - nome já existe na(s) Árvore(s) de Derivaçåo.

711 - Problema com o gerenciador.

\section{VEJA TAMBÉM}

MNVER em (ROTINA/Versão).

\section{EXEMPLO}

main()

1

pal2 erro;

cadeia nome;

.....

nome $=$ "-.v1";

erro $=\operatorname{NAVER}(85,71,17$, nome $)$; 
NOME

MNVER - Muda o nome principal de uma Versão.

SINOPSE

pal2 MNVER (codver, tcol, co, nome)

coditipo tcoli

codiobjeto co;

codicol codver;

cadeia nome

\section{DESCRIÇÃo}

Esta rotina estabelece um novo nome principal para uma Versão.

\section{RETORNO}

erro (vide ERROS).

\section{RESTRIÇÕES}

o Objeto indicado deve constringir a Versão indicada.

\section{NOTA}

O nome de uma Versão é composto de 6 caracteres e pode ser tanto uma cadeia normal (formato padrão CCMX\&CO - cadeia com campo tamanho máximo e corrente) quanto uma cadeia formato "-.".

Mesmo a Versão já tendo um nome, este será substituído pelo novo nome indicado.

\section{ERROS}

0 - operação bem sucedida.

5 - código de tipo de Colônia é inválido.

30 - código de Objeto inválido

40 - Objeto não constringe esta Colônia.

300 - código de Versão não existe

303 - nome já existe na(s) Árvore(s) de Derivação.

711 - Problema com o gerenciador.

\section{VEJA TAMBÉM}

NAVER em (ROTINA/Versão).

\section{EXEMPLO}

main ()

1

pal2 erro;

cadeia nome;

.....

nome $=$ "-.v1";

erro $=\operatorname{MNVER}(85,71,17$, nome );

… 
NOME

CTVER - Cria uma Versão.

\section{SINOPSE}

pal2 CTVER (ccol, parente, copia, codver) codicol ccol, ${ }^{\star}$ codver;

pal2 parente, copia

\section{DESCRIÇÃO}

Esta rotina cria uma Versão de Colônia (codver) cujo tipo é o mesmo da Colônia original (ccol).

\section{RETORNO}

. codver

erro (vide ERROS)

\section{RESTRIÇÕES}

. a Colônia original deve estar aberta.

- o Objeto corrente deve constringir a Colônia original.

. a Colônia original deve ser do tipo "versionable".

\section{NOTA}

O valor de "parente" pode ser:

1 cria-se uma FILHA da Versão original

2 cria-se uma IRMÃ da Versão original
O valor de "copia" pode ser:

1 a Versão é criada contendo uma cópia e todos os Objetos da Versão original.

2 a Versão é criada vazia.

\section{ERROS}

0 - fechamento bem sucedido.

7 - não existe objeto corrente.

28- Colônia original não está aberta

300 - código de Versão de Colônia não existe.

301 - Tipo de Colônia "non-versionable".

711 - Problema com o gerenciador.

\section{VEJA TAMBÉM}

CPVER em (ROTINA/Versão).

\section{EXEMPLO}

main ()

1

pal2 erro;

codicol ccol, codver;

/*Cria uma Versão da Colônia Aberta*/

erro=CTVER (ccol, 1, 1, codver):

/*Versão é filha da Colônia Aberta */

..... 


\section{NOME}

CPVER - Copia uma Versão.

\section{SINOPSE}

pal2 CPVER (tcol, codver_ori, codver_des)

coditipo tcol;

codicol codver_ori, codver_des;

\section{DESCRIÇÃO}

Esta rotina copia os objetos de uma Versão de Colônia (codver_ori) em outra Versão de Colônia (codver_des).

\section{RETORNO}

. erro (vide ERROS).

\section{RESTRIÇÕES}

as Colônias origem e destino devem ser de mesmo tipo.

a Colônia destino deve existir.

o Objeto corrente deve constringir a Colônia original.

a Colônia original deve ser do tipo "versionable".

NOTA

Não estabelece relaçăo de parentesco entre as Colônias. É realizada a duplicação de todos os Objetos contidos na Colônia original mas não de seus atributos e relac.. Objetos duplicados possuem os mesmos nomes/sinônimos porém códigos de identificação (oid) diferentes.

\section{ERROS}

0 - cópia bem sucedida.

5 - código de tipo de Colônia é inválido.

7 - não existe objeto corrente.

40 - Objeto corrente não constringe esta Colônia. 300 - código de Versão de Colônia não existe.

301 - Tipo de Colônia "non-versionable".

711 - Problema com o gerenciador.

\section{VEJA TAMBÉM}

CTVER em (ROTINA/Versão).

\section{EXEMPLO}

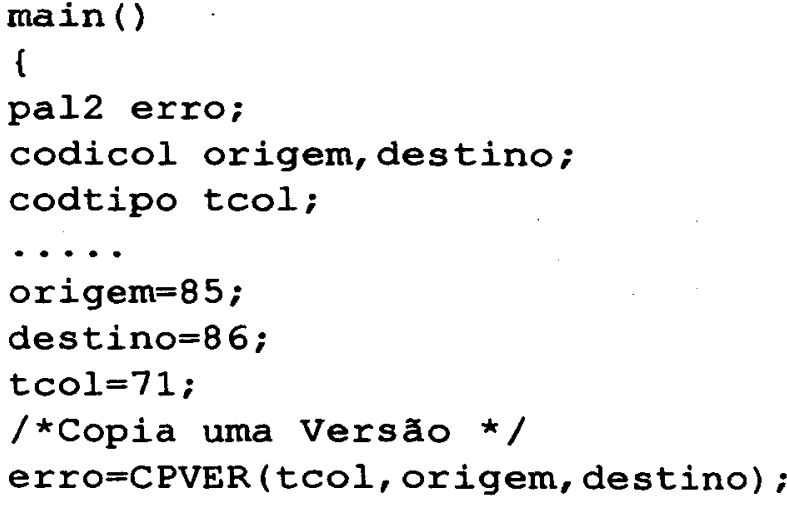




\section{NOME}

RNVER - Remove uma Versão Aberta

\section{SINOPSE}

pal2 RNVER (tcol)

coditipo tcol;

\section{DESCRIÇÃO}

Esta rotina remove uma Versão do tipo indicado.

\section{RETORNO}

. erro (vide ERROS).

\section{RESTRIÇÕES}

. o Objeto corrente deve constringir a Colônia p/ remoção

. a Versão de Colônia deve estar aberta.

. a Versão não pode ter filhas na Árvore de Derivação.

. a Versão não pode ter relac. com outras Colônias.

\section{NOTA}

A remoção de Colônias envolve verificações de dependências na Hierarquia de Composição e na Hierarquia de Derivaçðes.

Devido a complexidade e variaços com que se apresentam estas dependências, o algoritmo para remoção foi pouco estudado e parcialmente implementado.

\section{ERROS}

0 - remoção bem sucedida.

5 - código de tipo de Colônia é inválido.

7 - não existe objeto corrente.

28- não existe Colônia aberta deste tipo.

40 - Objeto corrente não constringe esta Colônia.

302 - Versão possui dependências.

711 - Problema com o gerenciador.

1000- Remoção não permitida

\section{VEJA TAMBÉM}

CTVER em (ROTINA/Versão).

\section{EXEMPLO}

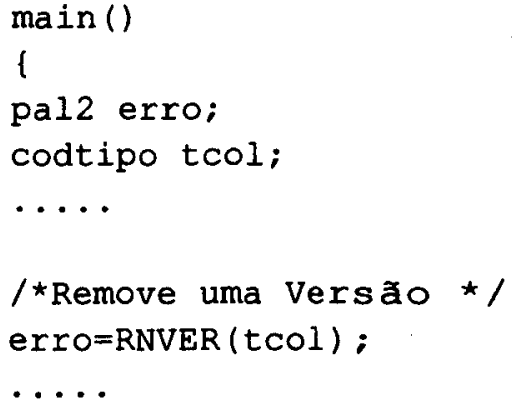


NOME

GEVER - Retira referência ao genérico.

\section{SINOPSE}

pal2 GEVER ()

\section{DESCRIÇÃO}

Esta rotina retira a referência ao objeto genérico que possa existir no objeto corrente.

\section{RETORNO}

erro (vide ERROS)

\section{RESTRIÇÕES}

. o Objeto deve estar corrente.

. o Tipo do Objeto deve permitir instâncias cujo papel seja de "objeto genérico"

\section{NOTA}

Um objeto genérico contem uma lista de atributos e relacionamentos que podem ser utilizados pelo objeto corrente. Caso estas listas não sejam de interesse dos usuários, pode-se retirar a referência ao genérico respectivo, de modo que, o Objeto corrente apresente apenas os atributos e relacionamentos especificamente atribuídos a ele.
ERROS

- não há erro.

7 - não existe objeto corrente.

307 - Objeto não possui genérico

711 - Problema com o gerenciador.

\section{VEJA TAMBÉM}

GenOBJ em (ROTINA/Esquema)

\section{EXEMPLO}

main()

1

pal2 erro:

codiobjeto co;

-...

$\mathrm{CO}=90$;

/* Tornar Objeto 90 corrente */

erro $=$ PNOBJ $(\mathrm{CO})$;

/* Retirar referência ao genérico */ erro = GEVER(); 
NOME

ESVER - Estabiliza uma Versão.

\section{SINOPSE}

pal2 ESVER (codver, tcol, co)

coditipo tcol;

codicol codver

codiobjeto co;

\section{DESCRIÇÃO}

Esta rotina estabiliza uma Versão "instável" indicada pelo seu código, tipo e Objeto que a constringe.

\section{RETORNO}

. erro (vide ERROS).

\section{RESTRIÇÕES}

. a Versão deve ser do Tipo indicado.

. o Objeto deve constringir a Versão indicada.

\section{NOTA}

Estabilizar um Versão consiste em alterar seu "estado" para conter o valor 1.

\section{ERROS}

0 - não há erro.

5 - código de tipo de Colônia é inválido.

30 - código de Objeto inválido.

40 - Objeto não constringe esta Colônia.

300 - código de Versão inválido.

306 - Versão encontra-se estável

711 - Problema com o gerenciador.

\section{VEJA TAMBÉM}

BFVER em (ROTINA/Versão)

\section{EXEMPLO}

main() 1

pal2 erro;

coditipo tcol;

codiobjeto co;

cadeia nome;

pal2 estado;

.....

/*Obter O tipo da Versão $85 * /$

erro $=\operatorname{BDVER}(85, \&$ tcol $)$;

/*obter código do objeto corrente */

erro $=$ BNOBJ $(\& \mathrm{CO})$;

/*Obter nome e estado */

erro $=\operatorname{BFVER}(t c o l, 85, \mathrm{co}$, nome, sestado);

if (estado $==0$ ) 
NOME

BAVER - Obtém código da primeira Versão.

\section{SINOPSE}

pal2 BAVER (tcol, co, codver)

coditipo tcol

codiobjeto co;

codicol *codver;

\section{DESCRIÇÃO}

Esta rotina obtém o código da primeira Versão do Tipo indicado do objeto especificado.

\section{RETORNO}

codver

erro (vide ERROS)

\section{RESTRIÇÕES}

o Objeto deve constringir a Colônia do Tipo indicado

\section{NOTA}

O código retornado corresponde à primeira Versão do tipo indicado que foi criada no objeto especificado.

A primeira Versão não possui um nome especifico atribuído pelo usuário, mas um nome padrão ("NONAME") definido pelo sistema.

\section{ERROS}

0 - não há erro.

5 - código de tipo de Colônia é inválido.

30 - código de Objeto inválido.

40 - Objeto nåo constringe esta Colônia.

304 - Objeto não possui Versão deste tipo.

711 - Problema com o gerenciador.

\section{VEJA TAMBÉM}

BDVER em (ROTINA/Versão)

\section{EXEMPLO}

main ()
pal2 erro;

coditipo tcol

codiobjeto co;

codicol codver;

….

$\operatorname{tcol}=71$

1*Obter oódigo do objeto corrente */

erro $=\operatorname{BNOBJ}(\& \mathrm{CO})$,

/*Obter código da primeira versão do tipo $71 * 1$

erro $=\operatorname{BAVER}($ tcol, co, \&codver $)$;

…… 


\section{NOME}

BCVER - Obtém o código de uma Versão.

\section{SINOPSE}

pal2 BCVER (tcol, co, nome, codver)

coditipo tcol;

codiobjeto co;

cadeia nome;

codicol ${ }^{\star}$ codver;

\section{DESCRIÇÃO}

Esta rotina obtém o código do tipo de uma Versão quando fornecido o seu nome, tipo e objeto que a constringe.

\section{RETORNO}

. codver

. erro (vide ERROS).

\section{RESTRIÇÕES}

. o Objeto deve constringir a Colônia do Tipo indicado

\section{NOTA}

Não é necessário que a Versão esteja acessível/ou aberta. O nome de uma Versão está limitado a 6 caracteres e pode ser tanto uma cadeia normal (formato padrão CCMX\&CO - cadeia com campo tamanho máximo e corrente) quanto uma cadeia formato "-.".

\section{ERROS}

0 - não há erro.

5 - código de tipo de Colônia é inválido.

30 - código de Objeto inválido.

40 - Objeto não constringe esta Colônia. 304 - Objeto não possui Versão deste tipo.

305 - Não existe Versão com este nome.

711 - Problema com o gerenciador.

\section{VEJA TAMBÉM}

BAVER e BDVER em (ROTINA/Versão).

\section{EXEMPLO}

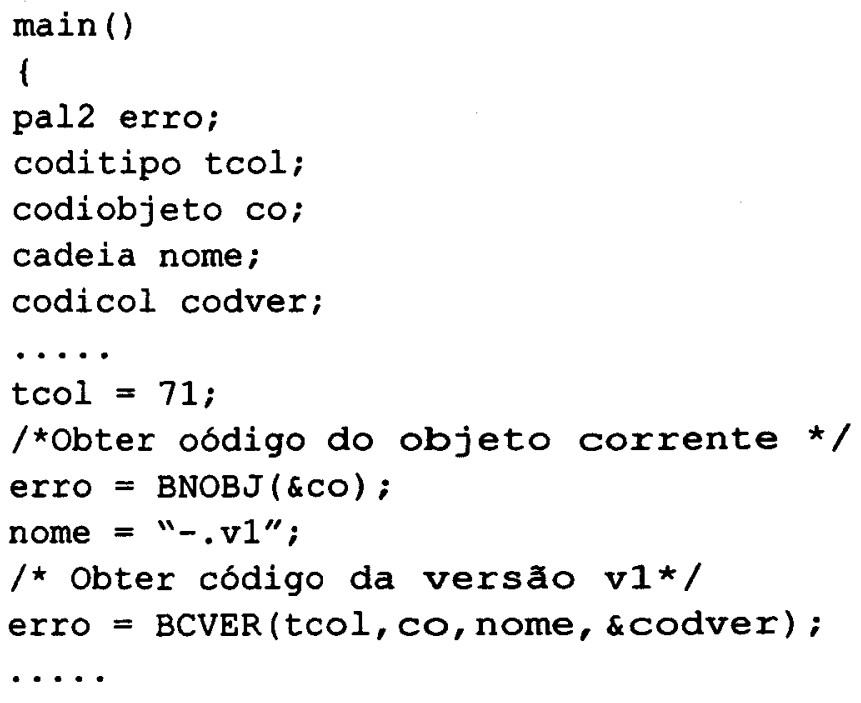


NOME

BDVER - Obtém o código do tipo de uma Versão.

SINOPSE

pal2 BDVER (codver, tcol)

coditipo *tcol;

codicol codver;

\section{DESCRIÇÃO}

Esta rotina obtém o código do tipo de uma Versão de Colônia indicada.

\section{RETORNO}

.tcol

erro (vide ERROS)

\section{RESTRIÇÕES}

NOTA

Não é necessário que a Versão esteja acessível/ou aberta e nem que o objeto corrente constrinja esta Versão.

\section{ERROS}

0 - não há erro.

300 - código de Versão inválido.
711 - Problema com o gerenciador.

\section{VEJA TAMBÉM}

BAVER em (ROTINA/Versão).

\section{EXEMPLO}

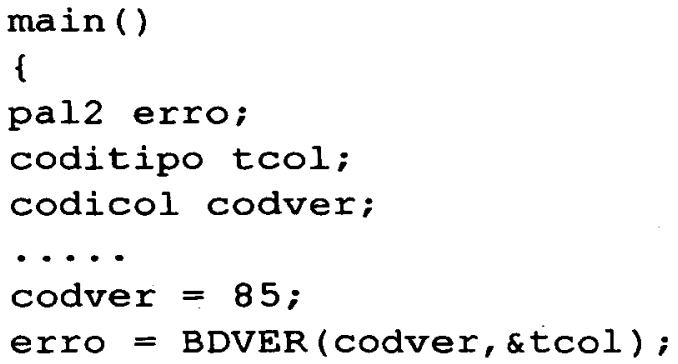


NOME

BFVER - Obtém o estado e o nome de uma Versão.

\section{SINOPSE}

pal2 BFVER (tcol, codver, co, nome, estado)

coditipo tcol;

codicol codver;

codiobjeto co:

cadeia nome;

pal2 *estado;

\section{DESCRIÇÃO}

Esta rotina obtém o nome e o estado de uma Versão indicada pelo seu tipo, código e objeto que a constringe.

\section{RETORNO}

. nome

- estado - recebe o valor 0 ou 1 dependendo da Versão estar "instável" ou "estável" respectivamente. . erro (vide ERROS)

\section{RESTRIÇÕES}

. o Objeto deve constringir a Colônia indicada.
O nome da Versão desejada pode ter sido atribuído pelo usuário, ou pode ser o nome padrão ("NONAME") definido pelo sistema.

\section{ERROS}

0 - não há erro.

5 - código de tipo de Colônia é inválido.

30 - código de Objeto inválido.

40 - Objeto não constringe esta Colônia.

300 - código de Versăo inválido.

711 - Problema com o gerenciador.

\section{VEJA TAMBÉM}

BAVER e BCVER em (ROTINA/Versão)

\section{EXEMPLO}

main() 1

pal2 estado, err;

coditipo tcol;

codicol codver;

codiobjeto co;

cadeia nome;

codver $=85$;

*obter o tipo da Versão $85 *$

err $=\operatorname{BDVER}($ codver, \&tcol);

/*Obter código do objeto corrente */

err $=$ BNOBJ $(\& \mathrm{CO})$;

$/$ obter nome e estado */

err $=B$ BVER (tcol, codver, co, nome, sestado); 
NOME

BNVER - Obtém o código de uma Versão aberta.

\section{SINOPSE}

pal2 BNVER (tcol, codver)

coditipo tcol;

codicol *codver;

\section{DESCRIÇÃO}

Esta rotina obtém o código da Versão aberta do tipo indicada.

\section{RETORNO}

. codver - código da Versão aberta do tipo indicado. . erro (vide ERROS).

\section{RESTRIÇÕES}

. Tipo de Colônia deve existir no Esquema de Dados

\section{NOTA}

Muitas Versð̃es podem estar acessíveis para o usuário independente de seus tipos.

Apenas uma Versão de cada tipo pode estar aberta ao mesmo tempo.

\section{ERROS}

0 - não há erro.

5 - código de tipo de Colônia é inválido.

28 - não existe Versão deste tipo aberta.

711 - Problema com o gerenciador.

\section{VEJA TAMBÉM}

BAVER e BCVER em (ROTINA/Versão)

\section{EXEMPLO}

main()

f

pal2 erro;

coditipo tcol;

codicol codver;

.....

$\operatorname{tcol}=71 ;$

/*Obter o código da Versão*/

erro $=\operatorname{BNVER}(t c o 1, \&$ codver $)$;

…. 
NOME

VerCOL - Obtém a condição Versão de um Tipo de Colônia

\section{SINOPSE}

pal2 Vercol (tcol, condição)

coditipo tcol

pal2 *ondição;

\section{DESCRIÇÃO}

Esta rotina obtém a condição Versão de um Tipo de Colônia que está no Esquema de Dados (Ativo).

\section{RETORNO}

. condição - recebe o valor 0 ou 1 dependendo do Tipo de Colônia ser "non-versionable" ou "versionable" respectivamente.

erro (vide ERROS)

\section{RESTRIÇÕES}

. o Tipo de Colônia deve existir no Esquema de Dados

\section{NOTA}

Esta rotina é parte integrante do conjunto de procedimentos de consulta ao Esquema de Dados. Sua execução pode ocorre tanto para o GEO/Mono-Esquema quanto para o GEO/Multi-Esquema.

\section{ERROS}

0 - não há erro.

801 - código de Tipo não corresponde à peça do Esquema. 802 - código de Tipo não corresponde a Tipo de Colônia. 831 - Atributo Condição não encontrado.

\section{VEJA TAMBÉM}

(ROTINA/Esquema).

\section{EXEMPLO}

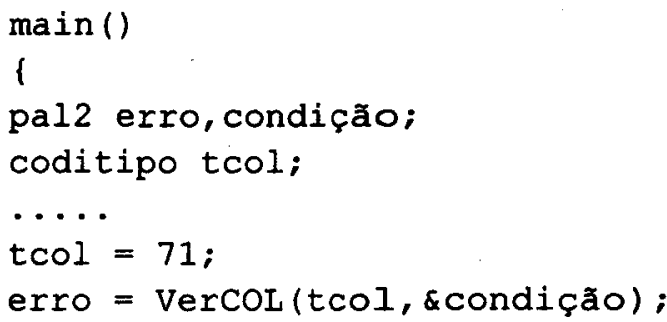

main()

1

pal2 erro, condição;

coditipo tcol;

$\mathrm{tcol}=71 ;$

erro $=\operatorname{VerCOL}($ tcol $\&$ condição $)$ 


\section{NOME}

GenOBJ - Obtém a condição Genérico de um Tipo de Obj.

\section{SINOPSE}

pal2 GenOBJ (tobj, condição)

coditipo tobj:

pal2 *condição;

\section{DESCRIÇÃO}

Esta rotina obtém a condição Genérico de um Tipo de Objeto que está no Esquema de Dados(Ativo).

\section{RETORNO}

. condição - recebe o valor 1 se as instâncias do Tipo de Objeto indicado puderem ser "objeto genérico" na Base de Dados. Caso contrário recebe o valor 0.

. erro (vide ERROS).

\section{RESTRIÇÕES}

. o Tipo de Objeto deve existir no Esquema de Dados

\section{NOTA}

Esta rotina é parte integrante do conjunto de procedimentos de consulta ao Esquema de Dados. Sua execução pode ocorre tanto para o GEO/Mono-Esquema quanto para o GEO/Multi-Esquema.

\section{ERROS}

0 - não há erro.

801 - código de Tipo não corresponde à peça do Esquema 803 - código de Tipo não corresponde a Tipo de Objeto.

831 - Atributo Condição não encontrado.

\section{VEJA TAMBÉM}

(ROTINA/Esquema).

\section{EXEMPLO}

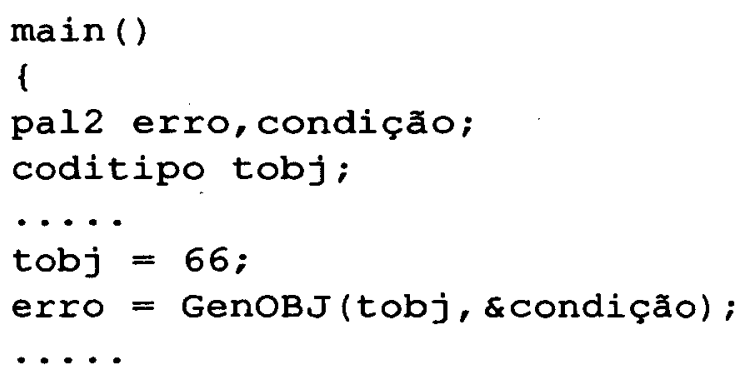




\section{APÊNDICE D}

\section{Manual Interno \\ - Estruturas envolvendo Versões -}

Nota:

Este apêndice apresenta o manual das estruturas que enoolvem Versões de Colônias em Bases de Dados criadas no GEO. Tais estruturas são utilizadas internamente nas rotinas sobre Versões e em outras rotinas do núcleo do GErenciador de Objetos. Aparecem nas páginas deste apêndice apenas as estruturas alteradas para possibilitar o desenvolvimento do subsistema de gerenciamento de Versōes.

As páginas deste manual seguem um padrão estabelecido pelo Grupo de Pesquisa do GEO. No cabeçalho de cada página, apresenta-se no canto superior esquerdo a funcionalidade da estrutura e no canto superior direito aparece ESTRUTURA/Geral indicando o trecho do manual do núcleo do GEO que corresponde às estruturas de uso geral das rotinas do núcleo. 


\section{NOME}

MROColonia - arquivo lógico de Colônia da BD

\section{SINOPSE}

\#include <globmro.h>

\section{DESCRIÇÃO}

extern struct MROColonia \{

codiobjeto raiz; /* Ponteiro da raiz da Colônia

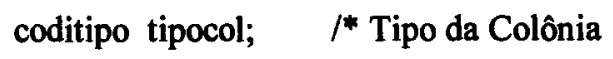

codiatr linha_atributo; $/ *$ sincronismo de Objetos long contador; $\quad / *$ Nro de Objetos nessa Colônia upal2 contr_acesso; /* Estrutura de Controle de Acesso codicol prox_col; /* Ponteiro para a próxima col. codicol col_filhas; /* Ponteiro $\mathrm{p} /$ uma versão filha codicol col_irmas; /* Ponteiro p/ uma versão irmã codicol col_pai; /* Ponteiro para a versão pai pal2 estado_v; $\quad / *$ estado da versão unsigned char nome[8]; /* nome da versão

\} MRO_colonia;

\section{RESTRIÇÕES}

. o nome da Versão deve ter no máximo 6 caracteres . "estado_v" deve ter o valor 1 -estável ou 0 -instável

\section{NOTA}

O registro lógico de uma Colônia é composto de 48 bytes e desta forma, um registro virtual pode conter 20 registros de Colônias.

As Colônias constritas por um mesmo Objeto são interligadas em lista através do ponteiro "prox_col".

As Colônias constritas por um mesmo Objeto e que são Versð̃es estão interligadas em listas através dos ponteiros “col_filhas", "col_irmas" ou "col_pai”, dependendo de suas relaçб̃es de derivação.

"MRO_colonia" é uma variável definida junto à estrutura e utilizada normalmente pelas rotinas do núcleo.

\section{VEJA TAMBÉM}

MROObjeto em (ESTRUTURA/Geral).

\section{EXEMPLO}

\#include <globmro.h>

main() (

struct MroColonia col_aux;

codicol endereco;

.....

endereco $=15$

/* Obter o registro da Colônia 15 */

erro=Mc_Le (endereco,Arq_COL, \&col_aux);

..... 
NOME

MROObjeto - arquivo lógico de Objeto da BD

\section{SINOPSE}

\#include <globmro.h>

\section{DESCRIÇÃO}

extern struct MROObjeto \{

codiide nome; $/ *$ Ponteiro $\mathrm{p} / \mathrm{o}$ identificador principal coditipo tipo; /* Tipo do Objeto

codirel relac[5], $/ *$ Ponteiro $\mathrm{p} / \mathrm{a}$ lista de relac rel identificador; $/ *$ Ponteiro para o relac identificador codiatr atrib; $1^{*}$ Ponteiro para o registro de atributos codicol constritas;/* Pont. p/ lista de Colônias constritas codiobjeto mestre; /* Ponteiro $\mathrm{p} / \mathrm{o}$ Objeto que constringe coditmp tempovida; /* Ponteiro p/o registro de tempo inicial de vida do Objeto

codiobjeto quem criou, $/ *$ Ponteiro $\mathrm{p} / \mathrm{o}$ autor quem_mudou; $/ *$ Ponteiro $\mathrm{p} /$ usuário da última alter. pal2 estado; $/ *$ Estado do Objeto (livre, congelado, etc.) long marca[MAX MARCAS]; /* Marcas temporárias codiobjeto generico; $/ *$ ponteiro para o Objeto genérico

\section{\} MRO objeto;}

\section{RESTRIÇÕES}

\section{NOTA}

O registro lógico de um Objeto é composto de 82 bytes e desta forma, um registro virtual pode conter 12 registros de Colônias.

O início da lista de Colônias constritas por um mesmo Objeto é indicado através do ponteiro "constritas".

A indicação do Objeto genérico é estabelecida no ponteiro "generico". Através deste ponteiro é possivel obter a lista de atributos (ponteiro "atrib") e a lista de relacionamentos (ponteiro "relac[0]") do Objeto que deu origem a um determinado Objeto.

"MRO_objeto" é uma variável definida junto à estrutura e utilizada normalmente pelas rotinas do núcleo.

\section{VEJA TAMBÉM}

MROColonia em (ESTRUTURA/Geral).

\section{EXEMPLO}

\#include <globmro.h>

$\operatorname{main}()$ (

struct MROObjeto obj_aux;

codicol endereco;

.....

endereco $=71$;

/*Obter o registro do objeto 71 */

erro=Mc_Le (endereco,Arq_OBJ, \&obj_aux);

..... 
NOME

IColonia_Corrente - indicação de Colônias abertas

\section{SINOPSE}

\#include $\langle g l o b m r o . h\rangle$

\section{DESCRIÇÃO}

extern struct IColonia_Corrente \{

codicol codigo; $\quad /^{*}$ código da Colônia codiobjeto quemconstringe; ${ }^{*}$ cód. do Obj que contringe codiide raiz; . . $*$ código da raiz da Colônia upal2 tipoacesso; /* Tipo de acesso permitido

\} IColCor[MAX_COLCOR];

\section{RESTRIÇÕES}

- o número máximo permitido de Colônias Abertas é definido em MAX_COLCOR (atualmente valendo 31).

. apenas uma Colônia (Versão) de cada tipo pode estar aberta ao mesmo tempo.

\section{NOTA}

"IColCor" é uma variável definida junto à estrutura e utilizada normalmente pelas rotinas do núcleo.
O valor de "tipoacesso" pode ser:

$$
\text { GEO_LE }
$$

0x0040

GEO_LE_ESCREVE

OxOFFF

ou uma combinação de:

GEO_CRIA_OBJETO

GEO_APAGA_OBJETO

0x0800

GEO_CRIA_RELACIONAMENTO 0x0020

GEO APAGA RELACIONAMENTO 0x0010

GEO_CRIA_ATRIBUTO 0x0004

GEO_APAGA_ATRIBUTO 0x0002

\section{VEJA TAMBÉM}

IColacessivel em (ESTRUTURA/Geral).

\section{EXEMPLO}


NOME

IColacessivel - indicação de Colônias requisitadas

\section{SINOPSE}

\#include 〈globmro.h>

\section{DESCRIÇÃO}

extern struct IColacessivel \{

codicol codigo; $\quad / *$ código da Colônia codiobjeto quemconstringe; $; *$ cód. do Obj que contringe codiide raiz; 1* código da raiz da Colônia

upal2 tipoacesso; /* Tipo de acesso permitido

coditipo tipocol; /* Tipo da Colônia

] IColAce[MAX COLACE];

\section{RESTRIÇÕES}

o número máximo permitido de Colônias requisitadas é definido em MAX_COLACE (atualmente valendo 62).

\section{NOTA}

Não existe limite para a quantidade de Colônia (Versão) de cada tipo que podem estar requisitadas ao mesmo tempo.

"IColAce" é uma variável definida junto à estrutura e utilizada normalmente pelas rotinas do núcleo.
O valor de "tipoacesso" pode ser:

GEO LE

0x0040

GEO_LE_ESCREVE

0x0FFF

ou uma combinaçăo de:

GEO_CRIA_OBJETO

GEO_APAGA_OBJETO

$0 \times 0800$

GEO_CRIA_RELACIONAMENTO 0x0020

GEO APAGA_RELACIONAMENTO 0x0010

GEO_CRIA_ATRIBUTO 0x0004

GEO APAGA ATRIBUTO 0x0002

\section{VEJA TAMBÉM}

IColonia_Corrente em (ESTRUTURA/Geral).

\section{EXEMPLO}

